\title{
EXPERIMENTAL AND NUMERICAL STUDY OF A WATER-TO-WATER HEAT PUMP WORKING WITH $\mathrm{CO}_{2}$
}

Renewable Energies and Energy Efficiency

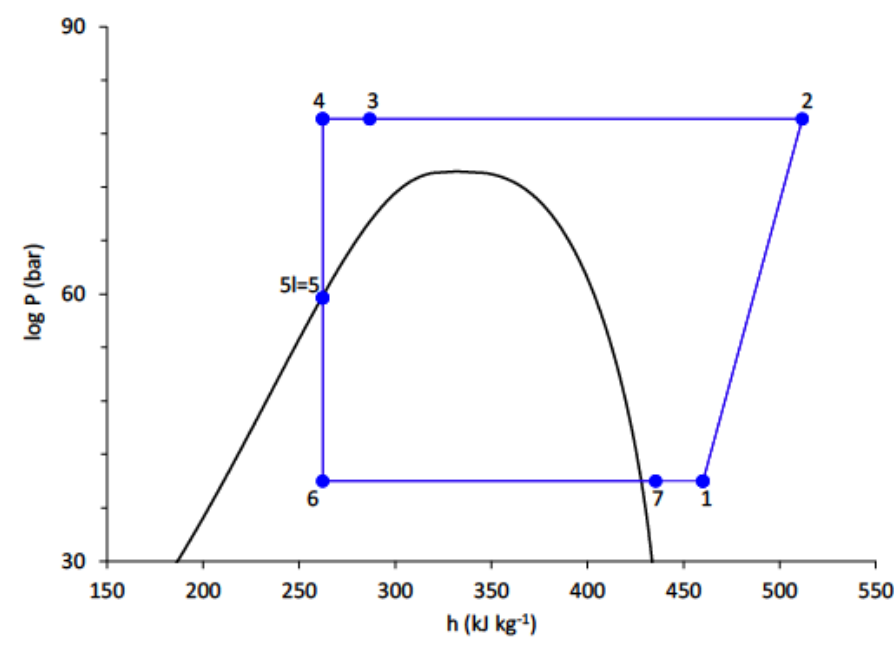

Author: Víctor Francisco Sena Cuevas

Director/s: José Ramón García Cascales Fernando Illán Gómez 


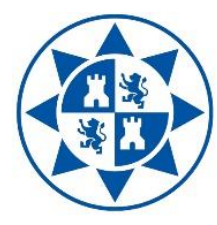

Universidad Politécnica de Cartagena

Campus de Excelencia Internacional

\title{
International Doctoral School
}

Renewable Energies and Energy Efficiency

\section{Doctoral Thesis}

Presented by

Víctor Francisco Sena Cuevas

\section{EXPERIMENTAL AND NUMERICAL STUDY OF A WATER-TO-WATER HEAT PUMP WORKING WITH $\mathrm{CO}_{2}$}

\author{
Doctoral advisors \\ José Ramón García Cascales, PhD \\ Fernando Illán Gómez, PhD
}

Thermal and Fluid Engineering Department (DITF)

Thermal and Energy Systems Modelling Group (MSTE) 
EXPERIMENTAL AND NUMERICAL STUDY OF A 


\section{CONFORMIDAD DE SOLICITUD DEAUTORIZACIÓN DE DEPÓSITO DE}

\section{TESIS DOCTORAL POR EL/LA DIRECTOR/A DE LA TESIS}

D/Da. JOSÉ RAMÓN GARCÍA CASCALES, director/a de la Tesis Doctoral "EXPERIMENTAL AND NUMERICAL STUDY OF A WATER-TO-WATER HEAT PUMP WORKING WITH $\mathrm{CO}_{2} "$.

\section{INFORMA:}

Que la referida Tesis Doctoral, ha sido realizada por D/Da. VÍCTOR FRANCISCO SENA CUEVAS, dentro del Programa de Doctorado ENERGÍAS RENOVABLES Y EFICIENCIA ENERGÉTICA, dando mi conformidad para que sea presentada ante el Comité de Dirección de la Escuela Internacional de Doctorado para ser autorizado su depósito.

- Informe positivo sobre el plan de investigación y documento de actividades del doctorando/a emitido por el Director/ Tutor (RAPI).

La rama de conocimiento en la que esta tesis ha sido desarrollada es:

Ciencias

Ciencias Sociales y Jurídicas

- Ingeniería y Arquitectura

En Cartagena, a 1 de Octubre de 2020

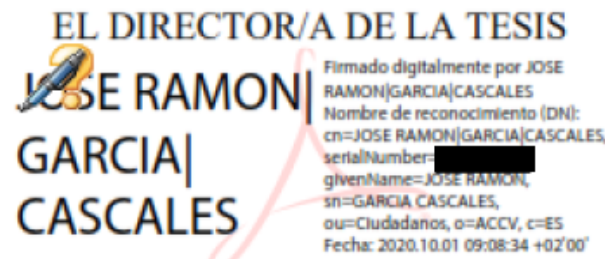

Fdo.: José Ramón García Cascales 
EXPERIMENTAL AND NUMERICAL STUDY OF A 


\section{CONFORMIDAD DE DEPÓSITO DE TESIS DOCTORAL POR LA COMISIÓN ACADÉMICA DEL PROGRAMA}

D/Da. ÁNGEL MOLINA GARCÍA, Presidente/a de la Comisión Académica del Programa ENERGIAS RENOVABLES Y EFICIENCIA ENERGÉTICA.

\section{INFORMA:}

Que la Tesis Doctoral titulada, "EXPERIMENTAL AND NUMERICAL STUDY OF A WATER-TO-WATER HEAT PUMP WORKING WITH $\mathrm{CO}_{2}$ ", ha sido realizada, dentro del mencionado Programa de Doctorado, por D/Da. VÍCTOR FRANCISCO SENA CUEVAS, bajo la dirección y supervisión del Dr./Dra. JOSÉ RAMÓN GARCÍA CASCALES.

En reunión de la Comisión Académica, visto que en la misma se acreditan los indicios de calidad correspondientes y la autorización del Director/a de la misma, se acordó dar la conformidad, con la finalidad de que sea autorizado su depósito por el Comité de Dirección de la Escuela Internacional de Doctorado.

- Informe positivo sobre el plan de investigación y documento de actividades del doctorando/a emitido por el Director/ Tutor (RAPI).

La Rama de conocimiento por la que esta tesis ha sido desarrollada es:

Ciencias

Ciencias Sociales y Jurídicas

- Ingeniería y Arquitectura

En Cartagena, a 16 de Octubre de 2020

EL PRESIDENTE DE LA COMISIÓN ACADÉMICA

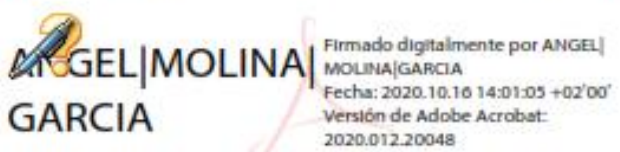

Fdo: Angel Molina García

\section{COMITÉ DE DIRECCIÓN ESCUELA INTERNACIONAL DE DOCTORADO}


EXPERIMENTAL AND NUMERICAL STUDY OF A 
EXPERIMENTAL AND NUMERICAL STUDY OF A

To

My family 
EXPERIMENTAL AND NUMERICAL STUDY OF A 


\section{Acknowledgments}

In order to advance following this dream, a combination of different factors have coincided and the final thesis would not have been completed without the guidelines and support received from different people and institutions.

I greatly appreciated the support received from my professors and doctoral advisors, José Ramón García Cascales and Fernando Illán Gómez, for being available at any time for any lectures, encourages, or assistances with the facility in the Lab and experimental and numerical tests.

I also appreciate the support from other researchers and partners, such as Javier Sánchez Velasco, and the lab technicians or UPCT employees, Paco, Julio and Juan, who were always available when help was needed in the facility and advice to not give up on my faith.

I'm also very grateful for my family for the support and care showed to me when I was overseas, always wondering if I was OK or needed any financial help. They also encouraged me to persist and follow my dreams when the timeline and the facility were not on the right track.

I appreciate the support from old and new friends that have always given any motivation and help to me during bad and good times, including the Dominican students that have come to study master or PhD at UPCT.

Last, but no least, I greatly appreciate the economical sponsorship. This work has been financed by project ENE2017-83665-C2-2-P, by the Ministry of Economy, Industry and Competitiveness and the European Regional Development Fund; and a doctoral scholarship from the Ministry of Higher Education from Dominican Republic (MESCYT) with the contract numbers BIM-0010-2018 and BIM-252-2020. 
EXPERIMENTAL AND NUMERICAL STUDY OF A 


\section{Abstract}

In this thesis, a one-stage transcritical $\mathrm{CO}_{2}$ water-to-water heat pump is numerically and experimentally analyzed in the production of hot water for the applications of space heating and domestic hot water (DHW). Different configurations commonly used in the market are studied and compared for the same water temperatures at the heat sink (evaporator) and heat source (condenser). From now on, since in $\mathrm{CO}_{2}$ transcritical cycles does not exist phase change, the condenser is called gas cooler.

Initially, four configurations (C\#) are presented, three of them belong to the dry evaporator group, C1 and C2 include liquid receiver, high pressure control and superheating control, and the remaining one, $\mathrm{C} 4$, does not use liquid receiver, neither has high pressure control, only superheating control. The difference between $\mathrm{C} 1$ and $\mathrm{C} 2$ is a bypass that is used in $\mathrm{C} 1$, but, when the bypass is closed, the cycle is working in $\mathrm{C} 2$. The other configuration, $\mathrm{C} 3$, is a flooded evaporator system, with high pressure control, but without superheating since it is a flooded evaporator cycle.

One of the most important studies in this thesis is the gas cooler optimal pressure. A numerical model to describe the behavior of a $\mathrm{CO}_{2}$ transcritical heat pump for hot water production is developed and experimentally validated. This model has allowed obtaining relatively simple expressions that can be programmed in a PLC to regulate the pressure in the gas cooler by measuring the temperature of the refrigerant in three points of the cycle. The proposed model is capable of limiting the compressor discharge temperature to $140{ }^{\circ} \mathrm{C}$ while maintaining the COP with theoretical deviations of less than $2 \%$ respect to optimal pressure conditions. The liquid receiver pressure, the evaporation temperature, the Internal Heat Exchanger (IHX) efficiency and the superheating degree, have relatively low influences on the system behavior. Furthermore, since the influence of the compressor efficiency is relatively low as well, the model is applicable for a wide range of reciprocating semi-hermetic compressor models, which are the most common in the field of stationary heat pumps.

Considering the comparison of the different configurations, one of the first decisions after performing the experimental tests, is letting $\mathrm{C} 4$ out of the comparison since this configuration is not able to compete with the other three due to the lack of high pressure control. The second decision after analyzing that the influence of the liquid receiver is negligible showing slightly better performances when the bypass is totally closed and followed by totally opened, the first two configurations were treated as a single configuration, called "C1\&C2". Therefore, the comparisons are mostly performed between "C1\&C2" and C3, Furthermore, the influence of varying the heat exchangers $(\mathrm{HX})$ surface is also studied for space heating applications.

For the space heating and DHW applications the differences between "C1\&C2" and C3, are negligible. However, in the dry evaporator cycles, if the liquid receiver is usually regulated by a gas bypass with the aim of reducing the pressure of the lines 
that distribute liquid to the evaporators, to allow an adequate pressure regulation range, the liquid receiver should be sized according to the rest of the components and to the usual operating conditions. Varying the HX surfaces showed improvement in most cases numerically studied for space heating application, but there exist optimal surfaces for the different temperature range and this should be considered when designing the heat exchangers, at least for low/medium and high/very high temperatures. 
EXPERIMENTAL AND NUMERICAL STUDY OF A 


\section{Resumen}

En esta tesis se analiza numérica y experimentalmente una bomba de calor aguaagua de $\mathrm{CO}_{2}$ transcrítico de una etapa en la producción de agua caliente para las aplicaciones de calefacción y agua caliente sanitaria (ACS). Se estudian y comparan diferentes configuraciones comúnmente utilizadas en el mercado para las mismas temperaturas del agua en el evaporador y condensador. A partir de ahora, dado que en los ciclos transcríticos del $\mathrm{CO}_{2}$ no existe cambio de fase, el condensador se denomina gas cooler.

Inicialmente se presentan cuatro configuraciones (C\#), tres de ellas pertenecen al grupo evaporador seco, C1 y C2 incluyen receptor de líquido, control de alta presión y control de sobrecalentamiento, y la restante, $\mathrm{C} 4$, no usa receptor de líquido, ni tiene control de alta presión, solo control de sobrecalentamiento. La diferencia entre C1 y C2 es un bypass que se usa en C1, pero, cuando el bypass está cerrado, el ciclo está funcionando en C2. La otra configuración, C3, es un sistema de evaporador inundado, con control de alta presión, pero sin sobrecalentamiento ya que es un ciclo de evaporador inundado.

Uno de los estudios más importantes de esta tesis es la presión óptima del gas cooler. Se desarrolla y valida experimentalmente un modelo numérico para describir el comportamiento de una bomba de calor de $\mathrm{CO}_{2}$ transcrítica para la producción de agua caliente. Este modelo ha permitido obtener expresiones relativamente simples que se pueden programar en un PLC para regular la presión en el gas cooler midiendo la temperatura del refrigerante en tres puntos del ciclo. El modelo propuesto es capaz de limitar la temperatura de descarga del compresor a $140{ }^{\circ} \mathrm{C}$ manteniendo el COP con desviaciones teóricas inferiores al $2 \%$ respecto a las condiciones óptimas de presión. La presión del depósito de líquido, la temperatura de evaporación, la eficiencia del Intercambiador de calor interno (IHX) y el sobrecalentamiento, tienen una influencia relativamente baja en el comportamiento del sistema. Además, dado que la influencia de la eficiencia del compresor también es relativamente baja, el modelo es aplicable para una amplia gama de modelos de compresores semiherméticos alternativos, que son los más comunes en el campo de las bombas de calor estacionarias.

Considerando la comparación de las diferentes configuraciones, una de las primeras decisiones después de realizar las pruebas experimentales, es dejar fuera de la comparación a C4 ya que esta configuración no puede competir con las otras tres por falta de control de alta presión. La segunda decisión tras analizar que la influencia del depósito de líquido es despreciable mostrando rendimientos ligeramente mejores cuando el bypass está totalmente cerrado y seguido de totalmente abierto, las dos primeras configuraciones se trataron como una única configuración, denominada "C1\&C2". Por lo tanto, las comparaciones se realizan principalmente entre "C1\&C2" 
y C3. Además, la influencia de variar la superficie de los intercambiadores de calor (HX) también se estudia para aplicaciones de calefacción.

Para las aplicaciones de calefacción y ACS, las diferencias entre "C1 \& C2" y C3 son insignificantes. Sin embargo, en los ciclos de evaporador seco, si el depósito de líquido suele estar regulado por un bypass de gas con el objetivo de reducir la presión de las líneas que distribuyen el líquido a los evaporadores, para permitir un rango de regulación de presión adecuado, el depósito de líquido debe dimensionarse según el resto de componentes y las condiciones de funcionamiento habituales. La variación de las superficies de los intercambiadores de calor mostró una mejora en la mayoría de los casos estudiados numéricamente para la aplicación de calefacción, pero existen superficies óptimas para los diferentes rangos de temperatura y esto debe tenerse en cuenta al diseñar los intercambiadores de calor, al menos para temperaturas bajas/medias y altas/muy altas. 


\section{CONTENT}

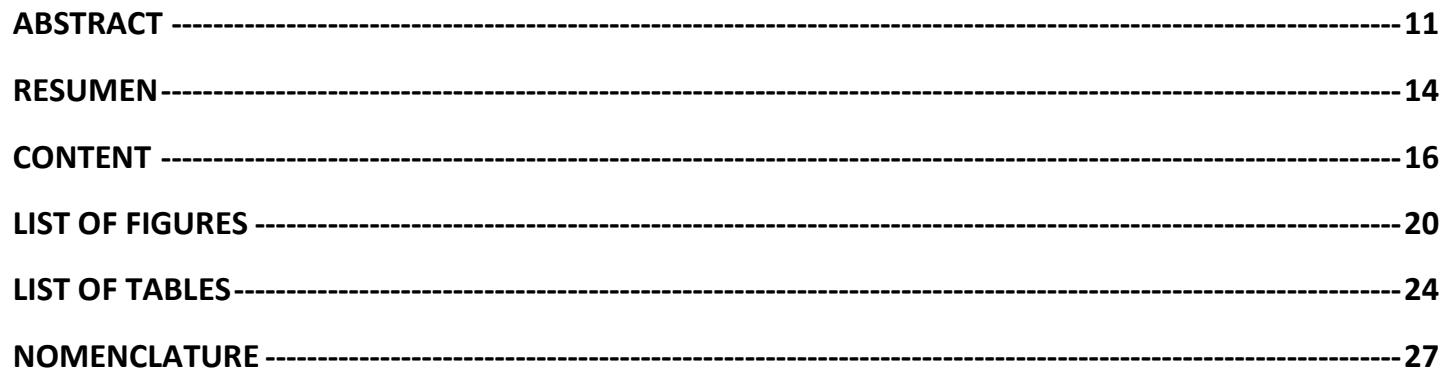

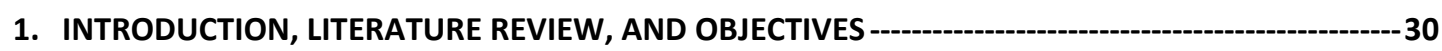

1.1. A BRIEF INTRODUCTION---------------------------------------------------------------------------------------------31

1.2. CURRENT TECHNOLOGICAL SITUATION OF THE HEAT PUMPS FOR HOT WATER GENERATION IN THE MARKET, AND

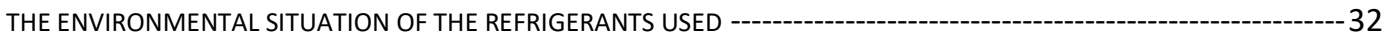

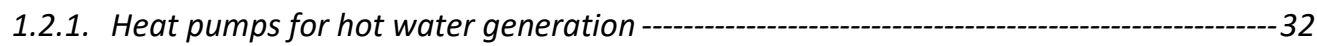

1.2.1.1. $\mathrm{CO}_{2}$ Heat pumps for hot water generation in the market-----

1.2.2. Environmental situation of the refrigerants used-------------------------------------34

1.2.2.1. First generation (1830-1930)---

1.2.2.2. Second generation, CFCs \& HCFCs (1931-1990) - 34

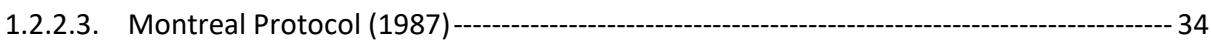

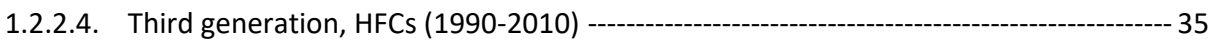

1.2.2.5. Fourth generation, Hydrofluoroolefin HFOs (2010-present) ---------------------------- 35

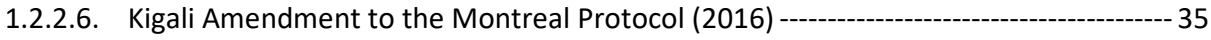

1.2.2.7. Hydrocarbons, HCs ----------------------------------------------------------------------------- 35

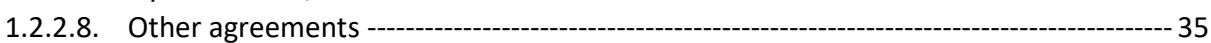

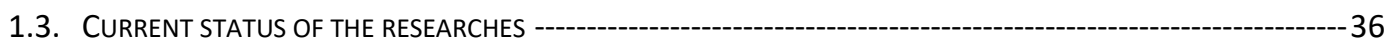

1.3.1. Sources of research disclosure -

1.3.2. Wastewater source heat pump ----------------------------------------------------36

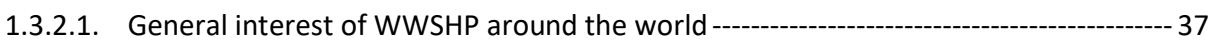

1.3.2.2. Classifications of WWSHP--- 37

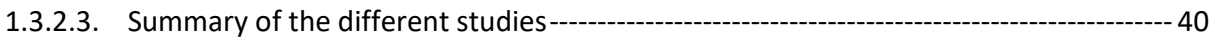

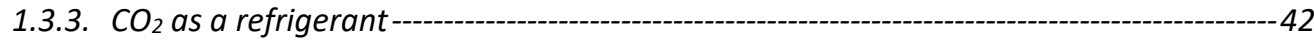

1.3.3.1. General interest of $\mathrm{CO}_{2}$ as a refrigerants-------------------------- 42

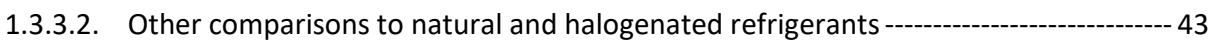

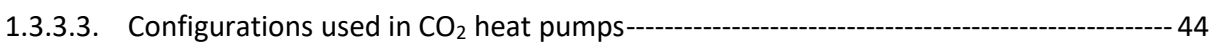

1.3.3.4. Most common types of compressors for $\mathrm{CO}_{2}$ applications ------------------------------- 48

1.3.3.5. Heat exchangers optimization -------------------------------------------------------------- 48

1.3.3.6. Optimal pressure studies -----on 48

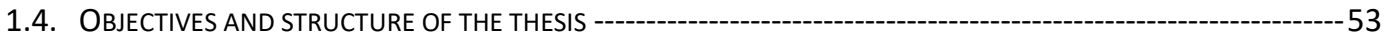

2. EXPERIMENTAL FACILITY DESCRIPTION-

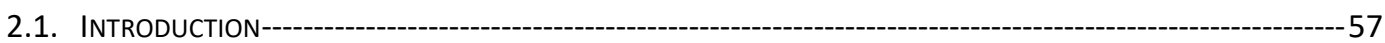

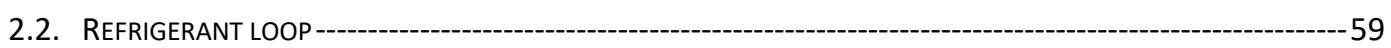

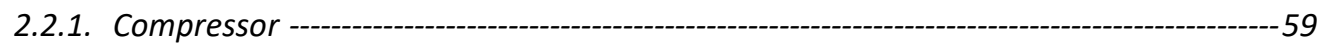

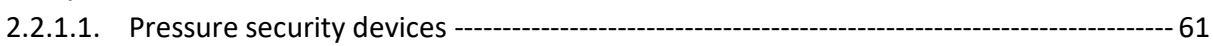

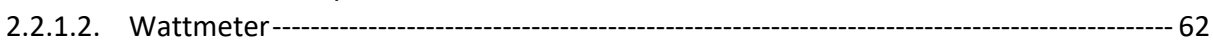

2.2.2. Gas cooler HX--------------------------------------------------------------------------------------------63

2.2.3. Evaporator heat exchanger--------------------------------------------------------------------------64

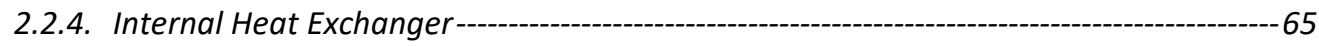

2.2.5. Liquid receiver or liquid separator --------------------------------------------------------------------66

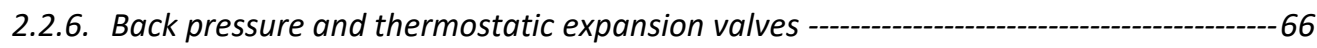




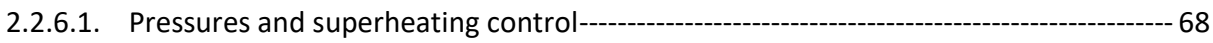

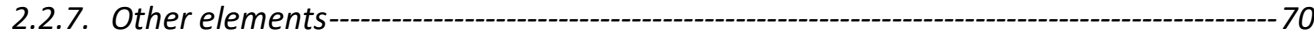

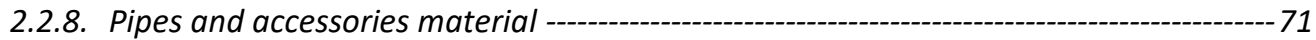

2.3. WATER LOOP-

2.3.1. Auxiliary electrical water heater and cooling machine---------------------------------- 71

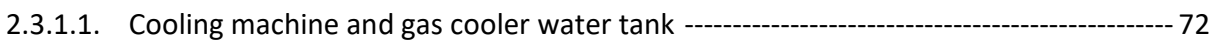

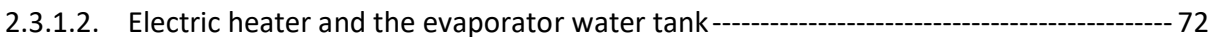

2.3.2. Evaporator and gas cooler water temperatures ------------------------------------------------ 73

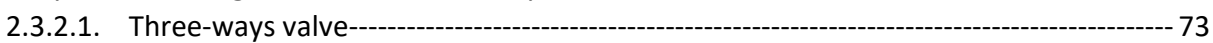

2.3.2.2. Water circulation pumps----------------------------------------------------------------- 73

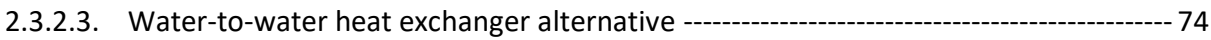

2.3.2.4. PID controller device and software--- 75

2.3.3. Pipe material --- 76

2.4. DATA ACQUISITION AND VARIABLES CONTROL FOR BOTH LOOPS--

2.4.1. Temperature sensors -------------------------------------------------------------------- 77

2.4.2. Pressure sensors -------- 77

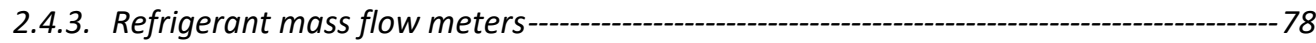

2.4.4. Water flow meters ------- 78

2.4.5. Summary of the sensors --------------------------------------------------------------------- 79

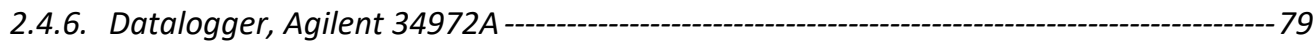

2.4.7. Laboratory Virtual Instrument Engineering Workbench (LabVIEW) ------------------80

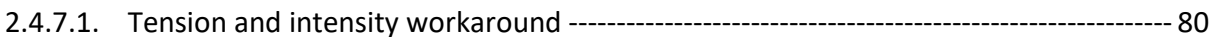

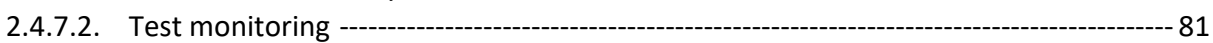

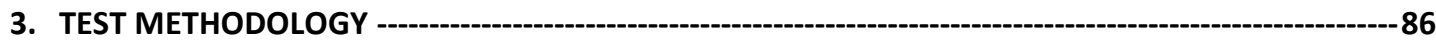

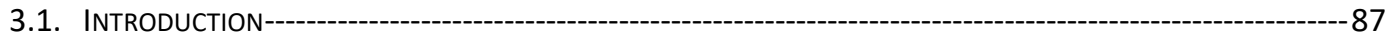

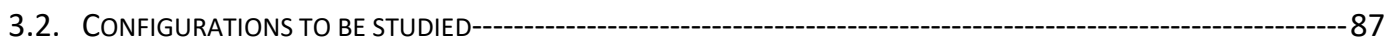

3.2.1. Configuration 1: Dry evaporator with double expansion \& bypass (C1) -------------88

3.2.2. Configuration 2: Dry evaporator with double expansion, without bypass (C2) -------- 88

3.2.3. Configuration 3: Flooded evaporator, single expansion, no superheating (C3) ---------88

3.2.4. Configuration 4: Dry evaporator, no high pressure control, no liquid receiver (C4) ---89

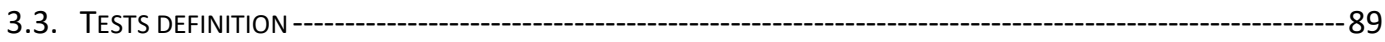

3.3.1. Intermediate liquid receiver pressure, influence on the $\mathrm{COP}$

3.3.2. Influence of the IHX efficiency--

3.3.3. Space heating study --------------------------------------------------------------------------------91

3.3.4. Domestic hot water generation study --

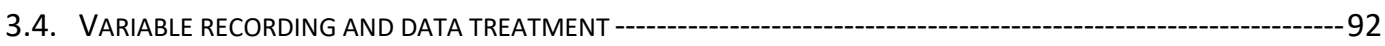

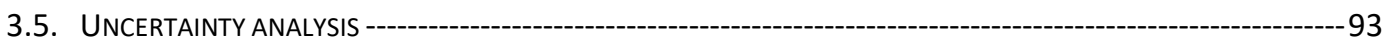

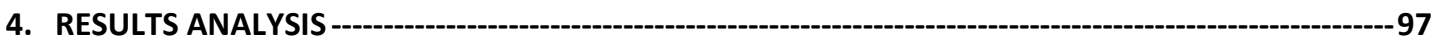

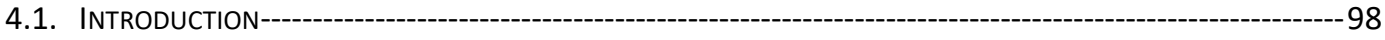

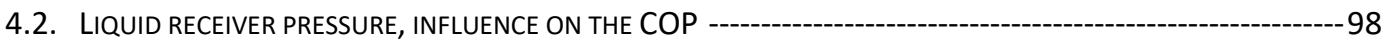

4.2.1. Theoretical analysis ---

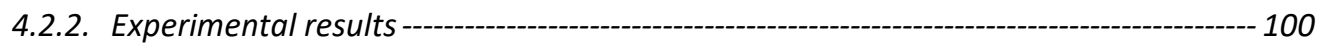

4.3. INTERNAL HEAT EXCHANGER EFFICIENCY, INFLUENCE ON THE COP---103

4.3.1. Efficiency calculation --- 103

4.3.2. Experimental results --- 104

4.4. OPtIMAL PRESSURE, NUMERICAL AND EXPERIMENTAL STUDY --- 111

4.4.1. Numerical model --

4.4.2. Numerical and experimental results -- 117

4.4.3. Influence of the compressor efficiency----------------------------------------------------- 121

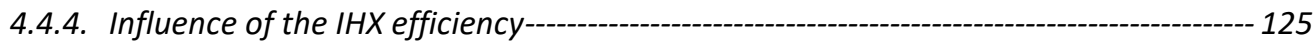


4.4.5. Influence of the liquid receiver-- 126

4.4.6. Influence of the evaporation temperature ---------------------------------------------------- 131

4.4.7. Influence of the superheating ---------------------------------------------- 132

4.4.8. Correlations for optimal heat rejection pressure control ------------------------------ 132

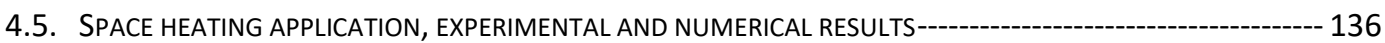

4.5.1. Model validation for the experimental and numerical study ------------------------- 136

4.5.2. Optimal pressure in this facility and tests conditions -------------------------------- 137

4.5.2.1. Seeking the optimal pressure manually ---o---o 138

4.5.3. Experimental and numerical comparison of the different configurations -------------- 140

4.5.3.1. Configuration $1 \& 2(C 1 \& C 2)$, experimental results----------------- 140

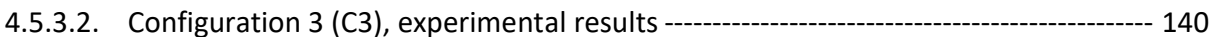

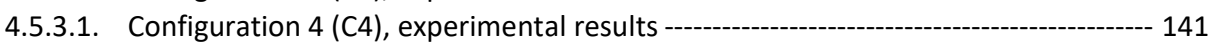

4.5.3.2. Summary of experimental results for all the configurations ---

4.5.3.3. Influence of the evaporator water temperature for space heating ------------------ 142

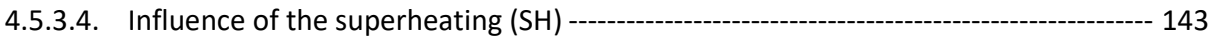

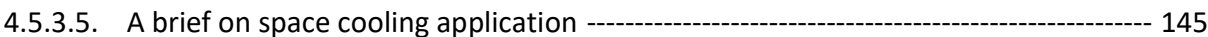

4.5.4. Study about varying $H X$ s surfaces--------------------------------------------------------------- 145

4.5.4.1. Influence of varying the IHX surface -

4.5.4.2. Influence of varying the evaporator surface ------------------------------------------ 148

4.5.4.3. Influence of varying the gas cooler surface----o--- 149

4.5.4.4. Influence of varying the surface of all the heat exchangers ------------------------ 151

4.6. DOMESTIC HOT WATER GENERATION, EXPERIMENTAL RESULTS ---------------------------------------- 152

4.6.1. Configuration $1 \& 2$ (C1\&C2)---------------------------------------------------------- 152

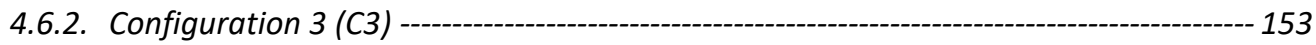

4.6.3. Comparison between the different configurations in DHW application -------------- 154

4.6.3.1. From the evaporator water temperature perspective--------------------------- 156

4.6.3.2. From the gas cooler water temperature perspective ---------------------------------- 157

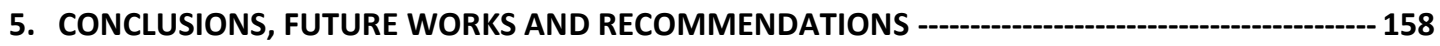

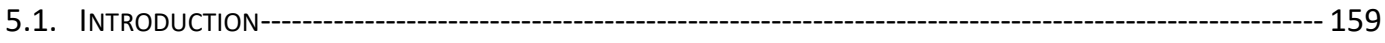

5.2. GAS COOLER OPTIMAL PRESSURE ---

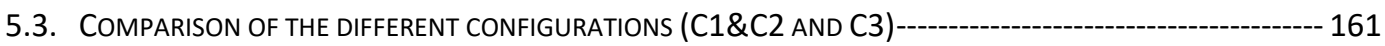

5.3.1. Space heating application-- 161

5.3.2. Domestic hot water generation ---

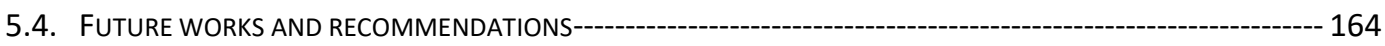

5.4.1. About the use of wastewater source jointly with a $\mathrm{CO}_{2}$ heat pump ------------------- 164

5.4.2. About the optimal pressure and hot water generation for space heating and DHW

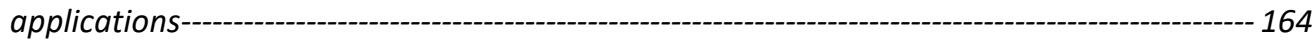


EXPERIMENTAL AND NUMERICAL STUDY OF A 


\section{List of figures}

Fig. 1. Possibilities of energy recovery from wastewater [12]................................ 39

Fig. 2. One-stage cycles found in the literature review. ........................................... 45

Fig. 3. Two-stage cycles with turbine and intercooler found in the literature review.

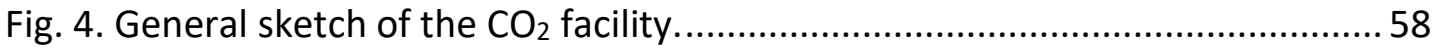

Fig. 5. The $\mathrm{CO}_{2}$ facility before and after insulation material..................................59

Fig. 6. Operational field of the CD-M and CD-H Doring $\mathrm{CO}_{2}$ compressors. ...............60 60

Fig. 7. Main elements of the compressor outer parts. ............................................ 61

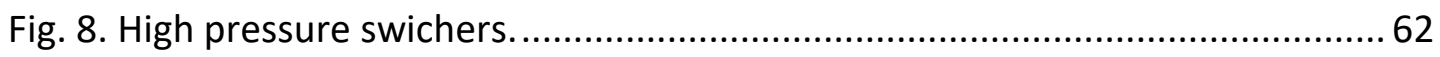

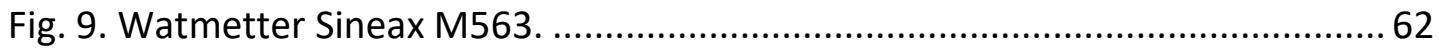

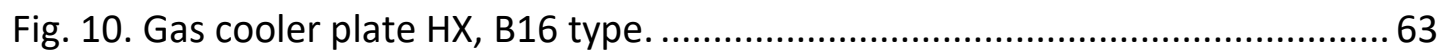

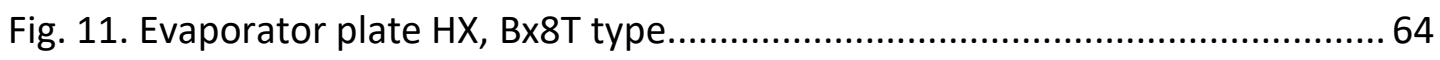

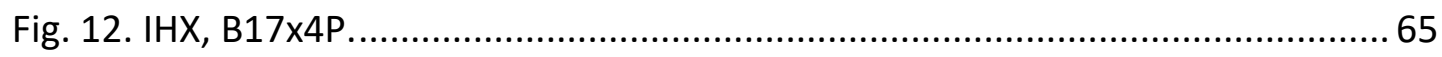

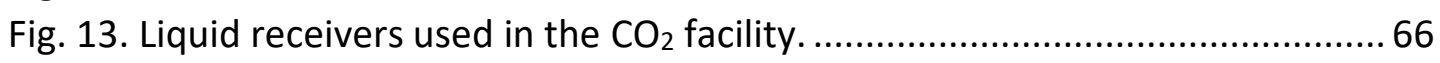

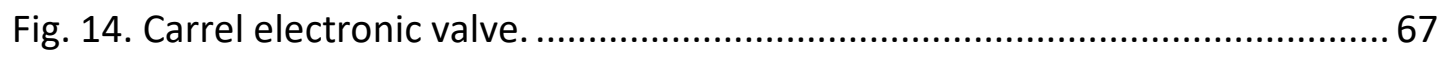

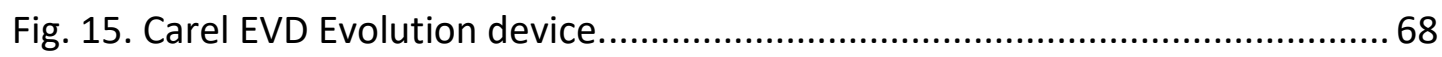

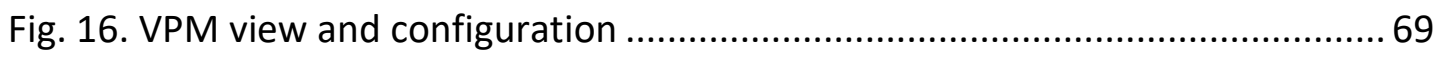

Fig. 17. Oil detector, visor and dehydration filter................................................... 70

Fig. 18. Swagelok stainless-steel pipes and accessories........................................ 71

Fig. 19. Auxiliary cooling machine and gas cooler water tank................................ 72

Fig. 20. Auxiliar lectrical water heater with the evaporator water tank. ................. 72

Fig. 21. Devices for the water temperature control. .............................................. 73

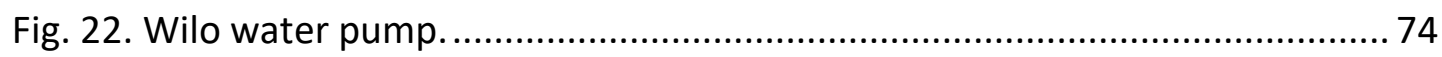

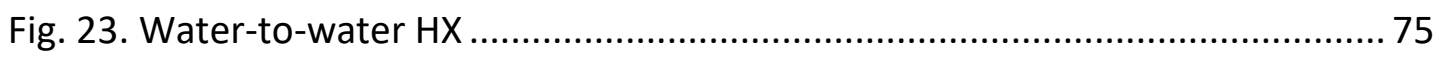

Fig. 24. PID variables measurement and setpoints.............................................. 75

Fig. 25. PID autotune configuration [122] ............................................................. 76

Fig. 26. 4-wire Resistance Temperature Detector (RTD) and example of a connection

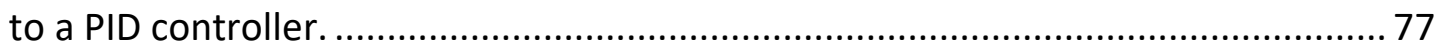

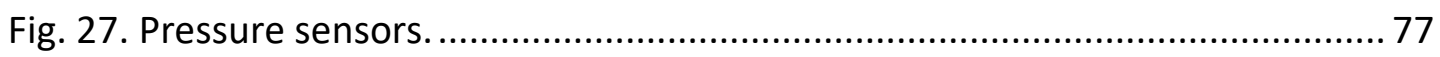

Fig. 28. Coriolis effect refrigerant mass flow meter. ............................................. 78

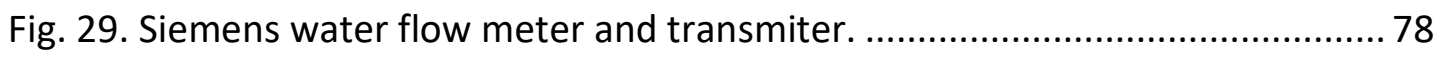

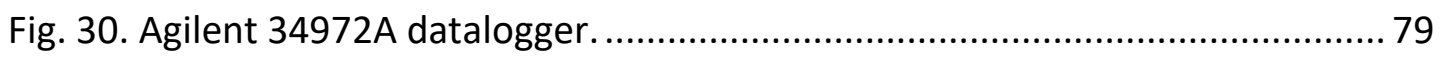

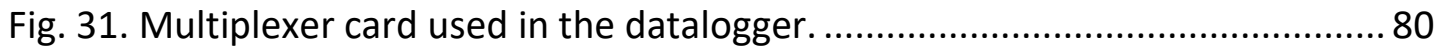

Fig. 32. Data logger in LabVIEW. Intensity workaround for pressure calculation

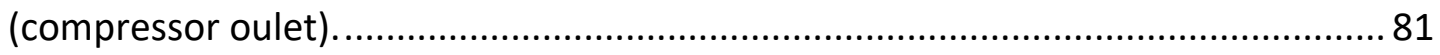

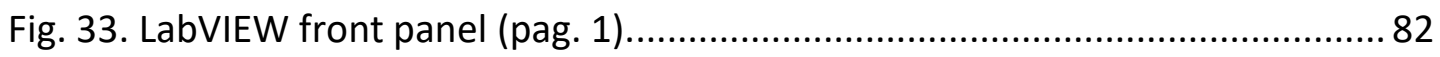

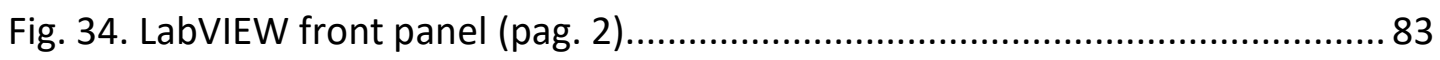

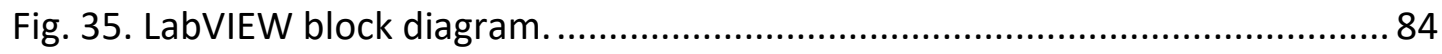

Fig. 36. Different configurations to be studied................................................ 87

Fig. 37. Refrigerant temperature out of the gas cooler with $0.15 \mathrm{~K}$ oscillation......... 93 
Fig. 38. Refrigerant pressure out of the gas cooler, with $0.1 \mathrm{~K}$ oscilation. 93

Fig. 39. High uncertainty values related to the inflection point.

Fig. 40. Liquid receiver pressure @ 45 bar, $T_{g c, r o}=25^{\circ} \mathrm{C}, P_{g c}=75$ bar, $T_{\text {evap }}=10{ }^{\circ} \mathrm{C}, S H=5$ $\mathrm{K}$

Fig. 41. Liquid receiver pressure @ $61 \mathrm{bar}, T_{g c, r o}=25^{\circ} \mathrm{C}, P_{g c}=75 \mathrm{bar}, T_{\text {evap }}=10^{\circ} \mathrm{C}, S H=5$ $\mathrm{K}$.

Fig. 42. Liquid receiver pressure @ 54 bar, $T_{g c, r o}=25^{\circ} \mathrm{C}, P_{g c}=75$ bar, $T_{\text {evap }}=10{ }^{\circ} \mathrm{C}, S H=5$ $\mathrm{K}$.

Fig. 43. Liquid receiver pressure @ 48.6 bar, $T_{g c, r o}=25.3^{\circ} \mathrm{C}, P_{g c}=75$ bar, $T_{\text {evap }}=10.3^{\circ} \mathrm{C}$, $\mathrm{SH}=5 \mathrm{~K}$. 101

Fig. 44. Liquid receiver pressure @ 60 bar, $T_{g c, r o}=25.3^{\circ} \mathrm{C}, P_{g c}=75$ bar, $T_{\text {evap }}=10.3^{\circ} \mathrm{C}$, $\mathrm{SH}=5 \mathrm{~K}$. 102

Fig. 45. System COP according to the liquid receiver pressure, working for the same $T_{\text {evap }}, T_{g c, r o}, P_{g c}$ and $\eta I H X=0$.

Fig. 46. Bypass valve (E2V09). Opening range and refrigerant mass flow rate...... 103

Fig. 47. IHX efficiency estimation by Chen \& Gu [53] ........................................... 103

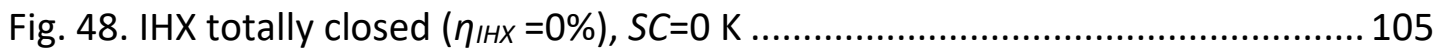

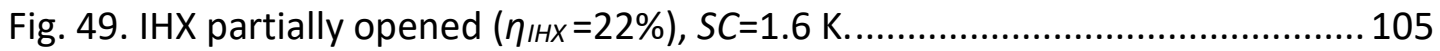

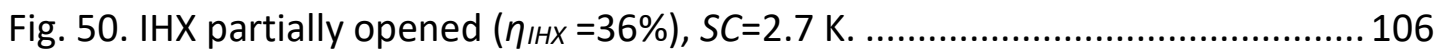

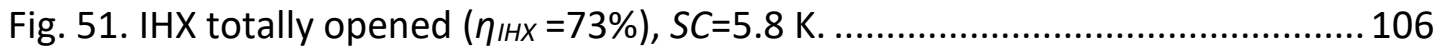

Fig. 52. Summary of the four cycles when increasing the SC from $0 \mathrm{~K}$ to $5.8 \mathrm{~K} . \ldots .107$

Fig. 53. Refrigerant temperature at the inlet and outlet of the evaporator when

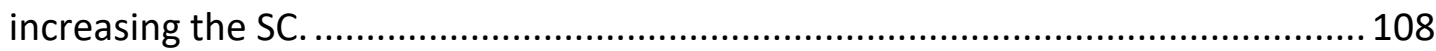

Fig. 54. Refrigerant temperature in the IHX low side when increasing SC............. 108

Fig. 55. Refrigerant temperature in the compressor when increasing SC............... 109

Fig. 56. Refrigerant mass flow rate and compressor work, when increasing the SC.

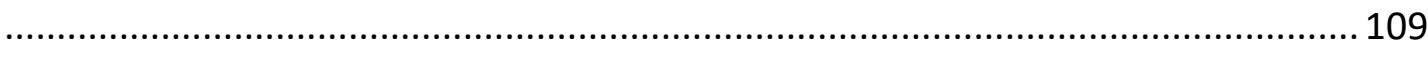

Fig. 57. Gas cooler refrigerant inlet and outlet temperature ................................ 110

Fig. 58. Gas cooler specific enthalpy difference when increasing the SC............... 110

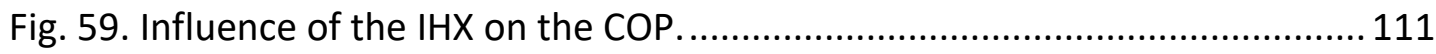

Fig. 60. Comparison of the experimental values and model for refrigerant mass flow rate and the power absorbed by the compressor.

Fig. 61. Evolution of mass flow rate and compressor power consumption predicted by the four models considered.

Fig. 62. Evolution of optimal pressure and maximum COP (at optimal pressure conditions) depending on the compressor model.

Fig. 63: Comparison between predicted and experimentally measured values of COP and $\mathrm{Q}_{\mathrm{gc}}\left(\mathrm{SH}=5 \mathrm{~K}, \eta_{\mathrm{IHX}} \approx 0.7\right)$. Best fit model (Eqs. 31\&32) \& DORIN Adjusted (Eqs. 29\&30).

Fig. 64. Influence of gas cooler pressure on system's heating capacity ( $\mathrm{SH}=5 \mathrm{~K}$, $\left.\eta_{I H X} \approx 0.7\right)$. 120 
Fig. 65. Influence of gas cooler pressure on compressor's performance $(S H=5 \mathrm{~K}$, $\left.\eta_{1 H X} \approx 0.7\right)$.

Fig. 66. Influence of compressor characteristics on system's behavior $\left(T_{\text {evap }}=5^{\circ} \mathrm{C}, \mathrm{SH}=5\right.$ $\left.\mathrm{K}, \eta_{1 H X}=0.7\right)$.

Fig. 67. Influence of IHX efficiency on system's behavior ( $\left.T_{\text {evap }}=10^{\circ} \mathrm{C}, S H=5 \mathrm{~K}\right) . \ldots 125$

Fig. 68. Influence of liquid receiver pressure on system's performance ( $\mathrm{SH}=5 \mathrm{~K}$ ).. 127

Fig. 69. P-h diagram $\left(T_{\text {evap }}=5{ }^{\circ} \mathrm{C}, T_{g c, r o}=45^{\circ} \mathrm{C}, S H=5 \mathrm{~K}, \eta_{I H X}=0.3, P_{g c}=125\right.$ bar, $P_{l r}=70.5$ bar).

Fig. 70. P-h diagram ( $\eta_{1 H \mathrm{x}}=0, T_{\text {evap }}=5{ }^{\circ} \mathrm{C}, T_{g c, r o}=50{ }^{\circ} \mathrm{C}, S H=5 \mathrm{~K}, P_{g c}=131$ bar). 129

Fig. 71. Influence of evaporation temperature on system's behavior ( $\mathrm{SH}=5 \mathrm{~K}$, $\left.\eta_{1 H X}=0.7\right)$.

Fig. 72. Influence of superheating on system's behavior $\left(T_{\text {evap }}=10^{\circ} \mathrm{C}, \eta_{1 H X}=0.7\right) \ldots . .132$

Fig. 73. Fit between numerical model and proposed correlation (35) without limiting the compressor discharge temperature $\left(T_{\text {evap }}=5-25^{\circ} \mathrm{C}, S H=3-7 \mathrm{~K}, \eta_{1 H X}=0-0.9, T_{g c, r o}=30-\right.$ $\left.60{ }^{\circ} \mathrm{C}\right)$.

Fig. 74. Fit between numerical model limiting the compressor discharge temperature to $140{ }^{\circ} \mathrm{C}$ and correlations (36) to (38) proposed ( $T_{\text {evap }}=5-25{ }^{\circ} \mathrm{C}, \mathrm{SH}=3-7 \mathrm{~K}, \eta_{1 H X}=0-0.9$, $\left.T_{g c, r o}=30-60^{\circ} \mathrm{C}\right)$. 134

Fig. 75. Fit between the COP calculated by using the optimal pressure provided by the MATLAB ${ }^{\circledR}$ model and the pressure obtained using equations (36) to (38). 134

Fig. 76. Comparison between the proposed model and previous models ( $T_{\text {evap }}=5{ }^{\circ} \mathrm{C}$, $S H=5 \mathrm{~K}, \eta_{1 H X}=0.6$.)

Fig. 77. Model validation. 137

Fig. 78. COP and compressor outlet temperature according to the high pressure and water temperature.

Fig. 79. Optimal pressure according to the evaporator water temperature for specific $T_{\text {gc wi/o }}$ conditions. 138

Fig. 80. Seeking the optimal pressure in the system. 139

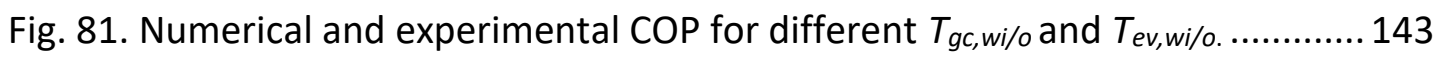

Fig. 82. Influence of the $\mathrm{SH}$ on the COP for different $T_{g c \text {, wi/o }}$ and $T_{e v, w i / o} \ldots \ldots \ldots . . . . . . . . .144$

Fig. 83. COP considering the IHX surface. 146

Fig. 84. Heating capacity according to the surface for a specific evaporator water temperature $\left(T_{e v, \text { wi } / o}=10 / 7^{\circ} \mathrm{C}\right.$ and $\left.30 / 27^{\circ} \mathrm{C}\right)$, when varying the $\mathrm{IHX}$ surface. 147

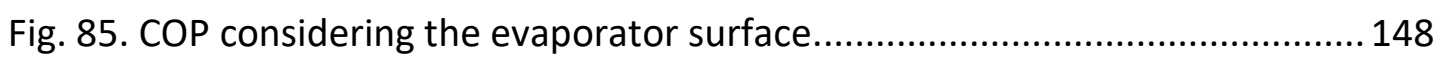

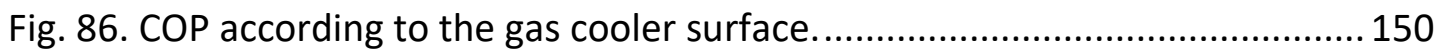

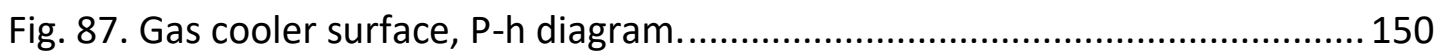

Fig. 88. Influence of varying all HX surface. ...................................................... 151

Fig. 89. COP according to the evaporator water temperature to produce $60^{\circ} \mathrm{C} \mathrm{DHW}$,

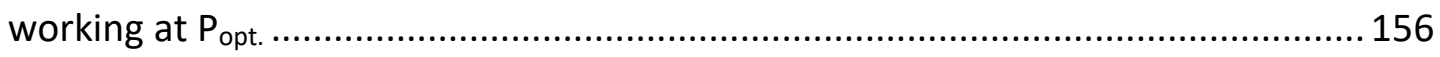
Fig. 90. COP according to the gas cooler water inlet temperature to produce $60{ }^{\circ} \mathrm{C}$ DHW, working at $P_{\text {opt. }}$ 
EXPERIMENTAL AND NUMERICAL STUDY OF A 


\section{List of tables}

Table 1. COP of some air-to-water $\mathrm{CO}_{2}$ heat pumps in the market........................... 33

Table 2. COP of some water-to-water $\mathrm{CO}_{2}$ heat pumps in the market. .................... 34

Table 3. Some wastewater source heat pump systems or studies........................... 41

Table 4. Some technical characteristics of the semi-hermetic compressor..............60 60

Table 5. Basic characteristics of the gas cooler HX (B16x34P).................................63

Table 6. Basic characteristics of the evaporator HX (Bx8Tx26P)................................64

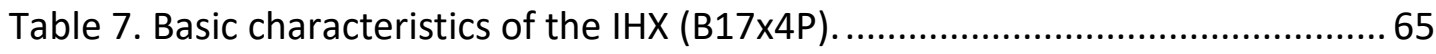

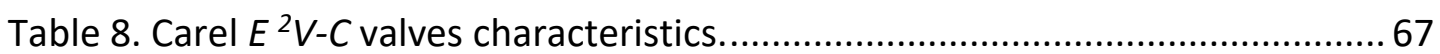

Table 9. Basic characteristics of the water-to-water HX (T2-BFG). .......................... 74

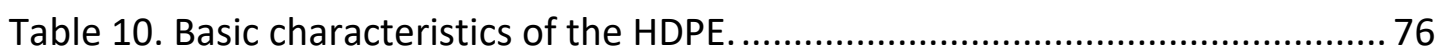

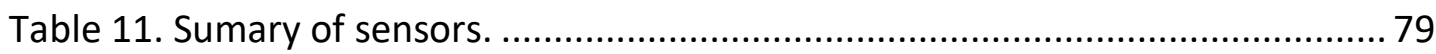

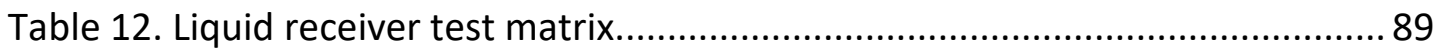

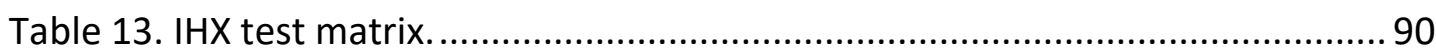

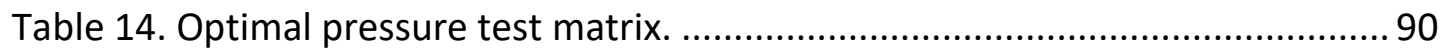

Table 15. Space heating test matrix according to UNE-EN 14511 standard.............. 91

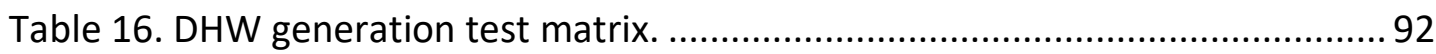

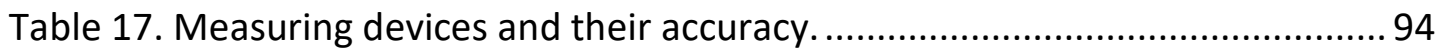

Table 18. Absolute and relative experimental uncertainty. ......................................95

Table 19. Liquid receiver influence on the COP, experimental results................... 101

Table 20. Influence of the IHX efficiency, experimental results. ............................ 104

Table 21. Variation range of the variables used to obtain the numerical model.... 112

Table 22. Adjustment coefficients for compressor behavior curves..................... 113

Table 23. Adjustment coefficients for compressor behavior curves. Equations (31) and

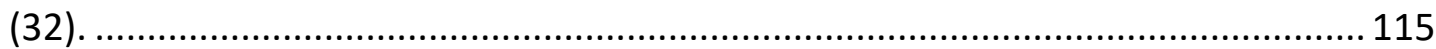

Table 24. Optimal pressure, experimental results............................................. 117

Table 25. Adjustment coefficients for compressor behavior curves [137] [138] and [139].

Table 26. Space heating, C1\&C2, experimental results according to UNE-EN 14511 standard.

Table 27. Space heating, C3, experimental results according to UNE-EN 14511 standard.

Table 28. Space heating, C4, experimental results according to UNE-EN 14511 standard.

Table 29. Space heating, $\mathrm{C} 1 \& \mathrm{C} 2, \mathrm{C} 3$ and $\mathrm{C} 4$, experimental results according to UNEEN 14511. standard

Table 30. SH behavior according to the hot water production and evaporator water temperature.

Table 31. A brief of space cooling application, C1, C2, and C3, experimental results.

Table 32. DHW generation test matrix, C1\&C2 experimental results, with Popt. .. 152 
Table 33. DHW generation test matrix, $\mathrm{C} 1 \& \mathrm{C} 2$ experimental results, with fix pressure $P_{g c}=80$ bar. 152

Table 34. DHW generation test matrix, C3 experimental results, with $P_{\text {opt }} . . . . . . . . . . .153$ Table 35. DHW generation test matrix, C3 experimental results, with fix pressure $P_{g c}=80$ bar. 154

Table 36. DHW test matrix, C1\&C2 and C3 experimental results, with $P_{\text {opt }} \ldots \ldots \ldots . . . .154$ Table 37. DHW generation test matrix, $\mathrm{C} 1 \& \mathrm{C} 2$ and $\mathrm{C} 3$ experimental results, with fix pressure $P_{g c}=80$ bar. 155 
EXPERIMENTAL AND NUMERICAL STUDY OF A 


\section{Nomenclature}

$A H R I$

CFC

$\mathrm{CH}_{4}$

EWT

$\mathrm{N}_{2} \mathrm{O}$

$\mathrm{COP}$

COPC

$\mathrm{COPh}$

$\mathrm{CO}_{2}$

$C 1, C 2, C 3$

DHW

Exp

EV

GC

GCWT

GFHX

$h$

HCFC

$H F C$

HFO

HP

$H P W H$

$H X$

IHX

$\dot{m}$

$N / I$

$\mathrm{N}_{2} \mathrm{O}$

Num

$O D P$

ODS

$P$

PFC

$q$

$S$

$\mathrm{SF}_{6}$

$S C$

SH

$T$

$\dot{W}$

WWHX

WWSHP

WWs

$W W W$

100-year GWP
Air-Conditioning, Heating, and Refrigeration Institute

Chlorofluorocarbons

Methane

Evaporator Water Tank

Nitrous Oxide

Coefficient Of Performance

Cooling COP

Heating COP

Carbon Dioxide

Configuration 1, 2 and 3

Domestic Hot Water

Experimental

Evaporator

Gas Cooler

Gas Cooler Water Tank

Gravity Film Heat Exchanger

enthalpy $\left(\mathrm{kJ} \cdot \mathrm{kg}^{-1}\right)$

Hydrochlorofluorocarbons

Hydrofluorocarbons

Hydrofluoroolefin

High pressure

Heat Pump Water Heater

Heat Exchanger

Internal Heat Exchanger

mass flow rate $\left(\mathrm{kg} \cdot \mathrm{s}^{-1}\right)$

Not indicated

Nitrous Oxide

Numerical

Ozone Depletion Potential

Ozone Depleting Substances

Pressure (bar)

Perfluorocarbons

Specific heat transfer $\left(\mathrm{kJ} \cdot \mathrm{kg}^{-1}\right)$

Surface

Sulfur hexafluoride

Subcooling

superheating degree $(\mathrm{K})$

temperature $\left({ }^{\circ} \mathrm{C}\right)$

compression work (kW)

Wastewater Heat Exchanger

Wastewater Source Heat Pump

Wastewater in summer

Wastewater in winter

Global Warming Potential during 100 years 


\section{Greek symbols}

$\Delta$

Increase (-)

$\eta$

Efficiency (-)

$\rho$

Density $\left(\mathrm{kg} \cdot \mathrm{m}^{-3}\right)$

$\tau$

Compression ratio (-)

\section{Subscripts and superscripts}

$a$

$a m b$

c

comp

ev

evap

gc

$H P$

in

is

$L P$

$l r$

$\max$

$\min$

opt

out

$r$

$r$

ri

ro

w

wi

wo

wi/o

WWs

WWW actual (suction) conditions

Ambient

Compressor

Compressor

Evaporator

Refrigerant Evaporation

Gas Cooler

High Pressure

Inlet

Isentropic

Low Pressure

liquid receiver

Maximum

Minimum

Optimal

Outlet

rated conditions, eq. (27)

refrigerant

refrigerant inlet

refrigerant outlet

water

water inlet

water outlet

water inlet and outlet

Wastewater in summer

Wastewater in winter 
EXPERIMENTAL AND NUMERICAL STUDY OF A 
1. Introduction, Literature review, and Objectives 


\subsection{A brief introduction}

The present doctoral thesis is based on the project "Maximization of the efficiency and minimization of the environmental impact of the heat pumps for the decarbonization of space heating and Domestic Hot Water generation (DHW) in the buildings with almost null energy expense", (ENE2017-83665-C2-2-P). As part of it, the researching team is considering the use of carbon dioxide $\left(\mathrm{CO}_{2}\right)$ in hot water generation through a water-to-water heat pump. The heat source water range used in the evaporator ( 10 to $25^{\circ} \mathrm{C}$ ) is according to the EN-14511-2-Standard [1]. These water inlet temperatures may be similar to the ones found in heat recovery application, such as wastewater, borehole and geothermal water. The experimental installation is located in the Calor y Frío Laboratory at Universidad Politécnica de Cartagena (UPCT). At the moment, the facility is using normal net water as heat source (evaporator) and heat sink (gas cooler).

Though some of the refrigerants from the families like Chlorofluorocarbons (CFC), Hydrochlorofluorocarbons (HCFC) and Hydrofluorocarbons (HFC) have low ozone depletion potential (ODP), they have a big influence on the global warming potential (100-yrs-GWP). The main motivation here is using the natural refrigerant $\mathrm{CO}_{2}$ in hot water generation instead of conventional refrigerants, which is being doing already as a result of world politics promoted by most of the developed and under development countries following commitments like the Montreal Protocol and its most recent adjustments [2]; the Kyoto Protocol [3]; and the Paris Agreement [4]. $\mathrm{CO}_{2}$ is environmentally friendly, no toxic, and no flammable, it has an ODP of zero and its 100-year GWP is one (or zero if taken from industrial processes).

The present research studies different configurations of the thermodynamic cycle grouped as dry evaporator and flooded evaporator. Those configurations have been previously studied in different researches in the field of heating and cooling, paying attention on the components of the cycle, the optimal pressure, comparing $\mathrm{CO}_{2}$ to a conventional refrigerant, among others. Furthermore, those configurations are commonly used in the heating and cooling market.

The different studies to be performed include the optimal pressure and the development of an optimal pressure correlation to be easily controlled by a PID controller, applicable for a wide range of semi-hermetic compressors, which are the most commonly used in the stationary heat pumps. The other study that is going to be performed in this work, is the comparison of the different configurations for the space heating and DHW applications. With these two studies, the influence of different variables is going to be studied, such as the pressure of the liquid receiver, the Internal Heat Exchanger (IHX) efficiency, the evaporation temperature, the refrigerant temperature out of the gas cooler, and the influence of varying the heat transfer areas of the different heat exchangers (HXs), among others. 


\subsection{Current technological situation of the heat pumps for hot water generation in the market, and the environmental situation of the refrigerants used}

This section presents different aspects related to the current situation of heat pumps technology. They include the efficiency and the use of environmentally friendly refrigerants.

\subsubsection{Heat pumps for hot water generation}

This section pays attention to technical aspects of some heat pumps found in the market.

When clients want to buy a heat pump, they analyze different offers and among many factors, they see the heating capacity of the machine, if it could satisfy their industrial or residential needs, the capacity of the water storage, and the physical characteristics, but here, factors like COP, refrigerants used, the type of heat pump considering the heat source, and some information about the control mode, are going to be presented.

The types of control found, show that all systems are up-to-date with LED screens to inform the users about the state of the heat pump, alarms, and they also include buttons for selecting the sought conditions according to the user's needs. Furthermore, some of them have the option of controlling using smart phones. Also, the ones working under extreme ambient air conditions (like $\mathrm{T}<-25{ }^{\circ} \mathrm{C}$ outside air), include intelligent defrosting device.

When exploring the market of heat pump water heaters, the catalogues do not give details of the used cycles, there can be found basic cycles with only the four main components showing the water loop passing through the condenser as an illustration of a heat pump. Regarding the type of heat source, air-to-water heat pumps are the most common among more than 20 catalogues. Considering the final water temperature, most of the heat pumps offer a water temperature between $50-60{ }^{\circ} \mathrm{C}$. The COPs are based on tests performed following the EN-14511-2 and UNE-EN-16147 Standards $[1,5]$.

In air-to-water heat pumps, considering the refrigerants used and the performance stated by the manufacturers, two of the most common HFC refrigerants, R-134a and R-410A, are found with COPs average around 3.30 and 4.26 , respectively. For the same type of heat pump, the natural refrigerant propane (R-290) is found offering a COP average of 4.13 for six different capacities. Those who offer $\mathrm{CO}_{2}$ air-to-water heat pumps, show an average around 3.59. 


\subsubsection{1. $\mathrm{CO}_{2}$ Heat pumps for hot water generation in the market}

Regarding the heat pumps working with $\mathrm{CO}_{2}$, which is the main subject of this thesis, the market offers control for the COP optimization. A high stratification storage tank is also found in the offers. There is information about the maximum high pressure at the refrigerant cycle $\left(P_{\max }<130\right)$ and also, a maximum water inlet temperature at the condenser is recommended to be $43^{\circ} \mathrm{C}$, and $35^{\circ} \mathrm{C}$ by another provider. Furthermore, the technology is up-to-date with the software and screen control for the user's needs. In most cases, the COPs found are related to hot water production between $50{ }^{\circ} \mathrm{C}$ and $65^{\circ} \mathrm{C}$, though some of them offer the capacity of producing water up to 85 ${ }^{\circ} \mathrm{C}$ and $90^{\circ} \mathrm{C}$.

Considering the air-to-water heat pump, when the heat source is from $-15^{\circ} \mathrm{C}$ to $0{ }^{\circ} \mathrm{C}$, the COP average is 2.76 ; when the air is from -26 to $43^{\circ} \mathrm{C}$, the COP average is around 3.70; and, when the air is from $5{ }^{\circ} \mathrm{C}$ to $25^{\circ} \mathrm{C}$, the COP average is found around 4.03. Table 1 shows some COPs found in the market for the $\mathrm{CO}_{2}$ air-to-water technology.

Table 1. COP of some air-to-water $\mathrm{CO}_{2}$ heat pumps in the market.

\begin{tabular}{|l|l|l|l|l|l|l|l|l|}
\hline \multicolumn{1}{|c|}{ Provider } & \multicolumn{1}{|c|}{ Temperatures $\left({ }^{\circ} \mathrm{C}\right)$} & \multicolumn{6}{c|}{ COP for different capacities } & AVG \\
\hline Aquatermic & $\begin{array}{l}\text { Air: }-10 \text { to } 40 \\
\text { Hot water: } 3 / 50\end{array}$ & 2.6 & 2.3 & 2.7 & 3.4 & & 2.8 \\
\hline \multirow{2}{*}{ Sanden } & $\begin{array}{l}\text { Air: }-26 \text { to } 43.3 \\
\text { Hot water: } 65\end{array}$ & 4.5 & 4.5 & & & & & 4.5 \\
\hline \multirow{2}{*}{ Tecna HP90 } & $\begin{array}{l}\text { Air: }-15 \text { to } 0 \\
\text { Hot water: } 10 / 60\end{array}$ & 2.6 & 2.8 & 3.1 & 3.5 & & & 3.0 \\
\cline { 2 - 10 } & $\begin{array}{l}\text { Air: } 5 \text { to } 25 \\
\text { Hot water: } 10 / 60\end{array}$ & 3.8 & 4.0 & 4.1 & 4.5 & 4.9 & 5.4 & 4.5 \\
\cline { 2 - 10 } & $\begin{array}{l}\text { Air }-15 \text { to } 0 \\
\text { Hot water: } 20 / 60\end{array}$ & 2.4 & 2.6 & 2.9 & 3.2 & & & 2.8 \\
\cline { 2 - 10 } & $\begin{array}{l}\text { Air: } 5 \text { to } 25 \\
\text { Hot water: } 20 / 60\end{array}$ & 3.5 & 3.6 & 3.8 & 4.1 & 4.4 & 4.8 & 4.0 \\
\cline { 2 - 9 } & $\begin{array}{l}\text { Air: }-15 \text { to } 0 \\
\text { Hot water: } 30 / 60\end{array}$ & 2.2 & 2.4 & 2.6 & 2.8 & & & 2.5 \\
\cline { 2 - 9 } & $\begin{array}{l}\text { Air: } 5 \text { to } 25 \\
\text { Hot water: } 30 / 60\end{array}$ & 3.1 & 3.2 & 3.4 & 3.7 & 4.0 & 4.3 & 3.6 \\
\hline $\begin{array}{l}\text { Automatic } \\
\text { heating. } \\
\text { cute }\end{array}$ & $\begin{array}{l}\text { Air:-25 to } 43 \\
\text { Hot water: } 65\end{array}$ & 3.2 & 3.6 & & & & & 3.4 \\
\cline { 2 - 9 } & $\begin{array}{l}\text { Air: }-20 \text { to } 43 \\
\text { Hot water: } 65\end{array}$ & 4.2 & 3.9 & 3.6 & & & & 3.9 \\
\hline $\begin{array}{l}\text { Mitsubishi, } \\
\text { ton }\end{array}$ & $\begin{array}{l}\text { Air: }-25 \text { to } 43 \\
\text { Hot water: } 10 \& 5 \text { to } 60\end{array}$ & 4.7 & 4.3 & & & & & 4.5 \\
\hline
\end{tabular}

As shown in Table 2, for water-to-water heat pumps, the COP average is 3.72. For the water temperature range in the evaporator from -2 to $22^{\circ} \mathrm{C}$, the COPs average are 4.04 (for $10 / 60{ }^{\circ} \mathrm{C}$ ), 3.66 (for $20 / 60{ }^{\circ} \mathrm{C}$ ), and 3.24 (for $30 / 60{ }^{\circ} \mathrm{C}$ ). Another provider offers a global combined COP of 9.6 (cooling + heating), using wastewater source at $37 / 32{ }^{\circ} \mathrm{C}$ (inlet/outlet) and producing hot water at $65^{\circ} \mathrm{C}$. 
Table 2. COP of some water-to-water $\mathrm{CO}_{2}$ heat pumps in the market.

\begin{tabular}{|c|l|c|c|c|c|c|c|c|}
\hline Provider & \multicolumn{1}{|c|}{ Temperatures $\left({ }^{\circ} \mathrm{C}\right)$} & \multicolumn{3}{|c|}{ COP for different capacities } & AVG \\
\hline Tecna HP90 & $\begin{array}{l}\text { Cold water: }-2 \text { to } 22, \text { with } \\
\Delta T=5 \mathrm{~K}, \text { Hot water: } 10 / 60\end{array}$ & 3.1 & 3.5 & 3.9 & 4.2 & 4.6 & 5.0 & 4.1 \\
\cline { 2 - 11 } & $\begin{array}{l}\text { Cold water: }-2 \text { to } 22, \text { with } \\
\Delta T=5 \mathrm{~K}, \text { Hot water: } 20 / 60\end{array}$ & 2.9 & 3.2 & 3.5 & 3.8 & 4.1 & 4.5 & 3.7 \\
\cline { 2 - 9 } & $\begin{array}{l}\text { Cold water: }-2 \text { to } 22, \text { with } \\
\Delta T=5 \mathrm{~K}, \text { Hot water: } 30 / 60\end{array}$ & 2.6 & 2.8 & 3.1 & 3.4 & 3.6 & 3.9 & 3.2 \\
\cline { 2 - 7 } & $\begin{array}{l}\text { Cold water: }-2 \text { to } 22, \text { with } \\
\Delta T=5 \mathrm{~K}, \text { Hot water: } 10 / 90\end{array}$ & 2.8 & 3.1 & 3.3 & 3.4 & 3.6 & 3.8 & 3.3 \\
\hline Cooltherm & $\begin{array}{l}\text { Cold water: } 20 / 14, \text { Hot water: } \\
20 / 80\end{array}$ & 4.3 & 4.3 & 4.1 & 4.2 & 4.2 & 3.9 & 4.2 \\
\hline Unimo WW & $\begin{array}{l}\text { Cold water: }-5 /-9,12 / 7,37 / 32, \\
\text { Hot water: } 17-65,90 \text { max }\end{array}$ & 3.0 & 4.1 & 5.3 & & & & 4.1 \\
\hline
\end{tabular}

For the COPs found in the catalogues, and since being environmentally friendly, $\mathrm{CO}_{2}$ seems to be competitive with the conventional refrigerants which have high global warming potential and are predestined to disappear considering the international policies on this matter.

\subsubsection{Environmental situation of the refrigerants used}

Possibly, the perfect refrigerant does not exist, and the environment is the most important factor nowadays. So, a brief synthesis is going to be presented about the refrigerants evolution, the environmental impact, the agreements, and the objectives sought in order to limit the $\mathrm{CO}_{2}$ emission.

\subsubsection{First generation (1830-1930)}

During the $19^{\text {th }}$ and early $20^{\text {th }}$ centuries surged the first generation of refrigerants, there can be found ethyl chloride (R-160), sulfur dioxide (R-764), methyl chloride (R40), ammonia (R-717), and $\mathrm{CO}_{2}$ (R-744), among others. Though they do not register high ODP or 100-year GWP, all, with the exception of $\mathrm{CO}_{2}$ and ammonia, were phased out due to their toxicity and flammability.

\subsubsection{Second generation, CFCs \& HCFCs (1931-1990)}

With the objectives of reducing toxicity, flammability and all damages on the planet, around 1930, new refrigerants appeared after modifying the molecular structure of hydrocarbons using chlorine and flour atoms instead of hydrogen atoms, bringing a second generation which included Chlorofluorocarbons (CFC) and Hydrochlorofluorocarbons (HCFC), being dichlorodifluoromethane (R-12), trichlorofluoromethane (R-11), chlorodifluoromethane (R-22), chloropentafluoroethane ( $R-115$ ), and R-502 (a mixture between $R-22$ and $R-115$ ) part of the most notable ones.

\subsubsection{Montreal Protocol (1987)}

Before the Montreal protocol [2], Molina \& Rowland [6] studied and identified the CFCs as the main responsible for the atmospheric chlorine. The results were validated 
by Kaufman [7] in a report from the National Academy of Sciences. In 1985, a study by Farman et al. [8] overwhelmed the world with a work about the large losses in the ozone layer. Thereafter, in 1987 the Montreal Protocol is signed for a global agreement to protect the ozone layer by phasing-out the production and consumption of ozone-depleting substances (ODS). The agreement is still active and is being revised in its annual meeting and the most recent details are found in [2].

\subsubsection{Third generation, HFCs (1990-2010)}

The third generation, HFC, appears as an effort to eliminate chlorine in order to protect the ozone layer and to fulfill the agreement trying to match the performance of R-22. Among this generation can be found pure gases like: R-134a, R-32, R-125, and R-143a, and also mixtures options like: $R-407 C$ (R-125+R-32+R-134a), R-404A (R$125+R-134 a+R-143 a)$, and $R-410 A$ (R-32+R-125), among others. Most of these refrigerants have $O D P=0$, but high 100-year GWP.

\subsubsection{Fourth generation, Hydrofluoroolefin HFOs (2010-present)}

The purposes of the third generation to reduce the ODP was successful, but even though the ODP is zero in almost all of the refrigerants, they still have 100-year GWP. Now the objective was to develop new refrigerants with zero ODP and very low $100-$ year GWP. There, refrigerants like R-1234yf and R-1234ze, can be found, which have $O D P=0$ and a very low 100-year GWP closed to 1.

\subsubsection{Kigali Amendment to the Montreal Protocol (2016)}

During the $28^{\text {th }}$ meeting of the Montreal Protocol [2], although the ODP goal was met, the parties reached the Kigali-Amendment [9] to try to phase-down the HFCs since the 100-year GWP range goes from high to very high (12 to 14800). The HFOs were not included in this agreement because they are not as dangerous to the ozone layer and atmosphere as the HFCs.

\subsubsection{Hydrocarbons, HCs}

Other refrigerants being used are hydrocarbons refrigerants, such as propane (R$290)$, isobutane ( $R-600 a)$, propylene ( $R-1270)$, and ethane ( $R-170)$. All have ODP $=0$, and have a 100-year GWP average around 4.0. The main problem is their flammability, thus, the installations should be prepared to handle this problem.

\subsubsection{Other agreements}

Besides the Montreal Protocol, there is a Kyoto Protocol [3], which plans to reduce the green-house gases $\left(\mathrm{CO}_{2}, \mathrm{CH}_{4}\right.$ and $\left.\mathrm{N}_{2} \mathrm{O}\right)$ and industrial flour gases (HFC, PFC, and $\left.\mathrm{SF}_{6}\right)$. The agreement is supposed to finish on December 2020. Just after finishing Kyoto Protocol [3], the Paris Agreement [4] signed by 97 countries on November 2016, will start. Part of the objectives is to strengthen the world's responses to the climatic change. 


\subsection{Current status of the researches}

This section presents the current status of the researches. For the water-to-water heat pumps the use of ground water or wastewater as heat source could be interesting alternatives. A literature review about researches in the use of wastewater as heat source and the use of $\mathrm{CO}_{2}$ as a refrigerant is going to be presented. The advantages of these technologies, the limitations that should be considered when designing these types of facilities, and other important factors are going be reviewed according to the available literature.

\subsubsection{Sources of research disclosure}

The two alternatives: Wastewater Source Heat Pump (WWSHP) and $\mathrm{CO}_{2}$ as a refrigerant, are two emerging technologies in the developed countries. They are considered as renewable energies and represent an improvement when compared with conventional systems, but they still represent challenges in order to improve their performances.

Considering the use of WWSHP, the most common topics studied in wastewater technologies are based on feasibility and economic analysis, the wastewater temperature ranges, evaluation of technologies already existing, the wastewater collection, the cleaning devices, and characteristics of the wastewater heat exchanger (WWHX).

Regarding the $\mathrm{CO}_{2}$, the main topics found in the existing literature are based on the use of an IHX, mixtures with other refrigerant, the use of a turbine as expansion device, the heat pump mode regarding the heat source and heat sink (i.e.: water-towater), the comparison of $\mathrm{CO}_{2}$ with conventional refrigerant, the heat pump application (space heating, space cooling, or DHW), control strategies, and the $\mathrm{CO}_{2}$ optimal pressure.

Both subjects have been presented in different scientific congress, conferences and journals, being the International Journal of Refrigeration and Applied Thermal Engineering the most commonly used to spread the knowledge of these areas. Other sources are Energy, International Journal of Thermal Sciences, Energy and Building, Energy Procedia, Energy Conversion Management, Applied Energy, and Energies, among others. Purdue University, International Refrigeration and Air Conditioning Conference, and CYTEF, are among the conferences and congresses that present this type of studies.

\subsubsection{Wastewater source heat pump}

This section presents the general interest of the use of wastewater for heating and cooling application and some important energy information, such as COPs and temperatures found in the numerical and experimental studies. 


\subsubsection{General interest of WWSHP around the world}

The wastewater treatment has been a challenge around the world, especially in times or places with disposal problems. As stated by Asano et al. [10], Japan has launched urban wastewater reclamation and reuse projects since 1968 . They presented the wastewater treatment policies, reuse, and characteristics considering two applications already working in Tokyo and Fukuoka. They state that the key to success of wastewater reclamation and reuse is the quality of the reclaimed water.

Since the 1980s, the first European WWSHPs were installed, such as in Germany, Switzerland, Norway, and Sweden, using the heat from wastewater either in the sewage system or in the effluent of sewage treatment plants, as heat source or heat sink for supplying heating or cooling for refrigeration and water heating. Furthermore, numerical and experimental studies have been performed in England, and by the end of the $20^{\text {th }}$ century, in Japan, China and USA. Currently, hundreds of WWSHPs are in operation world-wide as stated by Zhou \& Li [11], Schmid [12], Hepbasli et al. [13], Cipolla \& Maglionico [14], Culha et al. [15], and Shen et al. [16].

Wastewater is seen as a renewable heat source for heat pumps due to their advantages of relatively high energy utilization efficiency and environmental protection. In the past two decades, the WWSHPs have become popular among different applications and researches, such as in schools, industries, swimming pools, gyms, hospitals, municipal buildings, homes for elderly, urban townhomes, and train stations, among others $[12,13,14,15,16,17,18]$.

Even though great efforts have been made in order to improve the efficiency of individual systems, and significant progress has been achieved in the last decades, researchers and manufacturers still have some environmental challenges in USA, such as Ni et al. [19] state. Regarding the quality of the wastewater and WWHX cleaning concern, some researchers of WWSHPs have been engaged in study and development of two kinds of critical equipment in China, such as wastewater collection device and WWHX [16].

\subsubsection{Classifications of WWSHP}

When exploring the literature, there exist different studies, such as general or descriptive studies, feasibility studies, evaluation of already working facilities, and general reviews. There is information about the WWSHP types, wastewater temperatures, the WWHX, COP, and the refrigerants used. For any reasons, some of the papers do not specify any refrigerants, but other details are found.

\subsection{Based on the wastewater quality}

From the available literature, the first studies are related to the use of treated wastewater as it is the case of Tassou [20], using winter effluent water from sewage treatment plants of England. It is shown that both gas engine driven and electrically driven heat pumps can provide substantial savings when compared to natural gas fired boilers. When producing hot water at $45^{\circ} \mathrm{C}$, the COP was 4.5. In USA, Walker [21], recovering heat from treated sewage water and supplying heat to the anaerobic denitrifying pool where the sewage is treated with heat, found the COP average 
around 2.8. A study in Japan, performed by Asano et al. [10], presented examples of Tokyo and Fukuoka with special reference to toilet-flushing in high-rise business buildings applications. The water temperature was $10.8-12{ }^{\circ} \mathrm{C}$ in winter, and $26-19{ }^{\circ} \mathrm{C}$ in summer. A plate $\mathrm{HX}$ with auto-cleaning heat transfer surface is used.

Furthermore, for the first time in Japan, the Japan-National-Team [22] used untreated wastewater for district heating and cooling. It adopted an open-type automatic rotary screen machine as the wastewater collection device and stainlesssteel+titanium HX. The cooling COP is 4.3 and heating COP is 3.9. This result is considerable energy saving and contributes significantly to the mitigation of greenhouse gas emissions.

Using in-house technology in Tennessee, the US Department of Energy (US-DOE) [23] proposed a gravity film heat exchanger (GFHX) for wastewater coming down directly after being used in the shower. The GFHX could raise the inlet temperature from 15 ${ }^{\circ} \mathrm{C}$ to $30{ }^{\circ} \mathrm{C}$ by maintaining shower conditions around $120{ }^{\circ} \mathrm{F}$ (closed to $50{ }^{\circ} \mathrm{C}$ ), an additional water heater was used to guarantee the setpoint. The temperature of the WW inlet to the GFHX was $12^{\circ} \mathrm{F}$ lower than the shower temperature $\left(120^{\circ} \mathrm{F}-12^{\circ} \mathrm{F}=\right.$ $\left.108^{\circ} \mathrm{F}=42^{\circ} \mathrm{C}\right)$.

In a numerical and economical study, Zhou \& Li [11] state that the COP can reach 3.5 to 4.5 in the whole winter. According to their study, they concluded that the application is more economical than convention electrical based systems. It is important to avoid blocking, corrosion and fouling in the WWHX. Wastewater temperature in North China, in winter, is about $20^{\circ} \mathrm{C}$ higher than the outdoor temperature and $10{ }^{\circ} \mathrm{C}$ lower than outdoor temperature in summer. Also, in China, in an exergy study, Qian [24] considered an urban untreated sewage heat pump project in Harbin. During the winter conditions, the ambient temperature was -9.5 ${ }^{\circ} \mathrm{C}$, the wastewater supply temperature was in the range of $10-14{ }^{\circ} \mathrm{C}$ and the return temperature in the range of $6-10{ }^{\circ} \mathrm{C}$. The device used was a shell-and-tube WWHX, and the wastewater was running through the tubes side.

As seen in the previous studies, the WWSHP systems, according to the wastewater quality, can be divided into untreated sewage and treated sewage. And, according to the location of the heat pump equipment, they can be divided into central, semicentral, and disperse. [11]. Central (in-house) are considered small scale applications, and may be costly, semi-central (from the sewer), are considered as medium scale, and disperse (from wastewater treatment plants) are considered as large scale, as stated by different authors, such as Schmid [12] and Garmsiri et al. [25]. Fig. 1 represents both classifications in a single image. 


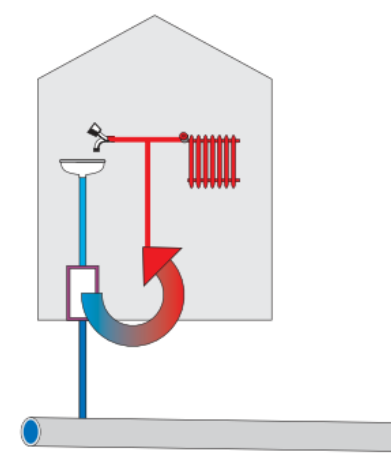

Recovery in building (from raw wastewater)

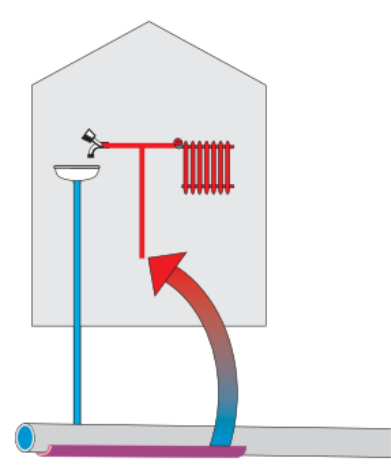

Recovery in sewer (from raw wastewater)

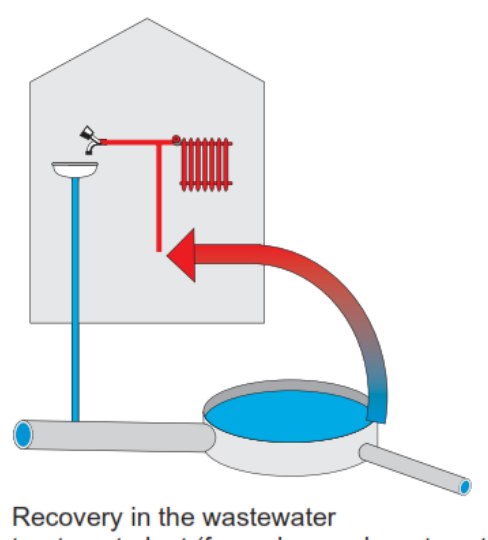

treatment plant (from cleansed wastewater)

Fig. 1. Possibilities of energy recovery from wastewater [12]

\subsection{Differences between treated or untreated wastewater}

When sing untreated sewage as heat source, municipal sewage from a pumping station nearby can be utilized, and the cold or hot water produced by the heat pump is sent to the people who need them. But because untreated sewage contains a large amount of impurity, water treatment equipment and heat transfer equipment are relatively more complicated [11], and, a WWHX with cleaning capability is needed. When untreated WWSHP starts, at first, it would wipe off the big filth in the sewage by special equipment. In case of using shell-and-tube $\mathrm{HX}$, the wastewater goes through the tube and the intermediary water goes through the shell [24].

Regarding the untreated wastewater, whether the wastewater directly flows into the evaporator or the condenser of the main heat pump, WWSHP can be divided into two kinds of systems, using direct wastewater source (direct-type) or indirect wastewater source (indirect-type). Direct-type systems have higher requirements for the source and quality of the water flowing into the condenser or the evaporator, which also should be designed to work with poor water quality. It needs reliable anti-clogging, anti-pollution and anti-corrosion ability. Indirect-type systems have lower requirements for water quality, but this kind of systems needs an additional WWHX, where the wastewater goes through one side, and the intermediate water (condenser or evaporator water) goes through the other side, as stated by Gu \& Deng [26]. However, the direct-type WWHSP system can save $7 \%$ of energy than the indirect-type system [27].

Using treated sewage as heat source, for example, secondary effluent, treated process is simpler than that of untreated sewage. The system may only need onestage filter or may not need the filter at all. Furthermore, the system does not need a WWHX. The evaporator or condenser HX could be plat-type. However, sewage treatment plants are mostly located on the edge of the city that is relatively far from heat users, therefore, if WWSHP equipment room is located in the sewage treatment plant, the pipeline for heating and cooling is relatively longer and the costs are relatively larger [11]. 


\subsection{Main types of wastewater heat exchanger}

According to Hepbasli et al. [13] and Shen et al. [16], direct-type HX or the additional WWHX used in indirect-type, could be divided by: spraying film, immerse, shell and tube, and plate HX. Whereas, according to Mazhar [28] shell-and-tube HX along with plate $\mathrm{HX}$, are the most common for liquid-to-liquid applications; concentric pipes or tube-in-tube $H X$ are simple and cheap and can only be installed in vertical orientation; falling-film $\mathrm{HX}$ is the most common type with numerous commercial manufacturers; and, the other commonly used is the plate $\mathrm{HX}$, which can be installed at building level or inline harnessing in sewage pipes due to its flexibility.

\subsubsection{Summary of the different studies}

According to the studies, the range of the wastewater temperature in most cases is from $10^{\circ} \mathrm{C}$ to $30^{\circ} \mathrm{C}$. Regarding the COP found in WWSHP: overall cooling COP (COPC) average is 4.13 , overall heating $\mathrm{COP}\left(\mathrm{COP}_{\mathrm{H}}\right)$ average is 4.09 . Aside from the case where the COP was over 10.0, the $82 \%$ of registered COPs are in the range from 2.0 to 4.75 , with an average of 3.59. Furthermore, $91 \%$ of them are in the range from 2.0 to 5.75 , with an average of 3.77 .

Considering the refrigerant information found in the studies, $85 \%$ of them are performed using $3^{\text {rd }}$ generation refrigerants (HFC), being R-134a the most common among them. Some tests using propane and city water (in the temperature range found in wastewater), are presented, such as Pitarch et al. [29, 30, 31], whose also stated that although $\mathrm{CO}_{2}$ systems have an advantage in the DHW production because of the heat rejection in the transcritical region, they might have limitations at high discharge pressure since high evaporation temperatures can be reached in WWSHP. Besides the critical pressure (73.8 bar), it has a low critical temperature $\left(31^{\circ} \mathrm{C}\right)$.

Table 3 presents a summary of the COPs found in the literature review considering: wastewater conditions, type of study (numerical or experimental), and refrigerant. For Table 3, $W W_{s}$, is the wastewater in summer; $W W_{w}$, is the wastewater in winter; $H W$, is hot water; Ref, is refrigerant; $N / I$, is Not indicated; $H P$ is Heat Pump, and $T_{a m b}$, is ambient temperature. 
Table 3. Some wastewater source heat pump systems or studies

\begin{tabular}{|c|c|c|c|c|c|c|c|c|}
\hline \multirow{2}{*}{ Study } & \multirow{2}{*}{ Country } & \multirow{2}{*}{$\begin{array}{c}\text { Study } \\
\text { type }\end{array}$} & \multirow{2}{*}{ Refrigerant } & \multicolumn{2}{|c|}{ Wastewater temperatures $\left({ }^{\circ} \mathrm{C}\right)$} & \multicolumn{2}{|c|}{ Temperature of $\mathrm{HW}$ production $\left({ }^{\circ} \mathrm{C}\right)$} & \multirow[t]{2}{*}{ COP $(-)$} \\
\hline & & & & $W W_{s}$ & $w w_{w}$ & $H W_{\text {in }}$ & $H W_{\text {out }}$ & \\
\hline$[20]$ & England & $\operatorname{Exp}$ & $\mathrm{N} / \mathrm{I}$ & $\mathrm{N} / \mathrm{l}$ & & & 45 & 4.5 \\
\hline [21] & USA & Exp & $\mathrm{N} / \mathrm{I}$ & $\mathrm{N} / \mathrm{I}$ & & & & 2.8 \\
\hline [10] & Japan & Exp & $\mathrm{N} / \mathrm{I}$ & HXin: 26, HXout:19 & $\begin{array}{l}\text { HXin:10.8, } \\
\text { HXout: } 12 \\
\end{array}$ & & & $\mathrm{~N} / \mathrm{I}$ \\
\hline [22] & Japan & Exp & $\mathrm{N} / \mathrm{I}$ & $\mathrm{N} / \mathrm{l}$ & & & & $\begin{array}{l}\text { Heat 4.3, } \\
\text { Cool 3.9 }\end{array}$ \\
\hline$*[23]$ & USA & $\operatorname{Exp}$ & $\mathrm{N} / \mathrm{I}$ & \multicolumn{2}{|l|}{$42^{*}$} & & 50 & \\
\hline [11] & China & Num & $\mathrm{N} / \mathrm{I}$ & $T_{\mathrm{amb}}-10$ & $20+T_{a m b}$ & & & 3.5 to 4.5 \\
\hline [18] & Korea & Num & R-134a & \multicolumn{2}{|c|}{ Spring/Autumn: 18} & 28 & 50 & 4.5 to 5 . \\
\hline$\#[32]$ & China & Num & \# & \multicolumn{2}{|c|}{ EVin: 20} & $15,20,25$ & $20,25,30$ & $6.4,4.2,3.5$ \\
\hline$[24]$ & China & Both & & \multicolumn{2}{|c|}{$\begin{array}{c}\text { WWHXin: } 10 \text { to } 14, W W \text { to EVin: } 6 \\
\text { to } 9\end{array}$} & & & $\mathrm{~N} / \mathrm{I}$ \\
\hline [33] & Turkey & Num & R-134a & \multicolumn{2}{|c|}{$\begin{array}{c}\text { EVin: } 65 \\
\text { EVout: } 25\end{array}$} & 20 & 60 & 4.37 \\
\hline \multirow[t]{3}{*}{ [34] } & \multirow[t]{3}{*}{ France } & \multirow[t]{3}{*}{ Both } & \multirow{3}{*}{$\begin{array}{l}\text { R-410A, R-407A } \\
\text { Blend 1; } \\
\text { Blend } 2\end{array}$} & \multicolumn{2}{|c|}{ EVin: 21 to 26} & 26 to 28 & 61 & $\begin{array}{l}3.55 \\
3.68\end{array}$ \\
\hline & & & & \multicolumn{2}{|c|}{ EVin: 21 to 26} & 26 to 28 & 61 & $\begin{array}{l}5.44 \\
5.60\end{array}$ \\
\hline & & & & \multicolumn{2}{|c|}{ EVin: 21 to 26} & 26 to 28 & 38 & 6.98 (annual) Optimal blend \\
\hline [12] & Germany & Exp & $\mathrm{N} / \mathrm{I}$ & \multicolumn{2}{|c|}{10 to 25 (al the year) } & & & 3.8 (annual) \\
\hline [35] & Turkey & Exp & R-134a & \multicolumn{2}{|c|}{$20,30,40$} & 15 & 44.5 to 50.4 & 2.6 to 2.8 \\
\hline [36] & China & Exp & $\mathrm{N} / \mathrm{I}$ & \multicolumn{2}{|l|}{$17-5.3$} & 25 & 40 & 3.55 \\
\hline [37] & Finland & Exp & $\mathrm{N} / \mathrm{I}$ & \multicolumn{2}{|c|}{10 to 18} & & 90 & Heat: 3.3, Cool: 2.23 \\
\hline [38] & China & $\operatorname{Exp}$ & $\mathrm{N} / \mathrm{I}$ & 8 to 14 & & & & 1st\&2nd. stage: $4.2 \& 2.0$ \\
\hline [39] & Switzerland & Num & $\mathrm{N} / \mathrm{I}$ & EV: (HWout-5 & $(1)-20$ & & 55 & 6.0 (annual) \\
\hline [40] & China & $\operatorname{Exp}$ & $\mathrm{R}-22$ & $\mathrm{~N} / \mathrm{I}$ & & & & Heat: 3.8 , Cool: 3.34 \\
\hline [41] & China & $\operatorname{Exp}$ & $\mathrm{N} / \mathrm{I}$ & EV10.7-7.7 & EV10-7 & 33-37 (summer) & 40-45 (Winter) & Heat: 4.3, Cool: 3.5 \\
\hline [42] & China & $\operatorname{Exp}$ & $\mathrm{N} / \mathrm{I}$ & & & & & $\begin{array}{c}\text { 1st\&2nd. stage: } 3.4 \& 3.3, \\
\text { Cool: } 3.12\end{array}$ \\
\hline$[43]$ & China & Exp & R-134a & & & & 45 to 50 & 2.5 to 3.04 \\
\hline [17] & China & Exp & R-134a & $27-33$ & & & 40 to 55 & 2.46 to 2.9 \\
\hline [44] & China & Exp & R-134a & 31.4 to 33 & & & 30 to 50 & 2.87 to 3.8 \\
\hline [45] & Turkey & Num & R-134a & Tevin: 23,35 & & & & 6.6 to 10.63 \\
\hline [19] & USA & Num & $\mathrm{N} / \mathrm{I}$ & 4.4 to 28 & & & 49 & Cool: 4.0 \\
\hline [26] & China & Num & $\mathrm{N} / \mathrm{I}$ & $10-18$ & $20-26$ & 40 & 50 & $\mathrm{~N} / \mathrm{I}$ \\
\hline [46] & USA & Exp & $N / I$ & 21.1 & & 30 & 49 & Heat: 4.0 to 4.5 \\
\hline [47] & USA & Exp & $N / I$ & 23.9, 29.4, & & & & Cool: $4.75,4.5,4.4$ \\
\hline [48] & Korea & Num & $N / I$ & & & & & $\begin{array}{c}\text { Heat: } 3.53 \text { to } 4.06 \text {, Cool: } 4.48- \\
5.35\end{array}$ \\
\hline [49] & Korea & Num & $N / I$ & 20.7 [10-25 range) & $\begin{array}{l}9.9 \text { (3 to } 15 \\
\text { range) }\end{array}$ & $\begin{array}{r}\text { Hot water } \\
\text { (39 to } 43 \text { in w } \\
\text { sun }\end{array}$ & $\begin{array}{l}\text { orage tank } \\
\text { ter), (10-15 in } \\
\text { her) }\end{array}$ & $\begin{array}{c}\text { Single HP: Cool: } 4.79 \text {, Heat: } \\
3.76 . \\
\text { Two HP: Cool: } 4.92 \text { Heat: } \\
3.68\end{array}$ \\
\hline$[50]$ & China & Both & $\mathrm{R}-22$ & 10.9 to 35 & & 14.9 to 35.6 & 36.6 to 53.9 & $3.69-5.70$ \\
\hline [51] & China & Both & $\mathrm{N} / \mathrm{I}$ & $10-18$ & $20-26$ & 40 & 50 & Heat: 4.7, Cool: 4.1 \\
\hline [52] & China & Exp & R-134a & $9-6$ & & $25-45$ & 30,50 & Normal HP: 4.3, WWSHP 3.6 \\
\hline [53] & China & Num & $\mathrm{N} / \mathrm{I}$ & 22 to 36 & 7 to 27 & 20 & 40 & $\begin{array}{l}\text { Heat: } 5.0 ; \\
\text { Cool: } 4.5 \\
\end{array}$ \\
\hline [54] & Russia & Num & $N / I$ & 20 & 8 & & 60 & 3.3 \\
\hline [55] & USA & Both & $\mathrm{N} / \mathrm{I}$ & 21.1 & & 30 & 49 & $4.5,4.75$ \\
\hline$-[14]$ & Italy & Num & $\mathrm{N} / \mathrm{I}$ & $\begin{array}{r}\text { Summer:18-22, Spri } \\
\text { Winter: } 10\end{array}$ & $\begin{array}{l}\text { g/fall: } 14-18, \\
14\end{array}$ & & & 4.0 \\
\hline [56] & China & Both & R-134a & 18 to 3 & & & & 2.4 to 3.5 \\
\hline [57] & Scotland & Exp & $\mathrm{N} / \mathrm{I}$ & 12 to 1 & & & 45 & 2.5 to 3 \\
\hline [58] & Spain & Both & R-410A & $20-15$ (normal & water) & 10 & 60 & 5.5 \\
\hline
\end{tabular}




\subsection{3. $\mathrm{CO}_{2}$ as a refrigerant}

This section presents the use of $\mathrm{CO}_{2}$ as a refrigerant following the literature and the most common topics found in the studies, such as general interest, the relation of conventional and natural refrigerants with $\mathrm{CO}_{2}$, optimal pressure studies, components of the cycle, hot water generation, and the different configurations of the cycle.

\subsubsection{General interest of $\mathrm{CO}_{2}$ as a refrigerants}

This section presents the interest of the $\mathrm{CO}_{2}$ as described in the literature by the first researchers that studied the resurgence of this natural refrigerant. Reader may see that there was a first use of $\mathrm{CO}_{2}$ as a refrigerant, a replacement by CFCs and HCFCs, later, the health and environmental problems of the synthetic substances were demonstrated, and, as soon as the need to preserve the environment came out, the $\mathrm{CO}_{2}$ resurged as a replacement.

\subsubsection{1. $\mathrm{CO}_{2}$ first use}

Since $\mathrm{CO}_{2}$ is part of the first generation's refrigerants, it is used in the refrigeration industry during the mid-1800s and mid-1900s, being commonly used with brine distribution for most ship's installations and also in air-conditioning stationary facilities, Lorentzen [32]. Though the Evans-Perkins process was developed in 1834, it was not until 1866 when the ice production facility started its operations. Following a period of further development, the first documented $\mathrm{CO}_{2}$ compressor was built by Windhausen in 1880. Other uses of $\mathrm{CO}_{2}$ in refrigeration include the first marine installation performed by J \& E Hall in 1890, and the first continuous production of $\mathrm{CO}_{2}$ refrigeration equipment in the US by Kroeschell Bros. of Chicago in 1897. As $\mathrm{CO}_{2}$ has not flammability and toxicity, food-related industries and places of human occupancy (theaters, hospitals, restaurants, etc.) used it in refrigerators and air conditioners almost exclusively, Robinson \& Groll [33].

\subsection{Arrival of the CFC and HCFC}

In the 1930s and 1940s, the fluorocarbons were introduced with a massive advertising campaign, and quickly took over a large part of the market. The main arguments used in the marketing campaign were their complete safety and harmless to the environment, also the fact that cycles that employed fluorocarbons had substantially lower heat rejection pressures than those of $\mathrm{CO}_{2}$. Fluorocarbons quickly replaced $\mathrm{CO}_{2}$ as the refrigerating fluids alternatives. As a result, machines that were based on using $\mathrm{CO}_{2}$, were phased out by the 1950s and have not been massively produced since then. Thus, most of the conventional fields of application were completely dominated by the various types of CFC and $\operatorname{HCFC}[32,33]$.

\subsection{Problems with the CFC and HCFC refrigerants}

The arguments defending the synthetic substances presented before, turned out to be wrong. Many people have died by suffocation in small spaces and ships, others have suffered injuries from dissociation products. Damages to the global 
environment have led to the Montreal Protocol and universal banning of most CFC and HCFC compounds, as stated by Lorentzen [32] and Robinson \& Groll [33]. Refrigerant emissions from mobile and unitary air-conditioning equipment is likely to pass 100000 metric tons, corresponding to a global warming impact of more than 150 million metric tons of $\mathrm{CO}_{2}$, as Pettersen et al. [34] state. The synthetic halocarbons that replaced $\mathrm{CO}_{2}$ are now phased out due to their negative impact on the global environment, Nekså et al. [35]

\subsection{Needs of a safe alternative}

It has become necessary to find a suitable replacement for fluorocarbon-based refrigeration cycles. Such replacement must perform comparable to current refrigerants, be economically feasible, and significantly reduce the possibility of a negative environmental impact compared with current refrigerants [33]. The world efforts to limit greenhouse gas emissions, therefore, include the development of energy-efficient and safe air-conditioning systems ideally based on natural refrigerants with zero global warming potential $[32,34]$.

\subsubsection{5. $\mathrm{CO}_{2}$ resurges as a refrigerant}

$\mathrm{CO}_{2}$, which had been completely abandoned for more than 40 years, is environmental-friendly, safe, inexpensive, non-flammable, and compatible with lubricants and normal machines construction materials. Its relatively high pressure is perfectly adapted to modern machines design and gives a dramatic reduction in the required compressor volume and pipe dimensions. The excellent heat transfer characteristics around the critical point is another advantage. It is believed that $\mathrm{CO}_{2}$ system will have a bright future as a practical solution to the difficulties presented by the Montreal Protocol restrictions, thanks to safety properties, the $O D P=0$, and GWP100-years=1 (or 0 if it is taken from industrial process) [32]. Aside of using it in automobile air conditioning systems, there are also interesting possibilities of using $\mathrm{CO}_{2}$ systems in residential air conditioning and heat pumps. The heat transfer characteristics with $\mathrm{CO}_{2}$ are higher than with fluorocarbons, then, reduced internal surface areas can therefore be allowable and cost efficiently [34, 35]. As studied by [33], another feature of the operating pressures of a $\mathrm{CO}_{2}$ cycle is the lower pressure ratio with respect to an R-22 cycle. The pressure ratios of $\mathrm{CO}_{2}$ vary from 2.5 to 10.2 (using expansion valve as expansion device) and 2.4 to 9.9 (using turbine as expansion device), whereas the pressure ratios of R-22 vary from 2.9 to 14.9 over the same range of evaporation temperatures. Since the isentropic efficiency of a compressor is mainly a function of the pressure ratio, a compressor properly designed for a $\mathrm{CO}_{2}$ cycle could be more efficient than one designed for an R-22 cycle.

\subsubsection{Other comparisons to natural and halogenated refrigerants}

Besides the first comparisons performed to R-22, the previous mentioned authors compared $\mathrm{CO}_{2}$ to $\mathrm{R}-134 \mathrm{a}$ and ammonia $\left(\mathrm{NH}_{3}\right)$. For nearly all of refrigerants, the critical pressure ranges between 30 bar and 50 bar, except water vapor (221 bar), ammonia (113 bar), and $\mathrm{CO}_{2}$ (73.8 bar), as presented by Lorentzen [32]. 
Since the first studies, many authors have performed comparisons to conventional and natural refrigerants, such as Sarkar et al. [36], who compared $\mathrm{CO}_{2}$, ammonia $\left(\mathrm{NH}_{3}\right)$, propane (R-290) and isobutane (R-600a) in high heating applications; Pitarch et al. [31], who compared propane to an air-to-water $\mathrm{CO}_{2}$ water heater already in the market, and Saikawa \& Koyama [37], who theoretically evaluated R-22, R-134a, R$407 \mathrm{C}, \mathrm{R}-410 \mathrm{~A}$, and R-32 as fluorocarbons, and $\mathrm{CO}_{2}$, isobutane, propane and propylene as natural refrigerants. Most of the other $\mathrm{CO}_{2}$ comparisons have been performed to R-134a and R-410A refrigerants, such as Bullard et al. [38], Brown et al. [39], Richter et al. [40], Cecchinato et al. [41], Minetto et al. [42], Stene [43], Nawaz et al. [44], and Song et al. [45]. Furthermore, Ma et al. [46], includes R-1234yf in the comparison of $\mathrm{CO}_{2}$ and other conventional refrigerants.

Aside from the environmental characteristics mentioned before, general studies conclude that $\mathrm{CO}_{2}$ can compete in the market with the reference refrigerants for water heating applications, including when working at low ambient temperatures. A heating COP over 4.0 can be reached when heating water from $9{ }^{\circ} \mathrm{C}$ to $60^{\circ} \mathrm{C}$ at an evaporation temperature of $0{ }^{\circ} \mathrm{C}$, with the possibility of heating up to $90{ }^{\circ} \mathrm{C}$ without operational difficulties [35].

$\mathrm{CO}_{2}$ has also been used as blend with other refrigerants by different researchers, such as Wang et al. [47], who studied the blend of R-744/R-41, for water heating application. The mixture seems to be a good substitute for the pure $\mathrm{CO}_{2}$ because of the low optimal gas cooler pressure. $\mathrm{CO}_{2}$ has also been used in mixtures with propane (R-290/R-744) by different authors, such as Niu \& Zhang [48], who compared the blend to R-13 in a cascade refrigeration system, the COP and refrigeration capacity for the mixture were higher than those of R-13. On a different comparison, in a water heater heat pump, Ju et al. [49] compared an R-744/R-290 mixture to R-22, and the optimal blend of $12 \% / 88 \%$ is a good replacement. Furthermore, Ju et al. [50] presented the numerical results and they agreed with the experimental ones. In the three studies presented, the mixture, with zero ozone depletion potential (ODP) and very low global warming potential (100-year GWP), was better in COP and heating capacity than the conventional refrigerants.

\subsubsection{Configurations used in $\mathrm{CO}_{2}$ heat pumps}

Most of the hot water applications demand temperatures over $30^{\circ} \mathrm{C}$, which requires to work in transcritical cycles. There are different configurations and optional or varying elements, such as whether using IHX or not, one or more expansion devices, the use of a turbine as expansion device which can produce energy, the use of an ejector, the use of a liquid receiver, etc. Depending on the number of stages of the cycle, heat pumps can be divided into one and multiple stage systems. In addition, one may encounter the evaporator can be divided as dry or flooded. In dry evaporator system, there may be a liquid receiver/separator or not. 


\subsection{One-stage compression systems}

Considering the group when the compression work is performed by a single compressor, studies can be found using dry and flooded evaporator, and some of them use it with or without IHX, and with one or two expansion devices, as shown in Fig. 2.

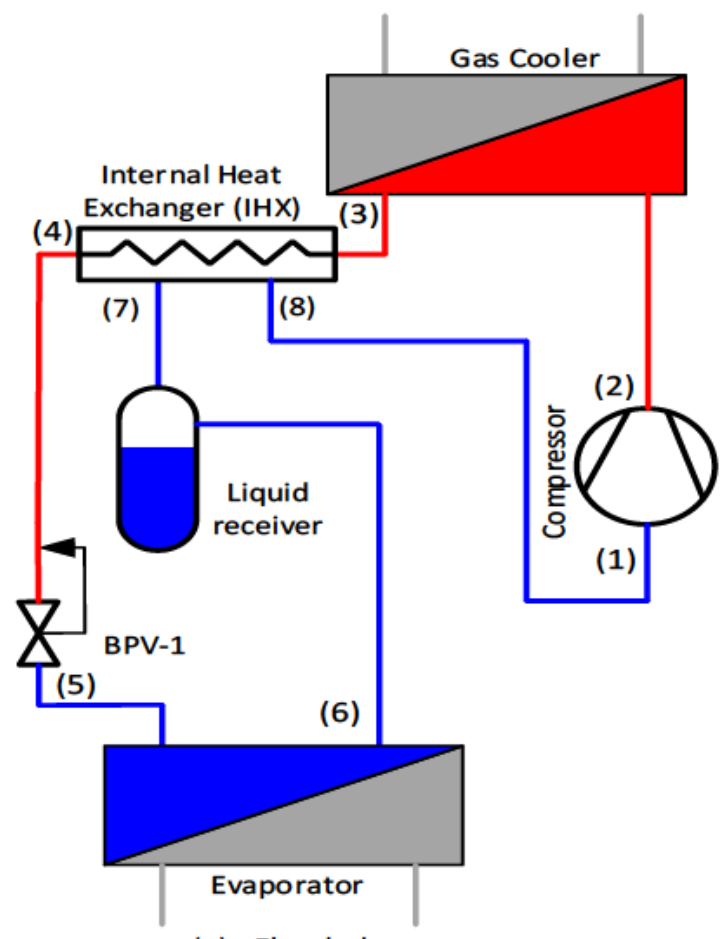

(a) Flooded evaporator

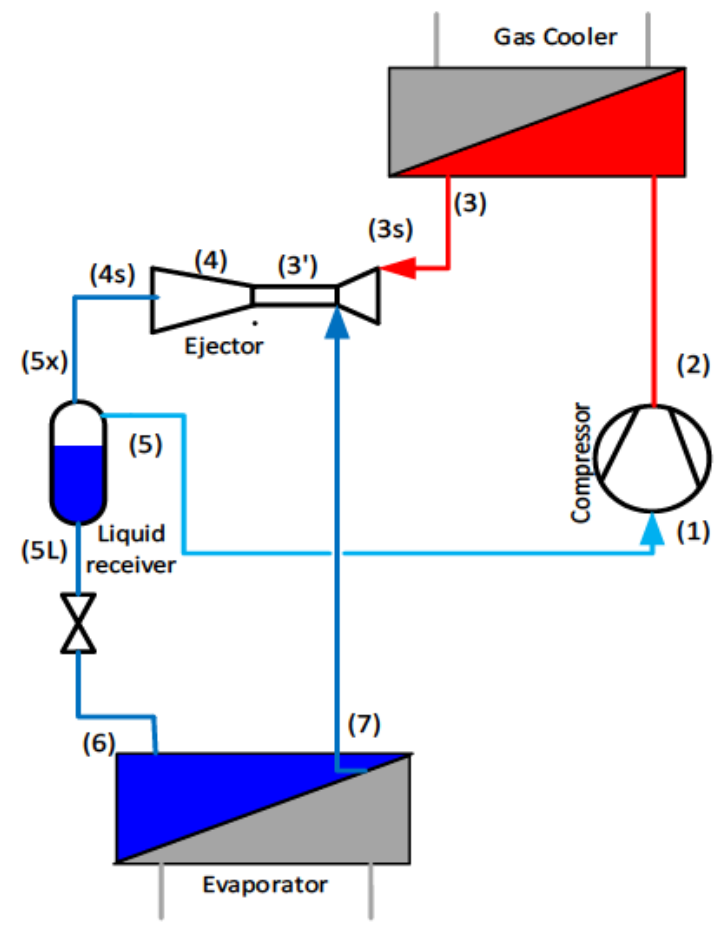

(c) Single stage transcritical cycle using an ejector

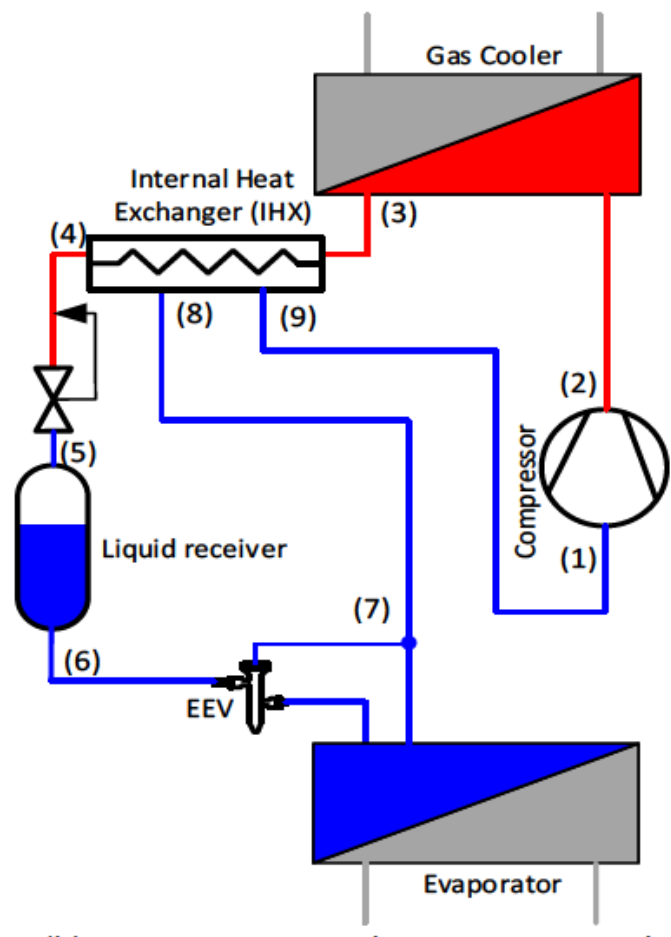

(b) Dry evaporator with two expansion valve

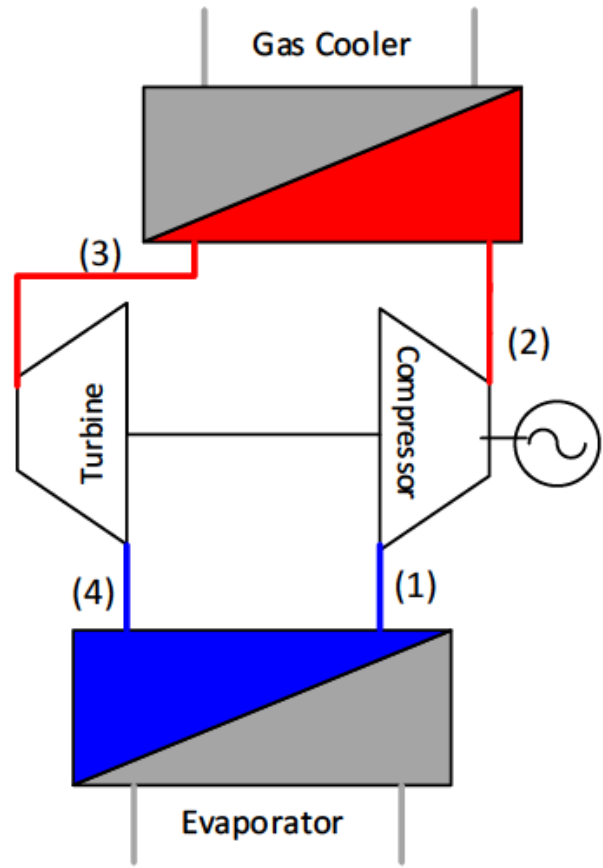

(d) Single stage transcritical cycle with turbine

Fig. 2. One-stage cycles found in the literature review. 


\section{With flooded evaporator:}

In this type of cycle, only one expansion valve is needed. Among the authors who have studied the cycle with IHX, can be found the works by Lorentzen [32], Nekså et al. [35], Liao et al. [51], Aprea \& Maiorino [52], Chen and Gu [53], Pérez-García et al. [54], Minetto et al. [42], Shao et al. [55] and Cao et al. [56]. On the other hand, other authors have presented the cycle without IHX, such as $[54,57]$.

Regarding the type of expansion device, in all the papers mentioned before, authors use expansion valve, but Pérez-García et al. [54] and Minetto et al. [42], besides the expansion valves, analyzed a turbine and ejector, respectively.

According to the literature, cycles which use turbine as expansion devices produce better performance. The power generated contributes to decrease the system power consumption $[33,54]$. However, testing of a transcritical $\mathrm{CO}_{2}$ system with a turbine is inconvenient, high cost and time-consuming [58]. Therefore, cheaper devices are used in facilities, such as thermostatic valves. Another disadvantage of this device is the complexity for adapting it on the cycle. This application is generally recommended when the facility needs high power [54].

\section{With dry evaporator:}

Among the authors who have presented the cycle with IHX, one may highlight the research performed by Robinson \& Groll [33], Kim et al. [59], Cabello et al. [60], Torrella et al. [61], Zhang et al. [62], Cabello et al. [63], Pérez-García et al. [54], Sánchez et al. [64], Nebot-Andrés et al. [65], Deng et al. [66], Elbel \& Hrnjak [67], and Yari et al. [68]. On the other hand, other authors have presented the cycle without IHX, such as $[46,54,61,63,64,69,58,70,71,72]$.

Some authors have presented the cycle with one expansion device, such as $[33,46$, $59,66,58,70,72]$. And, on the other hand, authors like $[46,54,60,61,62,63,64,65$, $69,70]$, have presented the cycle with two expansion devices. Different authors have used ejector in the cycles, such as Deng et al. [66], Elbel \& Hrnjak [67], Sarkar et al. [72], and Xu et al. [73]. Regarding the double expansion cycle (Fig. 2.b), it allows to control the high pressure and the superheating degree separately, this is a reliable alternative and represents an improvement to the transcritical systems [54] [62]. However, attention must be paid to the liquid receiver pressure.

Regarding the type of expansion device, most of all authors used expansion valve, with exception of Yang et al. [58] and Ma et al. [46] that only presented the cycles with turbine, and Robinson \& Groll [33] compared the cycle working with turbine to the one working with expansion valve. 


\subsection{Multiple-stages compression systems}

In multi-stages systems, besides the optimal high pressure, there exists an optimal intermediate pressure. However, this one has little influence on COP [46]. The most common configurations are those that use dry expansion evaporator having $\mathrm{IHX}$ or not, depending on the case, and one or several expansion devices as shown in Fig. 3.

Among the authors that have presented the cycle with IHX, can be found [32, 52, 68, $74,75,76]$. On the other hand, other authors have presented the cycle without IHX, such as $[32,46,74,76]$, who have presented the cycle with and without intercooler between both compressors.

As presented by [46], two-stage $\mathrm{CO}_{2}$ transcritical cycle can overcome the excessively high discharge temperature in single-stage cycle. Using economizer or intercooler improves the COP. However, different from other intercooling methods, flash intercooling reduces the COP.

Some authors have presented the cycle with one expansion device, such as $[32,46$, $76]$. And, on the other hand, works by $[46,74]$, have presented the cycle with two expansion devices. While, [68], presented the cycle with and without ejector.

Regarding the type of expansion device, $[32,46,76]$ present the cycle with turbine as expansion device. On the other hand, $[32,52,68,74,75,76]$ present the cycle using valve as expansion device.

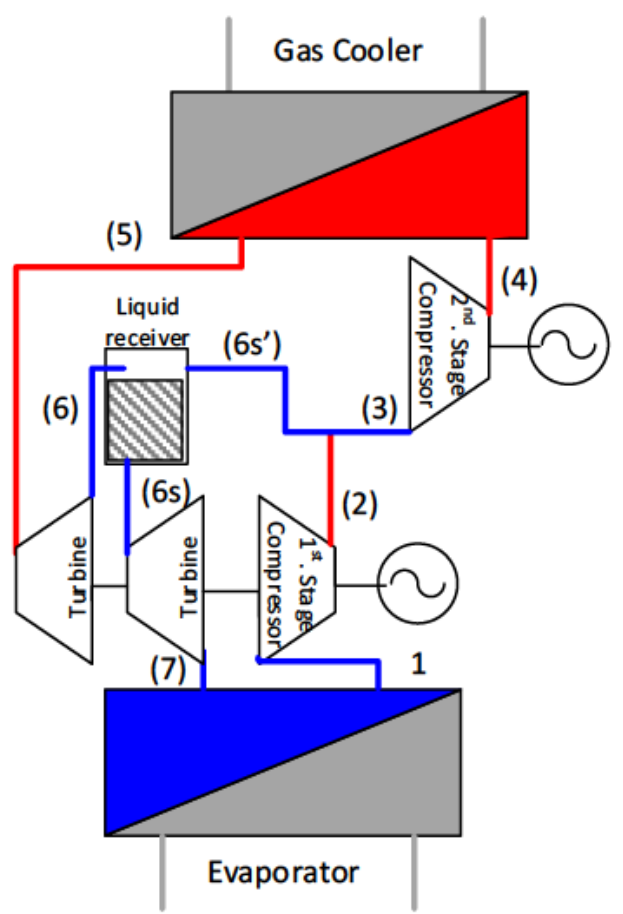

(a) Two-stage transcritical cycle with liquid separator using turbine two-stage expansion to drive the low stage compressor

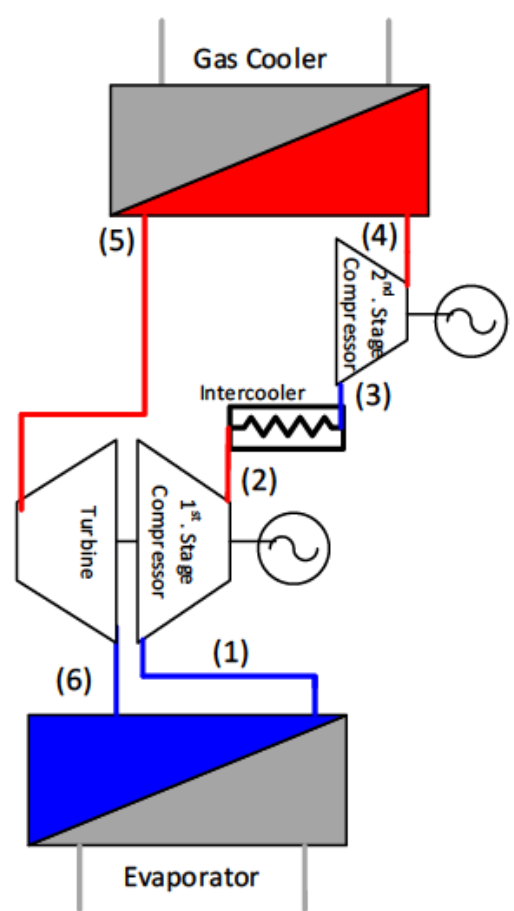

(b) Two-stage transcritical cycle with intercooler using expander to drive low stage compressor

Fig. 3. Two-stage cycles with turbine and intercooler found in the literature review. 


\subsubsection{Most common types of compressors for $\mathrm{CO}_{2}$ applications}

This part of the thesis presents the most common types of compressor found in the studies. Compressors used in cooling and heating applications are often classified as hermetic, open, or semi-hermetic.

On the information found in the available literature of $\mathrm{CO}_{2}$ studied cycles, around $84 \%$ of the compressor belongs to semi-hermetic type, and the other $16 \%$ is split between open and hermetic type.

Considering the most common compressor type, semi-hermetic, from the study about the development of a semi-hermetic $\mathrm{CO}_{2}$ compressor by Nekså [77] in the $20^{\text {th }}$ International Congress of Refrigeration in 2002, to the most recent studies [56, 65, $78,79,80,81,82]$, in $\mathrm{CO}_{2}$ applications, it is widely the most used type of compressor.

On the other hand, some authors have used open type compressors, such as Nekså et al. [35], Brown et al. [39] and Sawalha [75], and full hermetic type, such as Saikawa \& Koyama [37], Stene [43], and Zhang et al. [62]. Stene recommended using a more energy efficient compressor in order to achieve higher COPs.

\subsubsection{Heat exchangers optimization}

The design and optimization of $\mathrm{HX}$ in the cycle are of great importance [34]. White et al. [83] studied the use of shell-and-tube HXs experimental and numerically, recommending the suppression of the IHX in favor of a larger gas cooler. Whereas, in a cycle without IHX, Cecchinato et al. [41], using finned tube HX evaporator and multitubular pipe-in-pipe gas cooler, simulated the gas cooler surface 3 and 6 times ( $3 * S$ and $\left.6^{*} \mathrm{~S}\right)$, and the results show a clear improvement on the COP. While, Wang et al. [84], in a numerical and experimental study, evaluated the geometrical parameters in a tube-in-tube gas cooler for an air-to-water heat pump. Results show that a larger heat transfer area of the gas cooler, increases the heating capacity.

Regarding the IHX, some studies have been performed, such as the one of Kim et al. [59], in a study about the IHX length, they state that the COP increases when increasing the length of the IHX, but the heating capacity tends to decrease due to the trade-offs between the effectiveness and pressure drop in the IHX. They also state that there exists an optimal size for an IHX. In experimental analysis of a facility with and without IHX, Torrella et al. [61] studied the efficiency of the IHX and the influence that other parameters have on the system. The results show that efficiency is higher for lower evaporation temperatures, lower gas cooler pressures, and higher gas cooler outlet temperatures. Whereas, Zhang et al. [85] studied the IHX in subcritical and transcritical cycle. Results show that in the subcritical cycle, an IHX is not justified, but in a transcritical cycle the IHX helps to improve the COP. There are other studies that confirm the improvement of the system when using IHX, such as Cao et al. [56], Sánchez et al. [64], and Jiang et al. [86].

\subsubsection{Optimal pressure studies}

After the "revival of carbon dioxide as a refrigerant", presented by Lorentzen [32], several researchers started to pay attention to the influence that the gas cooler 
pressure has on the efficiency of $\mathrm{CO}_{2}$ transcritical systems, such as Robinson \& Groll [33], Pettersen et al. [34] and Nekså et al. [35], but it was with the publications of Kauf [87] when the study of the optimal pressure became the focus of research for many different authors.

Initially, most research works were based on numerical simulation, as the work of Kauf [87], who numerically studied a $\mathrm{CO}_{2}$ transcritical cycle without IHX to be used in a vehicle air-conditioning system. He considered constant efficiencies of evaporator and gas cooler, and concluded that the influence of the evaporation pressure or the compressor operating conditions on the optimal pressure were almost negligible when compared to the influence of the refrigerant outlet temperature. He finally proposed a correlation for the optimal pressure based only on the gas cooler outlet temperature, which he also related to the ambient temperature:

$$
P_{\text {opt }}(\text { bar })=2.6 \cdot T_{a m b}=2.6 \cdot T_{c}-7.54 \text {. }
$$

Where: $35^{\circ} \mathrm{C}<T_{a m b}<50{ }^{\circ} \mathrm{C}$, and 91 bar $<P_{o p t}<130$ bar.

The original equation (1) had a plus sign instead of a minus sign, but, since $T_{c}=$ $T_{a m b}+2.9$, the original plus sign in the literature should be a typo, and has been corrected by Yang et al. [88].

After Kauf's work [87], many optimal pressure studies have been presented and different correlations have been proposed, such as Liao et al. [51], who analyzed a system with flooded evaporator equipped with an IHX, concluding that, besides the gas cooler outlet temperature, the evaporation temperature and the compressor efficiency also had a certain influence on the optimal pressure. They proposed a simplified correlation which only consider the evaporation temperature and the gas cooler outlet temperature.

$$
P_{\text {opt }}(\text { bar })=\left(2.778-0.0157 \cdot T_{e}\right) \cdot T_{c}+0.381 \cdot T_{e}-9.34 \text {. }
$$

$$
\text { Where: }-10^{\circ} \mathrm{C}<T_{C}<20^{\circ} \mathrm{C}, 30^{\circ} \mathrm{C}<T_{C}<60^{\circ} \mathrm{C} \text {, and } 71<P_{\text {opt }}<120 \mathrm{bar} \text {. }
$$

Also considering the evaporation and the gas cooler outlet temperatures, for simultaneous heating and cooling application, Sarkar et al. [89] proposed another correlation.

$$
\begin{aligned}
& P_{\text {opt }}(\text { bar })=4.9+2.256 \cdot T_{c}-0.17 \cdot T_{e}+0.002 \cdot T_{c}{ }^{2} . \\
& \text { Where: }-10^{\circ} \mathrm{C}<T_{e}<10 \text {, and } 35^{\circ} \mathrm{C}<T_{c}<50^{\circ} \mathrm{C} .
\end{aligned}
$$

In another study, using a flooded evaporator system, Sarkar et al. [90] worked in the optimization of another transcritical cycle for simultaneous cooling and heating application, and proposed a simpler correlation using the gas cooler water inlet temperature.

$$
P_{\text {opt }}(\text { bar })=85.45+0.774 \cdot T_{G C, w i} \text {. }
$$


Where: $20^{\circ} \mathrm{C}<T_{w i}<40{ }^{\circ} \mathrm{C}$.

In a study that considered the efficiency of the IHX and the evaporator quality, Chen $\& \mathrm{Gu}[53]$ developed two optimal pressure correlations.

When there is not IHX and evaporator quality is $\mathrm{X}=1.0$ :

$$
P_{\text {opt }}(\text { bar })=2.304 \cdot T_{a m b}+19.29 \text {. }
$$

If using $2.9^{\circ} \mathrm{C}$ as the temperature approach at the gas cooler outlet:

$$
\begin{aligned}
& P_{\text {opt }}(\text { bar })=2.68 \cdot T_{a m b}+0.975=2.68 \cdot T_{C}-6.797 . \\
& \text { Where: }-10^{\circ} \mathrm{C}<T_{e}<10^{\circ} \mathrm{C} ; 35^{\circ} \mathrm{C}<T_{c}<50^{\circ} \mathrm{C} \text {, and } 80 \mathrm{bar}<P_{o p t}<135 \mathrm{bar} .
\end{aligned}
$$

In a two-stage compression cycle, Agrawal et al. [74] proposed three different correlations, with flash gas bypass cycle, with flash intercooling and with compression intercooling. They proposed the following correlation for the flash gas bypass:

$$
\begin{aligned}
& P_{\text {opt }}(\text { bar })=25.11-0.087 \cdot T_{e}+\left(0.973+0.019 \cdot T_{c}\right) \cdot T_{c} . \\
& \text { Where: }-50^{\circ} \mathrm{C}<T_{e}<-30^{\circ} \mathrm{C} \text {, and } 30^{\circ} \mathrm{C}<T_{c}<50^{\circ} \mathrm{C} .
\end{aligned}
$$

Considering supermarket refrigeration systems, Sawalha [75] proposed several optimal pressure correlations for low, intermediate, and high pressure zones. The correlation for the high pressure zone.

$$
P_{\text {opt }}(\text { bar })=2.7 \cdot\left(T_{a m b}+T_{c}\right)-6.1 \text {. }
$$

Where: $25^{\circ} \mathrm{C}<T_{a m b}<45^{\circ} \mathrm{C}$, and 75 bar $<P_{\text {opt }}<135$ bar.

In a flooded evaporator system, Kim et al. [91] developed an optimal pressure correlation for vehicles air conditioning systems.

$$
P_{\text {opt }}(\text { bar })=1.938 \cdot T_{c}+9.872 \text {. }
$$

Where: $25^{\circ} \mathrm{C}<T_{a m b}<45^{\circ} \mathrm{C}$, and 75 bar $<P_{o p t}<135 \mathrm{bar}$.

Different authors and different papers presented experimental studies where they developed optimal pressure correlations following Liao's [51] expression and using flooded evaporator cycle:

Aprea \& Maiorino [52]:

$$
P_{\text {opt }}(\text { bar })=P_{\text {opt }, \text { Liao }}-0.003 \cdot T_{c}+0.174 \text {. }
$$

Where: $P_{\text {opt,Liao }}$ is presented in equation 3.

And Zhang et al. [62]:

$$
P_{\text {opt }}(\text { bar })=P_{\text {opt }, \text { Liao }}+0.00473 \cdot T_{c}-0.1801 \text {. }
$$


In a refrigeration application, Ge \& Tassou [92] proposed optimal pressure correlations for supermarket boost refrigeration system in a full temperature range.

$$
P_{\text {opt }}=\left\{\begin{array}{c}
1.352 \cdot T_{a m b}+44.34, \quad \text { where }: 0^{\circ} \mathrm{C} \leq T_{a m b} \leq 20^{\circ} \mathrm{C} \\
72.05 \text { bar, when: } 20^{\circ} \mathrm{C} \leq T_{a m b} \leq 22^{\circ} \mathrm{C}(\text { subcritical cycle }) \\
75 \text { bar, when: } 20^{\circ} \mathrm{C} \leq T_{a m b} \leq 22 \\
75 \text { bar, when: } 22^{\circ} \mathrm{C} \leq T_{a m b} \leq 27^{\circ} \mathrm{C} \\
2.3426 \cdot T_{a m b}+11.541, \text { when }:\left(T_{a m b} \geq 27^{\circ} \mathrm{C}\right.
\end{array}\right.
$$

In an experimental air-to-water heat pump using a fixed water inlet temperature, Wang et al. [84] developed two optimal pressure correlations.

$$
\begin{aligned}
& \begin{aligned}
P_{o p t}(\text { bar })= & 23.08391+1.22379 \cdot T_{G C, w o}-0.004707 \cdot T_{w o}{ }^{2}+0.16207 \\
& \cdot T_{a m b} .
\end{aligned} \\
& \text { Where: }-15^{\circ} \mathrm{C} \leq T_{a m b} \leq 5^{\circ} \mathrm{C} \\
& P_{o p t}(\text { bar })=10.98+1.06442 \cdot T_{w o}+1.01404 \cdot T_{a m b}-0.01216 T_{a m b}{ }^{2} .
\end{aligned}
$$

Where: $T_{w o}$, is water outlet temperature, in the range: $55^{\circ} \mathrm{C}<T_{w o}<80^{\circ} \mathrm{C}$.

Another different expression was proposed by Qi et al. [93], in which a third-order polynomial correlation based on experimental data, was presented:

$$
\begin{aligned}
& P_{\text {opt }}(\text { bar })=132.2-8.4 \cdot T_{c}+0.3 \cdot T_{c}^{2}-27.7 \cdot 10^{-4} \cdot T_{c}^{3} . \\
& \text { Where: }-15^{\circ} \mathrm{C}<T_{a m b}<30^{\circ} \mathrm{C} \text {, and } 25^{\circ} \mathrm{C}<\mathrm{TC}<45^{\circ} \mathrm{C} .
\end{aligned}
$$

Using an operation condition range similar to Liao et al. [51], a superheating degree of $5{ }^{\circ} \mathrm{C}$, and constant compressor isentropic efficiency, Yang et al. [88] developed a correlation with the objective of minimizing COP loss from optimal high pressure correlation.

$$
P_{\text {opt }}(\text { bar })=2.759 \cdot T_{c} \text {. }
$$

Shao et al. [55] numerically studied a transcritical system equipped with a flooded evaporator and proposed a method to calculate the optimal pressure constrained to practical pressure limits. In their method, the system actually did not work at optimal pressure, but at the lowest pressure at which the efficiency reduction is lower to $5 \%$ compared to that one obtained under unconstrained optimal pressure conditions.

$$
P_{o p t}(M P a)=\min \left\{0.240 \cdot T_{c}, 0.132 \cdot T_{c, \max }+3.89\right\} \text {. }
$$

Where $40^{\circ} \mathrm{C} \leq T_{c, \max } \leq 60^{\circ} \mathrm{C}$, and $30^{\circ} \mathrm{C} \leq T_{c} \leq T_{c, \max }$.

In a water-precooler-based transcritical $\mathrm{CO}_{2}$ system for space heating applications in which the water return temperature is too high to the standard transcritical $\mathrm{CO}_{2}$ 
systems, Song \& Cao [94] proposed an optimal pressure correlation using the ambient temperature and water supply and return temperatures.

$$
P_{o p t}(\text { bar })=34.5+1.135 \cdot T_{w, f}+1.1 \cdot\left(T_{w, s}-T_{w, f}\right)+0.7 \cdot T_{a i r} .
$$

Where:

Ambient temperature: $-20^{\circ} \mathrm{C}<T_{a m b}<-7^{\circ} \mathrm{C}$

Water return temperature, $(w f): 40^{\circ} \mathrm{C}<w, f<50^{\circ} \mathrm{C}$,

and water suply temperature $(w, s): 50^{\circ} \mathrm{C}<w, s<70^{\circ} \mathrm{C}$.

Other authors, such as Elbel and Hrnjak [67], Sarkar [72], Yari [68], and Xu et al. [73] presented correlations using ejector in the $\mathrm{CO}_{2}$ thermodynamic cycles.

All research works cited before were focused on obtaining an approximated equation capable to generate a reference setpoint that can be tracked by a PID feedback loop. A new approach to the control of the optimal pressure appeared around 2010, when Cecchinato et al. [95] claimed that the best solution to control the optimal pressure could be provided by computational intelligence algorithms. Since then, several studies have been developed, in those the authors try to keep the system working under optimal pressure conditions without following a pre-calculated model for the optimal pressure. Zhang \& Zhang [96] proposed a correlation-free on-line optimal control method, based on the use of a control software that continuously calculated and corrected the value of the optimal pressure for the actual operating conditions. Minetto [97] similarly used a logic control able to develop a real time calculation of COP using the compressor discharge and suction pressures and the gas cooler outlet and inlet temperatures as input variables. Cecchinato et al. [98] proposed a more complex control system, based on an on-line artificial neural network system identification technique (ANN) that solved the optimization problem using a particle swarm optimization technique (PSO). Liu et al. $[99,100]$ developed a model-based optimization strategy that employed a genetic algorithm to optimize the transient COP by adjusting the controlled variables, such as the compressor frequency, expansion valve opening and hot and cold water mass flow rates $\left(\dot{m}_{w}\right)$, and setting points within the feasible range. Yin et al. [101] and Song et al. [82] employed a group method of data handling-type $(\mathrm{GMDH})$ to obtain the relationship between the optimal pressure and the operating conditions and a PSO-BP-type (particle swarm optimization and back-propagation) neural network to find the optimal discharge pressure at different operating conditions. In order to minimize the number of sensors required, Peñarrocha et al. [71] used a Perturb and Observe approach (P\&O) that, instead of maximizing the COP, tried to minimize the compressor consumption. Finally, Hu et al. [102] and Rampazzo et al. [78] used a perturbation based extremum seeking control scheme (ESC). That kind of algorithms is a self-optimizing control strategy that can search for the unknown or slowly varying optimum input (the optimal discharge pressure) with respect to certain performance index (the system's 
COP). The control perturbs the system, observes the corresponding response (COP variation), and then tunes the system input (discharge pressure).

In 2004, Stene [43] discussed the influence of the pinch point on the optimum discharge pressure and the performance of a $\mathrm{CO}_{2}$ heat pump water heater (HPWH). More recently, Chen $[103,104]$ analyzed the influence of pinch point on the gas cooler design and the optimal pressure of $\mathrm{CO}_{2} \mathrm{HPWH}$ and presented a correlation for the optimal pressure as a function of the pinch point temperature difference, the evaporation temperature and the water temperature at gas cooler inlet and outlet. Liang et al. [105] applied a response surface methodology (RSM) to analyze the interactive effects that the different influence factors have on the optimal pressure. According to their conclusions, whereas in refrigeration systems the temperature of the refrigerant at the gas cooler outlet is the predominant factor, in HPWH the factors that control the optimal pressure are water inlet and outlet temperature, evaporation temperature and pinch point temperature difference. The authors proposed a correlation similar to that one proposed by Chen [104].

From the literature review presented, it is clear that there are several ways to approach the optimal pressure control. Model-based approaches can be easily implemented using standard PID control systems, but may lead to non-optimal results if the calibration of the model parameters is not accurately performed. As an alternative to overcome that drawback, an on-line model-based control system can be employed. This system simulates the process and calculates the optimal pressure, but that approach requires a great effort for the model training calibration and updating as well as computational resources that are not usually employed in refrigerant systems [78]. Finally, other model-free approaches have been proposed by different authors, such as [71, 78, 102], but those algorithms also have their drawbacks. The selection of the control parameters can significantly affect the control performance and therefore it must be done carefully. Under variable operating conditions, they can be slow or even evolve to the wrong direction until the limit of the allowed pressure is achieved, and then, the control changes the direction towards the optimum value.

\subsection{Objectives and structure of the thesis}

The main objective of this thesis is to experimental and numerically study different configurations of a $\mathrm{CO}_{2}$ water-to-water heat pump for hot water generation for both space heating and DHW applications, in order to contribute to the design and optimization of $\mathrm{CO}_{2}$ water-to-water heat pumps and the environmental preservation.

In order to achieve the main objective, some specific objectives may be defined:

-To present the refrigerant and water loops in the experimental facility that is being tested. 
-To define the test methodology, the configurations and the test matrix to be followed.

-To study the optimal pressure, the influence of different parameters and to develop an optimal pressure correlation.

-To study the performance of the $\mathrm{CO}_{2}$ water-to-water heat pump in both space heating and DHW applications, and compare the different configurations.

This dissertation has been structured as follows:

-Chapter 1. This been presented a brief introduction of the thesis, a description of the current technological situation about the heat pumps in the market, the refrigerants commonly used, and the current researches about the wastewater heat pumps and the $\mathrm{CO}_{2}$ as a refrigerant.

-Chapter 2. This chapter describes the experimental facility, paying attention to the elements of the refrigerant and water loops, such as the compressor, the gas cooler, the evaporator, the liquid receiver, the IHX, the hot and cold water tanks, and the devices for the data acquisition and variables control for both loops, such as the datalogger, the PID controllers, and the temperature and pressure sensors.

-Chapter 3. This part presents the different configurations to be studied during the experimental tests, divided in two groups (dry and flooded evaporator); the test matrixes to be followed for space both heating and DHW generation, the influence of the liquid receiver pressure, the optimal high pressure; and the post process of the different tests.

-Chapter 4. This part of the dissertation discusses the experimental results for all the test matrices, such as the influence of the liquid receiver pressure, IHX efficiency, the optimal pressure study and correlations, and a comparison between the different configurations in space heating and DHW application.

-Chapter 5. This chapter summarizes the numerical and experimental studies performed in this doctoral thesis, gathering the main conclusions of the work and the future works. 


\section{Experimental facility description}




\subsection{Introduction}

This chapter describes the elements of the experimental installation studied in this thesis. It pays attention to the different devices, the data acquisition systems and the control system employed.

Fig. 4 gives a general overview of the installation. Several loops may be identified for the refrigerant, evaporator and gas cooler. In the gas cooler water loop, the light blue line represents the cold water flow from the gas cooler water tank (GCWT), the red line represents the flow of the hot water production out of the gas cooler, and the orange line represents the gas cooler water inlet flow. The gas cooler water inlet flow is controlled by a three-ways valve by mixing water from the gas cooler water tank (GCWT) with part of the hot water production. The temperature of the gas cooler water tank (GCWT), working as a simulation of a domestic water tank, is guarantee by an auxiliary cooling machine. In the evaporator water loop, the light blue line represents evaporator outlet water flow, the red line represents the evaporator water tank (EWT) as a simulation of the heat source, and the orange line represents the evaporator water inlet flow. The evaporator water inlet temperature is controlled by a three-ways valve by mixing water from the evaporator water tank (EWT) with part of the cold outlet water. The temperature of the evaporator water tank (EWT), playing the role of the heat source, is guarantee by an auxiliary electric boiler. The water pumps (WP) guarantee that the $\dot{m}_{w}$ are the ones required by the test being performed.

Water temperature is accurately measured in 2 different points of the gas cooler and evaporator water loops (inlet and outlet) using high precision resistance temperature detectors (RTDs). Also, there are temperature probes to control the temperature of the tanks around specific values. Whereas the $\dot{m}_{w}$ are measured by two electromagnetic flow rate meters.

Considering the refrigerant loop, which exchanges heat with the evaporator and gas cooler water loops, it is presented with green, blue and purple lines. The green and purple lines represent the high pressure side, the blue line represents the intermediate pressure and low pressure side from liquid receiver inlet to the compressor suction. The green numbers indicate the 15 different points of the whole system. The main components of the cycle are well defined and presented in the legend of the figure, such as the compressor, gas cooler, evaporator, liquid receivers, expansion valves and manual valves, among others. The gas cooler $\left(P_{g c}\right)$ and liquid receiver pressures $\left(P_{I r}\right)$, are controlled by two different electronic back pressure valves (BPV-1 and BPV-2, respectively). Another electronic expansion valve (EEV) acts controlling the superheating at evaporator outlet (except for the flooded evaporator cycle). The manual valves ( $V$-\#) are used for changing among the different configurations of the cycle and whether or not using the IHX (V-1, V-2 and V-3). 


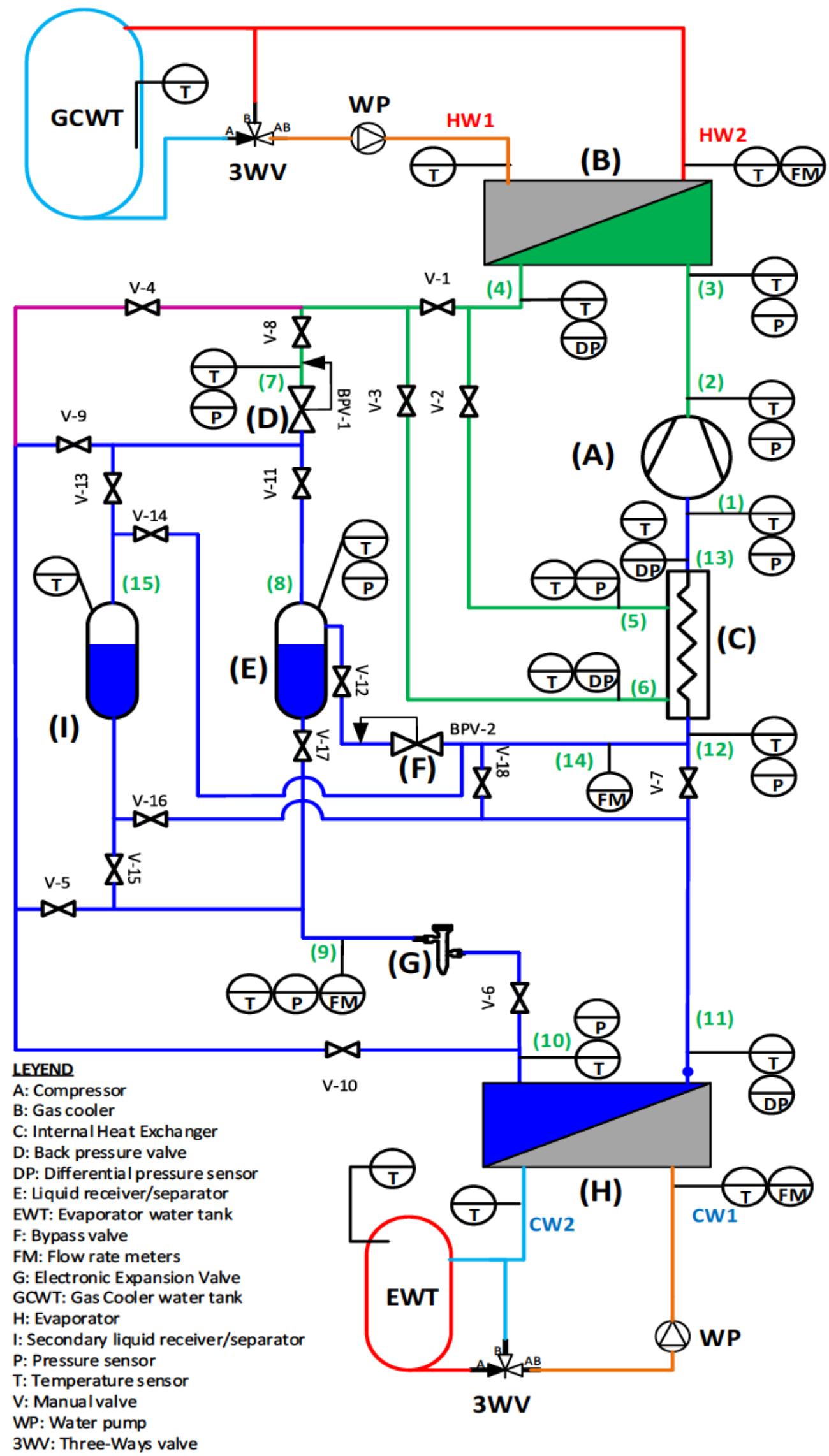

Fig. 4. General sketch of the $\mathrm{CO}_{2}$ facility. 
Refrigerant temperature is accurately measured in 14 different points of the refrigerant loop using high precision RTDs. Pressure is also measured in 13 different points using absolute pressure transmitters combined with differential pressure transmitters employed to measure pressure drop in each HX. The refrigerant mass flow rates flowing through the evaporator and the gas bypass are measured using two Coriolis Effect mass flow meters. Finally, an energy counter, not represented in the image, measures the energy consumption in the compressor, and, an oil separator between the compressor outlet and the gas cooler inlet, guarantees the oil return to the compressor.

\subsection{Refrigerant loop}

Fig. 5 shows its layout in the lab. This is included to illustrate this section and just to show the complexity of the facility already sketched in Fig. 4.
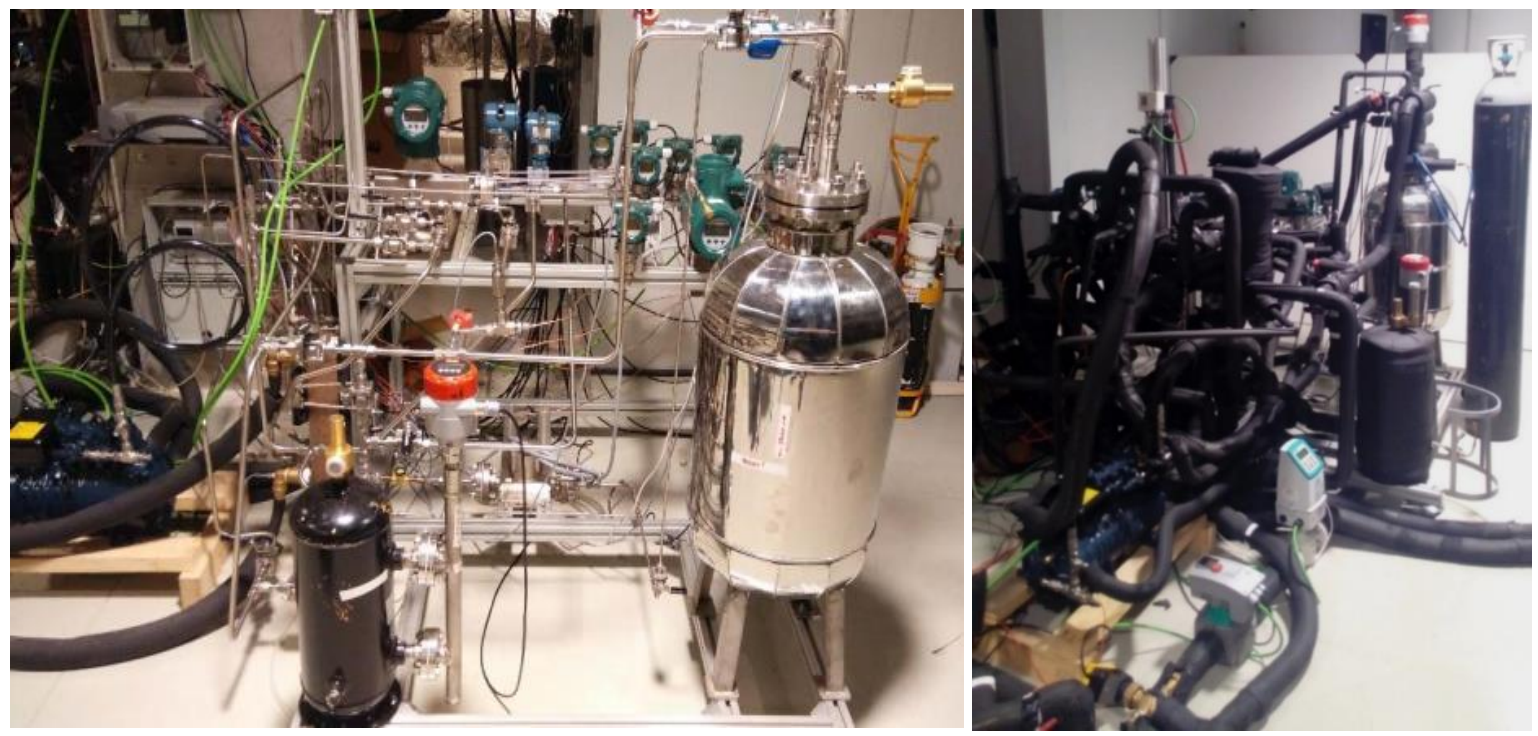

Fig. 5. The $\mathrm{CO}_{2}$ facility before and after insulation material.

\subsubsection{Compressor}

The compressor is the main element of the thermodynamic cycle. This device is located between the low and high pressure zone, with the objective of moving the refrigerant from the evaporator outlet to the condenser inlet (in a basic cycle without $\mathrm{IHX}$ or liquid receiver), separating the low and high pressure sides thanks to a mechanical work, which, as well, is produced by an electrical work. The compressor is the element that produces the necessary work to change the natural flow of the heat.

The compressor that is being used in the facility is a Dorin semi-hermetic compressor, model $\mathrm{CD} 300 \mathrm{H}$. Table 4 shows some technical characteristics. According to Fig. 6, provided by the Italian manufacturer, this $\mathrm{CO}_{2}$ compressor has been designed for the a specific operational field, with the restrictions of a delivery temperature of $160^{\circ} \mathrm{C}$ max, $-20{ }^{\circ} \mathrm{C}$ to $15{ }^{\circ} \mathrm{C}$ evaporation temperature, and a superheating at the suction 
between $5 \mathrm{~K}$ and $30 \mathrm{~K}$. More details could be found at the manufacturer information in the instruction manual provided by Dorin [106].

Table 4. Some technical characteristics of the semi-hermetic compressor.

\begin{tabular}{|l|c|l|}
\hline \multicolumn{1}{|c|}{ Part } & Measuring unit & \multicolumn{1}{c|}{ Value } \\
\hline Design power, heating and cooling capacity & $\mathrm{kW}$ & $1.58 ; 9.93 ; 8$ \\
\hline Number of cylinders & $\mathrm{N} / \mathrm{A}$ & 2 \\
\hline Diameter & $\mathrm{mm}$ & 22 \\
\hline Race & $\mathrm{mm}$ & 22 \\
\hline Flow rate at $50 \mathrm{~Hz}$ and $60 \mathrm{~Hz}$ frequency & $\mathrm{m}^{3} \cdot \mathrm{h}^{-1}$ & 1.46 and 1.75 \\
\hline Inner and outer diameter of the suction valve & $\mathrm{mm}$ & 10 and 14 \\
\hline Inner and outer diameter of the discharge valve & $\mathrm{mm}$ & 10 and 14 \\
\hline Oil charge & $\mathrm{kg}$ & 1.3 \\
\hline Weight & $\mathrm{kg}$ & 73 \\
\hline
\end{tabular}

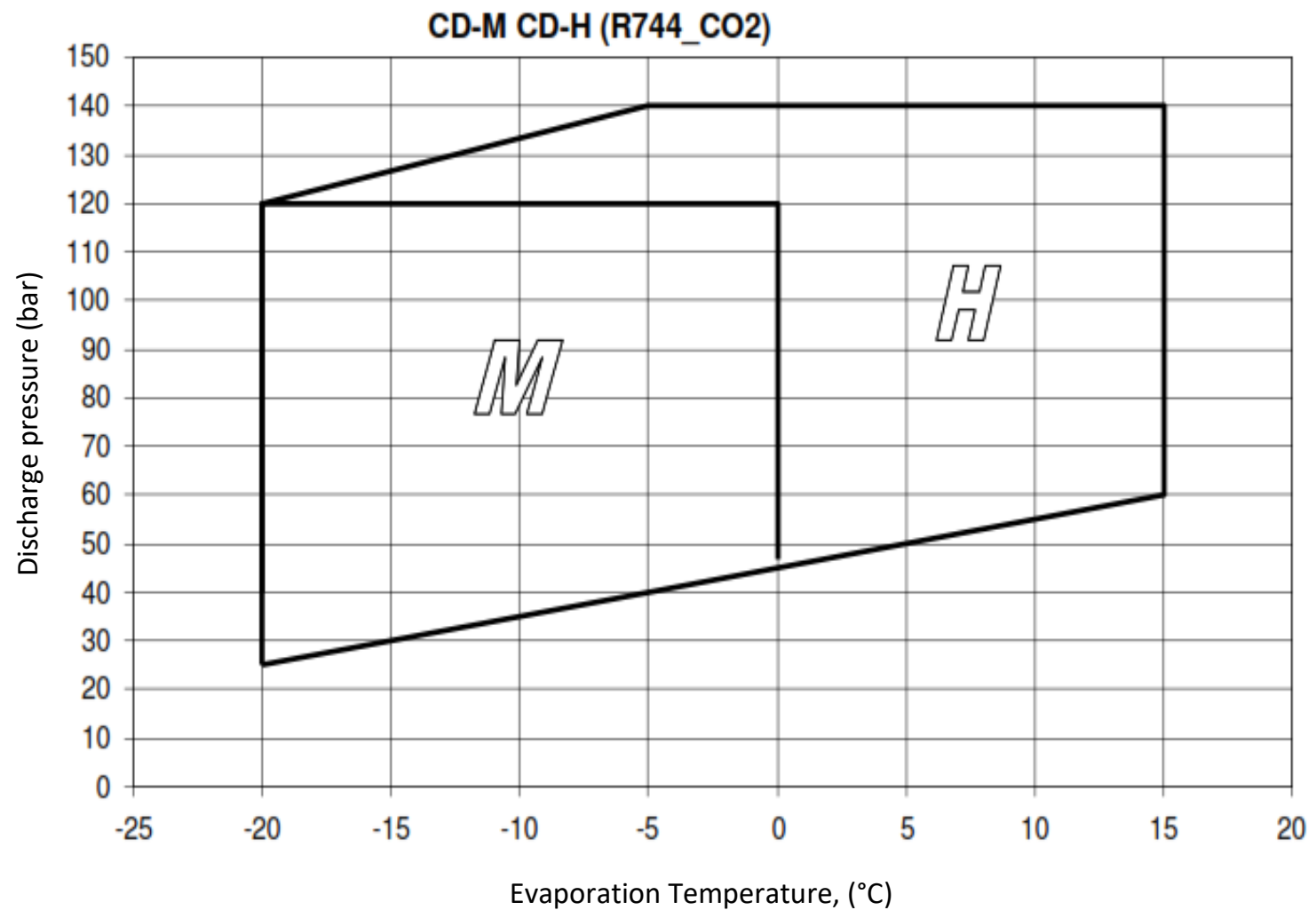

Fig. 6. Operational field of the $\mathrm{CD}-\mathrm{M}$ and $\mathrm{CD}-\mathrm{H}$ Doring $\mathrm{CO}_{2}$ compressors.

Fig. 7, divided in four parts, is summarized with the view of the electrical power input, oil return, security valve, and suction and discharge valves and pipes. 


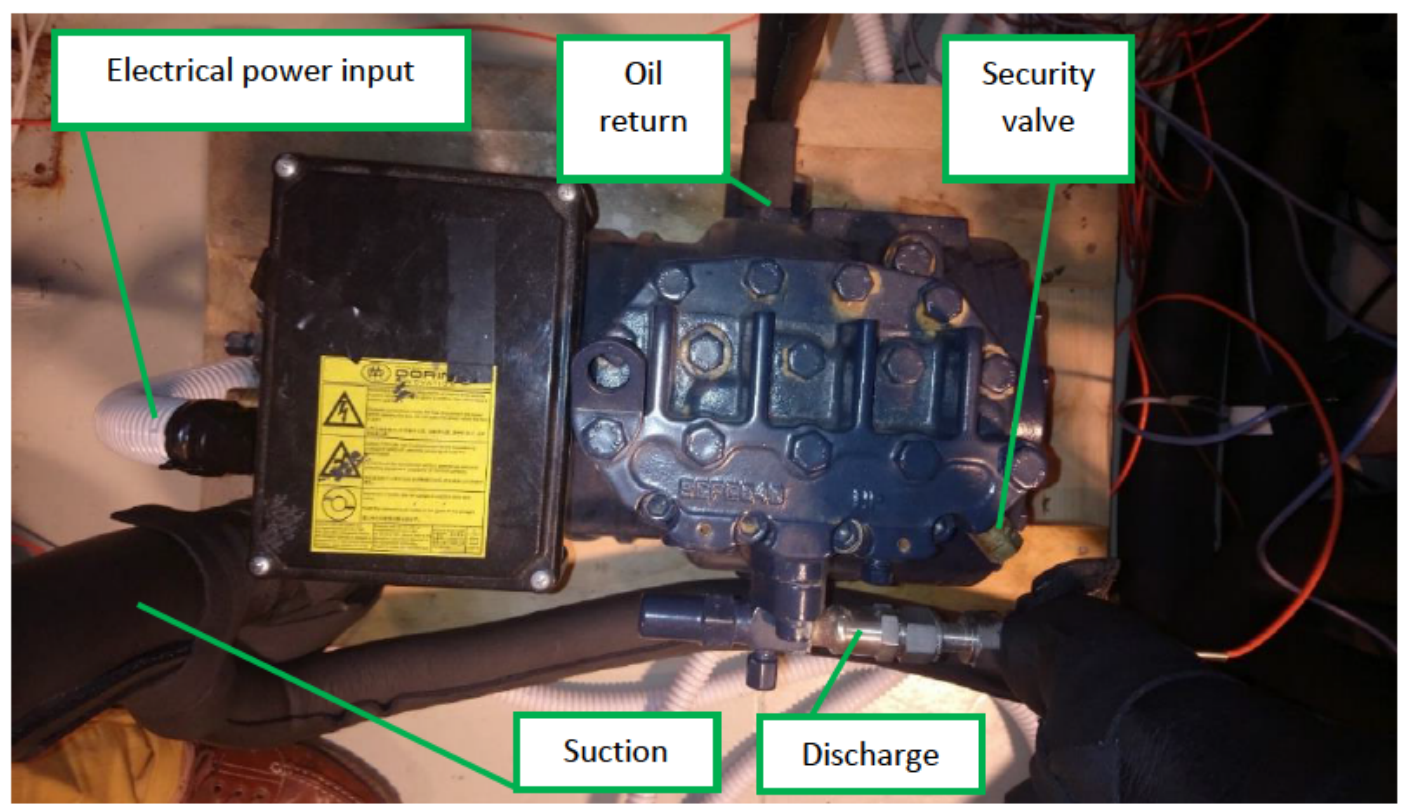

(a) Top view of the Dorin compressor

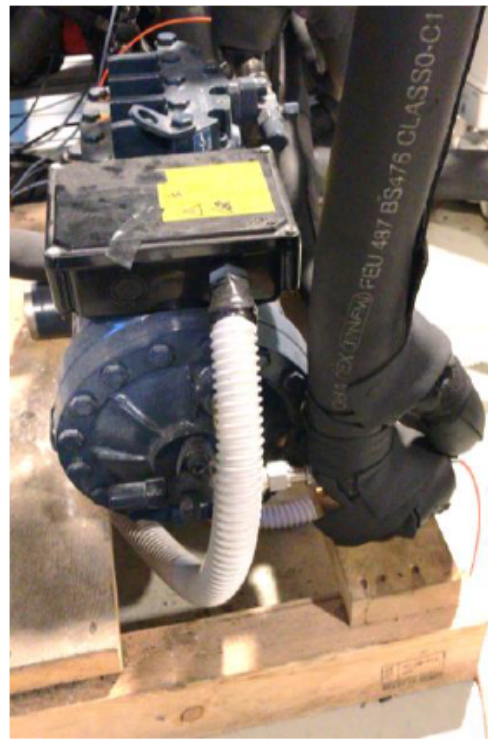

(b) Suction line and power input

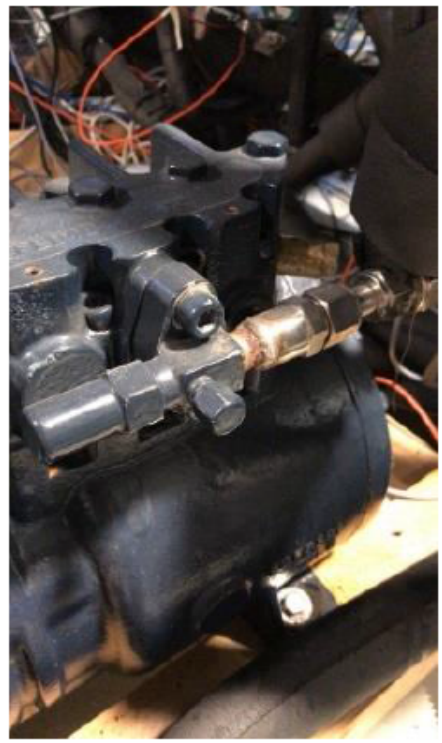

(c) Discharge line

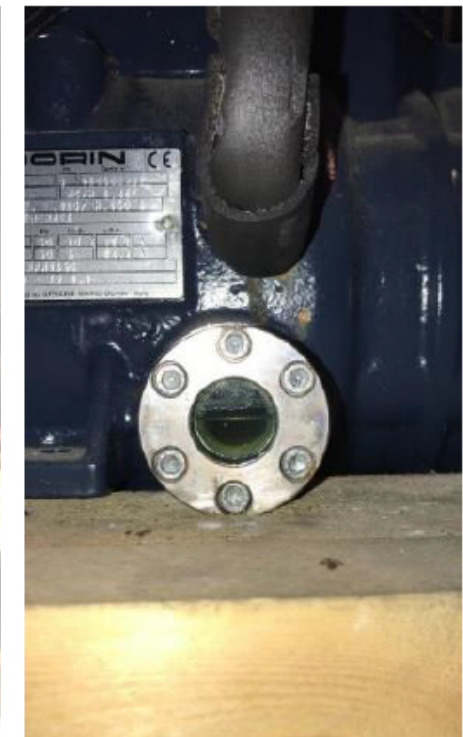

(d) Oil return and visor

Fig. 7. Main elements of the compressor outer parts.

The suction line is the one that communicates the evaporator or IHX outlet to the compressor inlet. The discharge line communicates the compressor outlet to the condenser (gas cooler) inlet, while passing through the oil separator between them. The oil in the compressor is necessary to guarantee the working conditions and the oil visor indicates the oil level. The security valve is automatically opened when the operating conditions surpass the designed maximum pressure.

\subsubsection{Pressure security devices}

Besides the compressor security valve, there are two pressure devices, which, besides protecting the compressor security, they represent a security to all elements of the facility, such as the pipes, valves and welded unions. See Fig. 8. 


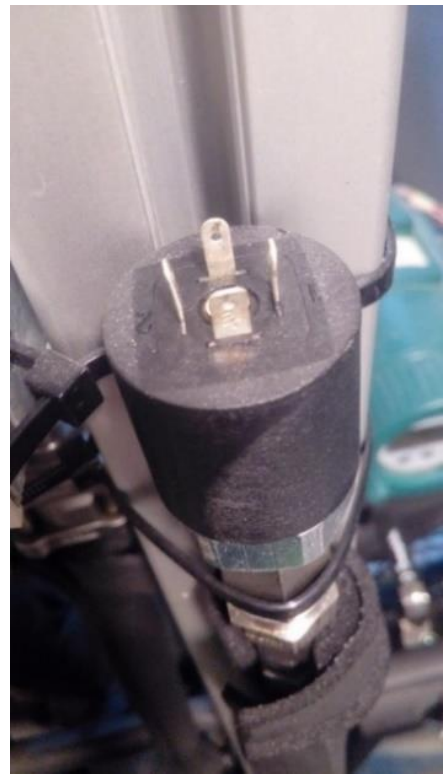

(a) High pressure swich

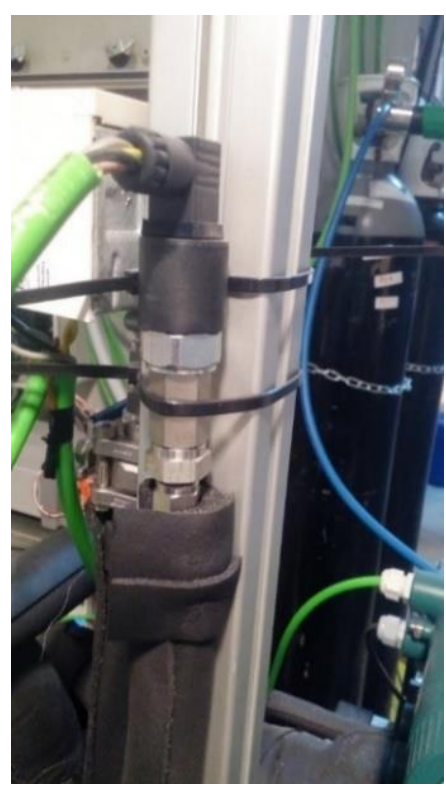

(b) High pressure swich

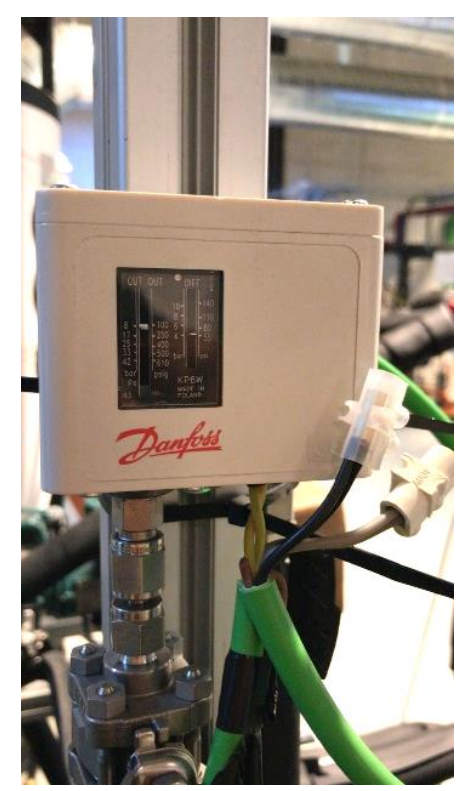

(c) Low pressure swich

Fig. 8. High pressure swichers.

\subsubsection{Wattmeter}

The wattmeter used to measure the electrical power input from the compressor is presented in the Fig. 9. The measuring device is a wattmeter manufactured by Camille Bauer, the model is SINEAX M 563. The device is able to register the active and reactive power, and the voltage. More information is found in the manual [107].

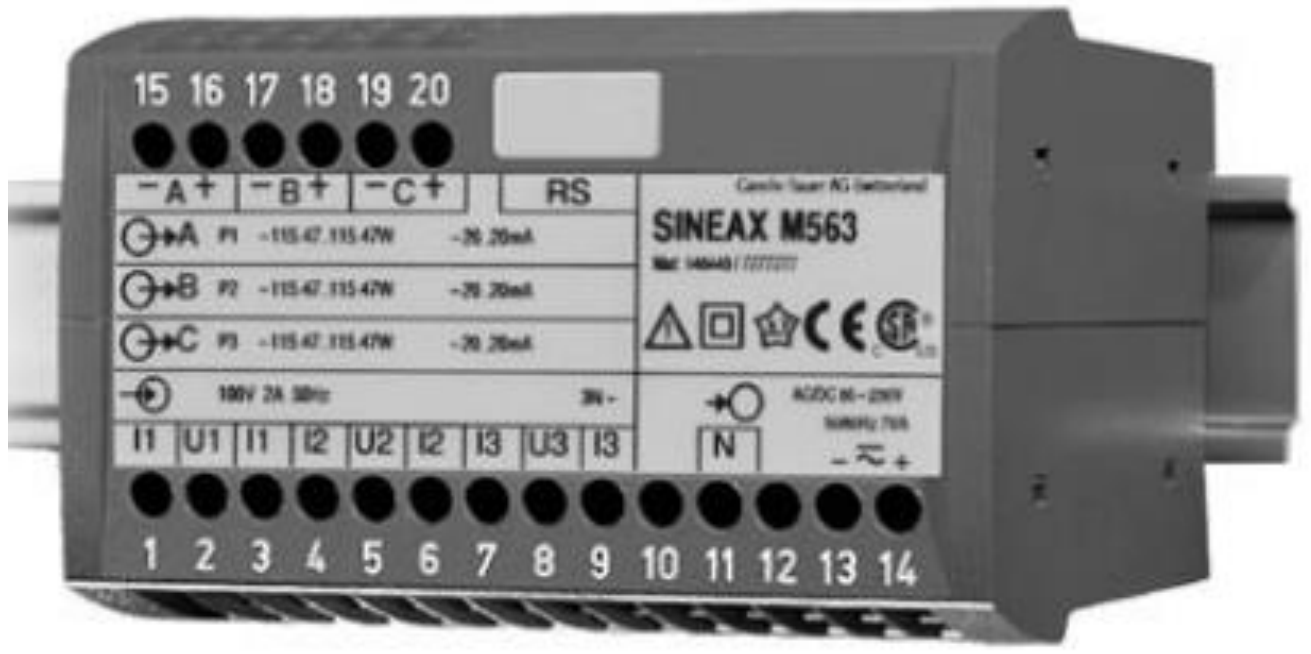

Fig. 9. Watmetter Sineax M563. 


\subsubsection{Gas cooler $\mathrm{HX}$}

As it is widely known, a $\mathrm{CO}_{2}$ transcritical ccycle is different from a traditional cycle since there is not phase change or condensation process, then, this device is called gas cooler, instead of condenser.

The gas cooler HX used in the facility is a SWEP plate HX with 34 plates (PHE, B16x34P). Table 5 presents some technical characteristics and Fig. 10 shows the B16 type plate HX. For more details, please refer to the manufacturer information [108].

Table 5. Basic characteristics of the gas cooler HX (B16×34P).

\begin{tabular}{|l|c|l|}
\hline \multicolumn{1}{|c|}{ Part } & $\begin{array}{c}\text { Measuring } \\
\text { unit }\end{array}$ & \multicolumn{1}{|c|}{ Value } \\
\hline Design heating capacity temperature, water and & $\mathrm{kW}$ & 9.55 \\
\hline $\begin{array}{l}{ }^{\circ} \mathrm{C} \\
\text { resign trigerant }\end{array}$ & $\begin{array}{l}10 / 60 \quad{ }^{\circ} \mathrm{C} \text { and } 80 / 15 \quad{ }^{\circ} \mathrm{C} \text {, } \\
\text { respectively }\end{array}$ \\
\hline Max number of plates & bar & 140 \\
\hline Max pressure @ $135{ }^{\circ} \mathrm{C}$ and $225^{\circ} \mathrm{C}$ & $\mathrm{m}^{3} \cdot \mathrm{h}^{-1}$ & 16.9 \\
\hline Max flow & $\mathrm{dm}^{3}$ & 0.082 \\
\hline Channel volume & $\mathrm{N} / \mathrm{A}$ & 316 stainless-steel plates \\
\hline Material & $\mathrm{N} / \mathrm{A}$ & Copper \\
\hline Brazing material & $\mathrm{m}^{2}$ & 1.28 \\
\hline Heat transfer area & $\mathrm{W} \cdot \mathrm{m}^{-2} \cdot \mathrm{K}^{-1}$ & 551 \\
\hline Overall heat transfer coefficient & $\#$ & 34 \\
\hline Number of plates & $\#$ & 17 and 16, respectively \\
\hline Number of channel $\mathrm{CO}_{2}$ and water side & & \\
\hline
\end{tabular}

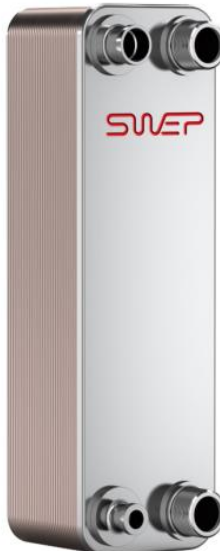

Fig. 10. Gas cooler plate HX, B16 type.

According to the manufacturer, the B16 has been specially designed for one-phase applications, and has been tailored to cover the capacities and specifications of district heating substations, radiator circuits, and tap water heating applications over a wide capacity range. 


\subsubsection{Evaporator heat exchanger}

The evaporator used in this $\mathrm{CO}_{2}$ facility is a plate $\mathrm{HX}$ with 26 plates (Bx8Tx26P). Table 6 presents some technical characteristics and Fig. 11 shows the BX8T type plate HX. For more details, please refer to the manufacturer information [109].

Table 6. Basic characteristics of the evaporator HX (Bx8Tx26P).

\begin{tabular}{|l|c|l|}
\hline \multicolumn{1}{|c|}{ Part } & Measuring unit & \multicolumn{1}{c|}{ Value } \\
\hline Design cooling capacity & $\mathrm{kW}$ & 8 \\
\hline $\begin{array}{l}\text { Design temperature, water and } \\
\text { refrigerant }\end{array}$ & ${ }^{\circ} \mathrm{C}$ & $20 / 16$ and $10 / 15$, respectively \\
\hline Max number of plates & $\#$ & 60 \\
\hline Max pressure @ $135^{\circ} \mathrm{C}$ and $225^{\circ} \mathrm{C}$ & $\mathrm{bar}$ & 45 and 36 \\
\hline Max flow & $\mathrm{m}^{3} \cdot \mathrm{h}^{-1}$ & 4 \\
\hline Channel volume & $\mathrm{dm}^{3}$ & 0.039 or 0.0014 , respectively \\
\hline Material & $\mathrm{N} / \mathrm{A}$ & 316 stainless-steel plates \\
\hline Braze material & $\mathrm{N} / \mathrm{A}$ & Copper \\
\hline Heat transfer area & $\mathrm{m}^{2}$ & 0.552 \\
\hline Overall heat transfer coefficient & $\mathrm{W} \cdot \mathrm{m}^{-2} \cdot \mathrm{K}^{-1}$ & 1790 \\
\hline Number of plates & $\#$ & 26 \\
\hline $\begin{array}{l}\text { Number of channel } \mathrm{CO}_{2} \text { and water } \\
\text { side }\end{array}$ & $\#$ & 12 and 13 , respectively \\
\hline
\end{tabular}

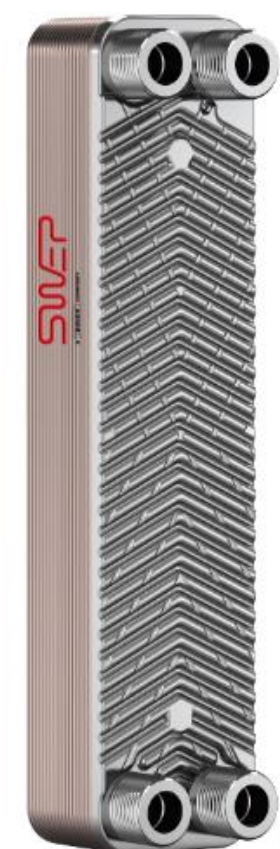

Fig. 11. Evaporator plate HX, Bx8T type.

According to the manufacturer information, the X-marked BX8T can work for a variety of one-phase and two-phase applications. It can be utilized in applications of container refrigeration and heat pumps. The X-plates on front and back give structural stability while being active heat transfer plates. This all-active plate pack maximizes the material utilization and makes the product an efficient and competitive product for demanding applications. 


\subsubsection{Internal Heat Exchanger}

This $\mathrm{HX}$ is responsible for overheating the vapor after the evaporator in order to guarantee that no liquid get into the compressor. In the other side, decreasing the refrigerant temperature out of the gas cooler (subcooling), improves the system performance. The IHX used in this $\mathrm{CO}_{2}$ facility is a plate $\mathrm{HX}$ with 4 plates (B17x4P). Table 7 and Fig. 12 shows the $\mathrm{HX}$ and some technical characteristics. For more details, please refer to the manufacturer information [110].

Table 7. Basic characteristics of the IHX (B17x4P).

\begin{tabular}{|l|c|l|}
\hline \multicolumn{1}{|c|}{ Part } & $\begin{array}{c}\text { Measuring } \\
\text { unit }\end{array}$ & \multicolumn{1}{c|}{ Value } \\
\hline Design heating capacity & $\mathrm{kW}$ & 0.3129 \\
\hline Design temperature, high and low side & ${ }^{\circ} \mathrm{C}$ & 15 and $9.9 @ \dot{m}=0.045 \mathrm{~kg} \cdot \mathrm{s}^{-1}$ \\
\hline Max number of plates & $\#$ & 140 \\
\hline Max pressure @ $155^{\circ} \mathrm{C}$ and $225^{\circ} \mathrm{C}$ & $\mathrm{bar}$ & 123 and 104, respectively \\
\hline Max flow & $\mathrm{m}^{3} \cdot \mathrm{h}^{-1}$ & 5 \\
\hline Channel volume & $\mathrm{dm}^{3}$ & 0.061 \\
\hline Material & $\mathrm{N} / \mathrm{A}$ & 316 stainless-steel plates \\
\hline Braze material & $\mathrm{N} / \mathrm{A}$ & Copper \\
\hline Heating capacity & $\mathrm{kW}$ & 0.1342 \\
\hline Heat transfer area & $\mathrm{m}^{2}$ & 0.082 \\
\hline Overall heat transfer coefficient & $\mathrm{W} \cdot \mathrm{m}^{-2} \cdot \mathrm{K}^{-1}$ & $109 / 792$ \\
\hline Number of plates & $\#$ & 4 \\
\hline Number of channel $\mathrm{CO}_{2}$ and $\mathrm{CO}_{2}$ & $\#$ & 1 and 2, respectively \\
\hline
\end{tabular}

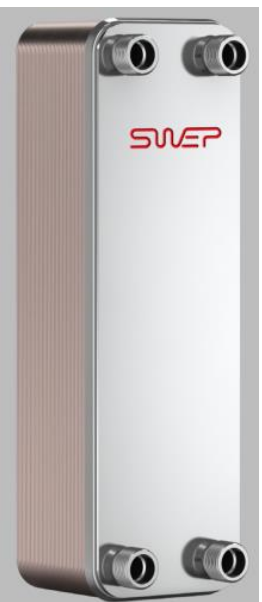

Fig. 12. IHX, B17X4P.

According to the manufacturer, this type of $\mathrm{HX}$ can work for transcritical applications touching 140 bar. The B17 is optimized for high heat pump capacities (up to $60 \mathrm{~kW}$ as a gas cooler and up to $40 \mathrm{~kW}$ as an evaporator). The device can work for heat pumps (evaporator and gas cooler) and for mobile air-conditioning. 


\subsubsection{Liquid receiver or liquid separator}

As shown in Fig. 4, the facility has two intermediate liquid receivers to guarantee that refrigerant enters the thermostatic expansion valve as saturated liquid and refrigerant mass for every working condition.

Both liquid receivers cannot be used simultaneously, but allow to test different configurations when using dry or flooded evaporator. Each liquid receiver is well insulated, has a level sensor [111] and a security valve set at maximum allowable pressure. Fig. 13 shows the receivers used in the $\mathrm{CO}_{2}$ facility. The main liquid receiver (Fig. 13.a) has a capacity of 30 liters and a maximum allowable pressure of 70 bar. Whereas, the secondary liquid receiver (Fig. 13.b) has a capacity of 10 liters and a maximum allowable pressure of 90 bar.

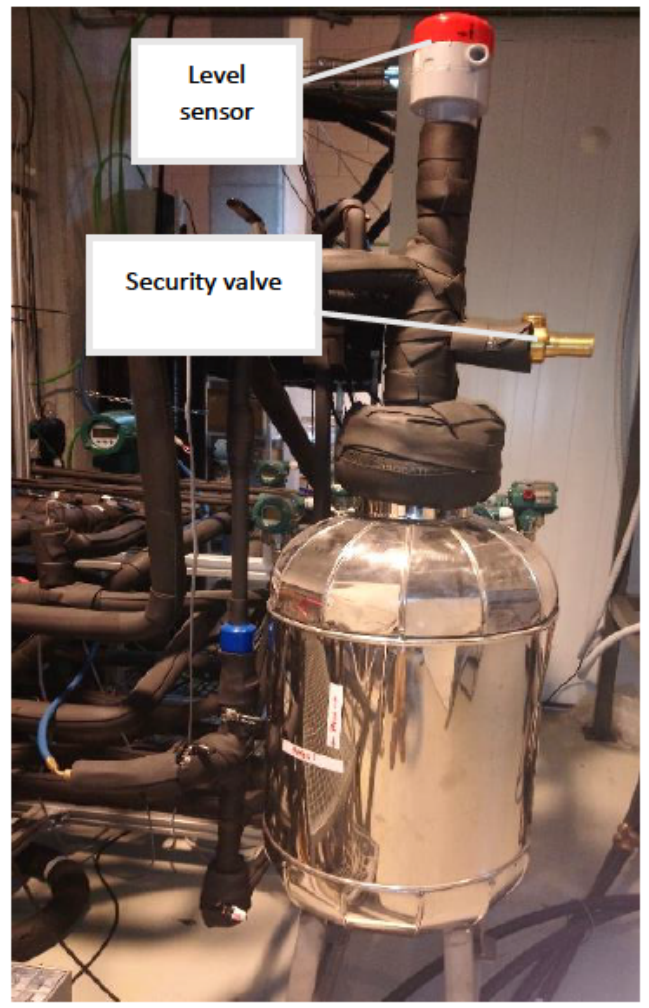

(a) Main liquid receiver

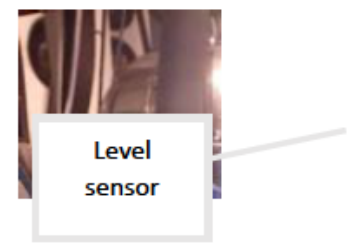

Security valve

Fig. 13. Liquid receivers used in the $\mathrm{CO}_{2}$ facility.

\subsubsection{Back pressure and thermostatic expansion valves}

In this part of the thesis, the model of the three EEVs mentioned in Fig. 4, is presented in Fig. 14. As was said before, the maximum number of valves is three (3), the gas cooler pressure and liquid receiver pressure are controlled by two back pressure valves (BPV-1 and BPV-2), respectively. Another EEV acts as a thermostatic expansion valve controlling the superheating at evaporator outlet. The valves used in the facility are manufactured by Carel, the model is $E^{2} V-C$.

Table 8 shows the $E^{2} \mathrm{~V}-\mathrm{C}$ characteristics. The device to control the valves is the Carel EDV Evolution [112]. 

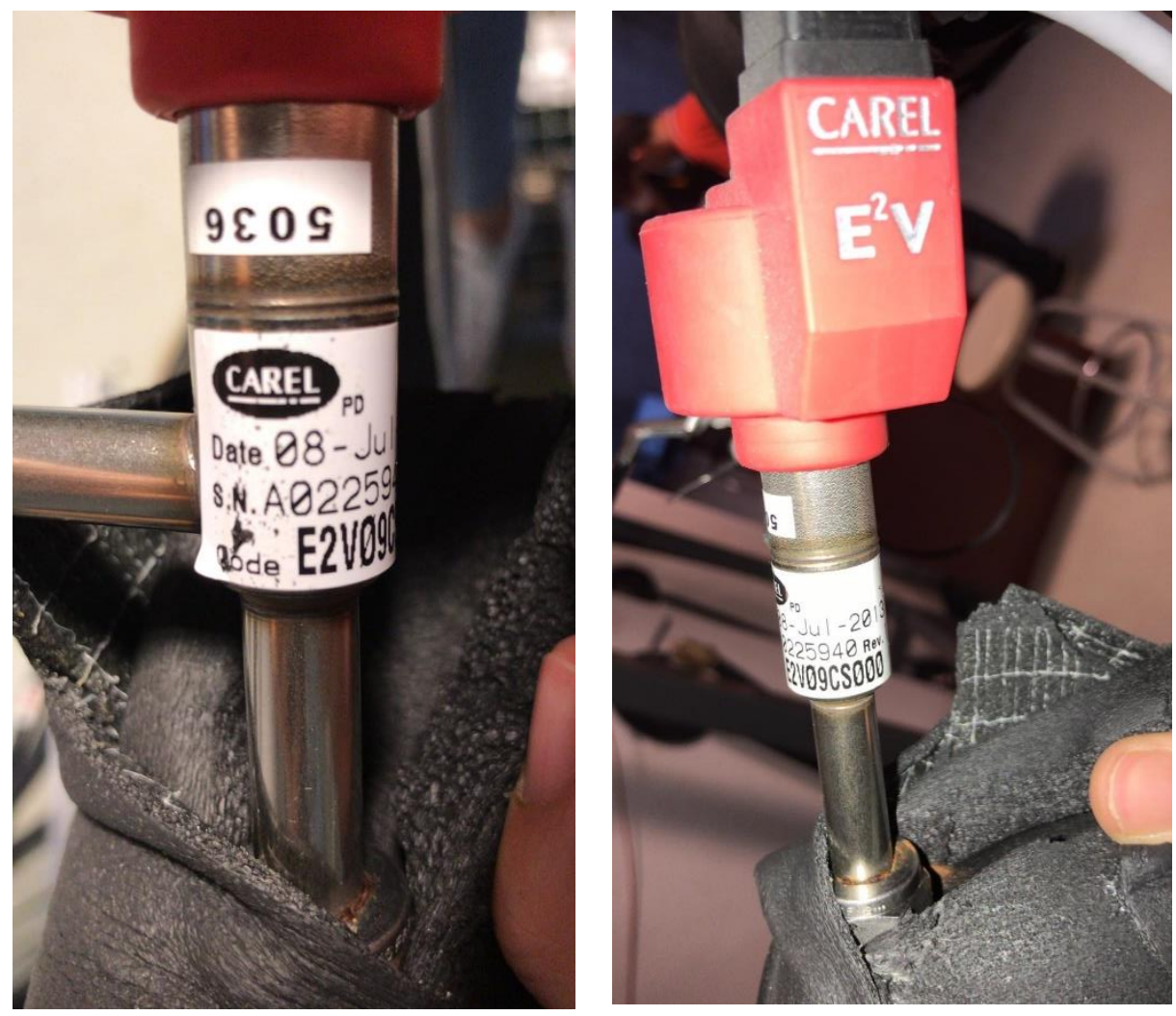

Fig. 14. Carrel electronic valve.

Table 8. Carel $E^{2} V$-C valves characteristics.

\begin{tabular}{|c|c|c|}
\hline Part & Measuring unit & Value \\
\hline \multicolumn{3}{|c|}{ Carel $E^{2} V-C$} \\
\hline Refrigerants compatibility & N/A & $\begin{array}{l}\text { R-22, R-134a, R-404A, R- } \\
\text { 407C, R-410A, R-744, R- } \\
\text { 507A, R-417A }\end{array}$ \\
\hline Maximum operation pressure (MOP) & bar & 140 or 2030 , respectively \\
\hline Minimum differential pressure (MODP) & bar & 120 or 1740, respectively \\
\hline Refrigerant temperature & ${ }^{\circ} \mathrm{C}$ & $-40<\mathrm{T}>60^{\circ} \mathrm{C}$ \\
\hline Ambient temperature & ${ }^{\circ} \mathrm{C}$ & $-30<\mathrm{T}>50^{\circ} \mathrm{C}$ \\
\hline \multicolumn{3}{|c|}{ Carel $E^{2} V-C$, Stator } \\
\hline Phase current & $\mathrm{mA}$ & 450 \\
\hline Frequency & $\mathrm{Hz}$ & $\begin{array}{l}50 \mathrm{~Hz} \text { (up to } 150 \text { in case of } \\
\text { emergency closing) }\end{array}$ \\
\hline Phase resistance & Ohm & 36 \\
\hline Step angle & $\circ$ & 15 \\
\hline Lineal advance/step & $\mathrm{mm}$ & $\begin{array}{l}0.03 \mathrm{~mm} \text { or } 0.0012 \text {, } \\
\text { respectively }\end{array}$ \\
\hline Connection & Wires & 4 \\
\hline Complete closing steps & $\#$ & 500 \\
\hline Regulation steps & $\#$ & 480 \\
\hline
\end{tabular}




\subsubsection{Pressures and superheating control}

This part of the thesis presents the software to control the pressure and superheating, as shown in Fig. 15. The EVD Evolution driver for EEV with bipolar stepper motor is a PID controller used for superheating and pressure regulation in the refrigerant loop.

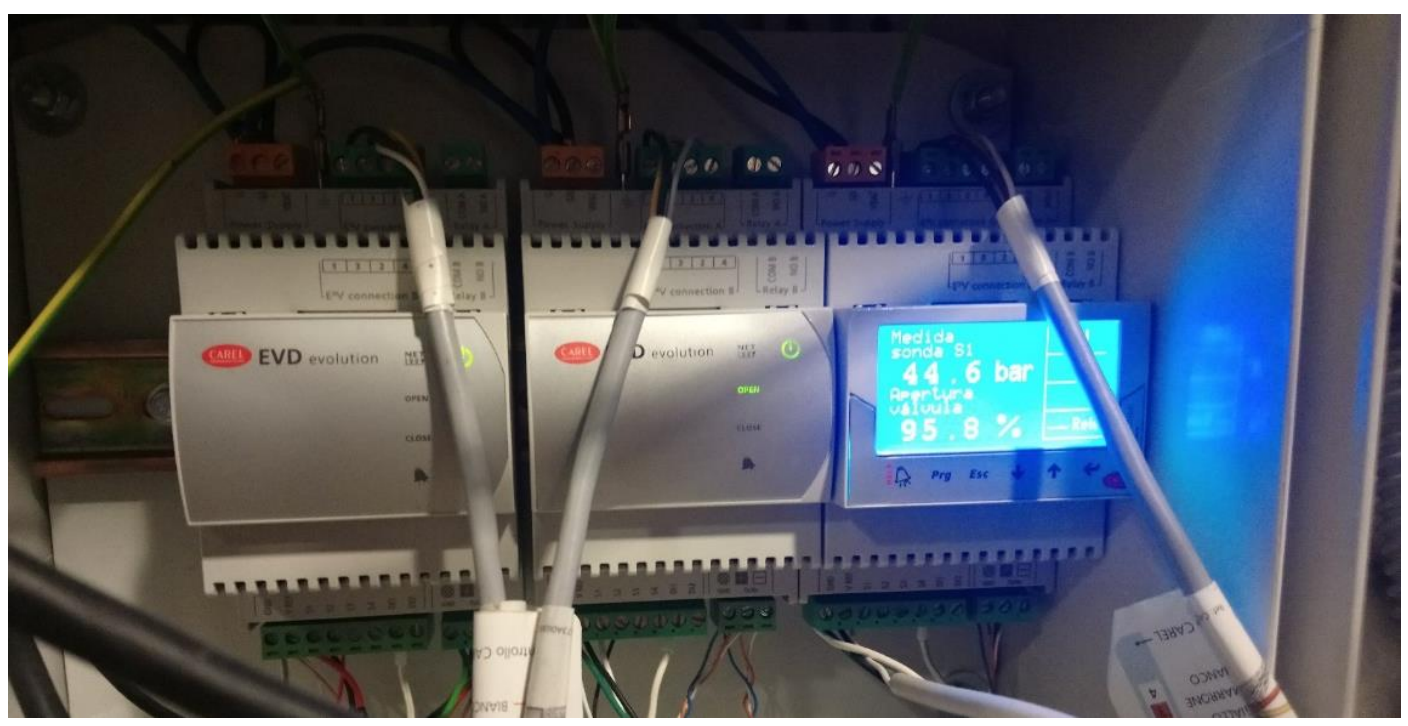

Fig. 15. Carel EVD Evolution device.

The driver configuration is set using a computer software called carrel visual parameter manager (VPM). Fig. 16 shows how the software is visualized in the computer. When a superheating value, gas cooler pressure or receiver pressure is assigned, the Proportional-Integral-Derivate (PID) control compares the measured value to the setpoint and corrects the difference to produce the required value.

The manual valve positions can be activated (1) or deactivated (0) as shown in Fig. 16.a. When the manual control is active, the PID constant are not regulating, but the pressure can be manually controlled within an opening range of manual position steps. 

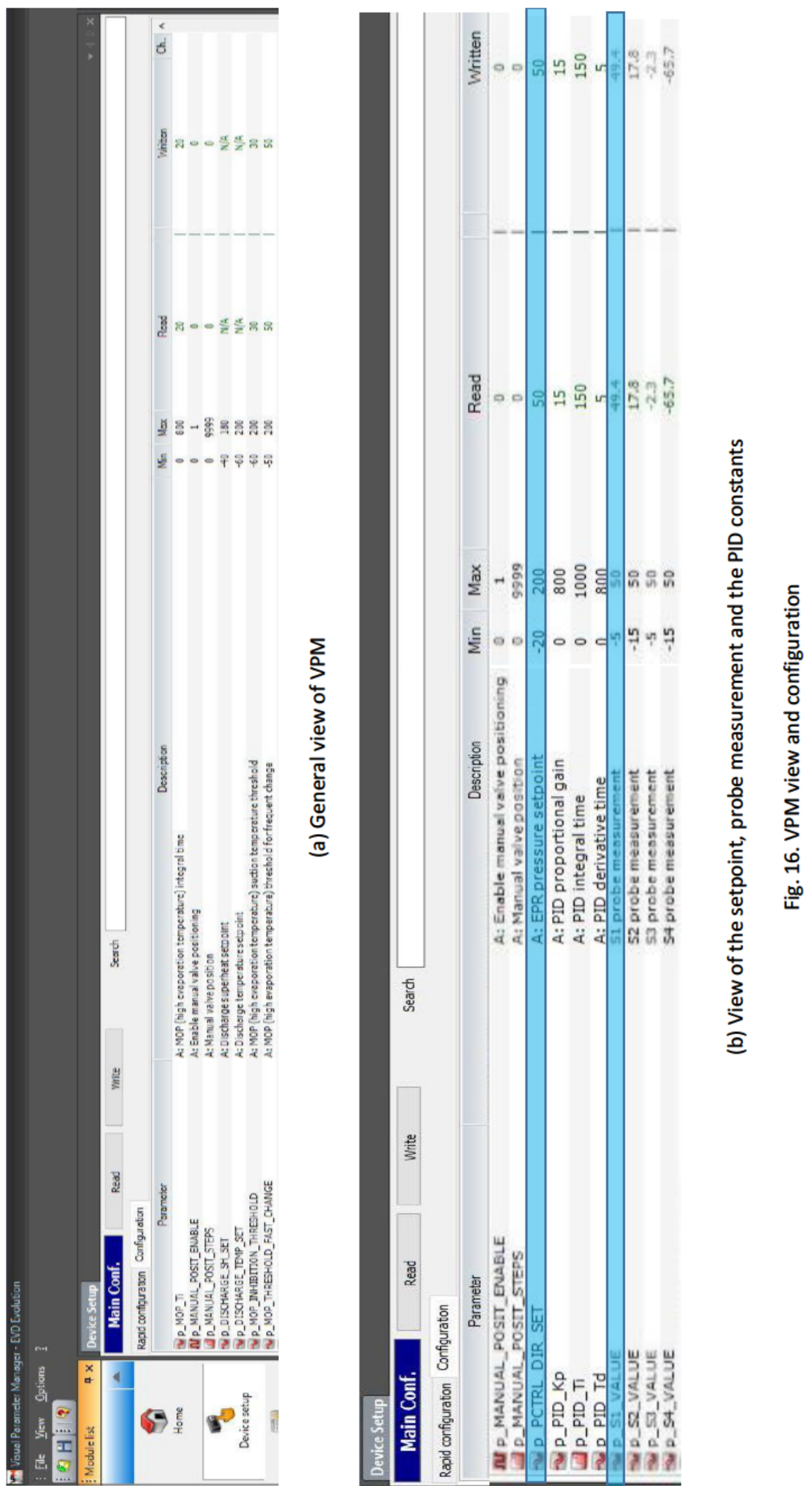


\subsubsection{Other elements}

Other elements of the refrigerant loop include the oil detector or oil separator, dehydration filter and refrigerant visor, as shown in Fig. 17.

The refrigerant, on its way to the gas cooler, can contain micro oil drops, and an oil detector is needed in order to separate the oil and return it to the compressor and guarantee correct working conditions. The one that is being used in the facility is provided by TECNAC, and the level sensor is KRIWAN INT 275L [113].

The refrigerant visor, located before the expansion valve, gives indication about the refrigerant charge in the facility in order for the user to be aware whether the system needs more refrigerant. When there is not bubbles, the refrigerant mass is enough. The visor used in the facility is a stainless-steel device with the following description: $\mathrm{CO}_{2}, 12 \mathrm{~mm}$ 3748E/M12 - Castel.

The filter is important in the vapor line, to detect and avoid the circulation of water and oil drops and any estrange particles produced during operation. The filter in the installation is the following: F SEC R-744 $\mathrm{CO}_{2} 3 / 8$ DMT083S 023Z8416, Danfoss.

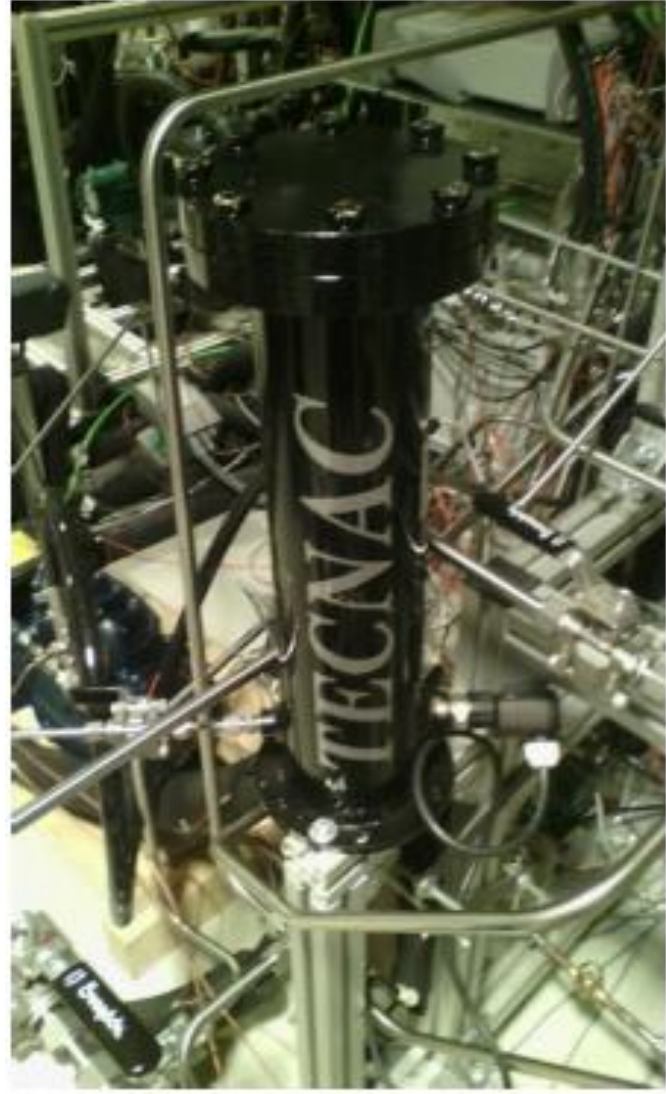

(a) Oil detector: TECNA, with a sensor Kriwan INT275L

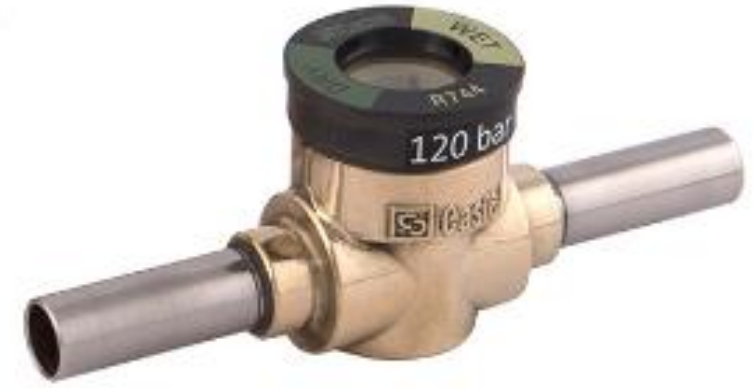

https://www.pecomark.com/es/c/p/404706

(b) Visor: SGN+6S 014-0181 DANFOSS

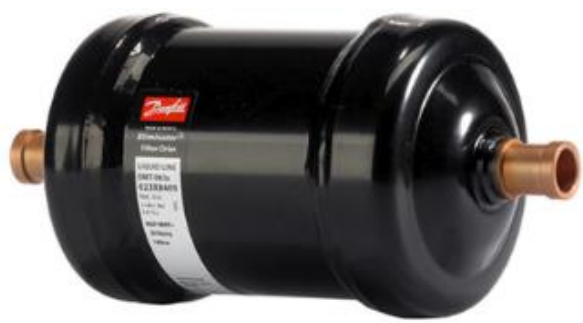

https://www.pecomark.com/es/c/p/402584

(c) Filter: F SEC R-744 CO 2 3/8 DMT083S $023 Z 8416$

Fig. 17. Oil detector, visor and dehydration filter. 


\subsubsection{Pipes and accessories material}

Due to the high pressures of the $\mathrm{CO}_{2}$ transcritical cycles, the materials should be selected considering the allowable pressure characteristics as a priority. The material used in the facility is stainless-steel 304 and 316, provided by Swagelok [114, 115, $116]$, such as the examples presented in Fig. 18. With allowable pressures of 255 and 517 bar, respectively.
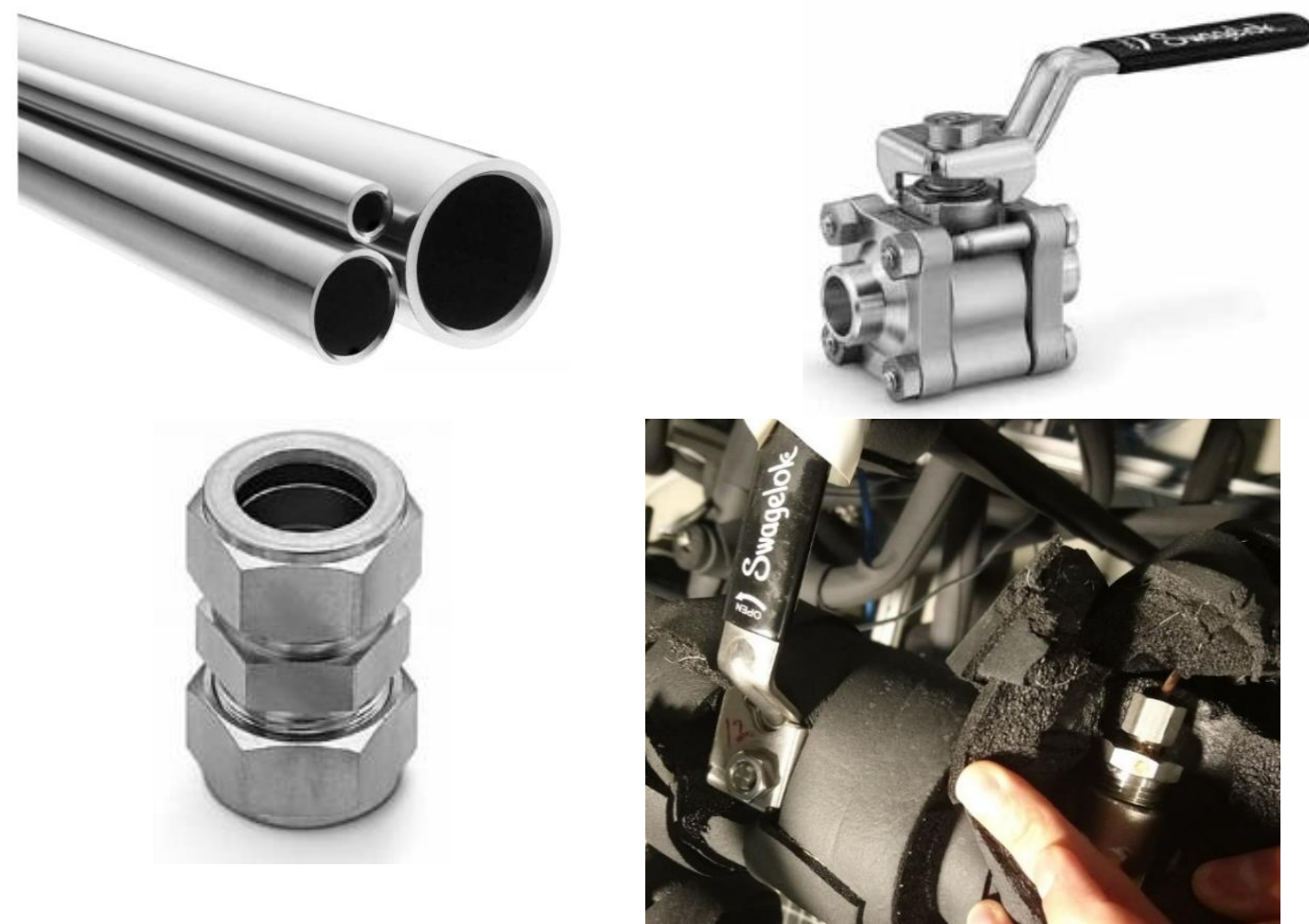

Fig. 18. Swagelok stainless-steel pipes and accessories.

\subsection{Water loop}

This section presents the different elements of the water loop, such as the electrical heater and the cooling machine to maintain the heat source and heat sink at specific temperatures; the three-ways valve, the water pumps and the water-to-water $\mathrm{HX}$ to guarantee the inlet water temperature to the gas cooler and evaporator; the water flow meters; and the PID controllers.

\subsubsection{Auxiliary electrical water heater and cooling machine}

This section describes the auxiliary cooling machine and electrical water heater. As was said before, depending on the water conditions of the $\mathrm{CO}_{2}$ heat pump, there is a cooling machine and an electrical water heater in order to maintain the gas cooler and evaporator water tank at specific temperatures in order to guarantee a heat sink and heat source, respectively. The water tanks for both sources are provided by IDROGAS, with 750 liters of capacity. 


\subsubsection{Cooling machine and gas cooler water tank}

The cooling machine and the gas cooler water tank are presented in the Fig. 19. The cooling machine is an AIRWELL, AQL H 30, R-410A facility, and the working conditions are the following: cooling water in the range from $18{ }^{\circ} \mathrm{C}$ to $-8{ }^{\circ} \mathrm{C}$ and heating in the range from $20^{\circ} \mathrm{C}$ to $50^{\circ} \mathrm{C}$. More information may be found in the manual [117].

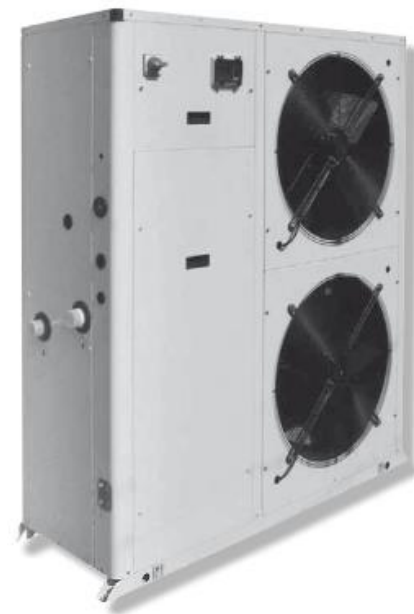

(a) Airwell AQL/AQH 20-75

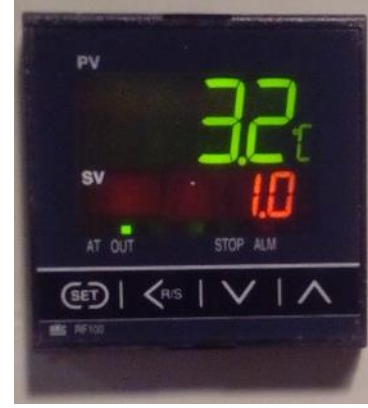

(b) GCWT circulation pump

Fig. 19. Auxiliary cooling machine and gas cooler water tank.

\subsubsection{Electric heater and the evaporator water tank}

The electric water heater and the evaporator water tank are presented in the Fig. 20. The boiler is a Gabarrón $30 \mathrm{~kW}$ facility located behind the water tank, which can heat water up to $120^{\circ} \mathrm{C}$. More information may be found in the manual [118].

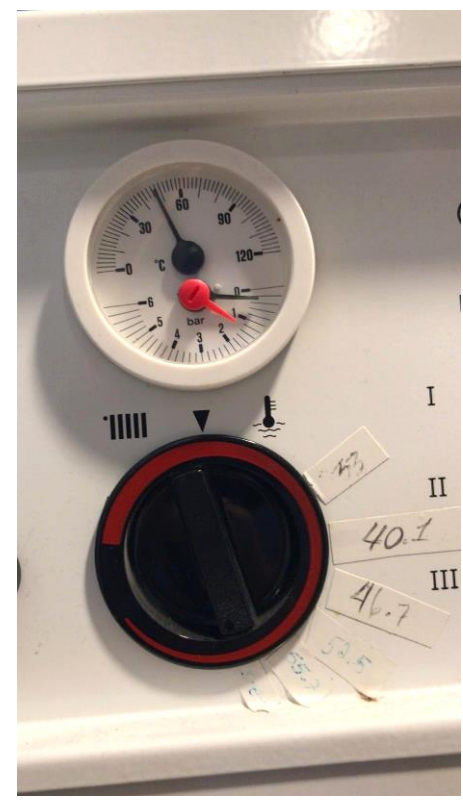

(a) Gabarrón 30kW boiler control

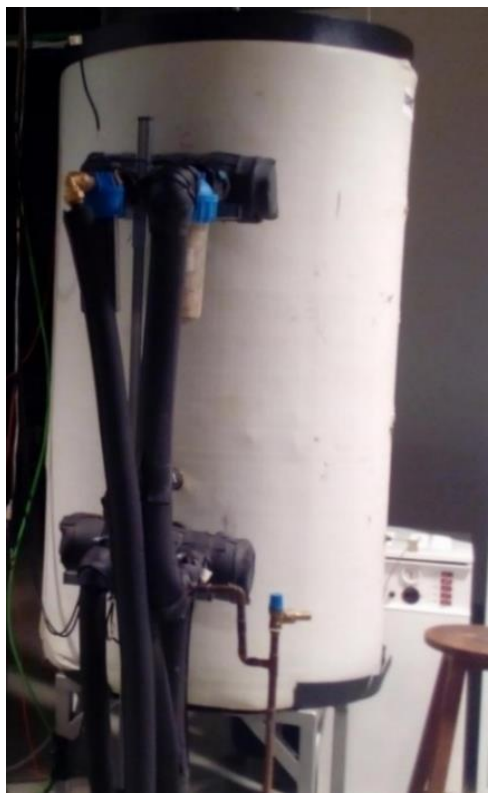

(b) Evaporator water tank

Fig. 20. Auxiliar lectrical water heater with the evaporator water tank. 


\subsubsection{Evaporator and gas cooler water temperatures}

This section presents the devices to control the inlet and outlet water temperature in the evaporator and gas cooler (Fig. 21), such as the three-ways valves, water pumps, water-to-water HX, and PID controller are going to be presented.

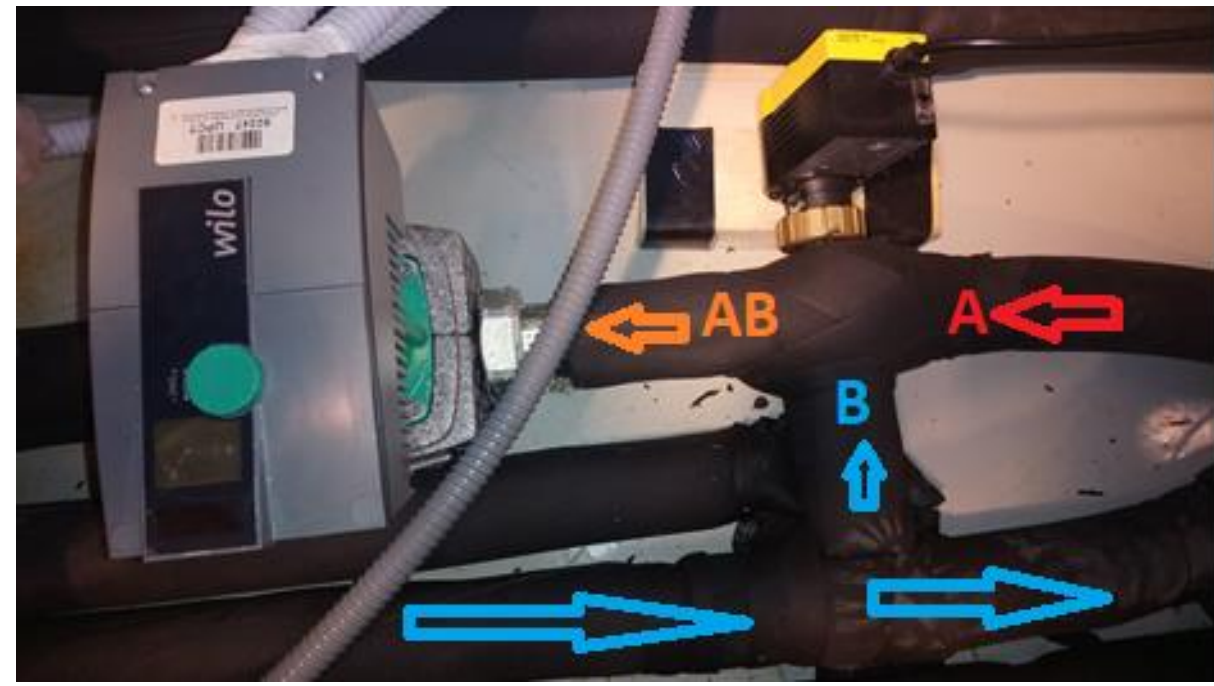

(a) A water pump and a three-ways valve

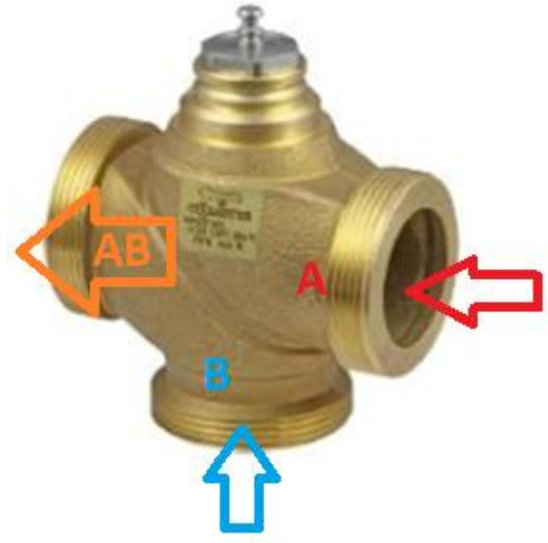

(b) three-ways valve

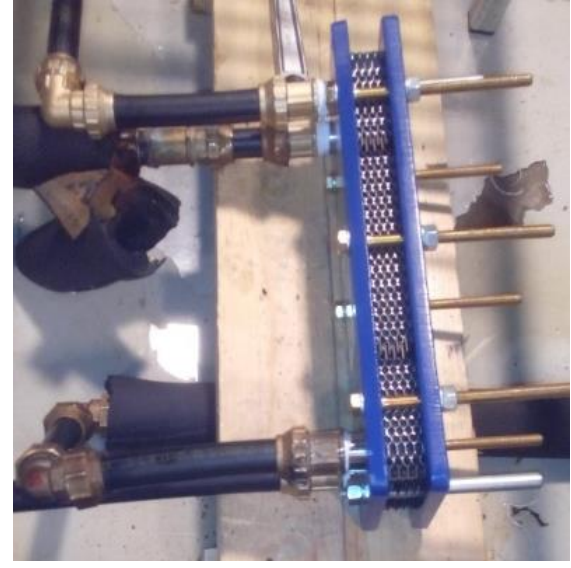

(c) water-to-water $\mathrm{HX}$

Fig. 21. Devices for the water temperature control.

\subsubsection{Three-ways valve}

This element (Fig. 21.c), as was said in section 2.1, control the water inlet temperature by mixing water from the tank and the water out of the any HXs (gas cooler or evaporator). The three-ways valve and the motor are provided by Sauter, the motor model is AVM105SF132 [119].

\subsubsection{Water circulation pumps}

The water pumps used in the facility are Wilo Stratos 30/1-12 [120], same as the one shown in Fig. 21.a. The pumps control the water outlet temperature and, when increasing or decreasing the pump power, the $\dot{m}_{w}$ will increase or decrease. Fig. 22 shows the water circulation pump electrical and control connection. 

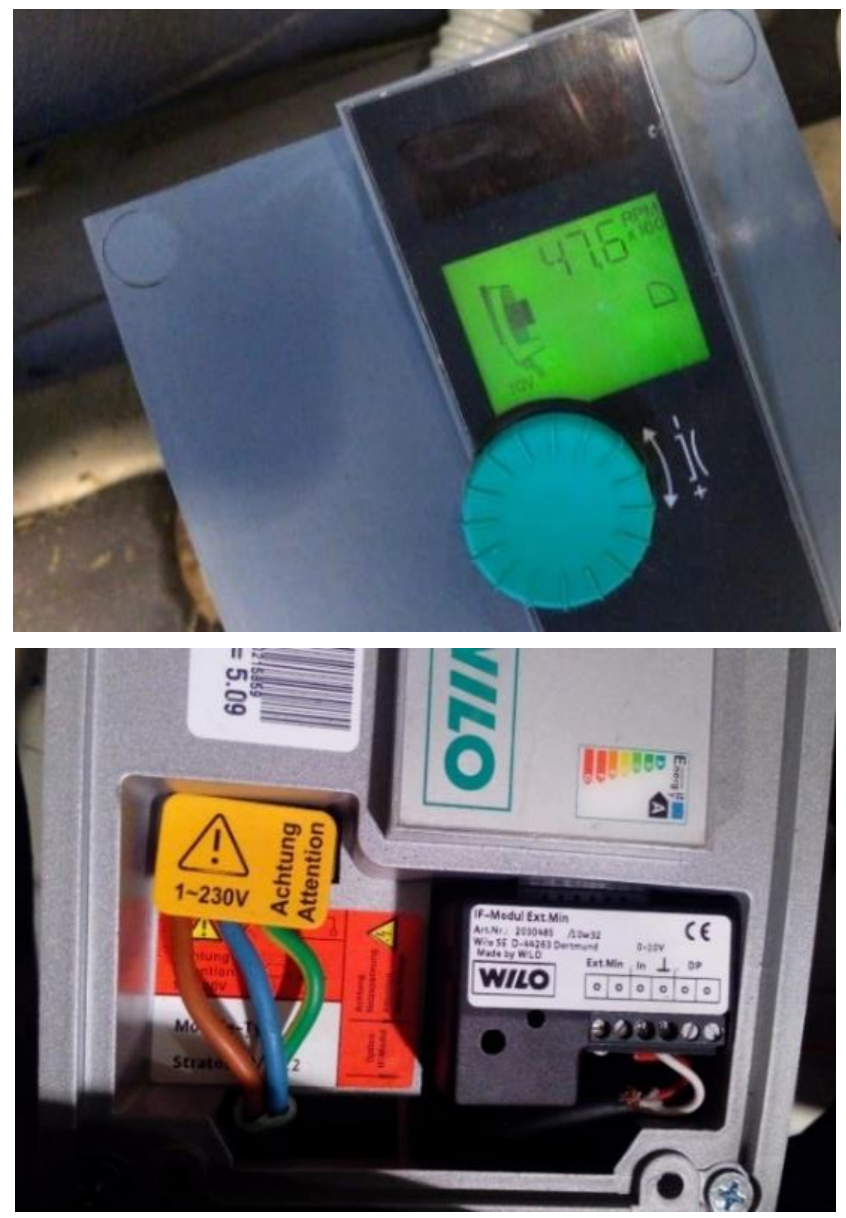

Fig. 22. Wilo water pump.

The water pump power is controlled using PID and the 0-10V signal. If a specific $\dot{m}_{w}$ is required, the $0-10 \mathrm{~V}$ signal should be OFF and the velocity (RPM) is set in a value that gives that flow rate.

\subsubsection{Water-to-water heat exchanger alternative}

Besides the three-ways valve, another alternative to control the inlet water temperature is using a water-to-water HX (Fig. 21.d and Fig. 23), as the one recently used in the gas cooler to replace the three-ways valve. The HX is provided by Alfa Laval, model T2-BFG [121].

Table 9 shows some characteristics of the water-to-water HX.

Table 9. Basic characteristics of the water-to-water HX (T2-BFG).

\begin{tabular}{|l|c|l|}
\hline \multicolumn{1}{|c|}{ Part } & Measuring unit & \multicolumn{2}{|c|}{ Value } \\
\hline Design heating capacity & $\mathrm{kW}$ & 8 \\
\hline Design temperature, high and low side & ${ }^{\circ} \mathrm{C}$ & $\begin{array}{l}35 / 30 \text { and 20/25, } \\
\text { respectively }\end{array}$ \\
\hline Design water flow rate, high and low side & $\mathrm{l} \cdot \mathrm{h}^{-1}$ & $\begin{array}{l}1512 \text { and 1463, } \\
\text { respectively }\end{array}$ \\
\hline Max number of plates & $\#$ & 9 \\
\hline Heat transfer area & $\mathrm{m}^{2}$ & 0.14 \\
\hline Overall heat transfer coefficient & $\mathrm{W} \cdot \mathrm{m}^{-2} \cdot \mathrm{K}^{-1}$ & 5673 \\
\hline Design pressure & $\mathrm{bar}$ & 10 \\
\hline
\end{tabular}




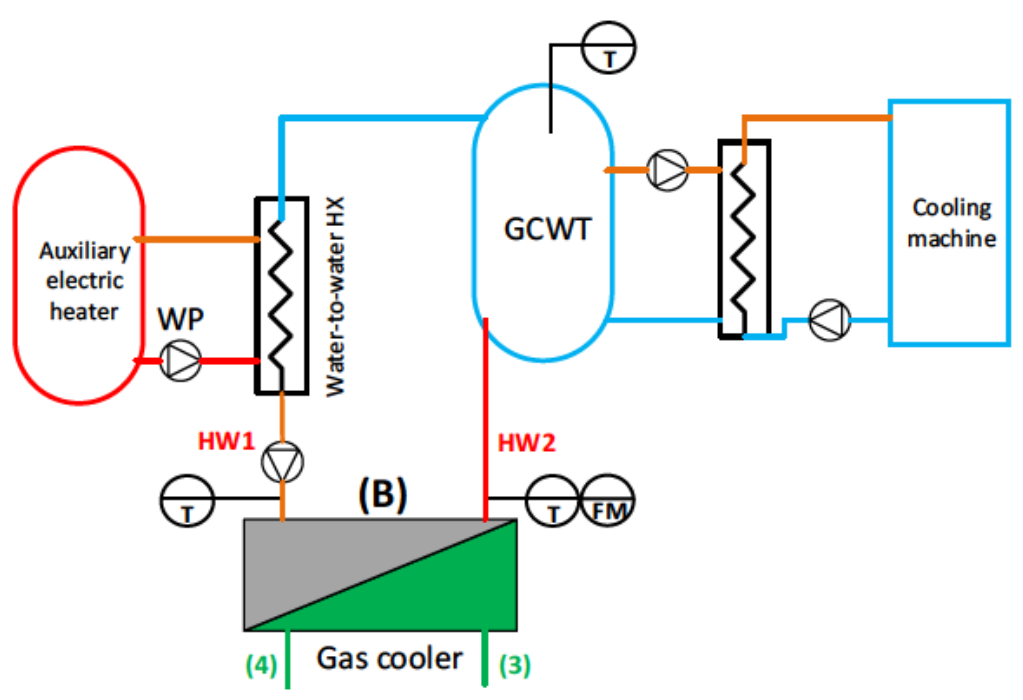

Fig. 23. Water-to-water HX

\subsubsection{PID controller device and software}

As it has been mentioned before, the water temperature at the inlet and outlet of the evaporator and gas cooler can be controlled by using PID controllers, provided by WATLOW [122]. Fig. 24 presents the PID controllers working during a test. The first value of every PID controller in the image is the process value of the water measured variable and the second value represents the setpoint. From the left to right, they go as: gas cooler inlet, evaporator inlet, gas cooler outlet and evaporator outlet.

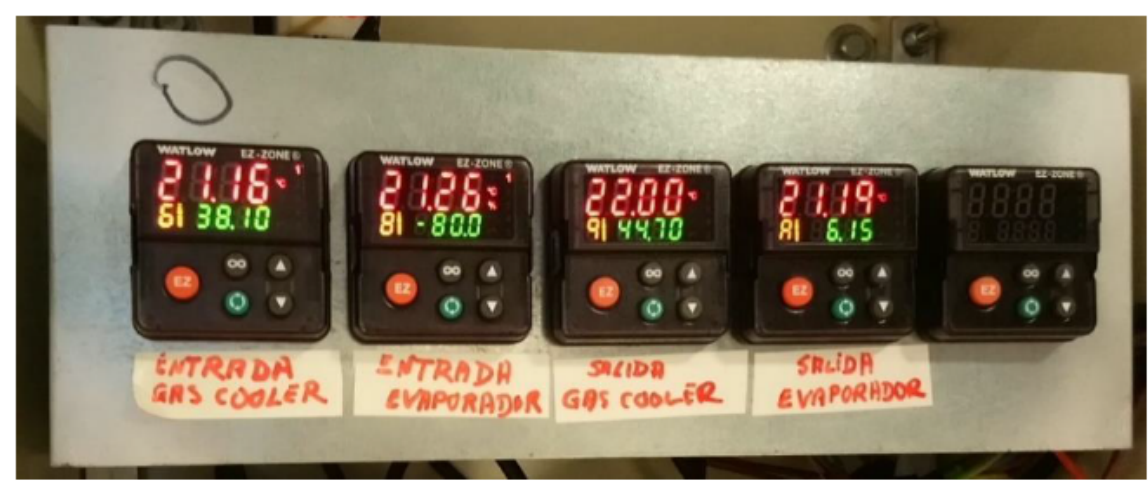

Fig. 24. PID variables measurement and setpoints.

One of the most important parameters is when setting the PID controller to work on manual or automatic in the operation menu. When the control is set to "manual", the PID constants do not make any effects. If the control is set to "auto", the system follows the PID constants through a 0-10V signal.

\subsection{PID constants adjusting modes}

The PID constants can be modified in the PID hardware, but a software to communicate through the computer, called Watlow EZ-ZONE ${ }^{\circledR}$ configurator, is used. In the PID controller exist some important parameters when working in automatic mode, the proportional band (PB), the integral time (IT) and the derivative time (DT). 
There are three types of PID adjusting mode as explained by [123], and they are: autotune, adaptive tune (TRU-TUNE+), and manual tune.

The autotune feature (Fig. 25), allows the controller to measure the system response to determine effective settings for PID parameters during a period of time. When autotuning is initiated, the controller reverts to on-off control. The temperature must cross the autotune setpoint four times to complete the autotuning process. Once complete, the controller starts following new PID parameters.

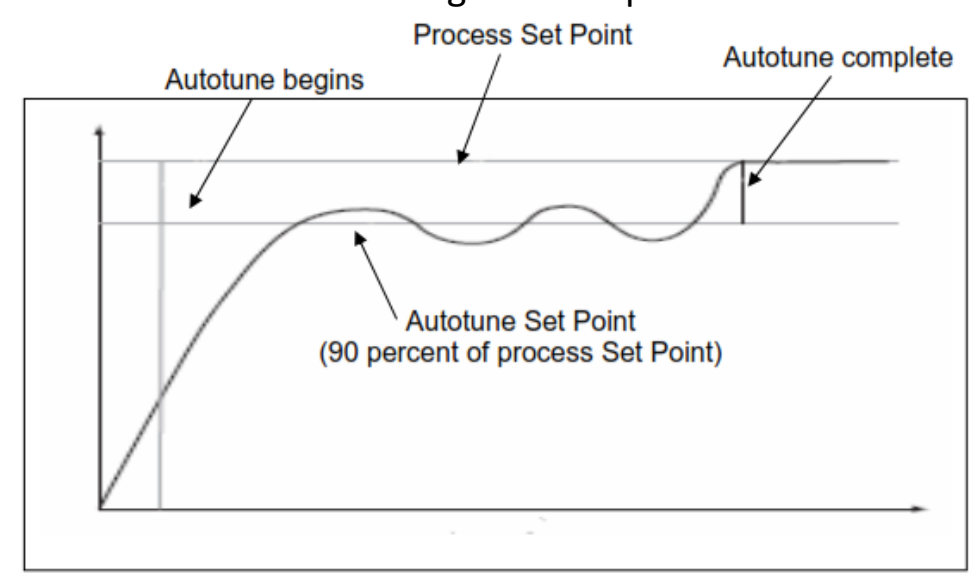

Fig. 25. PID autotune configuration [122].

The TRU-TUNE $+^{\mathrm{TM}}$ feature adjusts the PID parameters without further user interventions. This feature is always working and auto feeding in real time.

In the manual tune, a good PB should stabilize the process value in any value not necessarily similar to the setpoint, but, if a value is going to be arbitrarily assigned, is recommended to be around the setpoint. The IT, when increasing or decreasing its value, it helps to move the process value close or far from the setpoint. And finally, the TD is the last value to be set, a good TD should reduce the oscillation left by the previous two constants, and it is recommended to be calculated by dividing the IT by 6.

\subsubsection{Pipe material}

The water loop material is high density polyethylene (HDPE), with outer and inner diameter of $25 \mathrm{~mm}$ and $22 \mathrm{~mm}$, respectively. Also, the pipes are well insulated with Armaflex material of $19 \mathrm{~mm}$ of thickness with $0.034 \mathrm{~W} \cdot \mathrm{m}^{-1} \cdot \mathrm{K}^{-1}$ of thermal conductivity. Table 10 presents some characteristics of the HDPE [124].

Table 10. Basic characteristics of the HDPE.

\begin{tabular}{|l|c|l|}
\hline \multicolumn{1}{|c|}{ Part } & Measuring unit & \multicolumn{1}{c|}{ Value } \\
\hline Density & $\mathrm{kg} \cdot \mathrm{m}^{-3}$ & 965 \\
\hline Maximum work temperature & ${ }^{\circ} \mathrm{C}$ & 120 \\
\hline Melting point & ${ }^{\circ} \mathrm{C}$ & 130 \\
\hline Thermal conductivity & $\mathrm{W} \cdot \mathrm{m}^{-1} \cdot \mathrm{K}^{-1}$ & 0.48 \\
\hline
\end{tabular}




\subsection{Data acquisition and variables control for both loops}

This section presents the sensors, data acquisition process and variables control that belong to both loops, such as temperature and pressure sensors, and refrigerant and water flow meters.

\subsubsection{Temperature sensors}

The temperatures are going to be measured using 4-wire RTD. PT100 1/10 DIN, with a $0.03{ }^{\circ} \mathrm{C}$ of error. The RTD shown in the Fig. 26, are going to be used for measuring water and refrigerant temperature.
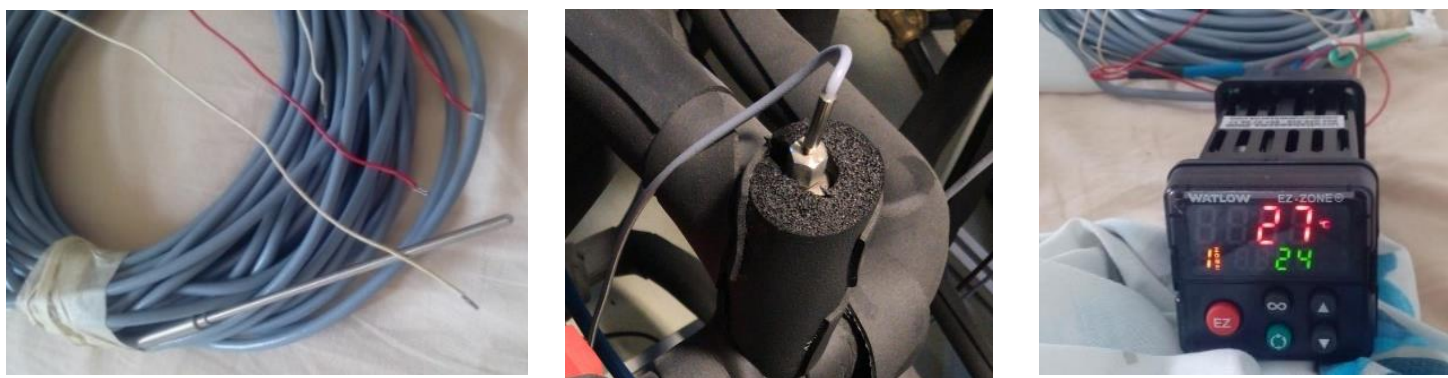

Fig. 26. 4-wire Resistance Temperature Detector (RTD) and example of a connection to a PID controller.

\subsubsection{Pressure sensors}

Regarding the pressure sensors used in the facility (Fig. 27), two model of Yokogawa absolute and differential pressure transmitter are widely used in the facility, such as EJX-510A [125] and EJX 110A [126], to measure absolute pressure and pressure drop, respectively, thanks to the intensity signal.

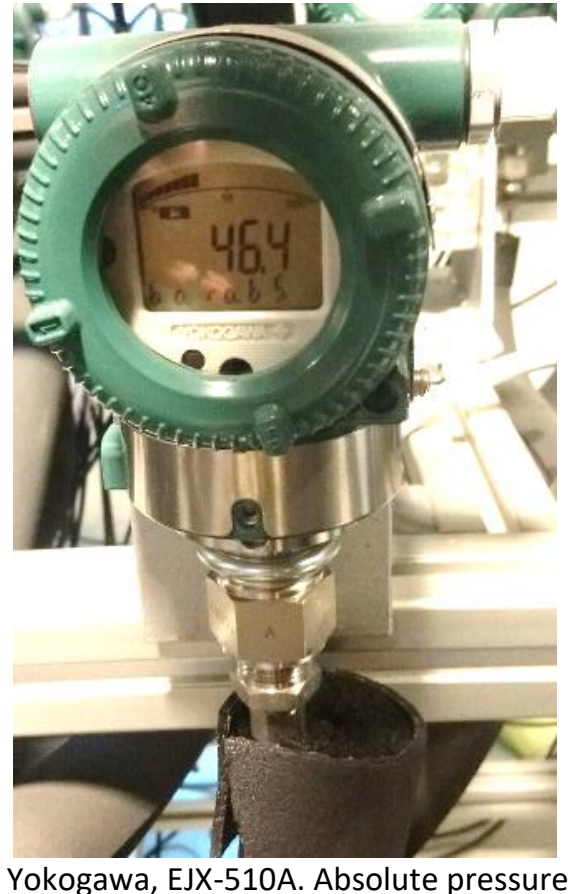

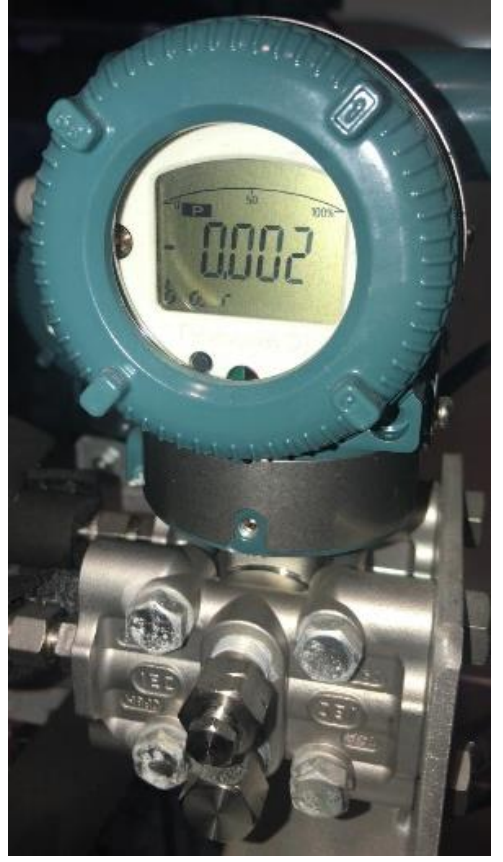

Yokogawa, EJX 110A. Differential pressure

Fig. 27. Pressure sensors. 


\subsubsection{Refrigerant mass flow meters}

The refrigerant loop has two Yokogawa Coriolis effect mass flow meters [127], one corresponds to the Model RCCS32 with the electronic unit (RCCF31) separated from the collecting device, with nominal flow rate of $0.37 \mathrm{t} / \mathrm{h}\left(0.103 \mathrm{~kg} \cdot \mathrm{s}^{-1}\right)$, and the other is a Yokogawa RCCT34, with nominal flow rate around $3 \mathrm{t} / \mathrm{h}\left(0.83 \mathrm{~kg} \cdot \mathrm{s}^{-1}\right)$. See Fig. 28.

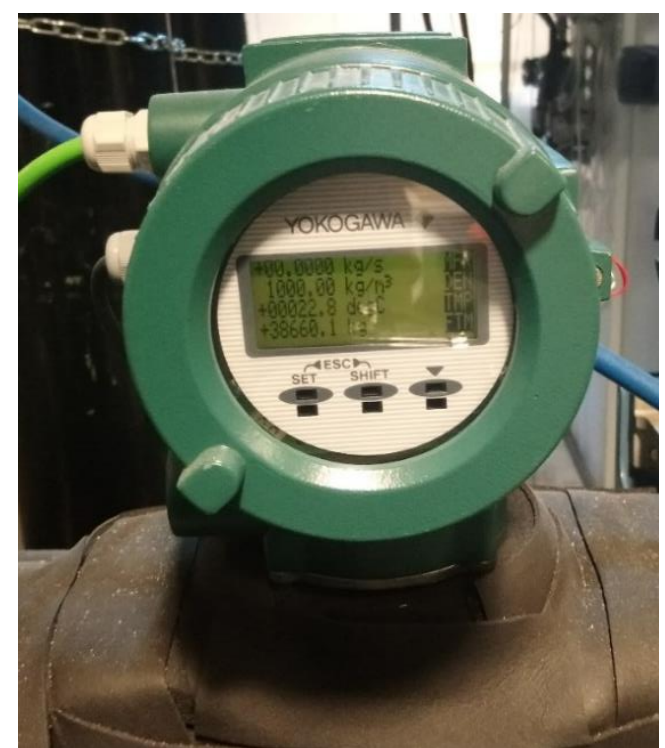

Fig. 28. Coriolis effect refrigerant mass flow meter.

\subsubsection{Water flow meters}

The water loop includes two electromagnetic mass flow meters for the gas cooler and the evaporator (Fig. 29). The brand of the water flow meters is SIEMENS, model FM MAG 5100 W [128], coupled with a transmitter FM MAG 6000 [129].
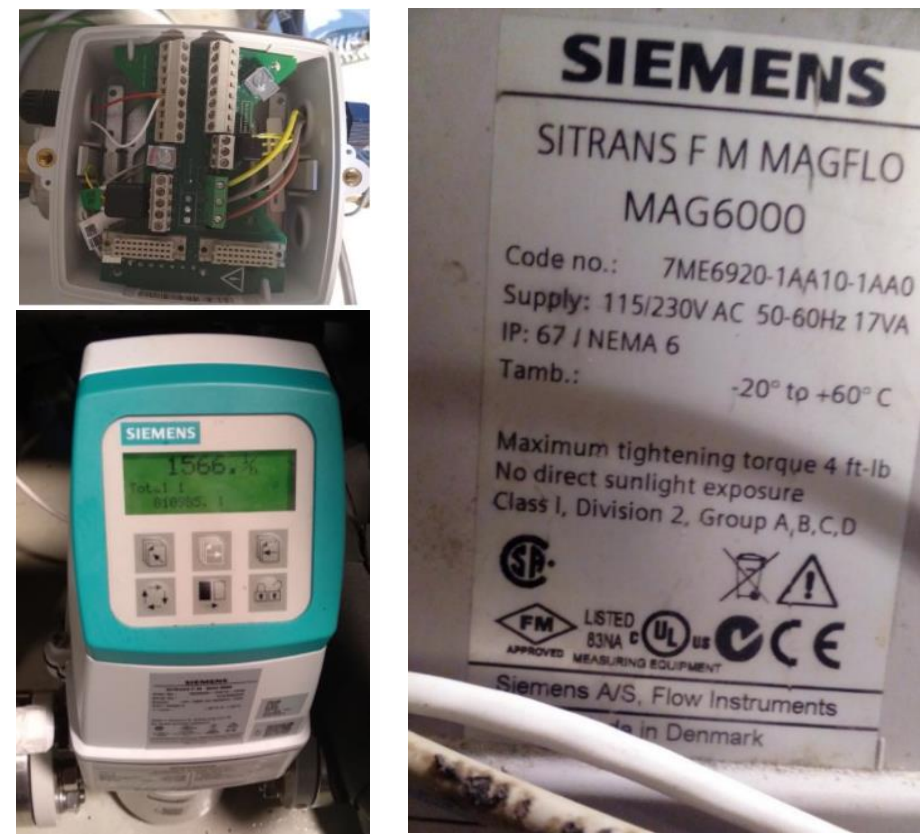

Fig. 29. Siemens water flow meter and transmiter. 


\subsubsection{Summary of the sensors}

Table 11 presents a summary of the sensors used in the facility including Resistance Temperature Detectors (RTD), pressure sensors, refrigerant mass flow meters and water mas flow rate meters. Also, the calibration range for $4 \mathrm{~mA}$ to $20 \mathrm{~mA}$ is presented.

Table 11. Sumary of sensors.

\begin{tabular}{|l|l|l|c|c|c|}
\hline \multicolumn{1}{|c|}{ Sensor } & \multicolumn{1}{|c|}{ Variable } & Magnitude & \multirow{2}{*}{$\begin{array}{c}\text { Sensor } \\
\text { precision }\end{array}$} & \multicolumn{2}{c|}{ Measurement range } \\
\cline { 5 - 7 } & & & 4mA & 20mA \\
\hline RTD, PT100 & Temperature & Temperature & $0.03{ }^{\circ} \mathrm{C}$ & $\mathrm{N} / \mathrm{A}$ & $\mathrm{N} / \mathrm{A}$ \\
\hline Yokogawa EJX510A & Absolute pressure & Intensity & $0,007 \mathrm{bar}$ & $0 \mathrm{bar}$ & $120 \mathrm{bar}$ \\
\hline Yokogawa EJX110A & $\begin{array}{l}\text { Differential } \\
\text { pressure }\end{array}$ & Intensity & $0,002 \mathrm{bar}$ & $0 \mathrm{bar}$ & $1 \mathrm{bar}$ \\
\hline $\begin{array}{l}\text { Fisher Rosemount } \\
\text { 3051CD }\end{array}$ & $\begin{array}{l}\text { Differential } \\
\text { pressure }\end{array}$ & Intensity & $0.001 \mathrm{bar}$ & $0 \mathrm{bar}$ & $1 \mathrm{bar}$ \\
\hline $\begin{array}{l}\text { Fisher Rosemount } \\
\text { 3051TA }\end{array}$ & Absolute pressure & Intensity & $0,035 \mathrm{bar}$ & $0 \mathrm{bar}$ & $50 \mathrm{bar}$ \\
\hline $\begin{array}{l}\text { Coriolis Yokogawa } \\
\text { RCCF31 }\end{array}$ & $\begin{array}{l}\text { Refrigerant mass } \\
\text { flow rate }\end{array}$ & Intensity & $0.166 \mathrm{~kg} \cdot \mathrm{s}^{-1}$ & $0 \mathrm{~kg} \cdot \mathrm{s}^{-1}$ & $0.1 \mathrm{~kg} \cdot \mathrm{s}^{-1}$ \\
\hline $\begin{array}{l}\text { Coriolis Yokogawa } \\
\text { RCCT34 }\end{array}$ & $\begin{array}{l}\text { Refrigerant mass } \\
\text { flow rate }\end{array}$ & Intensity & $0.166 \mathrm{~kg} \cdot \mathrm{s}^{-1}$ & $0 \mathrm{~kg} \cdot \mathrm{s}^{-1}$ & $0.1 \mathrm{~kg} \cdot \mathrm{s}^{-1}$ \\
\hline $\begin{array}{l}\text { SIEMENS FM MAGFLO } \\
\text { MAG6000 }\end{array}$ & Water flow rate & Intensity & $0,0286 \mathrm{l} \cdot \mathrm{s}^{-1}$ & $0 \mathrm{l} \cdot \mathrm{h}^{-1}$ & $600 \mathrm{l} \cdot \mathrm{h}^{-1}$ \\
\hline
\end{tabular}

\subsubsection{Datalogger, Agilent 34972A}

The device to record the data measured by the sensors is a Keysight Technologies Agilent 34972A datalogger [130], the one shown in Fig. 30. The device includes three slots for installing and connecting multiplexer cards (Fig. 31), where the sensors are connected. The device is capable of receiving signal of intensity, tension and frequency. The datalogger used in the facility has two (2) channels for receiving intensity in each card, while twenty (20) channel receive tension. Furthermore, it allows computer communication through a USB connection.

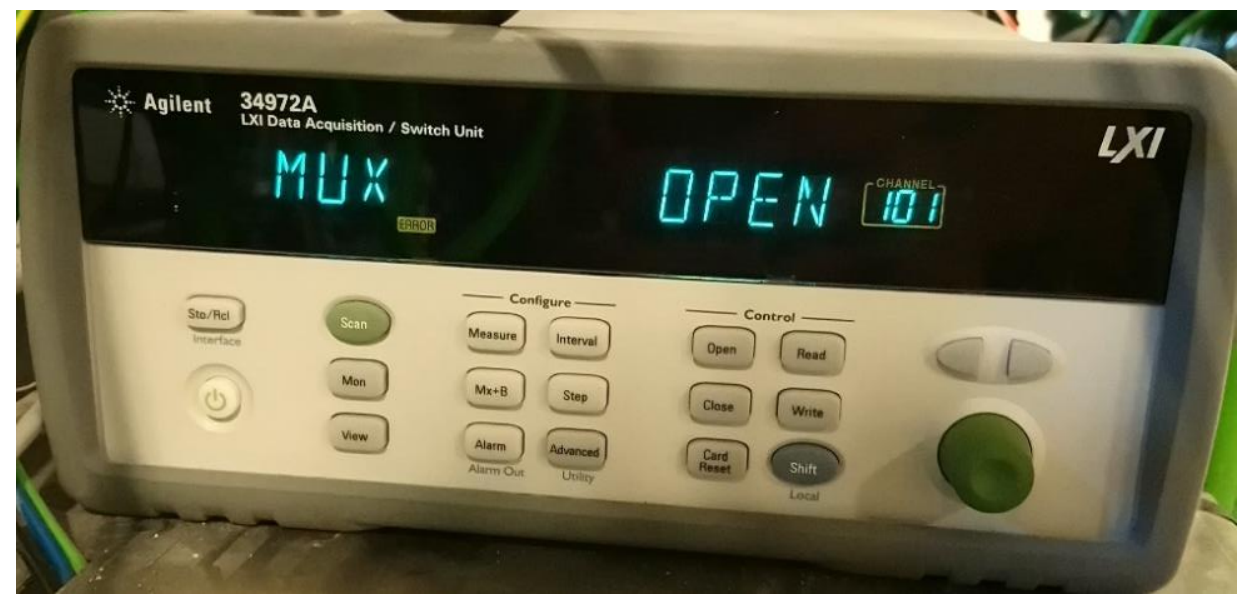

Fig. 30. Agilent 34972A datalogger. 


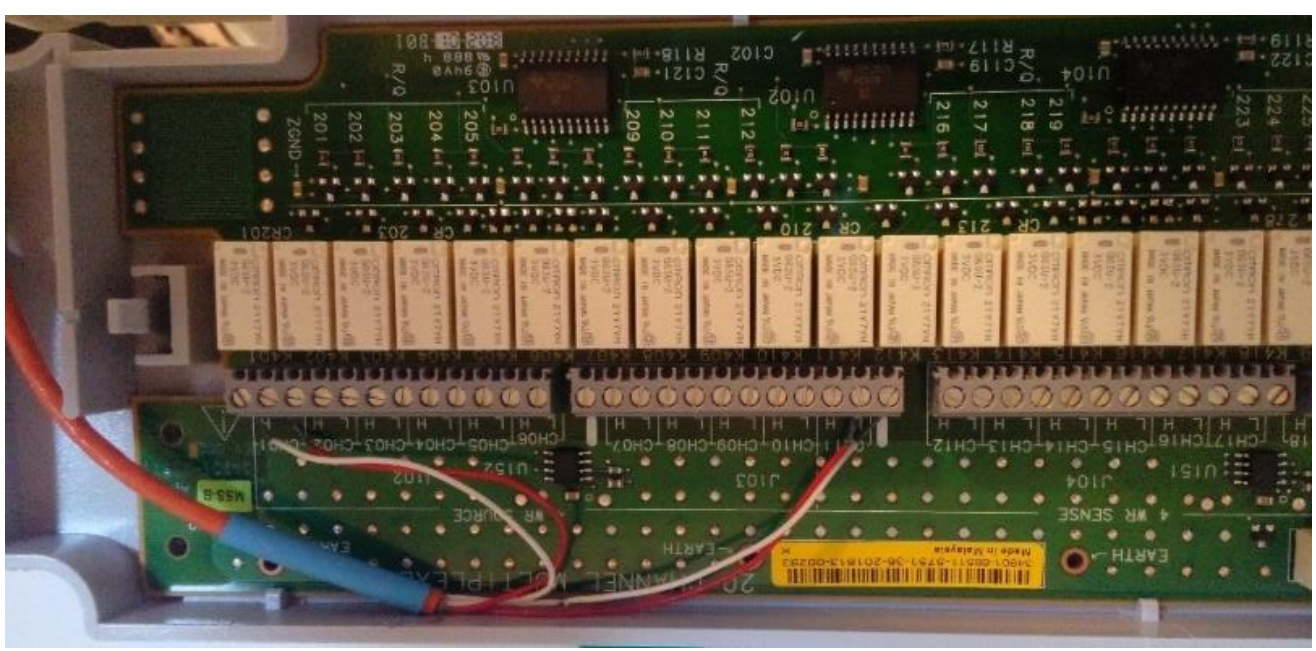

Fig. 31. Multiplexer card used in the datalogger.

\subsubsection{Laboratory Virtual Instrument Engineering Workbench (LabVIEW)}

LabVIEW $^{\circledR}$ is a graphical program application developed by National Instruments, which is widely used for developing plenty algorithm for different engineering applications. This software allows to visualize the variables recorded by the data logger in order to have a good real time control of the facility. User is always moving between a front panel and a block diagram when programing applications.

\subsubsection{Tension and intensity workaround}

As mentioned before, the datalogger used in the facility, only has two (2) channels for receiving intensity in each multiplexer card, while twenty (20) channels receive tension. Due to this situation, it is necessary to put electrical resistances in order to receive tension and calculate the intensity (Fig. 32 ). The value for all the electrical resistances installed is $470 \Omega$ (Fig. 32.c).

As show in Fig. 32.d, the intensity is calculated by dividing the tension by the resistance, then, the intensity $(I)$ times 1000 is for converting from amperes $(A)$ to miliamperes $(\mathrm{mA})$. The constants $x=7.5$ and $y=30$ are used for the pressure calculation for the sensor Yokogawa EJX510A JDS in the range of 0 bar to 120 bar for 4 to $20 \mathrm{~mA}$ range, as shown in equation (18) and (19)

$$
\begin{gathered}
P(\text { bar })=x * I_{\max }-y=120 \text { bar } \\
\text { Where } ; x=\frac{120 \text { bar }}{20 m A-4 m A} \text { and, } y=\frac{120 \mathrm{bar}}{4 m A}
\end{gathered}
$$




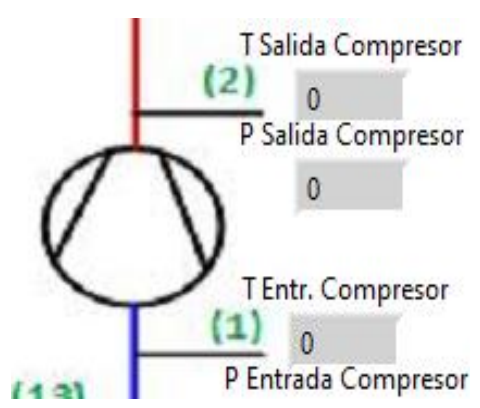

(a) Compressor (inlet and outlet). LabVIEW front panel

V_P_alta.vi Front Panel *

File Edit View Project Operate $\Rightarrow$ II 15 pt Applic

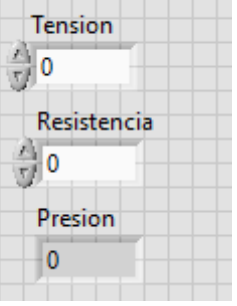

(b) Compressor outlet pressure calculation. LabVIEW front panel

\section{$201,202,204,206,208,210$}

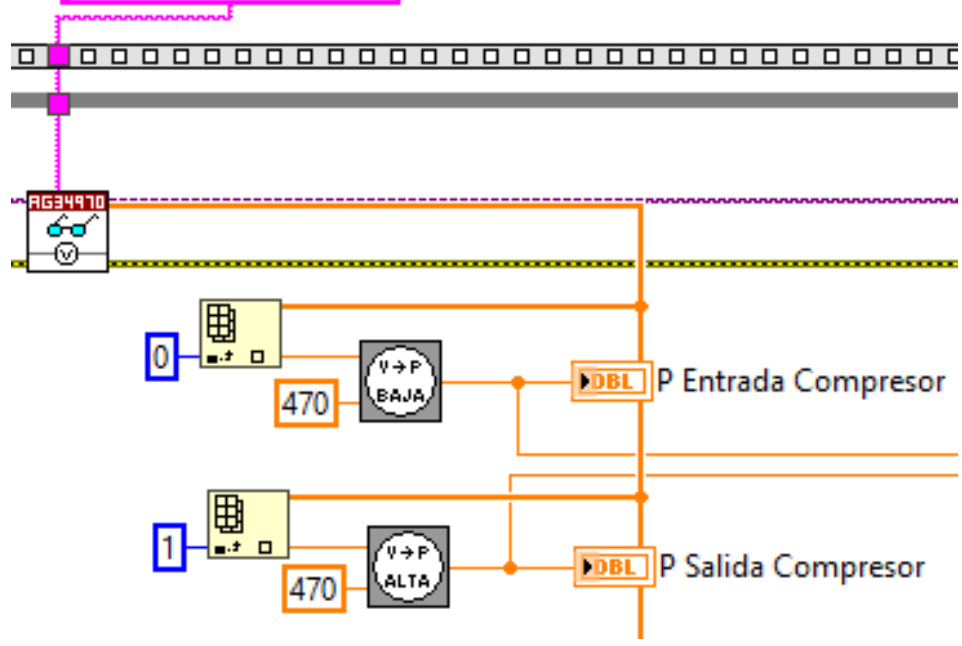

(c) Compressor (inlet and outlet). LabVIEW block diagram

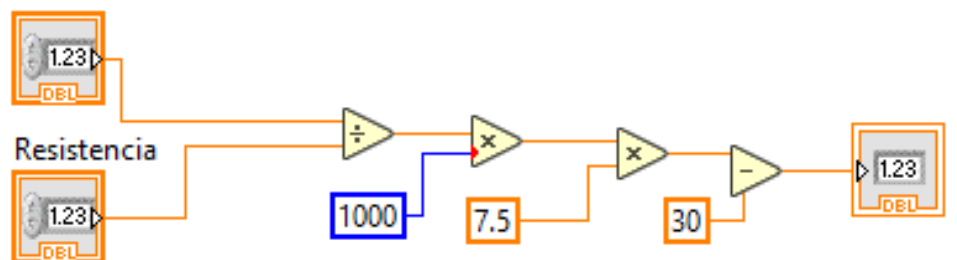

(d) Compressor outlet pressure calculation. LabVIEW block diagram

Fig. 32. Data logger in LabVIEW. Intensity workaround for pressure calculation (compressor oulet).

\subsubsection{Test monitoring}

The graphical programing for this $\mathrm{CO}_{2}$ facility, has two pages in the front panel (Fig. 33 and Fig. 34), where the user could find the datalogger information, the saving path, the test information, the graphical presentation of the thermodynamic cycle and measured variables. The block diagram (Fig. 35) shows the design, connections and all equations necessary to visualize the results. 







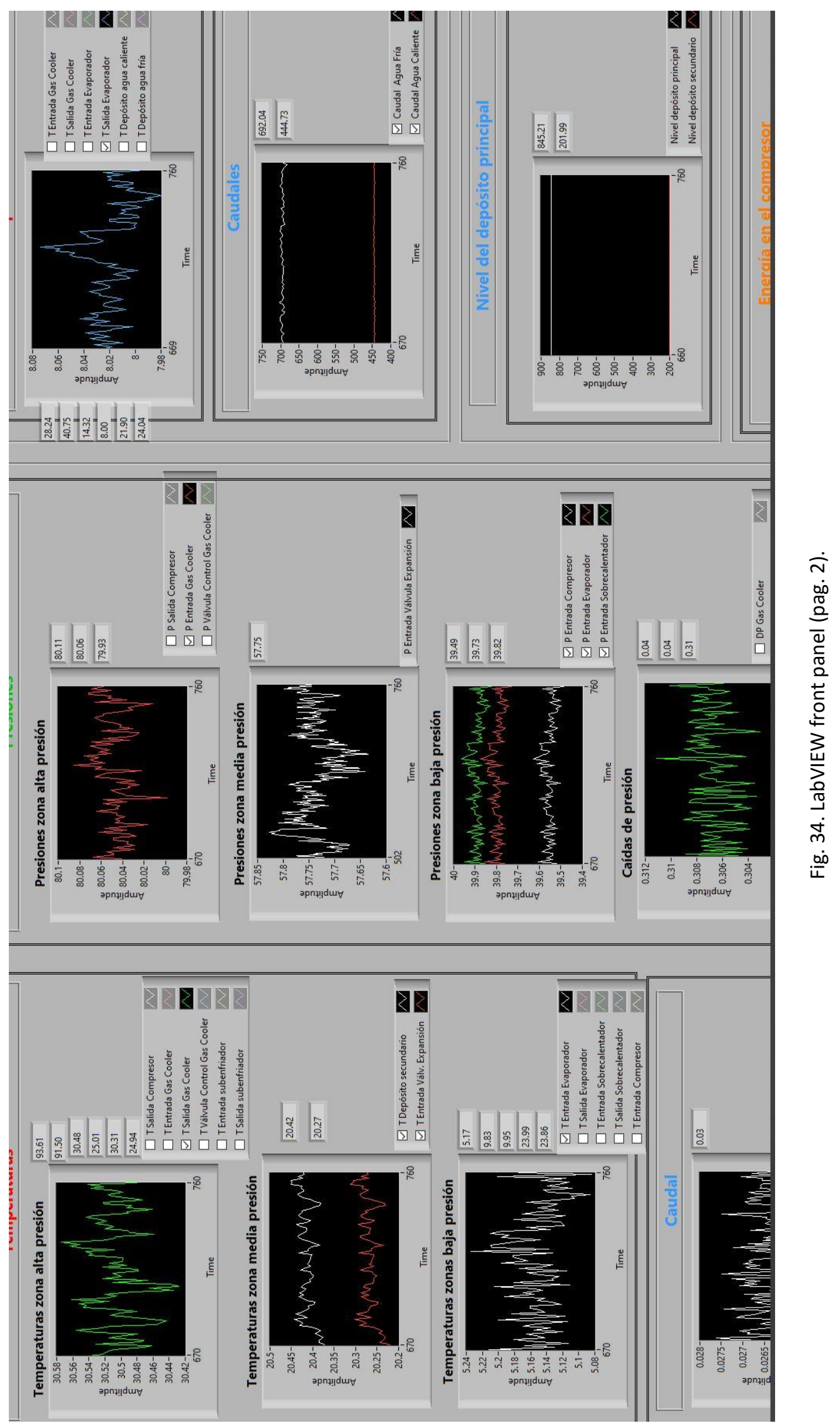




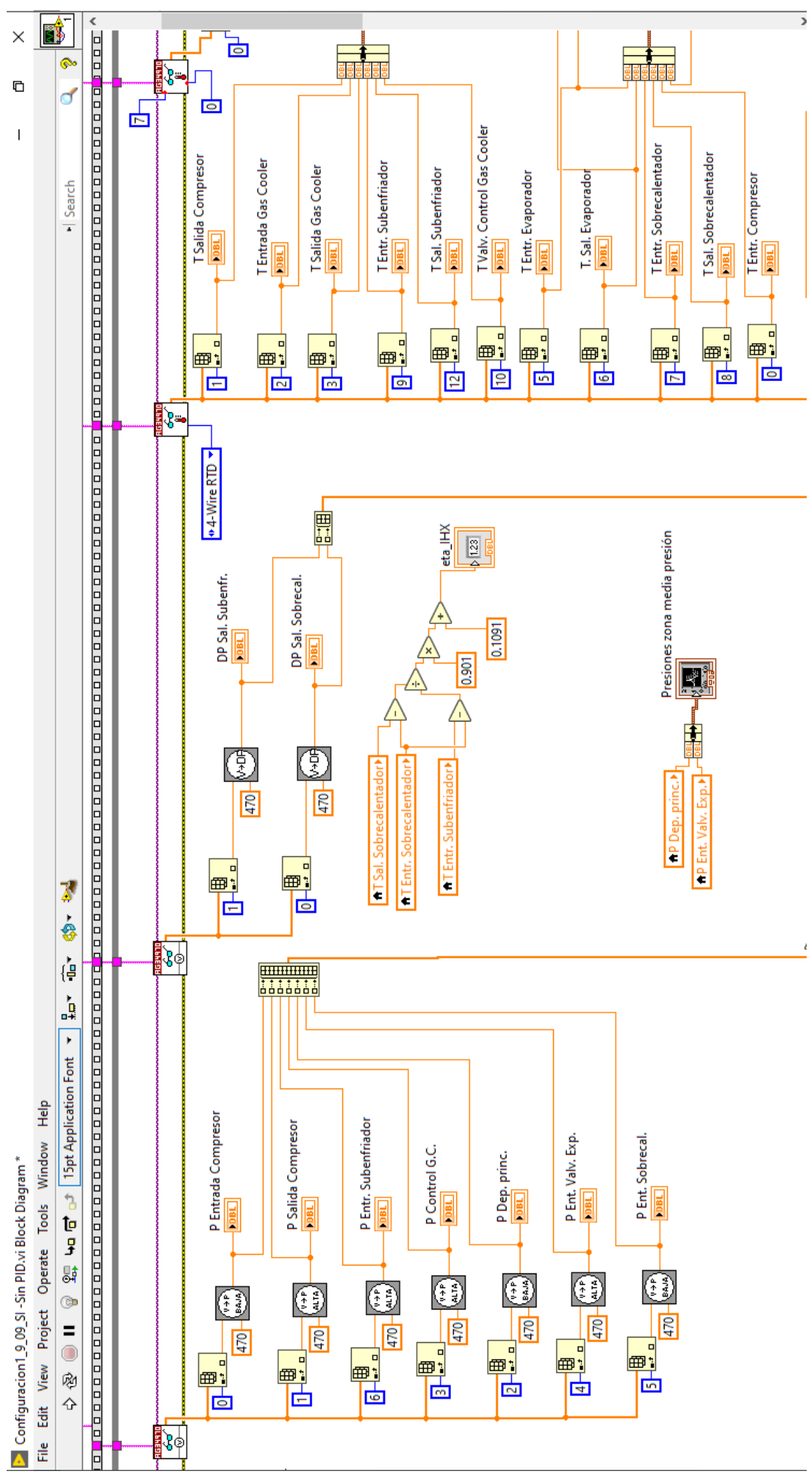

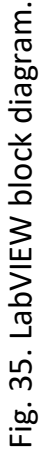




\section{Test methodology}




\subsection{Introduction}

This chapter presents the configurations experimentally studied in this work, the tests defined to do so, the analysis carried out to see the influence of different parameters on the system performance, such as the influence of the liquid receiver pressure, the IHX influence, the optimal pressure. Finally, the variable recording and treatment and the uncertainty analysis are presented.

\subsection{Configurations to be studied}

The general $\mathrm{CO}_{2}$ facility previously presented in Fig. 4 offers the capacity of testing four (4) different configurations (C\#), which are presented in Fig. 36. Three of them belong to the dry evaporator group with and without liquid receiver and one has flooded evaporator. All cycles are one-stage, and include IHX.

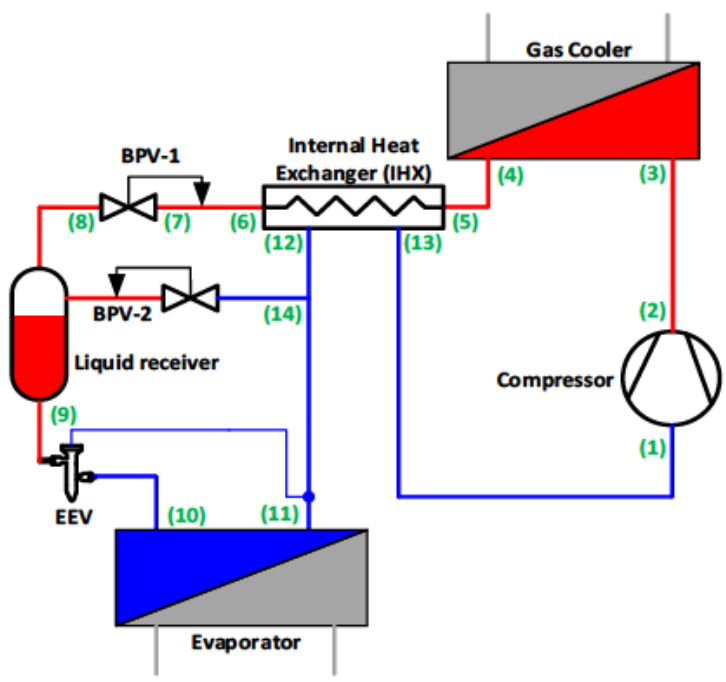

(a) Configuration 1 (C1)

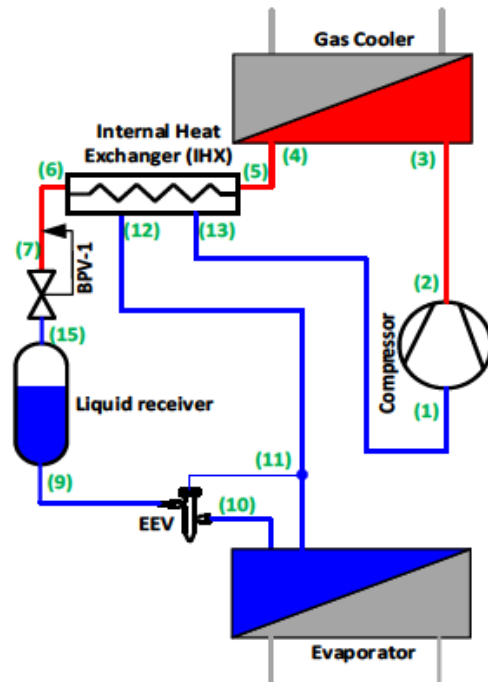

(b) Configuration 2 (C2)

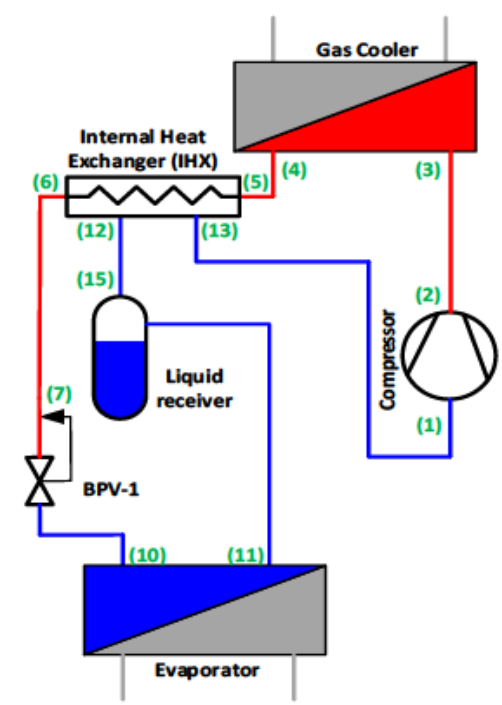

(c) Configuration 3 (C3)

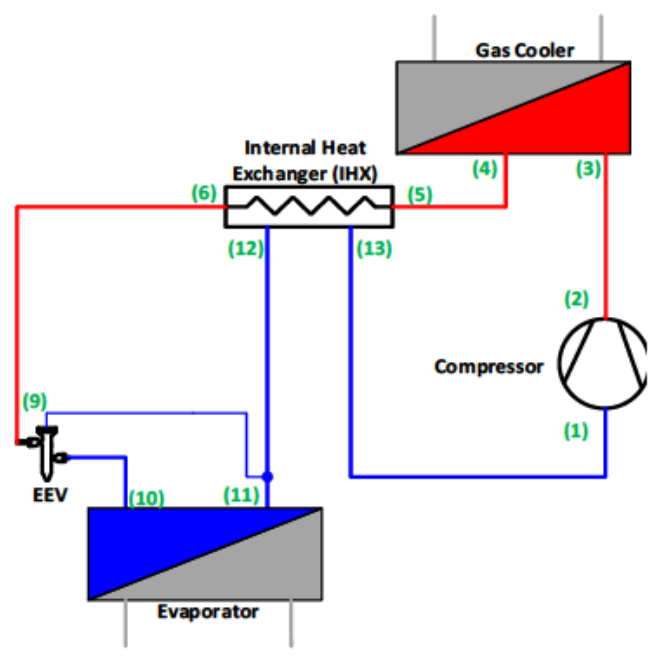

(d) Configuration 4 (C4)

Fig. 36. Different configurations to be studied. 


\subsubsection{Configuration 1: Dry evaporator with double expansion \& bypass (C1)}

This configuration has an intermediate liquid receiver with a capacity of 30 liters and 70 bar of maximum pressure, and a gas bypass. This is the only configuration that uses all three expansion valves. The total refrigerant mass flow rate passing through the compressor and gas cooler is that one passing through the evaporator plus the gas bypass. The gas cooler pressure is controlled by the first expansion valve, acting as a back pressure valve (BPV-1). The receiver pressure is controlled by the second back pressure valve (BPV-2), by allowing the gas bypass to the evaporator outlet while limiting the receiver to a specific pressure setpoint. As was said before, the maximum theoretical receiver pressure is reached when the refrigerant is in saturated liquid phase, where there would not be gas bypass out of the liquid receiver, and also, will depend on the high pressure of the cycle. On the other hand, the minimum theoretical receiver pressure would be the evaporation pressure, therefore, in one-stage cycles, that zone is often called the intermediate pressure zone. When the receiver back pressure valve (BPV-2) is closed, all refrigerant passes through the evaporator and the system is working in $\mathrm{C} 2$. The third expansion valve, located between the receiver and the evaporator, is an EEV that controls the superheating at the evaporator outlet, calculated by considering the measured pressure and temperature.

\subsubsection{Configuration 2: Dry evaporator with double expansion, without bypass (C2)}

This configuration is the $\mathrm{C} 1$ without gas bypass. The receiver upstream the thermostatic EEV, guarantees an appropriate feeding to the evaporator. This configuration controls the gas cooler high pressure through the BPV-1, and the superheating at the evaporator outlet through the thermostatic expansion valve EEV.

\subsubsection{Configuration 3: Flooded evaporator, single expansion, no superheating (C3)}

In this configuration, the refrigerant enters the evaporator with the same enthalpy as that of the IHX outlet (or the gas cooler outlet if there not IHX). The outlet is saturated vapor since the evaporator is flooded. The liquid receiver at the evaporator outlet will guarantee that no liquid gets into the compressor suction in case that the evaporator outlet was not saturated vapor. Also, the IHX produces an overheating. In this configuration there is not superheating at the evaporator outlet, but instead, a high pressure control at the gas cooler performed by the back pressure valve (BPV1). 


\subsubsection{Configuration 4: Dry evaporator, no high pressure control, no liquid receiver (C4)}

$\mathrm{C} 4$, is the basic cycle with IHX and superheating control, but without liquid receiver and high pressure control. The thermostatic EEV controls the superheating at the evaporator outlet.

\subsection{Tests definition}

This section describes the methodology followed to define the tests performed in this study. As mentioned before, the purpose is to study the heat pumps for space heating, DHW generation, and analyze the influence of different parameters, such as the intermediate liquid receiver pressure, the IHX, and the optimal high pressure of the cycle. Since this facility is based on using temperatures similar to the ones found in water recovery applications as the heat source, most of the studies are in the range from $10^{\circ} \mathrm{C}$ to $30^{\circ} \mathrm{C}$ at the evaporator inlet.

\subsubsection{Intermediate liquid receiver pressure, influence on the COP}

The intermediate liquid receiver pressure tests are performed following Table 12 . The first five tests ( 1 to 5 ) are going to be performed varying the receiver pressure between 48 and 60 bar, while the rest of the parameters of the cycle are kept constant. Water side conditions in the evaporator and the gas cooler are controlled in order to assure constant evaporation temperature ( $T_{\text {evap }}=10 \stackrel{\circ}{\circ}$ ) and gas cooler outlet temperature ( $T_{g c, r o}=25 \stackrel{\circ}{ } \mathrm{C}$ ). Since the optimal pressure for those conditions is around the critical pressure, BPV-1 keeps constant the gas cooler pressure at a slightly higher value (75 bar), while EEV keeps a constant superheating degree (5 K).

Table 12. Liquid receiver test matrix.

\begin{tabular}{|c|c|c|c|c|c|}
\hline \multicolumn{6}{|c|}{ Specific refrigerant conditions, without IHX } \\
\hline $\begin{array}{c}\text { Test } \\
\text { order (\#) }\end{array}$ & PIr (bar) & $\begin{array}{l}T_{\text {evap }} \\
\left({ }^{\circ} \mathrm{C}\right)\end{array}$ & $\begin{array}{l}\text { SH } \\
\text { (K) }\end{array}$ & $\begin{array}{l}T_{g c, r o} \\
\left({ }^{\circ} \mathrm{C}\right)\end{array}$ & $\begin{array}{c}P_{g c} \\
\text { (bar) }\end{array}$ \\
\hline 1 & Minimum & \multirow{5}{*}{10} & \multirow{5}{*}{$5 \mathrm{~K}$} & \multirow{5}{*}{25} & \multirow{5}{*}{75} \\
\hline 2 & 50 & & & & \\
\hline 3 & 52 & & & & \\
\hline 4 & 56 & & & & \\
\hline 5 & Maximum & & & & \\
\hline \multicolumn{6}{|c|}{ In DHW generation, IHX } \\
\hline $\begin{array}{c}\text { Test } \\
\text { order (\#) }\end{array}$ & $\begin{array}{l}\text { Liquid receiver bypass (totally opened or } \\
\text { totally closed) }\end{array}$ & $\begin{array}{l}T_{e v, w i / o} \\
\left({ }^{\circ} \mathrm{C}\right)\end{array}$ & $\begin{array}{l}\text { SH } \\
\text { (K) }\end{array}$ & $\begin{array}{l}T_{g c, w i / o} \\
\left({ }^{\circ} \mathrm{C}\right)\end{array}$ & $\begin{array}{c}P_{g c} \\
\text { (bar) }\end{array}$ \\
\hline 6 & Open & \multirow{2}{*}{$15 / 10$} & \multirow{2}{*}{$5 \mathrm{~K}$} & \multirow{2}{*}{$10 / 50$} & \multirow{2}{*}{75} \\
\hline 7 & Closed & & & & \\
\hline 8 & Open & \multirow{2}{*}{$15 / 10$} & \multirow{2}{*}{$5 \mathrm{~K}$} & \multirow{2}{*}{$10 / 50$} & \multirow{2}{*}{80} \\
\hline 9 & Closed & & & & \\
\hline
\end{tabular}

The next 4 tests are conducted to analyze the effect that the gas bypass has on the system performance during domestic hot water production. In the gas cooler the

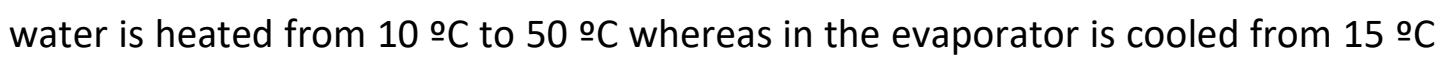


to $10 \stackrel{\circ}{ } \mathrm{C}$. Two different gas cooler pressures are studied ( 75 and 80 bar) and a constant superheating degree of $5 \mathrm{~K}$ is kept in all tests. The liquid receiver is studied as totally opened and totally closed bypass for both specific gas cooler pressures.

\subsubsection{Influence of the IHX efficiency}

The test matrix defined in Table 13 is used to study the influence that the IHX efficiency has in the system under low temperature heating conditions according to EN-14511-2-Standard [1].

Table 13. IHX test matrix.

\begin{tabular}{|c|c|c|c|c|c|c|}
\hline $\begin{array}{c}\text { Test } \\
\text { order (\#) }\end{array}$ & SC & $\begin{array}{l}\text { IHX valves } \\
\text { position }\end{array}$ & $\begin{array}{c}T_{e v, w i / o} \\
\left({ }^{\circ} \mathrm{C}\right)\end{array}$ & $\begin{array}{l}\text { SH } \\
\text { (K) }\end{array}$ & $\begin{array}{c}T_{g c, w i / o} \\
\left({ }^{\circ} \mathrm{C}\right)\end{array}$ & $\begin{array}{c}P_{g c} \\
\text { (bar) }\end{array}$ \\
\hline 1 & $0 \mathrm{~K}$ & Totally closed & \multirow{4}{*}{$10 / 7$} & \multirow{4}{*}{$5 K$} & \multirow{4}{*}{$30 / 35$} & \multirow{4}{*}{80} \\
\hline 2 & $1.5 \mathrm{~K}$ & \multirow{2}{*}{ Partially opened } & & & & \\
\hline 3 & $3 \mathrm{~K}$ & & & & & \\
\hline 4 & $\mathrm{XK}$ & Totally opened & & & & \\
\hline
\end{tabular}

Maintaining some fix conditions, such as the water temperature at the gas cooler $\left(T_{g c, w}\right)$ and evaporator $\left(T_{e v, w}\right)$, while keeping a superheating $\left.(S H) \leq 5 \mathrm{~K}\right)$, the $\mathrm{IHX}$ efficiency is going to be manually modified by controlling the manual valves mentioned in section 2.1, Fig. 4 (V-1, V-2 and V-3), in order to produce different subcooling $(S C)$, which is the difference between the refrigerant temperature out of the gas cooler and the inlet temperature at the first back pressure valve (BPV-1) which is located after the IHX, in the point 7 (Fig. 4 and Fig. 36Fig. 36). Influence of high pressure on cycle performance

As mentioned before, the high pressure has an optimum value at which the COP is the maximum, it is often called the optimal pressure. In the existing literature, many researchers have found that the most influential parameter is the gas cooler outlet temperature. Table 14 presents the test matrix for the study of the influence of the high pressure, which is going to be used for developing an optimal pressure correlation.

Table 14. Optimal pressure test matrix.

\begin{tabular}{|c|c|c|c|c|}
\hline$T_{g c, r o}\left({ }^{\circ} \mathrm{C}\right)$ & $T_{\text {evap }}\left({ }^{\circ} \mathrm{C}\right)$ & $S H(K)$ & $P_{g c}($ bar), range & $P_{\text {Ir }}$ position \\
\hline 30.5 & \multirow{3}{*}{5} & \multirow{3}{*}{$5 \mathrm{~K}$} & \multirow{3}{*}{ From 74 to 91 bar } & \multirow{3}{*}{$\begin{array}{l}\text { Totally closed and } \\
\text { totally opened }\end{array}$} \\
\hline 32.5 & & & & \\
\hline 36 & & & & \\
\hline 30.5 & \multirow{3}{*}{5} & \multirow{3}{*}{$5 \mathrm{~K}$} & \multirow{3}{*}{$\begin{array}{c}\text { Only for the } \\
\text { optimal pressure }\end{array}$} & \multirow{3}{*}{ Totally opened } \\
\hline 32.5 & & & & \\
\hline 36 & & & & \\
\hline 30.5 & \multirow{3}{*}{10} & \multirow{3}{*}{$5 \mathrm{~K}$} & \multirow{3}{*}{ From 74 to 91 bar } & \multirow{3}{*}{ Totally closed } \\
\hline 32.5 & & & & \\
\hline 36 & & & & \\
\hline
\end{tabular}


Refrigerant evaporation temperature $\left(T_{\text {evap }}\right)$ at $5{ }^{\circ} \mathrm{C}$ and $10{ }^{\circ} \mathrm{C}$, a superheating of $5 \mathrm{~K}$, and a totally closed bypass, for different refrigerant temperatures out of the gas cooler $\left(30.5^{\circ} \mathrm{C}, 32.5^{\circ} \mathrm{C}\right.$ and $\left.36^{\circ} \mathrm{C}\right)$, the optimal pressure is going to be sought in the range of $74 \mathrm{bar} \leq P_{g c} \leq 91 \mathrm{bar}$, considering the pressure limit of the elements in the facility. In order to study the influence that the liquid receiver has on the optimal pressure of the system, after finding the optimal pressure for every gas cooler outlet temperature, a test is performed with the bypass totally opened while keeping all the other parameters the same.

\subsubsection{Space heating study}

This section presents the space heating text matrix to be followed for the different configurations in order to produce water at $35^{\circ} \mathrm{C}$ and $45^{\circ} \mathrm{C}$. The evaporator water temperature (heat source), is studied from $10{ }^{\circ} \mathrm{C}$ to $25^{\circ} \mathrm{C}$ water inlet temperature $\left(T_{e v, w i}\right)$ with an increment of $\Delta T=5 \mathrm{~K}$. Following the EN-14511-2, (2018) standard [1]. The reference tests (bold ones) for every inlet water condition are those with a $\Delta T=3 \mathrm{~K}$ between the evaporator inlet/outlet water temperatures $\left(T_{e v, w i / o}\right)$, and the water generation temperatures in the gas cooler are $30 / 35^{\circ} \mathrm{C}$ and $40 / 45^{\circ} \mathrm{C}$ as inlet/outlet water $\left(T_{g c \text {,wi/o }}\right)$. As shown in Table 15, the tests after the reference ones, should have the same evaporator $\dot{m}_{w}$ that the reference tests, and, in the gas cooler side, the same gas cooler $\dot{m}_{w}$ and outlet water temperature $\left(T_{g c, w o}\right)$. The superheating value $(S H)$ is set to $5 \mathrm{~K}$, in all tests but in $\mathrm{C} 3$, where $\mathrm{SH}=0 \mathrm{~K}$.

Table 15. Space heating test matrix according to UNE-EN 14511 standard.

\begin{tabular}{|c|c|c|c|c|c|}
\hline \multirow{2}{*}{$\begin{array}{c}\text { Tests } \\
\text { order (\#) }\end{array}$} & \multicolumn{3}{|c|}{ Evaporator } & \multicolumn{2}{|c|}{ Gas cooler } \\
\hline & $T_{e v, w i / o}\left({ }^{\circ} \mathrm{C}\right)$ & $\dot{m}_{w}\left(\mathrm{~kg} \cdot \mathrm{s}^{-1}\right)$ & $S H(\mathrm{~K})$ & $T_{g c, w i / o}\left({ }^{\circ} \mathrm{C}\right)$ & $\dot{m}_{w}\left(\mathrm{~kg} \cdot \mathrm{s}^{-1}\right)$ \\
\hline 1 & $10 / 7$ & A & \multirow{4}{*}{$5 K$} & $30 / 35$ & B \\
\hline 2 & $15 / X$ & \multirow{3}{*}{ A } & & $x / 35$ & \multirow{3}{*}{ B } \\
\hline 3 & $20 / Y$ & & & $\mathrm{Y} / 35$ & \\
\hline 4 & $25 / Z$ & & & Z/35 & \\
\hline 5 & $10 / 7$ & C & \multirow{4}{*}{$5 K$} & $40 / 45$ & D \\
\hline 6 & $15 / X$ & \multirow{3}{*}{ C } & & $\mathrm{X} / 45$ & \multirow{3}{*}{ D } \\
\hline 7 & $20 / Y$ & & & $\mathrm{Y} / 45$ & \\
\hline 8 & $25 / Z$ & & & $\mathrm{Z} / 45$ & \\
\hline
\end{tabular}

\subsubsection{Domestic hot water generation study}

This section presents the test considered to characterize the behavior of the different configurations when they are used to produce domestic hot water at $60{ }^{\circ} \mathrm{C}$. The evaporator water inlet temperature $\left(T_{e v, w i}\right)$ varies from $10{ }^{\circ} \mathrm{C}$ and $30{ }^{\circ} \mathrm{C}$ with an increment of $\Delta T=5 \mathrm{~K}$. Five tests are defined for each evaporator water inlet temperature. These correspond to five water inlet temperature at the gas cooler $\left(T_{g c, w i}\right)$ being always the outlet temperature $\left(T_{g c, \text { wi/o }}=60^{\circ} \mathrm{C}\right)$. Please see Table 16. 
Table 16. DHW generation test matrix.

\begin{tabular}{|c|c|c|c|c|}
\hline \multirow{2}{*}{$\begin{array}{l}\text { Test order } \\
\text { (\#) }\end{array}$} & \multicolumn{3}{|c|}{ Evaporator } & \multirow{2}{*}{$\begin{array}{c}\text { Gas Cooler } \\
T_{g c, \text { wi/o }}\left({ }^{\circ} \mathrm{C}\right)\end{array}$} \\
\hline & $T_{e v, w i / o}\left({ }^{\circ} \mathrm{C}\right)$ & $\dot{m}_{w}\left(\mathrm{~kg} \cdot \mathrm{s}^{-1}\right)$ & $S H(K)$ & \\
\hline 1 & $10 / 5$ & $A$ & \multirow{5}{*}{$10 \mathrm{~K}$} & $10 / 60$ \\
\hline 2 & $10 / \mathrm{W}$ & \multirow{4}{*}{ A } & & $20 / 60$ \\
\hline 3 & $10 / X$ & & & $30 / 60$ \\
\hline 4 & $10 / Y$ & & & $40 / 60$ \\
\hline 5 & $10 / Z$ & & & $50 / 60$ \\
\hline 6 & $15 / 10$ & $B$ & \multirow{5}{*}{$10 \mathrm{~K}$} & $10 / 60$ \\
\hline 7 & $15 / W$ & \multirow{4}{*}{ B } & & $20 / 60$ \\
\hline 8 & $15 / X$ & & & $30 / 60$ \\
\hline 9 & $15 / Y$ & & & $40 / 60$ \\
\hline 10 & $15 / Z$ & & & $50 / 60$ \\
\hline 11 & $20 / 15$ & $C$ & \multirow{5}{*}{$10 \mathrm{~K}$} & $10 / 60$ \\
\hline 12 & $20 / W$ & \multirow{4}{*}{ C } & & $20 / 60$ \\
\hline 13 & $20 / X$ & & & $30 / 60$ \\
\hline 14 & $20 / Y$ & & & $40 / 60$ \\
\hline 15 & $20 / Z$ & & & $50 / 60$ \\
\hline 16 & $25 / 20$ & $D$ & \multirow{5}{*}{$10 \mathrm{~K}$} & $10 / 60$ \\
\hline 17 & $25 / W$ & \multirow{4}{*}{ D } & & $20 / 60$ \\
\hline 18 & $25 / X$ & & & $30 / 60$ \\
\hline 19 & $25 / Y$ & & & $40 / 60$ \\
\hline 20 & $25 / Z$ & & & $50 / 60$ \\
\hline 21 & $30 / 25$ & $E$ & \multirow{5}{*}{$10 \mathrm{~K}$} & $10 / 60$ \\
\hline 22 & $30 / \mathrm{W}$ & \multirow{4}{*}{$E$} & & $20 / 60$ \\
\hline 23 & $30 / x$ & & & $30 / 60$ \\
\hline 24 & $30 / Y$ & & & $40 / 60$ \\
\hline 25 & $30 / Z$ & & & $50 / 60$ \\
\hline
\end{tabular}

As shown in Table 16, the tests that are after the reference ones should follow the same evaporator $\dot{m}_{w}$ and evaporator water inlet temperature as in the reference tests (the bold ones), and, for the gas cooler, the pump should provide the necessary $\dot{m}_{w}$ to guarantee the required inlet/outlet water conditions $\left(T_{g c, w i} / o\right)$. The superheating value $(\mathrm{SH})$ is around $10 \mathrm{~K}$, except for $\mathrm{C} 3$, which is a flooded evaporator system, with no superheating.

\subsection{Variable recording and data treatment}

The experiments previously defined are performed as follow: Once the tests are defined, they are performed registering the variables of interest by mean of using a data logger connected to an interface developed in LabVIEW ${ }^{\circledR}$, National Instrument data acquisition software. Each experimental point is obtained as the average value of 90 data measured from each sensor during 1800 seconds of steady-state conditions as seen in (Fig. 34, Fig. 37 and Fig. 38). To work under steady-state conditions, the allowed oscillation difference between the maximum and minimum value around a specific setpoint is $0.2 \mathrm{~K}$. Thermodynamics properties are obtained by using REFPROP ${ }^{\circledR}$ [131]. Post process is carried out by mean of MATLAB ${ }^{\circledR}$ and Excel $^{\circledR}$. 


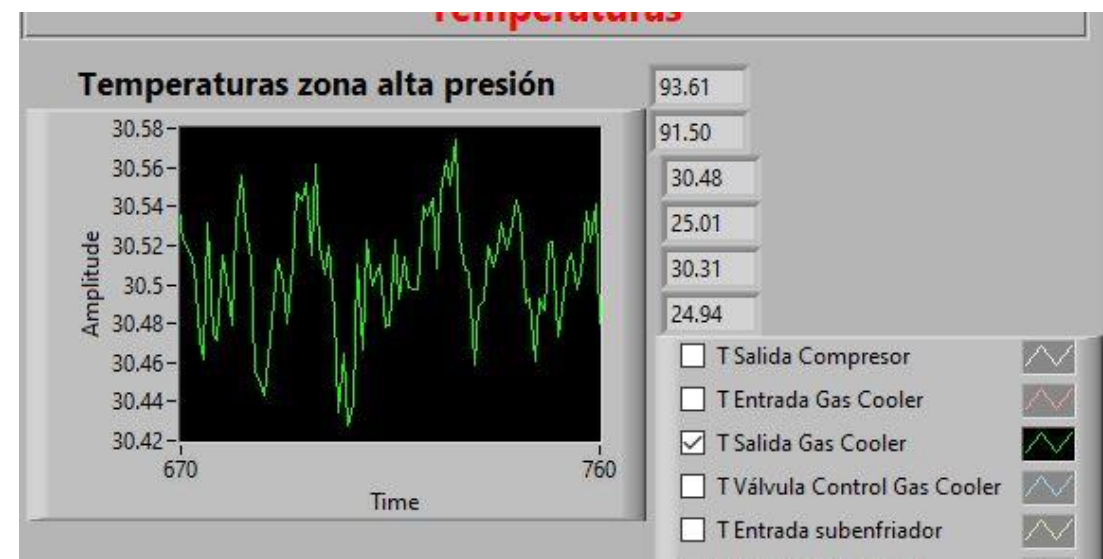

Fig. 37. Refrigerant temperature out of the gas cooler with $0.15 \mathrm{~K}$ oscillation.

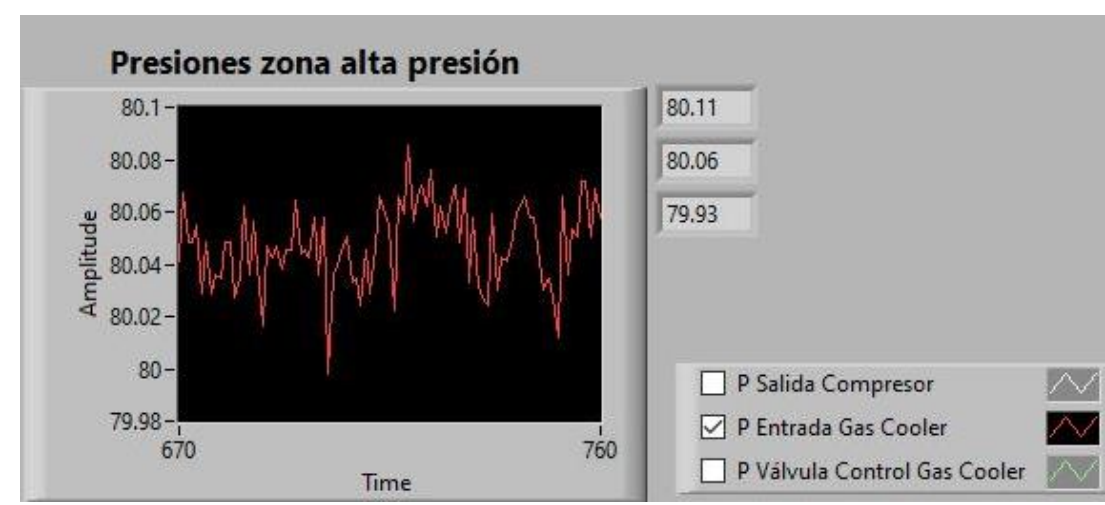

Fig. 38. Refrigerant pressure out of the gas cooler, with $0.1 \mathrm{~K}$ oscilation.

\subsection{Uncertainty analysis}

The uncertainty analysis has been done following the procedure described in the JCGM 100 [132]. Table 17 summarizes the accuracy of the measuring devices according to their manufacturers. The uncertainty of each variable directly measured has been obtained taking into account the accuracy of both the measuring devices and the datalogger used for data acquisition and storage (type B uncertainty), as well as the standard deviation of the data recorded during the test (type $A$ uncertainty).

Table 18 summarizes the uncertainty of the main parameters studied in this work, with a confidence level of $95 \%$. It has been calculated by using the uncertainty propagation method described in JCGM 100 [132]. For calculating the combined uncertainty of any thermodynamic property obtained from REFPROP ${ }^{\circledR}$ [131], $y=$ $f(T, P)$, where $y$ can be enthalpy, density, etc., and $T$ and $P$ are the temperature and the pressure experimentally measured, the partial derivatives $\partial f / \partial T$ and $\partial f / \partial P$ have been numerically evaluated as:

$$
\frac{\partial f}{\partial T}\left(T_{1}, P_{1}\right)=\frac{f\left(T_{1}+\Delta T, P_{1}\right)}{\Delta T}
$$




$$
\frac{\partial f}{\partial P}\left(T_{1}, P_{1}\right)=\frac{f\left(T_{1}, P_{1}+\Delta P\right)}{\Delta P}
$$

The step size has been fixed in $\Delta T=1 \cdot 10^{-8} \mathrm{~K}$ and $\Delta P=1 \cdot 10^{-2} \mathrm{~Pa}$ through a sensitivity analysis.

Table 17. Measuring devices and their accuracy.

\begin{tabular}{|c|c|c|c|c|}
\hline $\begin{array}{c}\text { Measured } \\
\text { variable }\end{array}$ & Device & Point & $\begin{array}{c}\text { Measuring } \\
\text { range }\end{array}$ & Accuracy \\
\hline Temperature & $\begin{array}{c}\text { Pt100 RTD class A } \\
1 / 10 \text { DIN }\end{array}$ & $\begin{array}{c}\text { 1-13, } \\
\text { CW1\&2, } \\
\text { HW1\&2 }\end{array}$ & $223-523 \mathrm{~K}$ & $\pm 0.1[\mathrm{~K}]$ \\
\hline \multirow{2}{*}{$\begin{array}{l}\text { Absolute } \\
\text { pressure }\end{array}$} & $\begin{array}{c}\text { Yokogawa EJX510A } \\
\text { ECS }\end{array}$ & $1,10,11$ & $0-5 \mathrm{MPa}$ & $\pm 2.1 \cdot 10^{-3}[\mathrm{MPa}]$ \\
\hline & $\begin{array}{c}\text { Yokogawa EJX510A } \\
\text { JDS }\end{array}$ & $\begin{array}{c}2,3,5,7 \\
9 \\
\end{array}$ & $0-12 \mathrm{MPa}$ & $\pm 5 \cdot 10^{-3}[\mathrm{MPa}]$ \\
\hline $\begin{array}{l}\text { Differential } \\
\text { pressure }\end{array}$ & $\begin{array}{c}\text { Yokogawa EJX110A } \\
\text { JHS }\end{array}$ & $\begin{array}{c}4,6,11, \\
13, \text { HW2, } \\
\text { CW2 }\end{array}$ & $0-0.1 \mathrm{MPa}$ & $\pm 0.26 \cdot 10^{-3}[\mathrm{MPa}]$ \\
\hline \multirow{2}{*}{ Mass flow rate } & Yokogawa RCCS32 & 9 & $0-0.1 \mathrm{~kg} \cdot \mathrm{s}^{-1}$ & $\begin{array}{c} \pm 0.0027 \cdot \dot{m} \pm 5.28 \cdot 10^{-6} \\
{\left[\mathrm{~kg} \cdot \mathrm{s}^{-1}\right]}\end{array}$ \\
\hline & Yokogawa RCCT34 & 14 & $0-0.1 \mathrm{~kg} \cdot \mathrm{s}^{-1}$ & $\begin{array}{c} \pm 0.0056 \cdot \dot{m} \pm 4.17 \cdot 10^{-5} \\
{\left[\mathrm{~kg} \cdot \mathrm{s}^{-1}\right]}\end{array}$ \\
\hline \multirow{2}{*}{ Flow rate } & $\begin{array}{c}\text { SIEMENS FM } \\
\text { MAGFLO MAG1100 }\end{array}$ & CW1 & $\begin{array}{c}0-0.1111 \cdot 10^{-2} \\
\mathrm{~m}^{3} \cdot \mathrm{s}^{-1}\end{array}$ & $\begin{array}{c} \pm 0.002 \cdot \dot{V} \pm 4.91 \cdot 10^{-7} \\
{\left[\mathrm{~m}^{3} \cdot \mathrm{s}^{-1}\right]}\end{array}$ \\
\hline & $\begin{array}{c}\text { SIEMENS FM } \\
\text { MAGFLO MAG5100 }\end{array}$ & HW1 & $\begin{array}{c}0-0.1111 \cdot 10^{-2} \\
\mathrm{~m}^{3} \cdot \mathrm{s}^{-1}\end{array}$ & $\begin{array}{c} \pm 0.002 \cdot \dot{V} \pm 4.91 \cdot 10^{-7} \\
{\left[\mathrm{~m}^{3} \cdot \mathrm{s}^{-1}\right]}\end{array}$ \\
\hline Electric power & SINEAX M563 & 1 & $0-2500 \mathrm{~W}$ & $\pm 0.01 \cdot \dot{W}[\mathrm{~W}]$ \\
\hline
\end{tabular}

As Table 18 shows, the uncertainty is very low. In most cases, the relative uncertainty is below $5 \%$. Only in two tests, the uncertainty for the evaporator heat transfer rate at the refrigerant side is higher than $2 \%$ (3.3\% and $9.8 \%$ ), although in several cases the uncertainty for the IHX heat transfer rate at the high pressure side is very high, reaching values higher than $70 \%$. Those high uncertainty values are related to the inflection point that appears above the critical point for most thermodynamic properties (Fig. 39). That inflection point provokes that around that point, the change in the enthalpy is stronger than usual and thus the uncertainty in its calculation is higher. Following the cycle presented in Fig. 36.a, when the IHX high pressure side outlet conditions (point 6) fall near that inflection point, the uncertainty in the enthalpy calculation affects the uncertainty in the IHX heat transfer rate (high pressure (HP) side). Since the enthalpy at evaporator inlet (point 10) is assumed to be the same as at the liquid receiver inlet (point 7), the same occurs for the evaporator heat transfer rate when point 7 falls near the inflection point. 
Table 18. Absolute and relative experimental uncertainty.

\begin{tabular}{|l|c|c|c|}
\hline \multicolumn{1}{|c|}{ Parameter } & Measuring range & Absolute uncertainty & Relative uncertainty \\
\hline $\begin{array}{l}\text { Compressor power input } \\
(\mathrm{kW})\end{array}$ & $1.24-1.64$ & $\pm 0.029-0.029$ & $1.76-2.33 \%$ \\
\hline Compression work (kW) & $1.18-1.55$ & $\pm 0.022-0.027$ & $1.54-2.32 \%$ \\
\hline $\begin{array}{l}\text { Evaporator heat transfer } \\
\text { rate-refrigerant side (kW) }\end{array}$ & $2.85-5.51$ & $\pm 0.049-0.280$ & $0.90-9.84 \%$ \\
\hline $\begin{array}{l}\text { Evaporator heat transfer } \\
\text { rate-water side (kW) }\end{array}$ & $2.50-5.43$ & $\pm 0.087-0.134$ & $2.01-3.20 \%$ \\
\hline $\begin{array}{l}\text { Gas cooler heat transfer } \\
\text { rate-refrigerant side (kW) }\end{array}$ & $4.05-6.93$ & $\pm 0.059-0.124$ & $0.89-2.82 \%$ \\
\hline $\begin{array}{l}\text { Gas cooler heat transfer } \\
\text { rate-water side (kW) }\end{array}$ & $4.06-7.58$ & $\pm 0.106-0.205$ & $1.71-3.92 \%$ \\
\hline $\begin{array}{l}\text { IHX heat transfer rate-HP } \\
\text { side (kW) }\end{array}$ & $0.49-1.15$ & $\pm 0.015-0.803$ & $2.83-72.3 \%$ \\
\hline $\begin{array}{l}\text { IHX heat transfer rate-LP } \\
\text { side (kW) }\end{array}$ & $0.48-0.97$ & $\pm 0.019-0.030$ & $2.36-5.59 \%$ \\
\hline COP (-) & $2.84-5.30$ & $\pm 0.063-0.136$ & $1.97-3.31 \%$ \\
\hline Evaporation pressure (MPa) & $3.97-4.51$ & $\pm 1.87 \cdot 10^{-3}-1.97 \cdot 10^{-3}$ & $0.042-0.050 \%$ \\
\hline Gas cooler pressure (MPa) & $7.40-9.10$ & $\pm 4.30 \cdot 10^{-3}-4.37 \cdot 10^{-3}$ & $0.048-0.058 \%$ \\
\hline $\begin{array}{l}\text { Refrigerant mass flow rate } \\
\left(\mathrm{kg} \cdot \mathrm{s}^{-1}\right)\end{array}$ & $0.0244-0.0336$ & $\pm 0.28 \cdot 10^{-3}-0.35 \cdot 10^{-3}$ & $0.88-1.28 \%$ \\
\hline
\end{tabular}

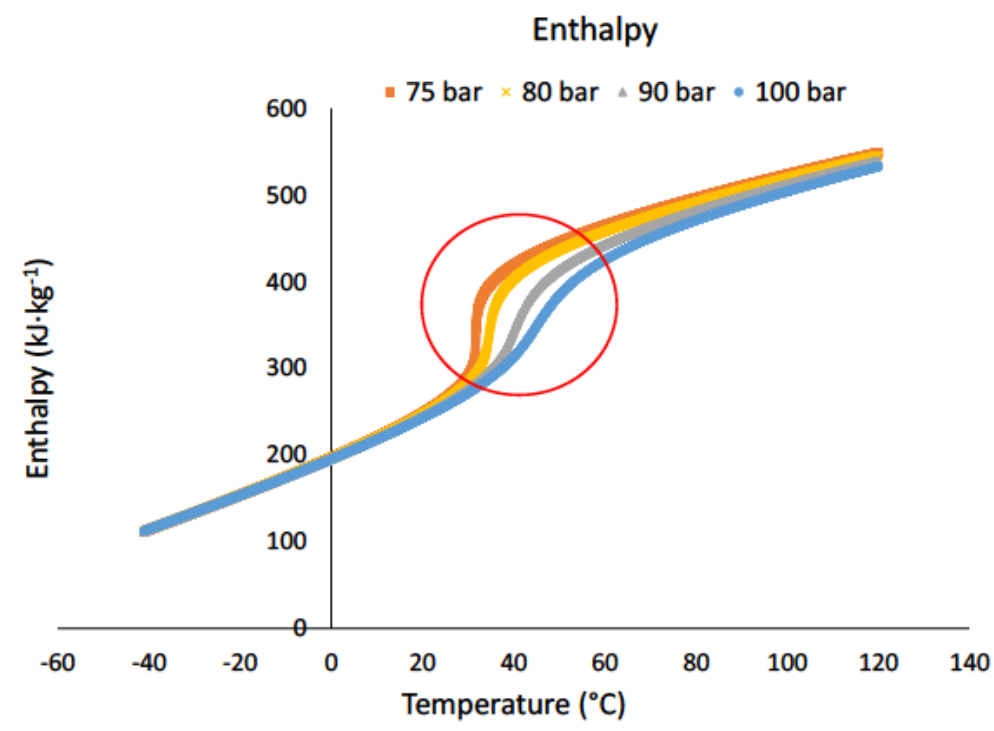

Fig. 39. High uncertainty values related to the inflection point. 


\section{Results analysis}




\subsection{Introduction}

This chapter presents an analysis of the influence that different parameters have on the system. In the first part, it presents the influence that the liquid receiver pressure and the IHX efficiency have in the system when working at a constant pressure different from the optimal one. Subsequently, it presents a numerical model developed to obtain the optimal pressure of operation, and, using this model, the influence that different variables have on the optimal pressure is analyzed. Once the model for the optimal pressure calculation is presented, different results for the system working at optimal pressure conditions are shown, including space heating at low and medium temperature following [1], which allow to analyze the influence that different variables have in the system, such as the evaporation temperature and the superheating at practical operating conditions, furthermore, the influence of varying the surface of the different heat exchangers is studied. Finally, the results when the system is working for domestic hot water generation are presented, including when working at the optimal pressure or a constant pressure.

\subsection{Liquid receiver pressure, influence on the COP}

This section presents the analysis of the influence that the liquid receiver has on the $\mathrm{COP}$. The gas bypass in transcritical one-stage $\mathrm{CO}_{2}$ systems is typically used to reduce the pressure in the distribution system, making possible to use standard pressure components in the lines that distribute liquid to the evaporators. Additionally, thanks to the gas bypass, the quality at the evaporator inlet is reduced, allowing smaller evaporators while the heat transfer in it is increased [133].

\subsubsection{Theoretical analysis}

This section presents a theoretical analysis of the influence that the liquid receiver pressure has on the operating conditions of the cycle.

Fig. 40 and Fig. 41 correspond to the theoretical minimum and maximum liquid receiver pressure, respectively. The minimum liquid receiver pressure corresponds to the evaporation pressure (around 45 bar), whereas the maximum liquid receiver pressure corresponds to the situation when the fluid enters at the liquid receiver as saturated liquid (around 61 bar). Both situations, in practical scenario, produce similar COPs. In both theoretical evaluation, the $\mathrm{SH}$ at the compressor inlet (point 1 ) or the IHX inlet (if there is IHX) is going to be the same as at the evaporator outlet (point 7), which is the maximum $\mathrm{SH}(5 \mathrm{~K})$. Between both situations exists an intermediate pressure in which the $\mathrm{SH}$ at the compressor inlet is the minimum. 


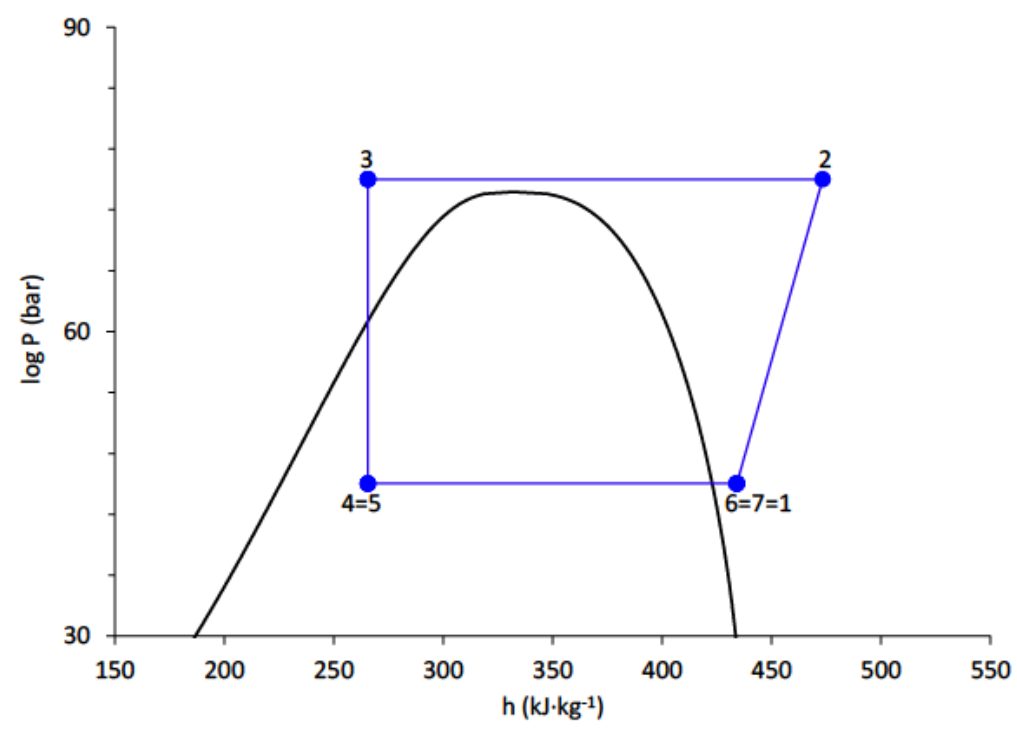

Fig. 40. Liquid receiver pressure @ 45 bar, $T_{g c, r o}=25^{\circ} \mathrm{C}, P_{g c}=75$ bar, $T_{\text {evap }}=10^{\circ} \mathrm{C}, S H=5 \mathrm{~K}$.

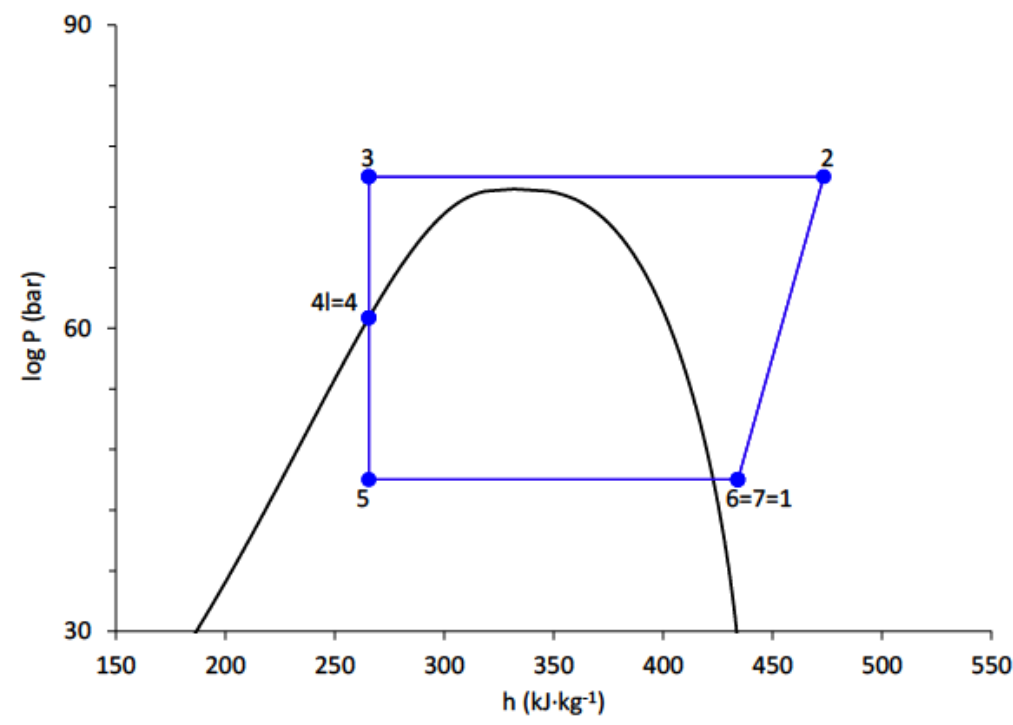

Fig. 41. Liquid receiver pressure @ $61 \mathrm{bar}, T_{g c, r o}=25^{\circ} \mathrm{C}, P_{g c}=75 \mathrm{bar}, T_{\text {evap }}=10^{\circ} \mathrm{C}, S H=5 \mathrm{~K}$.

Decreasing the liquid receiver pressure to be equal than the evaporation pressure (Fig. 40), in practical scenario, is impossible since there exists an expansion valve between the receiver and the evaporator, is like removing the liquid receiver. The refrigerant condition at the evaporator inlet is going to be the same than the BPV-1 outlet.

When the liquid receiver bypass is totally closed to reach the maximum liquid receiver pressure (Fig. 41), there is no gas bypass form the receiver, the refrigerant from the BPV-1 passes through the evaporator and the inlet conditions are going to be the same than BPV-1.

If the bypass is partially opened and the liquid receiver pressure decreases below the maximum theoretical value (Fig. 42), the refrigerant that enters to the receiver is 
separated in saturated vapor and saturated liquid. The vapor passes through the gas bypass (point $4 \mathrm{v}$ ) where an expansion occurs in the BPV-2, and the refrigerant conditions at the BPV-2 outlet (point 6) is biphasic. The liquid (point 4I) enters at the evaporator with a certain vapor quality (due to the expansion) and the conditions at the evaporator outlet presents a $\mathrm{SH}$ of $5 \mathrm{~K}$ (point 7). Both refrigerant flow are mixed, which produces a mix with a $S H<5 \mathrm{~K}$ (point 1 ).

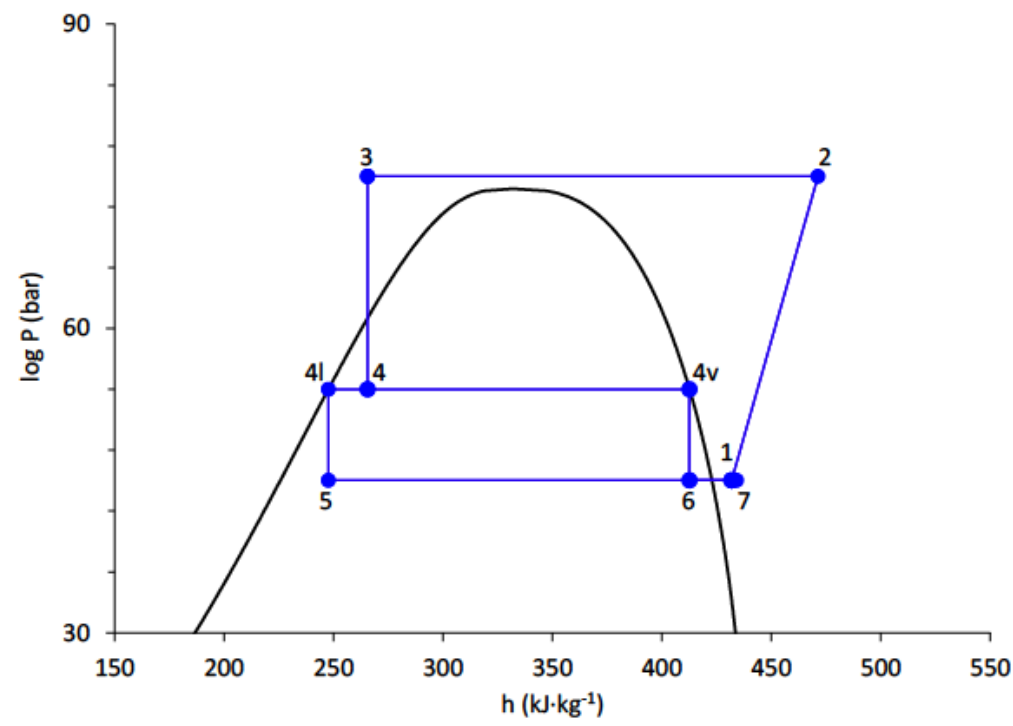

Fig. 42. Liquid receiver pressure @ 54 bar, $T_{g c, r o}=25^{\circ} \mathrm{C}, P_{g c}=75 \mathrm{bar}, T_{\text {evap }}=10^{\circ} \mathrm{C}, S H=5 \mathrm{~K}$.

As the liquid receiver pressure decreases, the mass flow through the bypass increases, but the vapor quality (point 6) increases and the conditions at the mixing point change. There exists a liquid receiver pressure at which the $\mathrm{SH}$ at the compressor inlet is the minimum. When moving either below or above that pressure, the $\mathrm{SH}$ value is going to increase.

In fact, the influence of the liquid receiver pressure comes from the existence of that pressure for which the $\mathrm{SH}$ is the minimum. This changes the compressor working conditions, and thus the conditions at the compressor outlet and gas cooler inlet. Finally, it affects the COP of the facility, although, according to the studied conditions, this influence is almost negligible.

\subsubsection{Experimental results}

In order to verify experimentally the theoretical discussion previously presented tests from 1 to 5 of Table 19, are analyzed. The evaporator water temperature $\left(T_{e v, w i / o}\right)$ is on the average of $17.1{ }^{\circ} \mathrm{C} / 12.7^{\circ} \mathrm{C}$, and, the gas cooler water temperature $\left(T_{g c, w i / o}\right)$ is $24.7^{\circ} \mathrm{C} / 31.1^{\circ} \mathrm{C}$. 
Table 19. Liquid receiver influence on the COP, experimental results.

\begin{tabular}{|c|c|c|c|c|c|c|c|}
\hline \multicolumn{8}{|c|}{ Specific refrigerant conditions, without IHX } \\
\hline $\begin{array}{l}\text { Test order } \\
\text { (\#) }\end{array}$ & $\begin{array}{l}T_{\text {evap }} \\
\left({ }^{\circ} \mathrm{C}\right)\end{array}$ & $\begin{array}{l}\text { SH } \\
\text { (K) }\end{array}$ & $\begin{array}{l}T_{g c, r o} \\
\left({ }^{\circ} \mathrm{C}\right)\end{array}$ & $\begin{array}{c}P_{g c} \\
\text { (bar) }\end{array}$ & $P_{\text {Ir }}$ (bar) & $\begin{array}{c}\text { Bypass } \dot{m}( \\
\left.\mathrm{kg} \cdot \mathrm{s}^{-1}\right)\end{array}$ & $\operatorname{COP}(-)$ \\
\hline 1 & \multirow{5}{*}{10.3} & \multirow{5}{*}{$5 \mathrm{~K}$} & \multirow{5}{*}{25.3} & \multirow{5}{*}{75} & 48.6 & 0.00733080 & 6.0736 \\
\hline 2 & & & & & 50.5 & 0.00658941 & 6.0610 \\
\hline 3 & & & & & 52.3 & 0.00565555 & 6.0496 \\
\hline 4 & & & & & 56.3 & 0.00028271 & 6.0499 \\
\hline 5 & & & & & 59.9 & 0.00000000 & 6.0862 \\
\hline \multicolumn{8}{|c|}{ In DHW generation } \\
\hline $\begin{array}{l}\text { Test order } \\
\text { (\#) }\end{array}$ & $\begin{array}{c}T_{e v, w i / o} \\
\left({ }^{\circ} \mathrm{C}\right)\end{array}$ & $\begin{array}{l}\text { SH } \\
\text { (K) }\end{array}$ & $\begin{array}{c}T_{g c, w i / o} \\
\left({ }^{\circ} \mathrm{C}\right)\end{array}$ & $\begin{array}{c}P_{g c} \\
\text { (bar) }\end{array}$ & $P_{\text {Ir }}$ (bar) & $\begin{array}{c}\text { Bypass m ( } \\
\left.\mathrm{kg} \cdot \mathrm{s}^{-1}\right)\end{array}$ & $\operatorname{COP}(-)$ \\
\hline 6 & \multirow{4}{*}{$15 / 10$} & \multirow{4}{*}{$5 \mathrm{~K}$} & \multirow{4}{*}{$10 / 50$} & \multirow{2}{*}{75} & 49 bar & 0.00139015 & 4.2328 \\
\hline 7 & & & & & 62 bar & 0.00000000 & 4.2627 \\
\hline 8 & & & & \multirow{2}{*}{80} & 45 bar & 0.00042668 & 4.6722 \\
\hline 9 & & & & & 55 bar & 0.00000000 & 4.7259 \\
\hline
\end{tabular}

Test number (1), is performed opening the gas bypass to the minimum pressure value in the liquid receiver, which is the evaporation pressure (45.36 bar) for the corresponding evaporation temperature $\left(T_{\text {evap }}=10.3^{\circ} \mathrm{C}\right)$ in order to produce a P-h diagram similar to the one shown in Fig. 40 . However, as previously said, in a practical scenario, the receiver pressure would never be similar to the evaporation pressure if there is an expansion valve between the liquid receiver and the evaporator. As a result, the minimum pressure for this test is 48.6 bar (Fig. 43). Though in the control software the valve is totally opened, the refrigerant mass flow rate $\left(\dot{m}_{r}\right)$ bypassed is $0.00733 \mathrm{~kg} \cdot \mathrm{s}^{-1}$, which corresponds to an opening range between $75 \%-80 \%$ according to the manufacturer information (Fig. 46). Considering the test for the maximum liquid receiver pressure, (test number 5 ) the final P-h diagram is the one shown in Fig. 44.

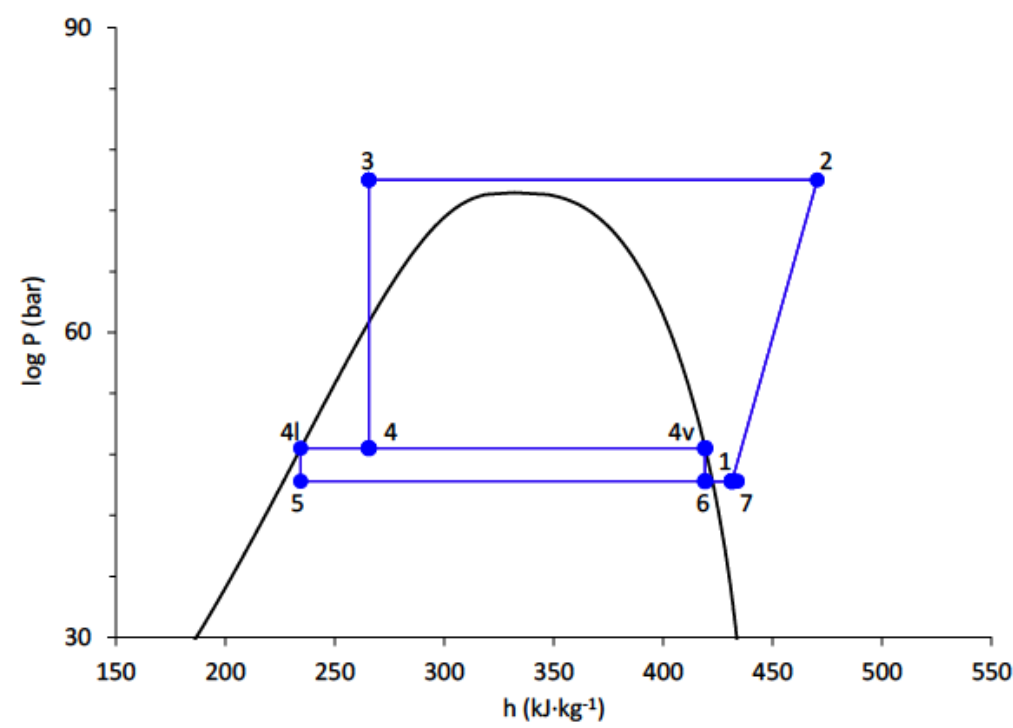

Fig. 43. Liquid receiver pressure @ $48.6 \mathrm{bar}, T_{g c, r o}=25.3^{\circ} \mathrm{C}, P_{g c}=75 \mathrm{bar}, T_{\text {evap }}=10.3^{\circ} \mathrm{C}, \mathrm{SH}=5 \mathrm{~K}$. 


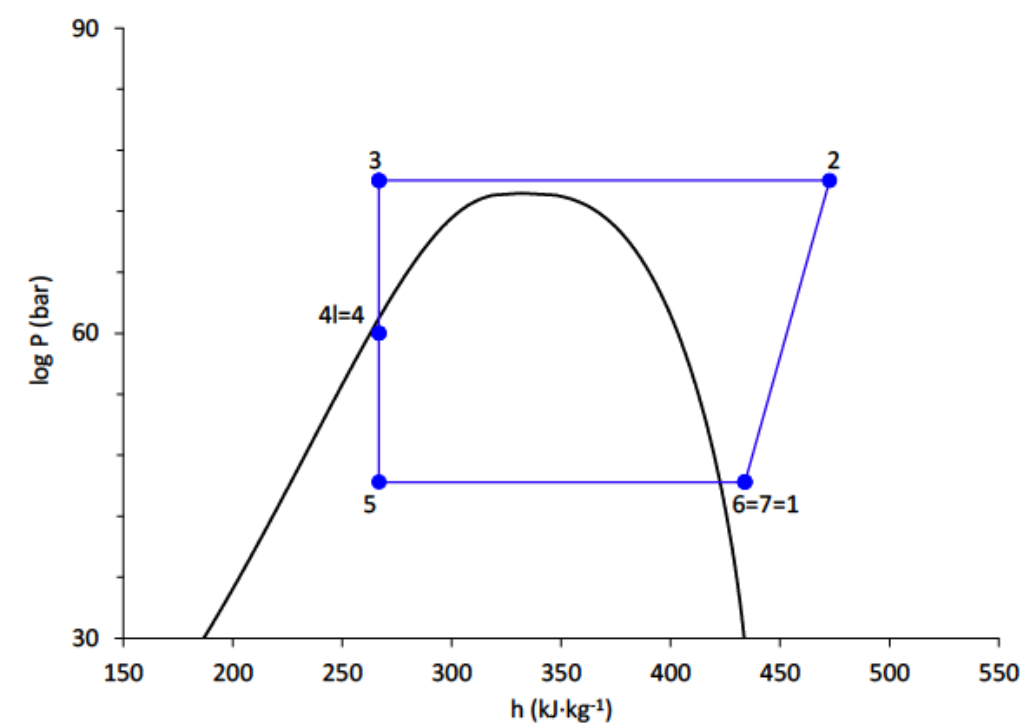

Fig. 44. Liquid receiver pressure @ $60 \mathrm{bar}, T_{g c, r o}=25.3^{\circ} \mathrm{C}, P_{g c}=75 \mathrm{bar}, T_{\text {evap }}=10.3^{\circ} \mathrm{C}, S H=5 \mathrm{~K}$.

Table 19 and Fig. 45 show the system COP obtained for the first five (5) tests, when varying its pressure from 48.6 to 60 bar while keeping the same initial conditions for the rest of the variables. The maximum COP is obtained at the maximum pressure of the liquid receiver, which is like totally closed bypass cycle. However, the influence of the bypass is negligible when talking about COP since the difference between the maximum and minimum COP value is -0.0366 . And, if the bypass needs to be opened to produce a pressure relief, totally opened is the best option since this one produces a COP difference of -0.0126 when compared to the maximum pressure.

Tevap $=10.3^{\circ} \mathrm{C}, \operatorname{Tgc}, \mathrm{ro}=25.3^{\circ} \mathrm{C}, \mathrm{Pgc}=74.8 \mathrm{bar}$

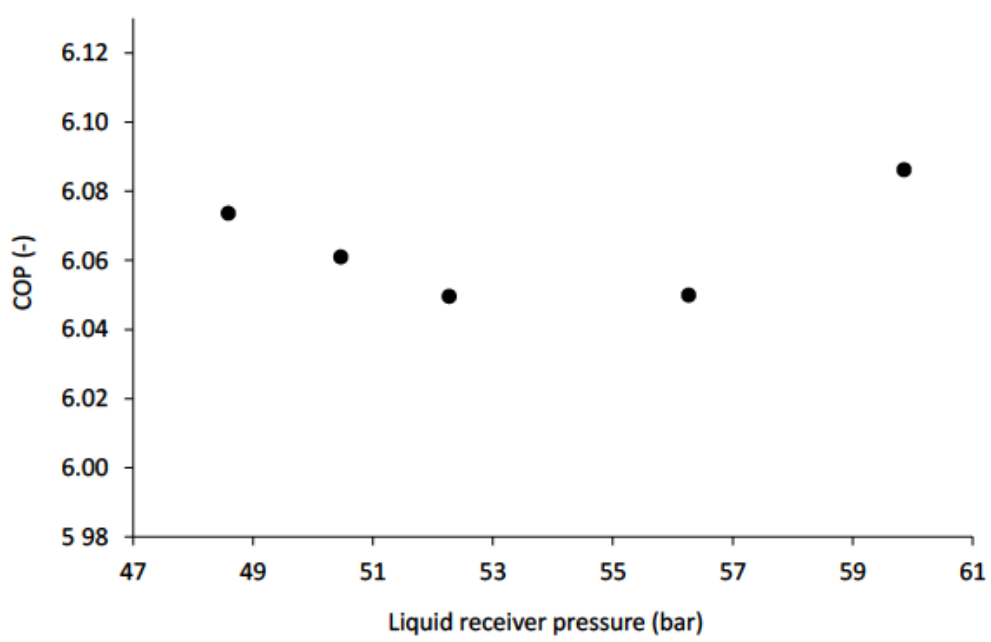

Fig. 45. System COP according to the liquid receiver pressure, working for the same $T_{\text {evap, }}, T_{g c, r o}, P_{g c}$, and $\eta_{I H X}=0$. 
Fig. 46. Bypass valve (E2V09). Opening range and refrigerant mass flow rate.

For the DHW application (from tests 6 to 9), the COP differences between totally opened or totally closed bypass are 0.0299 and 0.0537 when working at fix pressures of 75 bar and 80 bar, respectively. The results also confirm that the difference is negligible between totally closed or totally opened bypass.

\subsection{Internal heat exchanger efficiency, influence on the COP}

This section presents the influence that the IHX efficiency has on the COP according to the experimental study.

\subsubsection{Efficiency calculation}

Unless something different is said, the IHX efficiency $\left(\eta_{I H X}\right)$ in this thesis is calculated by using the method proposed by Chen \& Gu [53], shown in Fig. 47 and equation 22, 23 and $(24$, based on enthalpy differences.

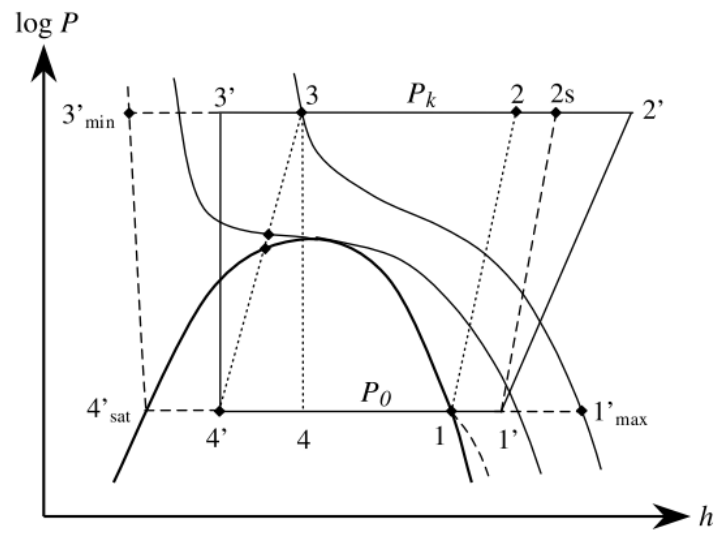

Fig. 47. IHX efficiency estimation by Chen \& Gu [53]. 


$$
\eta_{I H X}=\frac{h_{3}-h_{3^{\prime}}}{q_{\text {potn }}}=\frac{h_{1^{\prime}}-h_{1}}{q_{\text {potn }}}=\frac{h_{3}-h_{4^{\prime}}}{q_{\text {potn }}}
$$

Where, $q_{\text {potn }}$ represents the maximum specific heat transfer that can be used.

In the high pressure side of the IHX: $h_{3}, h_{3^{\prime}}$ and $h_{3^{\prime} \text {,min }}$ represent the refrigerant enthalpy at the inlet, outlet and minimum value that can be reached due to the $S C$ of the refrigerant in the $\mathrm{IHX}$, respectively.

Whereas, in the low pressure side, $h_{1}, h_{1^{\prime}}$ and $h_{1^{\prime}, \text { max }}$ represent the refrigerant temperature at the inlet, outlet, and maximum superheating that could be provided to the refrigerant by the IHX, respectively. $T_{3}, P_{3}$ and $T_{1}, P_{1}$ represent the refrigerant temperature and pressure at the high and low side of the IHX, respectively.

$$
q_{\text {potn }}=\min \left\{h_{3}-h_{3^{\prime}, \min } ; h_{1^{\prime}, \max }-h_{1}\right\}
$$

Following the isothermal:

$$
h_{1^{\prime}, \text { max }}=f\left(T_{3}, P_{1}\right) \text { and } h_{3^{\prime}, \text { min }}=f\left(T_{1}, P_{3}\right)
$$

\subsubsection{Experimental results}

Table 20 shows the results corresponding to the analysis of the influence of the IHX efficiency on the performance of the heat pump. The tests are carried out by

\begin{tabular}{|c|c|c|c|c|c|c|c|c|c|}
\hline $\begin{array}{c}\text { Test } \\
\text { order (\#) }\end{array}$ & $\begin{array}{l}\text { SC } \\
\text { (K) }\end{array}$ & $\begin{array}{l}\text { IHX valve } \\
\text { position }\end{array}$ & $\begin{array}{c}T_{e v, w i / o} \\
\left({ }^{\circ} \mathrm{C}\right)\end{array}$ & $\begin{array}{l}\text { SH } \\
\text { (K) }\end{array}$ & $\begin{array}{c}T_{g c, w i / o} \\
\left({ }^{\circ} \mathrm{C}\right)\end{array}$ & $\begin{array}{c}P_{g c} \\
\text { (bar) }\end{array}$ & $\begin{array}{l}{ }^{*} P_{l r} \\
\text { (bar) }\end{array}$ & $\eta_{I H X}$ & $\operatorname{COP}(-)$ \\
\hline 1 & $0 \mathrm{~K}$ & Totally closed & \multirow{4}{*}{$10 / 7$} & \multirow{4}{*}{$5 K$} & \multirow{4}{*}{$30 / 35$} & \multirow{4}{*}{80} & 67.2 & $0 \%$ & 3.9142 \\
\hline 2 & $1.6 \mathrm{~K}$ & Partially & & & & & 64.9 & $22 \%$ & 3.9709 \\
\hline 3 & $2.7 \mathrm{~K}$ & Opened & & & & & 63.2 & $36 \%$ & 4.0021 \\
\hline 4 & $5.8 \mathrm{~K}$ & Totally opened & & & & & 59.6 & $73 \%$ & 4.1630 \\
\hline
\end{tabular}
controlling the $\dot{m}_{r}$ passing through the IHX.

Table 20. Influence of the IHX efficiency, experimental results.

The first test is done bypassing the IHX. Graphically, point $3 \& 4$ and $7 \& 1$ coincide as there is not IHX. 


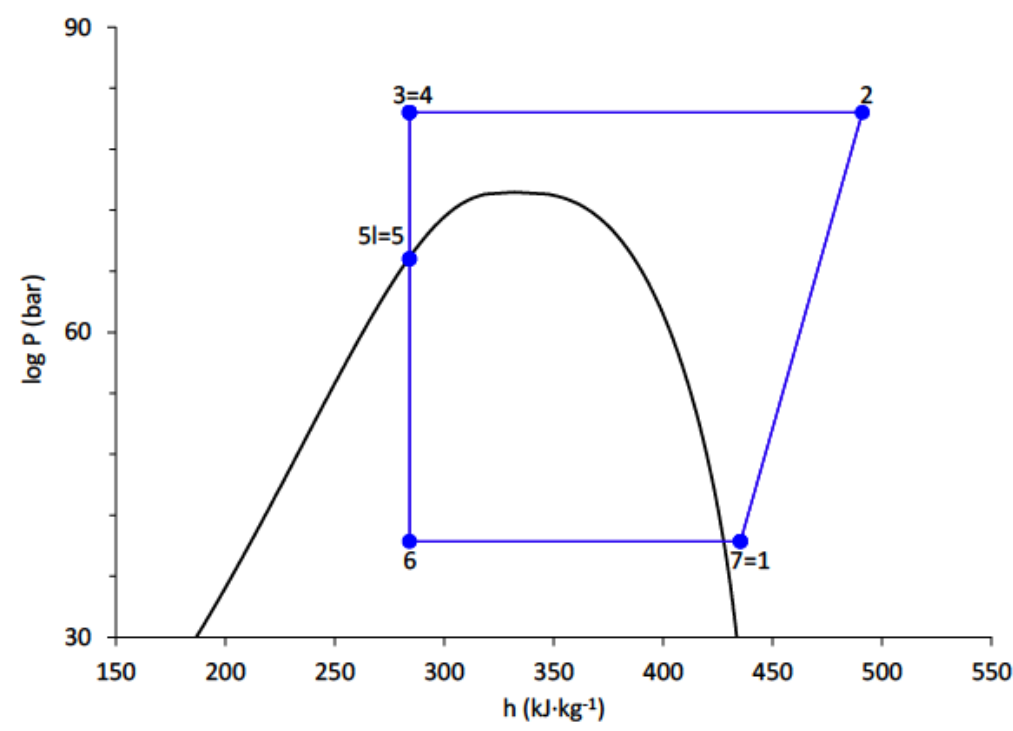

Fig. 48. IHX totally closed $\left(\eta_{I H X}=0 \%\right), S C=0 \mathrm{~K}$

In the second and third tests, part of the flow goes through the IHX and the other is bypassed, this is done to produce a SC of $1.6 \mathrm{~K}$ and $2.7 \mathrm{~K}$ as shown in Fig. 49 and Fig. 50 , respectively.

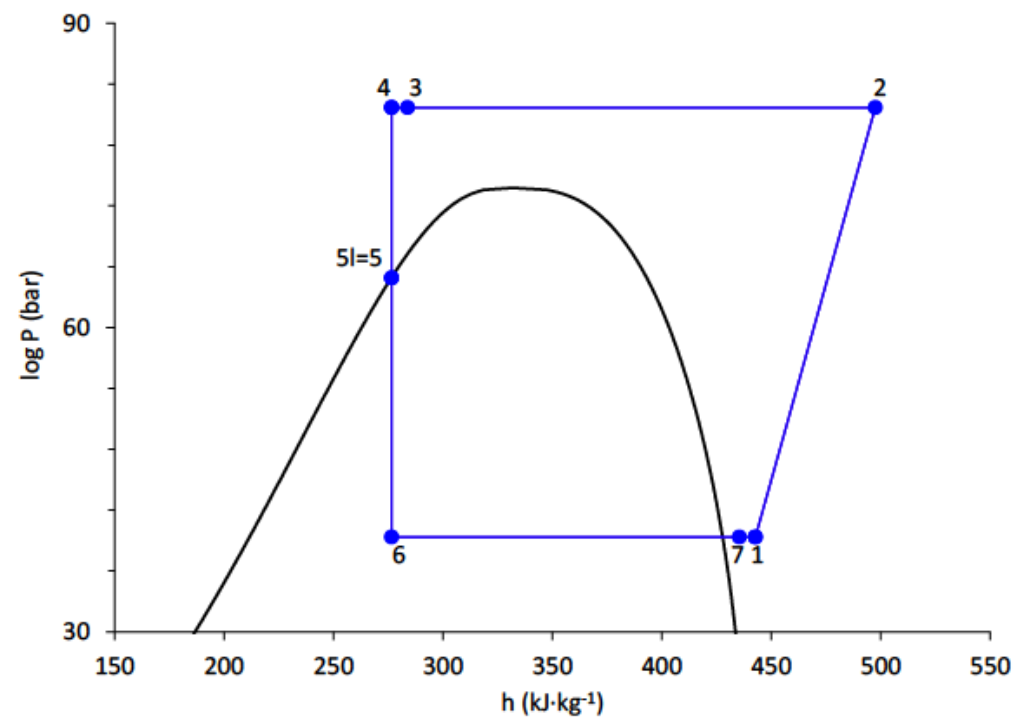

Fig. 49. IHX partially opened $\left(\eta_{I H X}=22 \%\right), S C=1.6 \mathrm{~K}$. 


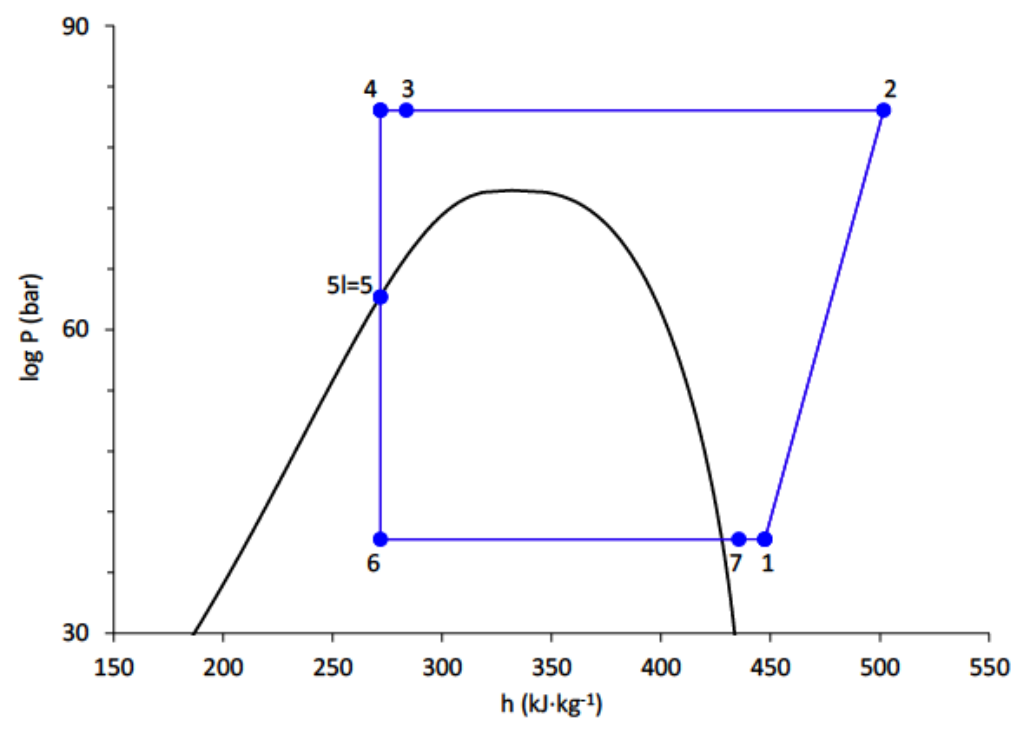

Fig. 50. IHX partially opened $\left(\eta_{I H X}=36 \%\right), S C=2.7 \mathrm{~K}$.

In the fourth test all the flow is driven through the IHX so the maximum SC is produced $(5.8 \mathrm{~K})$. The P-h diagram which corresponds to this case is that of Fig. $\mathbf{5 1 .}$ The highest enthalpy difference is clearly seen between the enthalpies for point 4 and 3 , and for point 7 and 1 . In the low pressure side, the refrigerant passes through the IHX when coming from the evaporator outlet, exchanging heat with the flow that passes through the high pressure side of the IHX.

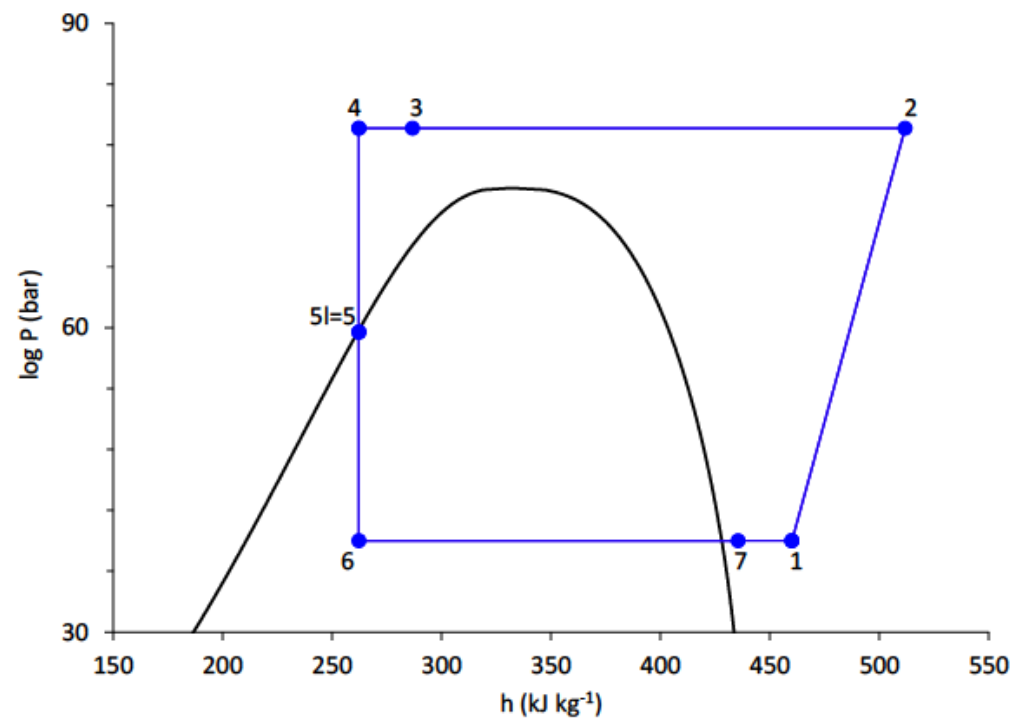

Fig. 51. IHX totally opened $\left(\eta_{I H X}=73 \%\right), S C=5.8 \mathrm{~K}$.

The tests for $5.8 \mathrm{~K}$ ( $80 \mathrm{bar}$ ) was not performed for the same high pressure than the other three (81.6 bar), but, for the objectives of this section, it is enough. Then, for P-h diagram comparison (Fig. 52), the high pressure used is similar to the other three tests. 
A summary of the P-h diagram produced when changing the $\mathrm{SC}$ from $0 \mathrm{~K}$ to $5.8 \mathrm{~K}$ is presented in Fig. 52. The cycle presented with blue lines, represents the system without IHX $(S C=O K)$, the green and purple lines represent the cycle with the IHX partially opened ( $1.6 \mathrm{~K}$ and $2.7 \mathrm{~K}$, respectively), and finally, the orange lines, represent the cycle with totally opened IHX (5.8 K).

These P-h diagrams are generated using the same $P_{g c}$ and the experimental results found for $S H, T_{\text {evap, }} T_{g c, r o}, \eta_{I H X}$ and $P_{l r}$, at each test.

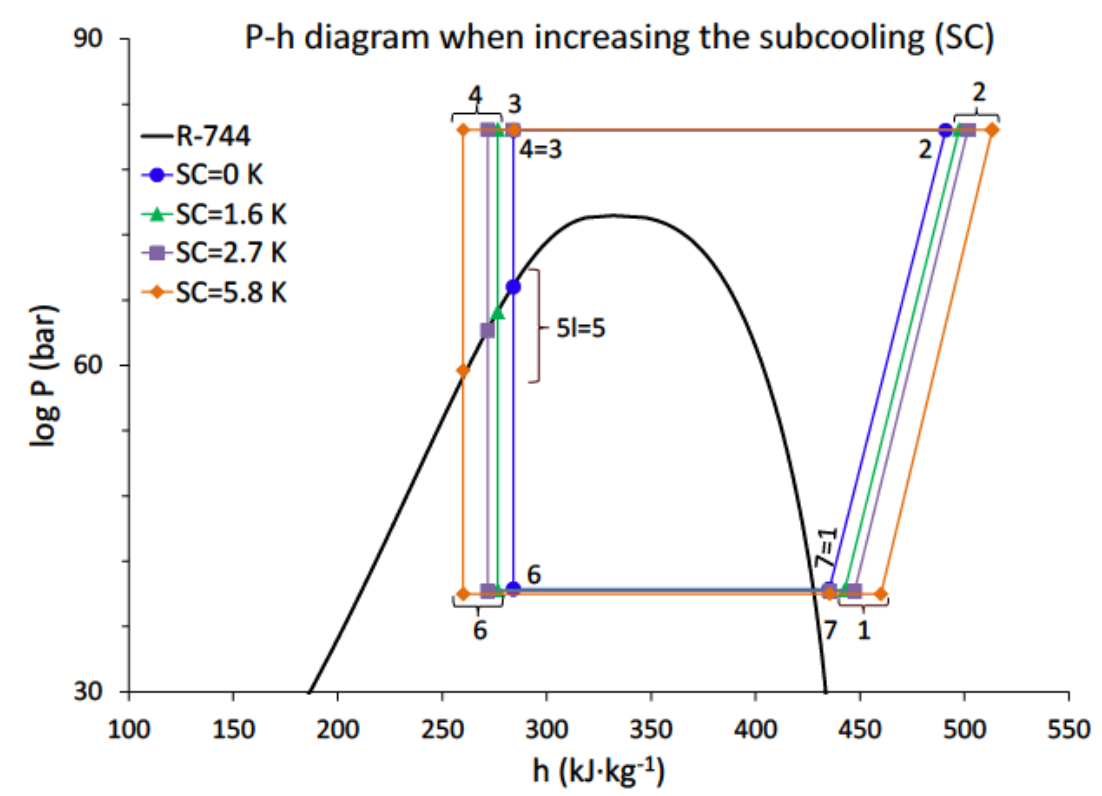

Fig. 52. Summary of the four cycles when increasing the SC from $0 \mathrm{~K}$ to $5.8 \mathrm{~K}$.

Results show that when increasing the $S C$, the compressor inlet and outlet move to the right side of the diagram, and the outlet-inlet enthalpy difference increases in $4 \%$ between $0 \mathrm{~K}$ and $5.8 \mathrm{~K}$ of SC. Whereas, from the gas cooler perspective, the inletoutlet enthalpy difference increases in $11 \%$. These enthalpy differences produce an increase of the specific volume and a decrease of the refrigerant mass flow rate, and subsequently, a COP improvement.

When increasing the $S C$, the evaporation temperature $\left(T_{\text {evap }}\right)$ and the refrigerant inlet temperature at the IHX low pressure side $\left(T_{I H X, r i, l o w}\right)$ decrease. And, since the $S C$ is increasing and the low side of the IHX is absorbing heat from the high side, the refrigerant temperature out of the IHX low pressure side $\left(T_{I H X, \text {,o,low }}\right)$ increases, (Fig. 53 and Fig. 54). 


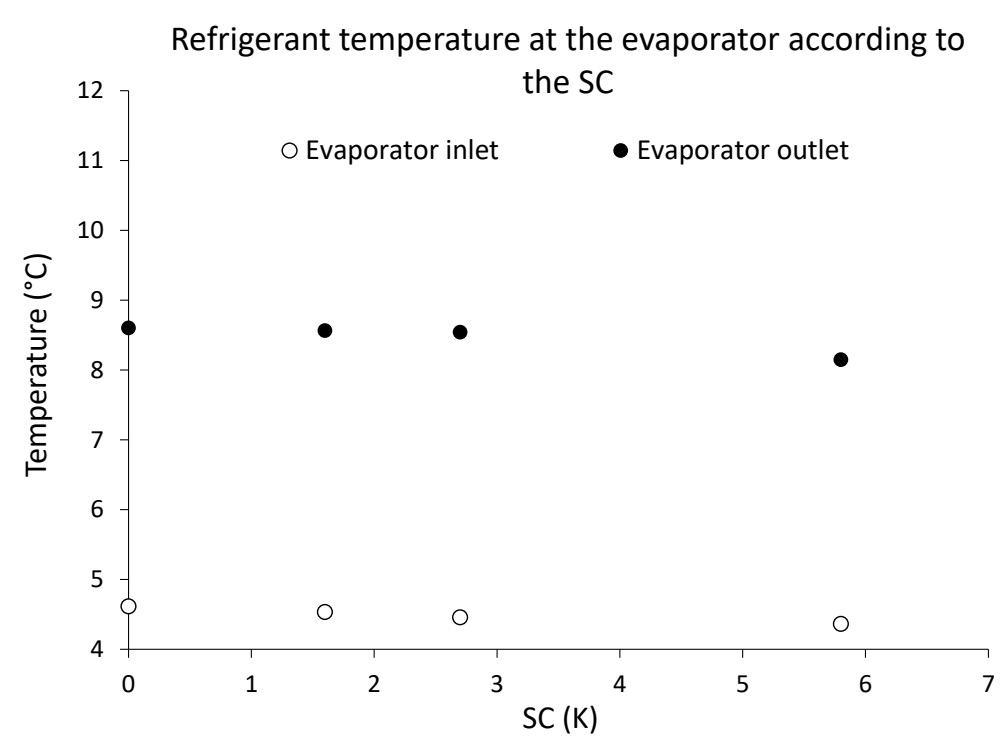

Fig. 53. Refrigerant temperature at the inlet and outlet of the evaporator when increasing the SC.

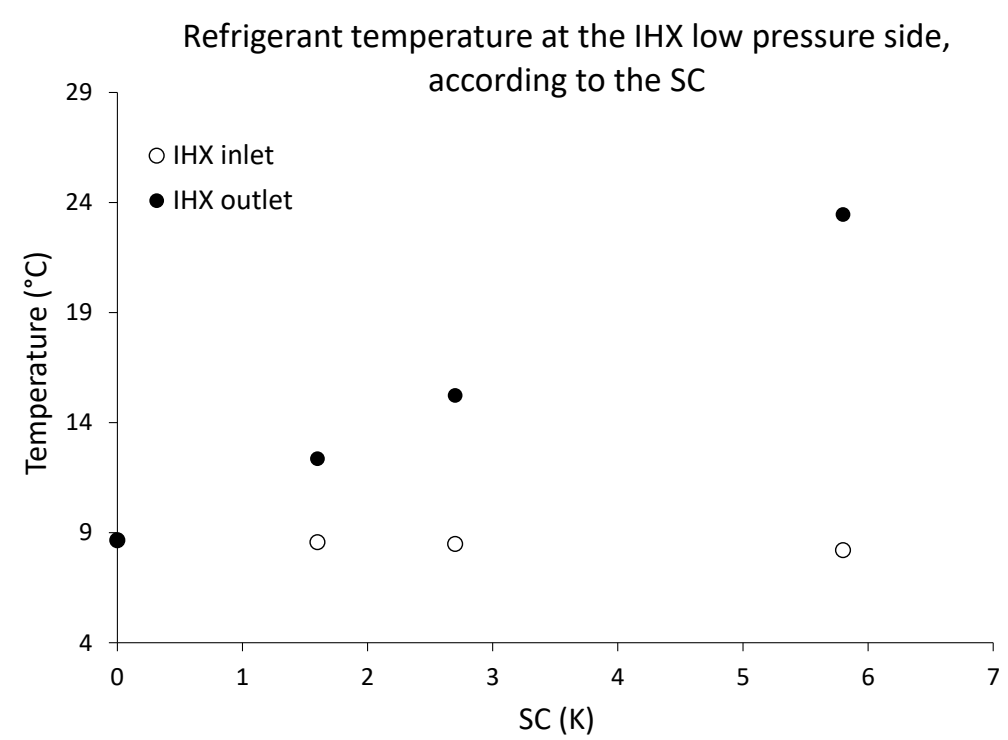

Fig. 54. Refrigerant temperature in the IHX low side when increasing SC.

Since the refrigerant temperature out of the low side of the IHX increases when increasing the $S C$, the compressor inlet temperature $\left(T_{c, r i}\right)$ increases, and thus, the specific volume at the compressor inlet increases, decreasing the $\dot{m}_{r}$ and the $\dot{W}_{\text {comp }}$ (Fig. 55 and Fig. 56). 
Refrigerant temperature at the compressor according

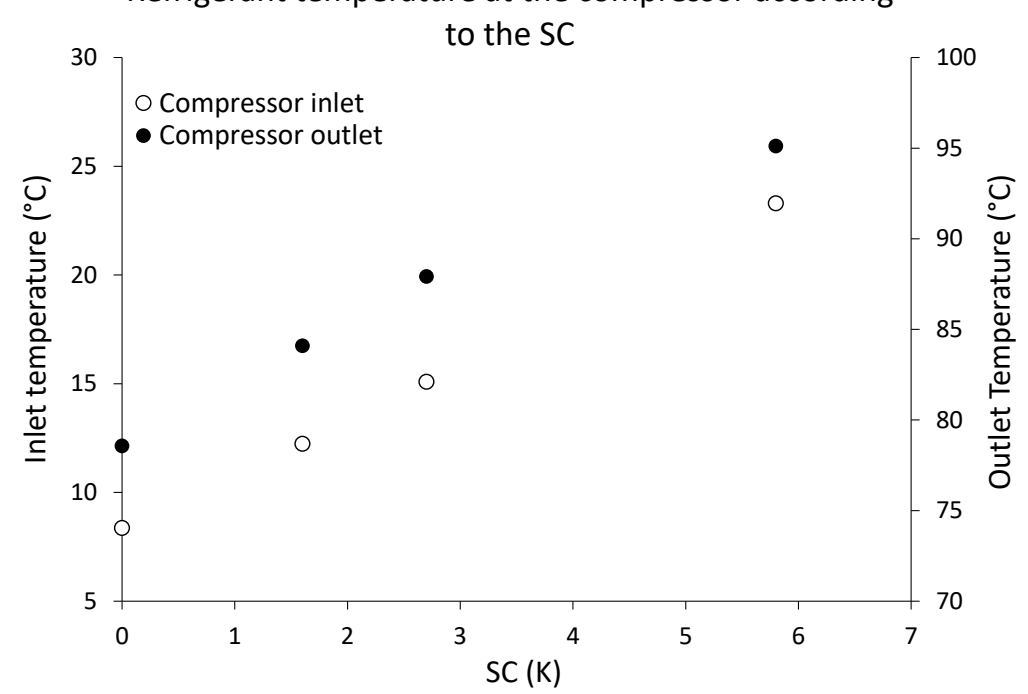

Fig. 55. Refrigerant temperature in the compressor when increasing SC.

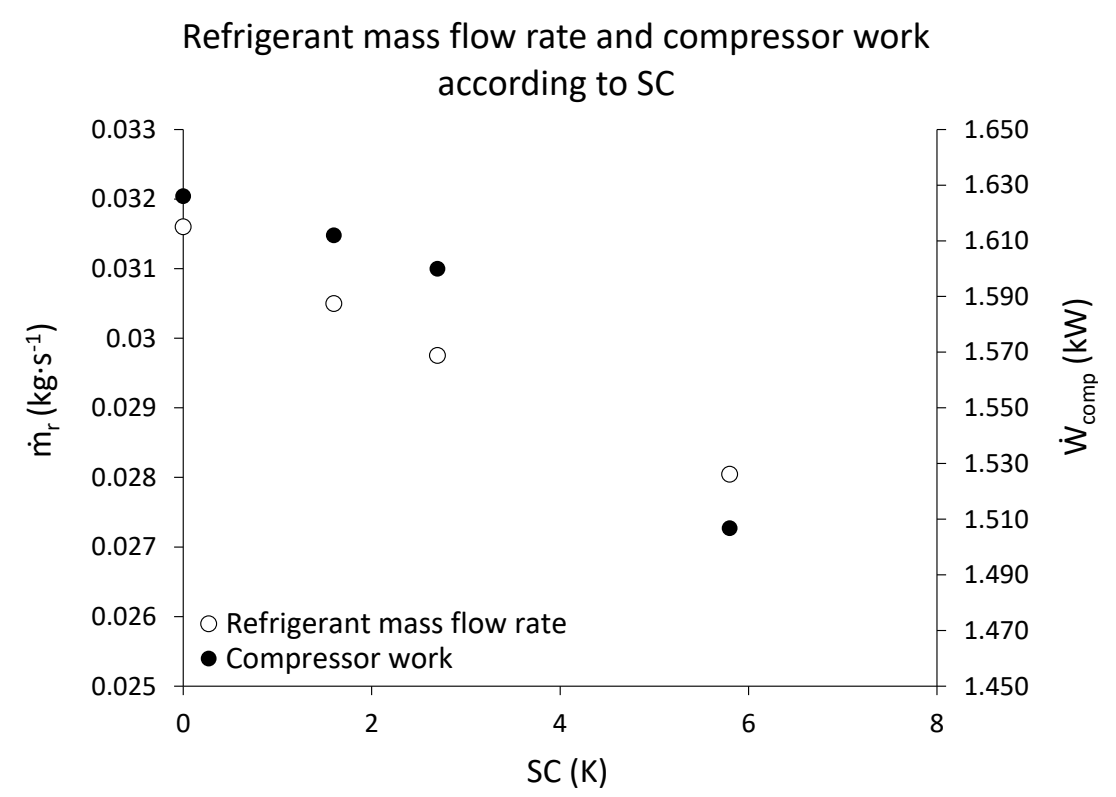

Fig. 56. Refrigerant mass flow rate and compressor work, when increasing the SC.

Due to the temperature increase at the compressor, the gas cooler inlet temperature increases, and, since the gas cooler outlet maintains almost the same temperature for the different $S C$ values, this produces an increase in the specific enthalpy difference (Fig. 57 and Fig. 58). And, finally, since the compressor work decreases, the COP of the facility improves. 


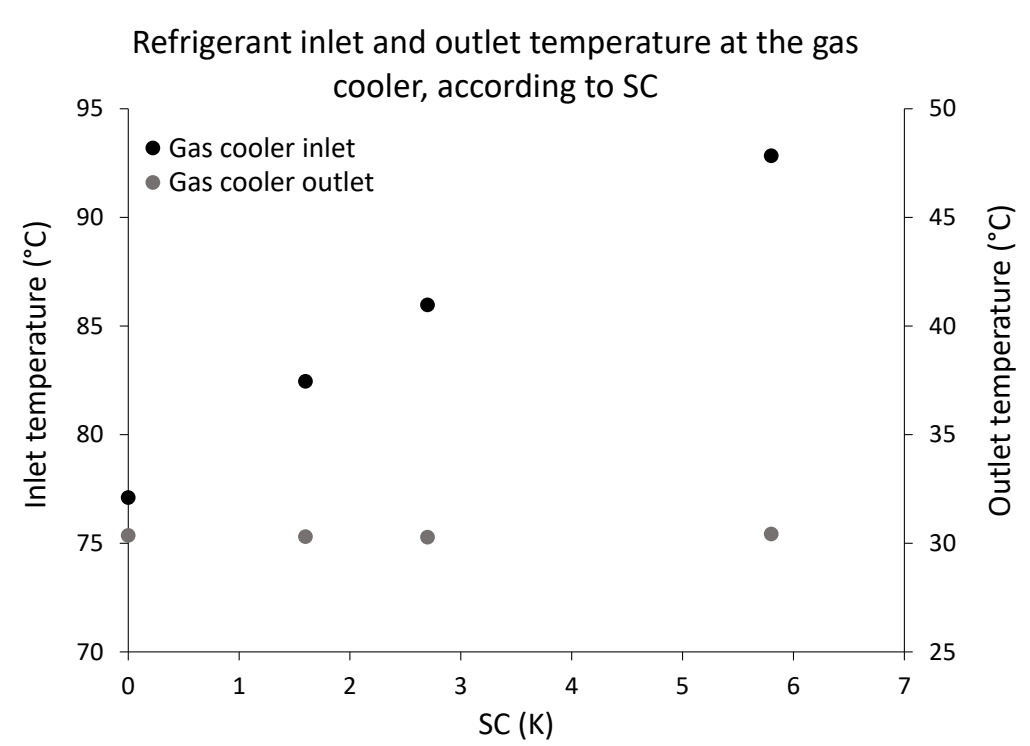

Fig. 57. Gas cooler refrigerant inlet and outlet temperature

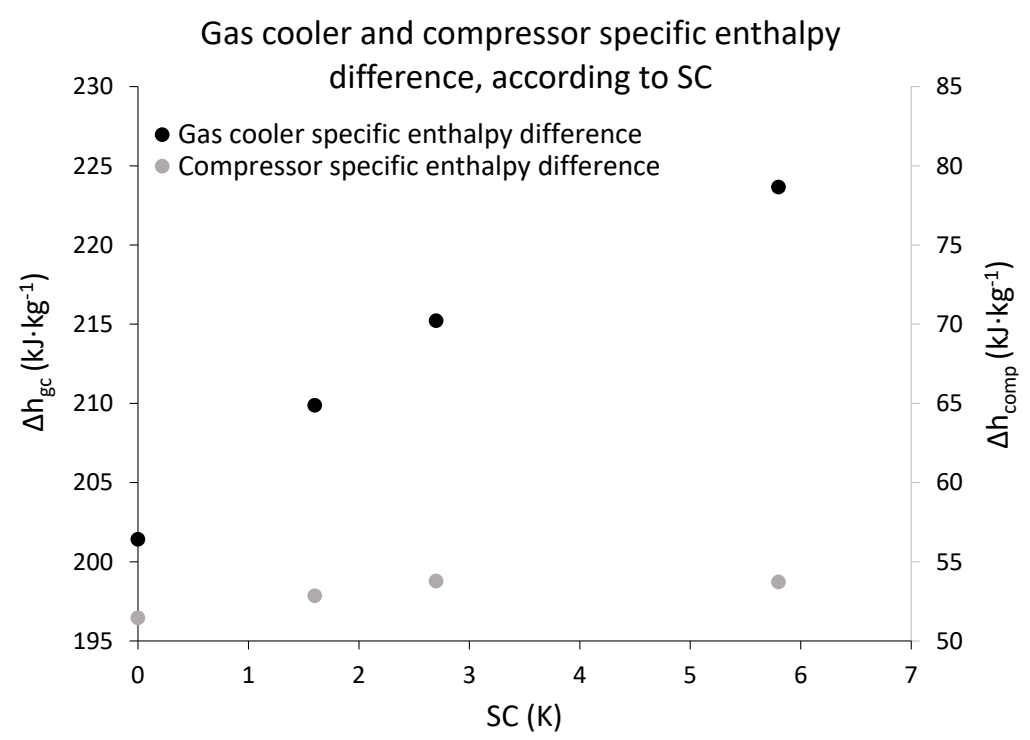

Fig. 58. Gas cooler specific enthalpy difference when increasing the SC.

Table 20 and Fig. 59 show the COP results for the different efficiencies considered. Namely, totally opened produced $\eta_{1 H x}=73 \%$, totally closed $\eta_{1 H X}=0 \%$; partially opened, for SC of $1.7 \mathrm{~K}$ and $3 \mathrm{~K}$, produced $\eta_{1 H X}=22 \%$ and $36 \%$, respectively. As can be seen, for $\mathrm{CO}_{2}$ transcritical cycles, the best performance is obtained when the IHX is totally opened, which was already reported by other researchers, such as Chen \& Gu [53], Cao et al. [56], Kim et al. [59], Torrella et al. [61], Sánchez et al. [64], Zhang et al. [85], and Jiang et al. [86]. 


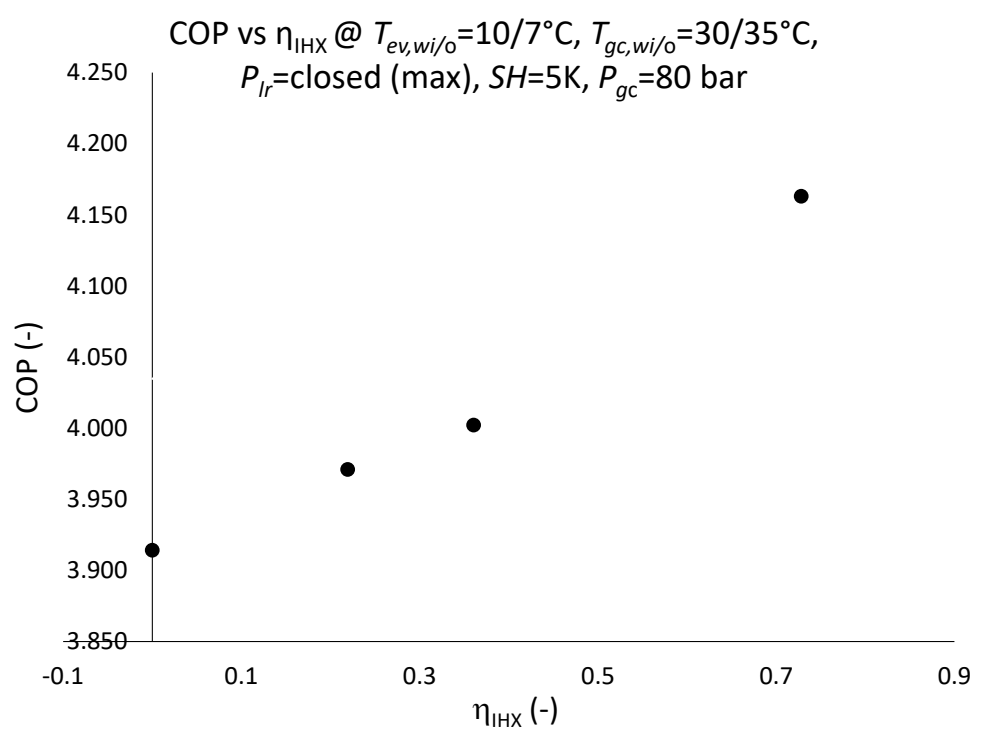

Fig. 59. Influence of the IHX on the COP.

\subsection{Optimal pressure, numerical and experimental study}

This section presents the results obtained when studying the optimal pressure. This analyzes the influence that different parameters have one it, namely liquid receiver pressure, the compressor efficiency, the IHX efficiency, the evaporation temperature and the superheating, and finally, provides a correlation for the optimal pressure.

This study is based on a model-based approached. So, the idea is to obtain a correlation that can be easily implemented using standard PID controllers. In order to obtain such a correlation, most of the research work available in the literature use a specific compressor model or quite simple expressions to characterize compressor efficiency, which usually limits the validity of the model to the case studied. In this thesis, the compressor behavior is characterized by using third degree polynomial equations according to the ANSI/AHRI 540-2015 [134] Standard. The regression coefficients employed are obtained from the analysis of different models of semihermetic compressor developed by three different manufacturers. The model will only consider those variables that can be directly measured, avoiding the use of variables like the IHX efficiency. Finally, the model will control the optimal pressure taking into account the maximum operating pressure and limiting the compressor discharge temperature so that the degradation of the lubricant oil is minimized.

\subsubsection{Numerical model}

In order to obtain an expression for the optimal pressure, a numerical model has been developed in $M A T L A B^{\circledR}$, which takes as input variables the properties of the refrigerant at different points of the refrigeration cycle and the performance of the IHX. Table 21 summarizes the ranges of variation evaluated for the properties considered. 
Table 21. Variation range of the variables used to obtain the numerical model.

\begin{tabular}{|c|c|c|c|c|c|}
\hline $\begin{array}{c}\boldsymbol{T}_{\text {evap }} \\
\left({ }^{\circ} \mathbf{C}\right)\end{array}$ & $\begin{array}{c}\boldsymbol{S H} \\
(\mathbf{K})\end{array}$ & $\begin{array}{c}\boldsymbol{\eta}_{\text {IHX }} \\
(-)\end{array}$ & $\begin{array}{c}\boldsymbol{P}_{\text {Ir }} \\
(\mathbf{b a r})\end{array}$ & $\begin{array}{c}\boldsymbol{T}_{\text {gc,ro }} \\
\left({ }^{\circ} \mathbf{C}\right)\end{array}$ & $\begin{array}{c}\boldsymbol{P}_{\text {gc }} \\
\text { (bar) }\end{array}$ \\
\hline $5-25$ & $3-7$ & $0-0.9$ & $\mathrm{P}_{\min } \& \mathrm{P}_{\max }$ & $10-60$ & $74-140$ \\
\hline
\end{tabular}

Although this work is focused on the refrigerant loop, evaporation temperature and gas cooler outlet temperature in Table 21 have been selected according to the typical ranges of variation in water temperature for water-water heat pumps in both, space heating and DHW generation according to the standards EN-14511-2-Standard [1] and UNE-EN-16147-Standard [5]. The evaporator water inlet temperature has been supposed to vary between 10 and $30^{\circ} \mathrm{C}$, which can be considered a typical variation range for greywater temperature in mild and warm-climate conditions [13]. A difference of $3 \mathrm{~K}$ between inlet and outlet temperature in the evaporator has been considered, according to EN 14511-2 and EN 16147, which leads to evaporation temperatures ranging approximately from $5{ }^{\circ} \mathrm{C}$ to $25^{\circ} \mathrm{C}$. Gas cooler water inlet temperature has been supposed to vary between $10{ }^{\circ} \mathrm{C}$ (water inlet temperature according to $\mathrm{EN} 16147$ ) and $55^{\circ} \mathrm{C}$ (water inlet temperature for very high temperature space heating according to EN 14511-2) or even slightly higher during the last stages of DHW generation at $60^{\circ} \mathrm{C}$, which leads to refrigerant temperature at the gas cooler outlet ranging approximately from $10^{\circ} \mathrm{C}$ to $60^{\circ} \mathrm{C}$.

As Table 21 shows, the model also includes the study of the influence of intermediate pressure. In this case, the pressure does not vary between fixed limits, but the minimum pressure is given by the evaporation pressure and the maximum pressure will correspond to a situation in which the storage bypass is completely closed and all the refrigerant is forced to pass through the evaporator.

To enable the comparison of the results of the model with the values obtained in the experimental tests, the model incorporates the behavior curves of the compressor used during those tests. According to the AHRI Standard 540-2015 [134], these curves are introduced into the model using the third degree polynomials given by equations (25) and (26):

$$
\begin{aligned}
& \dot{m}_{r}=C_{1}+C_{2} \cdot T_{0}+C_{3} \cdot p_{c}+C_{4} \cdot T_{0}^{2}+C_{5} \cdot T_{0} \cdot p_{c}+C_{6} \cdot p_{c}^{2}+C_{7} \cdot T_{0}^{3}+C_{8} \cdot p_{c} \cdot T_{0}^{2}+C_{9} \cdot T_{0} \cdot p_{c}^{2}+C_{10} \cdot p_{c}^{3} \\
& \dot{W}_{r}=C_{1}+C_{2} \cdot T_{0}+C_{3} \cdot p_{c}+C_{4} \cdot T_{0}^{2}+C_{5} \cdot T_{0} \cdot p_{c}+C_{6} \cdot p_{c}^{2}+C_{7} \cdot T_{0}^{3}+C_{8} \cdot p_{c} \cdot T_{0}^{2}+C_{9} \cdot T_{0} \cdot p_{c}^{2}+C_{10} \cdot p_{c}^{3}
\end{aligned}
$$

where $T_{0}$ is the evaporation temperature in degrees Celsius, $P C$ is the compressor discharge pressure in bar, and the adjustment coefficients $\mathrm{Ci}$ for the Dorin compressor used in the facility, are those shown in Table 22, provided by the compressor manufacturer, for a superheat of $10 \mathrm{~K}$ according to European Standard EN 12900, (2013) [135]. 
Table 22. Adjustment coefficients for compressor behavior curves.

\begin{tabular}{|c|c|c|c|c|c|}
\hline & $\mathrm{C}_{\mathbf{1}}$ & $\mathrm{C}_{\mathbf{2}}$ & $\mathrm{C}_{\mathbf{3}}$ & $\mathrm{C}_{\mathbf{4}}$ & $\mathrm{C}_{\mathbf{5}}$ \\
\hline$\dot{\boldsymbol{m}}$ & 0.040044 & 0.001141 & -0.000197 & $1.08 \cdot 10^{-5}$ & $-1.7 \cdot 10^{-6}$ \\
\hline$\dot{\boldsymbol{W}}$ & -1904.9 & -77.21 & 78.17 & -1.033 & 1.195 \\
\hline & $\mathbf{C 6}$ & $\mathbf{C 7}$ & $\mathbf{C 8}$ & $\mathbf{C 9}$ & $\mathbf{C 1 0}$ \\
\hline$\dot{\boldsymbol{m}}$ & $5.5 \cdot 10^{-7}$ & 0 & 0 & 0 & 0 \\
\hline$\dot{\boldsymbol{W}}$ & -0.5297 & -0.0048 & 0.0052 & -0.0032 & 0.0014 \\
\hline
\end{tabular}

Fig. 60 presents the experimental refrigerant mass flow rate and compressor power input compared to the ones calculated with the model used. Black circles (Dorin) compare the results obtained by using equations (25) and (26) with the experimental values measured directly during the tests. It can be clearly seen that these expressions tend to overestimate both the refrigerant mass flow rate and the compressor power input. The Mean Absolute Relative Deviation (MARD) is $13.9 \%$ for the mas flow rate and $10.2 \%$ for the compressor power input.

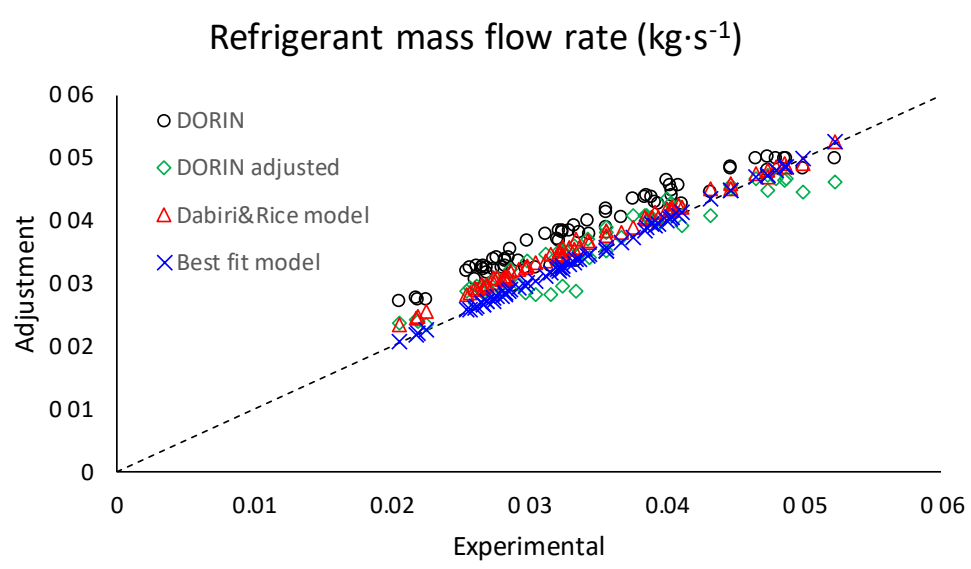

(a) Refrigerant mass flow rate

Compressor power input (kW)

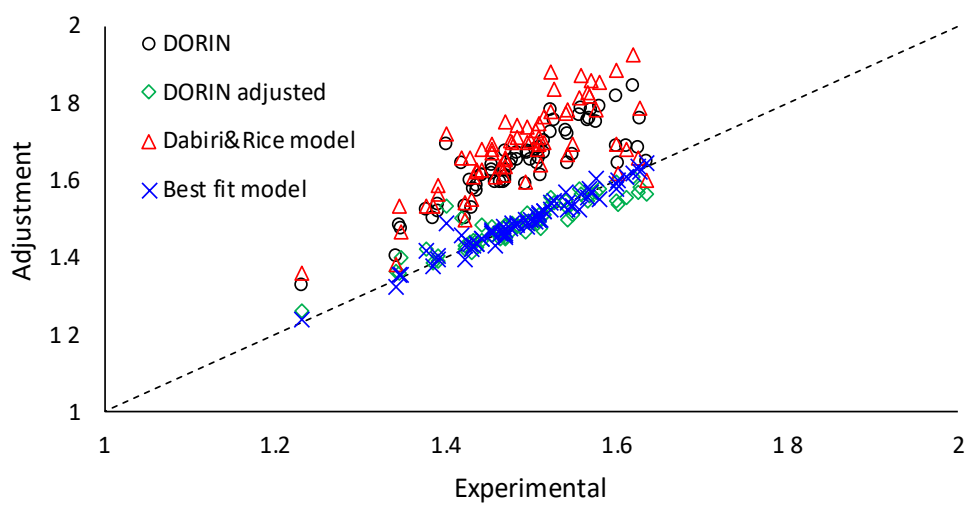

(b) Compressor power consumption

Fig. 60. Comparison of the experimental values and model for refrigerant mass flow rate and the power absorbed by the compressor. 
The differences shown in Fig. 60 could be explained by the fact that equations (25) and (26) do not take into account the effect of superheating. Besides, equation (26) provides the compressor power input, but the experimentally measured value represented in Fig. 59 is the compression work, which is the value used in the Matlab ${ }^{\circledR}$ model. In its Appendix D, the ANSI/AHRI Standard 540-2015 [134] provides a formula, referenced from Dabiri \& Rice [136], for the correction of mass flow rate taking into account the way in which superheating affects the density of the refrigerant at compressor suction conditions:

$$
\dot{m}_{D \& R}=\dot{m}_{r} \cdot\left[1+F \cdot\left[\left(\rho_{a} / \rho_{r}\right)-1\right]\right]
$$

Where $\rho$ is the density of the refrigerant at compressor suction, the subscript $r$ refers to the rated conditions and the subscript $a$, refers to the actual aspiration conditions. $F$ is an adjustment factor that, according to ANSI/AHRI 540-2015 [134], can be taken as 1 in a first approximation, although the Standard recommends contacting the manufacturer of the equipment to obtain more precise values. Dabiri \& Rice [136] proposed to adopt a value of 0.75 for $F$ which, in their opinion, provides values closer to the average of the data provided by the manufacturers. The red triangles (Dabiri\&Rice model) in Fig. 60.a, corresponds to the results obtained when using equation (27), for the refrigerant mass flow rate, with $F=0.75$. It is clear that the prediction improves when using $F=0.75$ instead of 1 , showing a better fit to the experimentally measured data. MARD value for the mass flow rate in this case is 6.8 $\%$.

Although according to the ANSI/ARHI 540-2015 [134], a change of superheat has negligible impact on power consumption, Dabiri \& Rice [136] proposed the correction of power consumption given by equation (28). This correction assumes that the isentropic performance of the compressor does not change between rated and actual conditions, but takes into account the change in the refrigerant mass flow rate and the isentropic compression work.

$$
\dot{W}_{D \& R}=\dot{W}_{r} \cdot \frac{\dot{m}_{D \& R}}{\dot{m}_{r}} \cdot \frac{\Delta h_{i s, a}}{\Delta h_{i s, r}}
$$

Red triangles (Dabiri\&Rice model) in Fig. 60 show the results obtained by using that correction shown in equation (28). The results are very similar to those obtained by directly using equation (27) and the difference with the experimentally measured values, when considering the compressor power input, seem to be worse than that found in the refrigerant mass flow rate (Fig. 60.a). MARD value in this case increases up to $12.8 \%$ for the compressor power input.

Since Dabiri \& Rice [136] correction does not improve the prediction of the compressor power input and there is no specific model for the compression work, several different corrections to equations (25) and (26) were tested looking for a 
better adjustment between the prediction and the experimental results. The best results are obtained when using the correction presented in equations (29) and (30):

$$
\begin{gathered}
\dot{m}_{D, a d}=1.04421184522382 \cdot \dot{m}_{r}-0.00557668566163589 \cdot\left(\rho_{a} / \rho_{r}\right) \\
\dot{W}_{D, a d}=0.720381369216144 \cdot \dot{W}_{r}+0.329684050844214 \cdot\left(\rho_{a} / \rho_{r}\right)
\end{gathered}
$$

Green diamonds (Dorin Adjusted), in Fig. 60, show the results obtained using equations (29) and (30). The prediction for both, mass flow rate and compressor power input, improve if compared to the results yielded by using equations (25) and (26), although there is still opportunity for improvement, especially for the mass flow rate prediction. MARD values in this case are $6.4 \%$ for the mass flow rate and $1.4 \%$ for the compressor power input.

Finally, the blue crosses (best fit model), of Fig. 60, show the results obtained with an alternative adjustment obtained by directly adjusting the experimental data to expressions of the type:

$$
\begin{gathered}
\dot{m}_{B F}=C_{1}+\left(\rho_{a} / \rho_{r}\right) \cdot\left[C_{2} \cdot T_{0}+C_{3} \cdot p_{c}+C_{4} \cdot T_{0}^{2}+C_{5} \cdot T_{0} \cdot p_{c}+C_{6} \cdot p_{c}^{2}+C_{7} \cdot T_{0}^{3}+C_{8} \cdot p_{c} \cdot T_{0}^{2}+C_{9} \cdot T_{0} \cdot p_{c}^{2}\right. \\
\left.+C_{10} \cdot p_{c}^{3}\right]
\end{gathered}
$$

Where the adjustment coefficients $\mathrm{Ci}$ are not those provided by the manufacturer but those shown in Table 23.

Table 23. Adjustment coefficients for compressor behavior curves. Equations (31) and (32).

\begin{tabular}{|c|c|c|c|c|c|}
\hline & $\mathbf{C}_{1}$ & $\mathbf{C}_{2}$ & $\mathbf{C}_{\mathbf{3}}$ & $\mathbf{C}_{4}$ & $\mathbf{C}_{5}$ \\
\hline$\dot{\boldsymbol{m}}$ & 0.004239 & -0.002140 & 0.001499 & $1.06 \cdot 10^{-5}$ & $9.69 \cdot 10^{-5}$ \\
\hline$\dot{W}$ & 953.285 & -105.8569 & -29.7006 & -0.44432 & 1.72393 \\
\hline & $\mathbf{C}_{6}$ & $\mathbf{C}_{\mathbf{7}}$ & $\mathbf{C}_{\mathbf{8}}$ & $\mathbf{C}_{\mathbf{9}}$ & $\mathbf{C}_{10}$ \\
\hline$\dot{\boldsymbol{m}}$ & $-2.48 \cdot 10^{-5}$ & $1.31 \cdot 10^{-6}$ & $1.73 \cdot 10^{-7}$ & $-6.63 \cdot 10^{-7}$ & $1.22 \cdot 10^{-7}$ \\
\hline$\dot{\boldsymbol{W}}$ & 0.815254 & -0.024705 & -0.00448 & -0.00461 & -0.00421 \\
\hline
\end{tabular}

As can be seen in Fig. 60, equation equations (31) and (32) provide the best fit to the experimentally measured values. MARD values are $0.45 \%$ for the refrigerant mass flow rate and $0.82 \%$ for the compressor power input.

However, due to the limitations existing at this time in the experimental facility, the pressure values that are experimentally tested and used to obtain equations (31) and (32), only reach up to 92 bar. As seen in Fig. 61, at pressures above 95 bar, the values of mass flow rate and power consumption predicted by the model begin to move away from the normal behavior marked by the other models. For this reason, the model finally adopted to describe the compressor behavior is the one given by equations (29) and (30). So, those are the equations used in the MATLAB ${ }^{\circledR}$ model developed to numerically simulate the facility experimentally studied. 


\section{Compressor behaviour $\left(\mathrm{T}_{\text {evap }}=5^{\circ} \mathrm{C}, \mathrm{SH}=7 \mathrm{~K}\right)$}

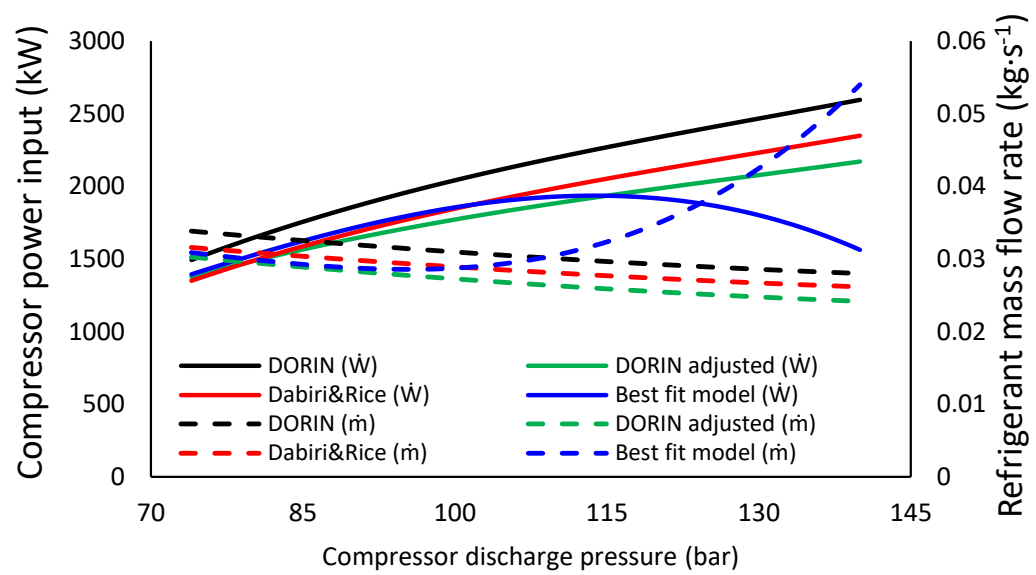

Fig. 61. Evolution of mass flow rate and compressor power consumption predicted by the four models considered.

Finally, Fig. 62 shows the influence that the model adopted to predict compressor behavior, has on the optimal pressure and optimal COP values obtained using the model developed in MATLAB ${ }^{\circledR}$. As can be seen, although the model used slightly affects the optimum COP value, the optimal pressure values obtained are practically independent of the model used for the compressor.

$$
\mathrm{T}_{\text {evap }}=5^{\circ} \mathrm{C}, \mathrm{SH}=5 \mathrm{~K}, \eta_{\mathrm{IHX}}=0.7
$$

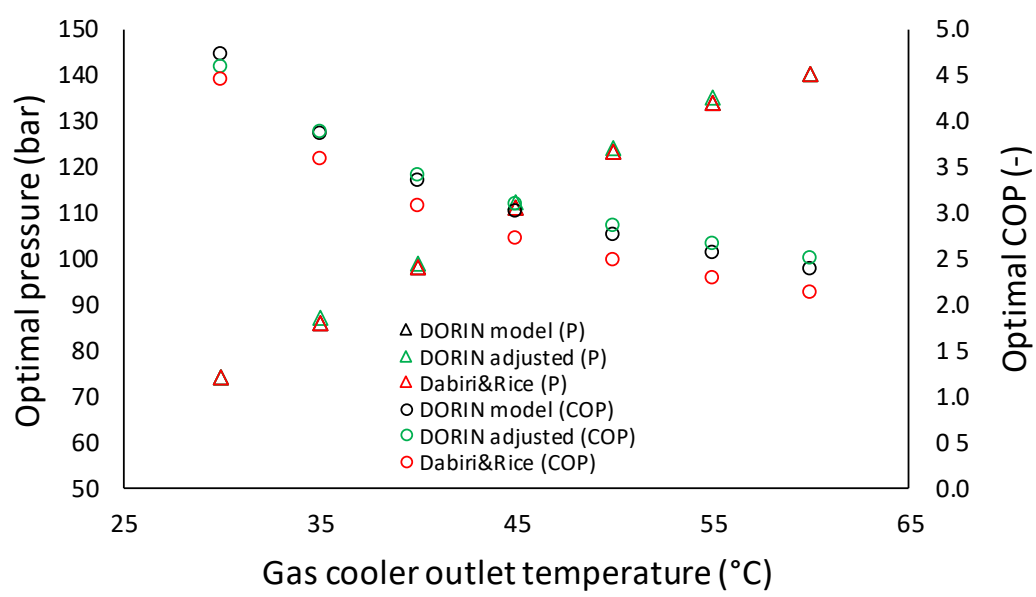

Fig. 62. Evolution of optimal pressure and maximum COP (at optimal pressure conditions) depending on the compressor model. 


\subsubsection{Numerical and experimental results}

This section presents and analyses the experimental results found during the optimal pressure study.

Table 24. Optimal pressure, experimental results.

\begin{tabular}{|c|c|c|c|c|c|c|}
\hline$T_{\text {evap }}\left({ }^{\circ} \mathrm{C}\right)$ & $S H\left({ }^{\circ} \mathrm{C}\right)$ & $T_{g c, r o}\left({ }^{\circ} \mathrm{C}\right)$ & $\eta_{I H X}(-)$ & $P_{g c}$ (bar) & $P_{\text {Ir }}$ (bar) & $\operatorname{COP}(-)$ \\
\hline 5.02 & 5.06 & 30.49 & 0.79 & 74.04 & 60.58 & 4.3983 \\
\hline 5.03 & 5.03 & 30.49 & 0.76 & 76.07 & 59.28 & 4.4011 \\
\hline 5.06 & 5.06 & 30.51 & 0.73 & 80.05 & 57.85 & 4.2783 \\
\hline 5.01 & 5.03 & 30.49 & 0.70 & 84.99 & 56.25 & 4.0779 \\
\hline 5.05 & 5.03 & 30.49 & 0.68 & 89.97 & 54.22 & 3.8871 \\
\hline 5.01 & 5.06 & 30.51 & 0.76 & 76.08 & 45.56 & 4.3847 \\
\hline 5.02 & 5.01 & 32.56 & 0.95 & 76.15 & 67.42 & 3.3275 \\
\hline 5.07 & 5.04 & 32.54 & 0.81 & 78.07 & 61.29 & 4.0485 \\
\hline 5.02 & 5.06 & 32.53 & 0.77 & 80.09 & 59.30 & 4.0580 \\
\hline 5.04 & 5.11 & 32.54 & 0.76 & 81.00 & 59.78 & 4.0101 \\
\hline 5.09 & 5.00 & 32.55 & 0.73 & 84.96 & 58.03 & 3.9303 \\
\hline 5.01 & 5.03 & 32.52 & 0.70 & 90.04 & 56.94 & 3.7669 \\
\hline 5.05 & 5.02 & 32.54 & 0.77 & 80.05 & 46.21 & 4.0435 \\
\hline 5.05 & 5.04 & 36.00 & 0.92 & 80.04 & 69.53 & 2.8378 \\
\hline 4.98 & 5.06 & 36.06 & 0.88 & 83.07 & 64.64 & 3.3450 \\
\hline 5.01 & 5.12 & 36.03 & 0.81 & 85.05 & 62.20 & 3.5090 \\
\hline 5.04 & 4.94 & 35.99 & 0.75 & 88.96 & 59.74 & 3.5479 \\
\hline 5.03 & 5.07 & 36.00 & 0.74 & 91.03 & 58.53 & 3.5263 \\
\hline 5.03 & 4.99 & 36.00 & 0.75 & 88.96 & 46.29 & 3.5221 \\
\hline 10.02 & 5.03 & 30.52 & 0.79 & 74.03 & 53.77 & 5.2987 \\
\hline 10.02 & 4.96 & 30.50 & 0.76 & 75.05 & 53.96 & 5.3039 \\
\hline 10.01 & 5.03 & 30.49 & 0.72 & 80.02 & 51.15 & 5.0667 \\
\hline 10.04 & 4.97 & 30.51 & 0.69 & 84.99 & 48.90 & 4.8008 \\
\hline 10.05 & 6.80 & 30.47 & 0.67 & 90.01 & 46.82 & 4.5518 \\
\hline 10.00 & 5.02 & 32.55 & 0.87 & 77.04 & 57.29 & 4.5695 \\
\hline 9.98 & 5.02 & 32.56 & 0.82 & 77.97 & 55.91 & 4.7028 \\
\hline 10.03 & 4.98 & 32.55 & 0.79 & 78.99 & 54.97 & 4.7717 \\
\hline 9.97 & 5.00 & 32.53 & 0.77 & 80.03 & 53.93 & 4.7323 \\
\hline 10.02 & 4.99 & 32.55 & 0.72 & 85.00 & 51.75 & 4.5759 \\
\hline 9.99 & 5.00 & 32.55 & 0.69 & 89.97 & 49.58 & 4.3785 \\
\hline 10.00 & 4.95 & 36.01 & 0.88 & 83.06 & 58.73 & 3.8738 \\
\hline 10.03 & 4.97 & 36.00 & 0.80 & 84.99 & 56.18 & 4.0517 \\
\hline 10.03 & 4.97 & 36.01 & 0.79 & 86.02 & 55.29 & 4.0675 \\
\hline 10.05 & 4.97 & 36.00 & 0.77 & 87.08 & 54.33 & 4.0811 \\
\hline 10.01 & 5.01 & 36.03 & 0.74 & 90.03 & 52.99 & 4.0503 \\
\hline
\end{tabular}

Bold: Indicate the optimal pressure with the maximum and minimum liquid receiver pressure. 
Fig. 63 shows a comparison between the COP and heating capacity values predicted by the model and the ones experimentally measured for two different evaporation temperatures and three different gas cooler outlet temperatures. Although the model obtained when using equations (31) and (32) provides a better fit than that obtained when using equations (29) and (30), the model obtained when using equations (29) and (30) also gives a quite close prediction.

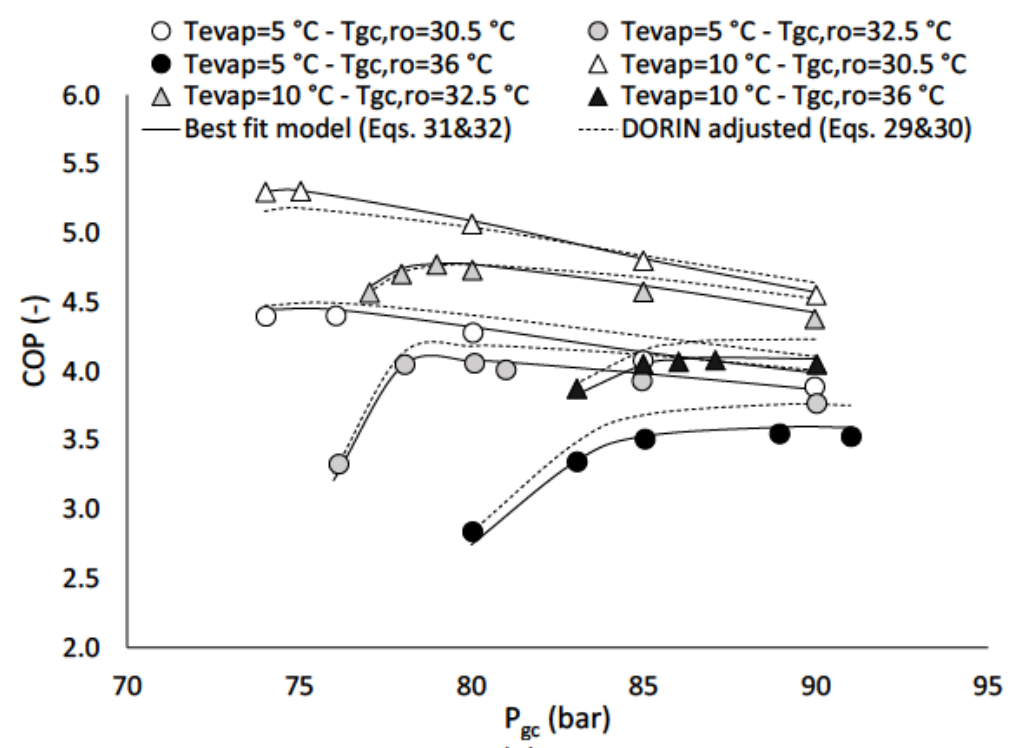

(a)

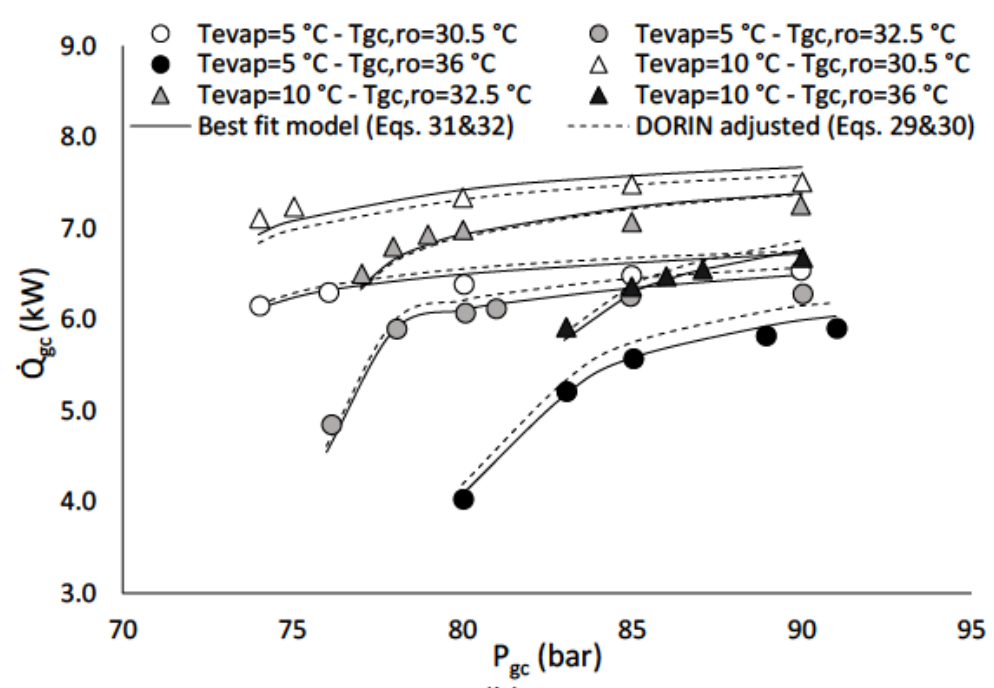

(b)

Fig. 63: Comparison between predicted and experimentally measured values of $\mathrm{COP}$ and $\mathrm{Q}_{\mathrm{gc}}(\mathrm{SH}=5$

$\mathrm{K}, \eta_{I H x} \approx 0.7$ ). Best fit model (Eqs. (31\&(32) \& DORIN Adjusted (Eqs. (29\&(30)

The optimal pressure value clearly increases as the gas cooler outlet temperature increases for both evaporation temperatures tested. Although it is much less clear, there is also certain influence of the evaporation temperature, which is difficult to see graphically. The optimal pressure increases as the evaporation temperature decreases for a given gas cooler outlet temperature, independently of compressor model employed to describe the compressor behavior. 
Despite the small differences in the COP values depending on the model adopted for the compressor, the shape of the curves is very similar and both models provide almost exactly the same optimal pressure value.

Other experimental results are presented in Fig. 64 and Fig. 65. According to them, an increase in the gas cooler pressure has opposite effects on the system's performance. On one hand, it has a positive effect on the system's heating capacity, which increases as the gas cooler pressure increases. On the other hand, it has a negative effect on compressor performance, increasing the power input and decreasing the mass flow rate. Since the increase in the compressor power input and the increase in the heating capacity have different paces, the COP presents an optimum that depends on the operating conditions as can be seen in Fig. 63.

As expected and can be seen in Fig. 65.a, the refrigerant mass flow rate decreases as the gas cooler pressure increases. Despite that decrease in the mass flow rate, both, the heating capacity and the compressor power input increase due to an increase in the specific heating capacity and the specific compression work.

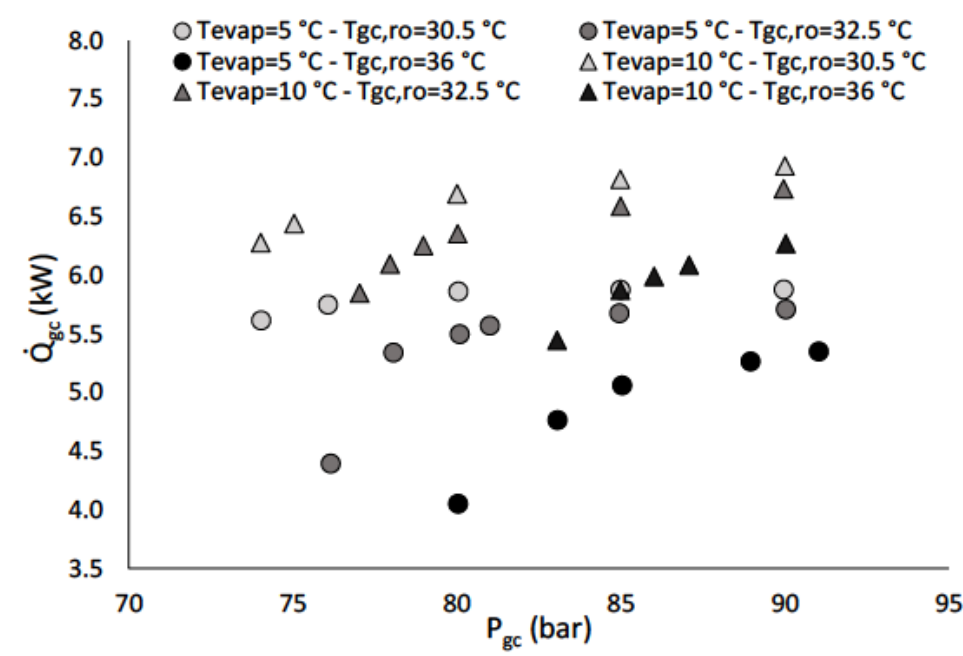

(a)

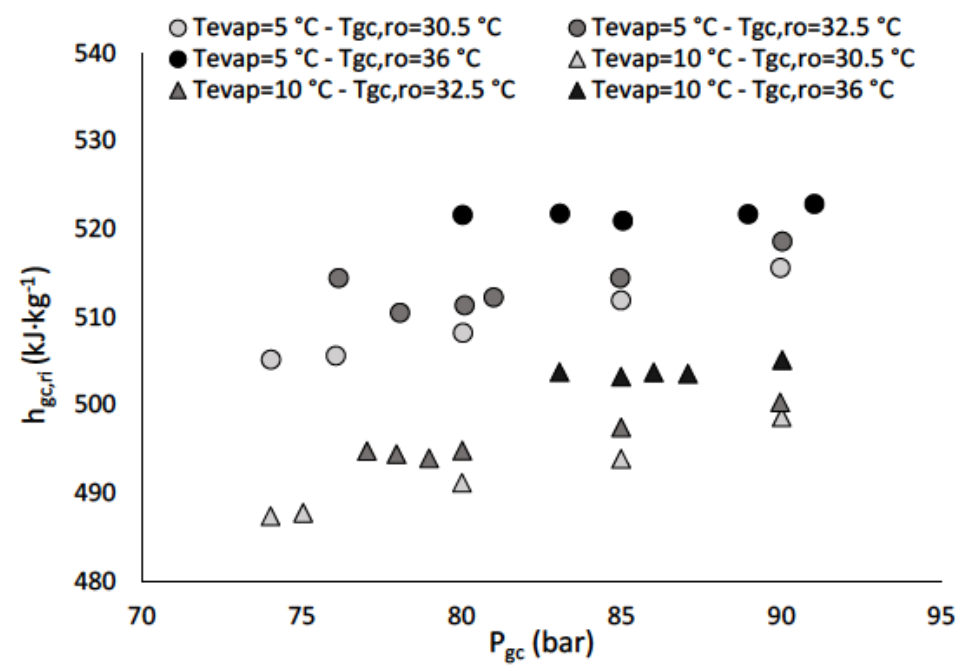

(b) 


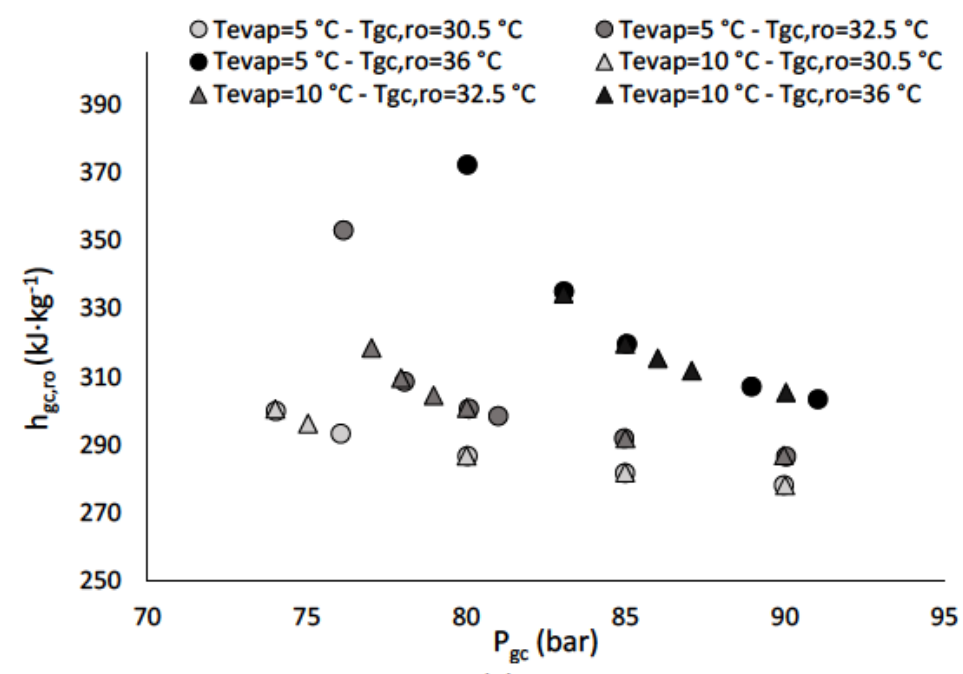

(c)

Fig. 64. Influence of gas cooler pressure on system's heating capacity $\left(\mathrm{SH}=5 \mathrm{~K}, \eta_{\mathrm{HX}} \approx 0.7\right)$.

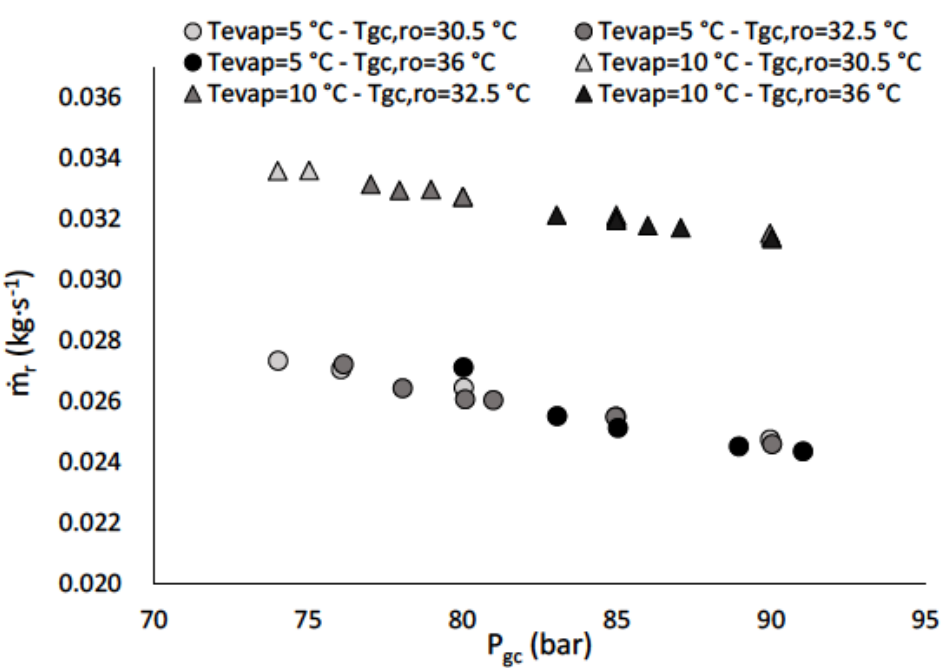

(a)

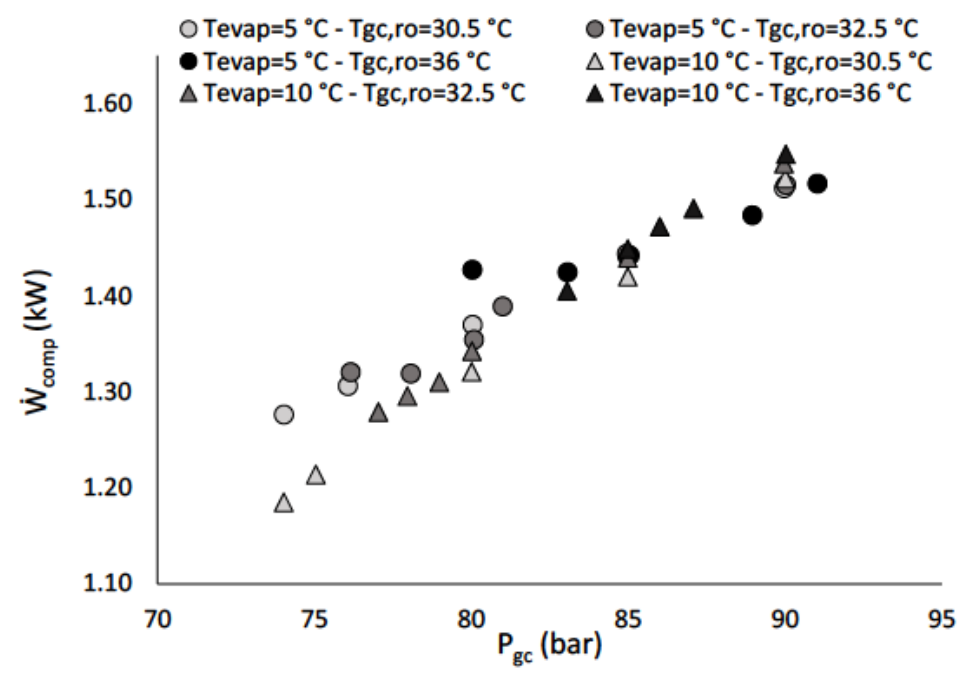

(b) 


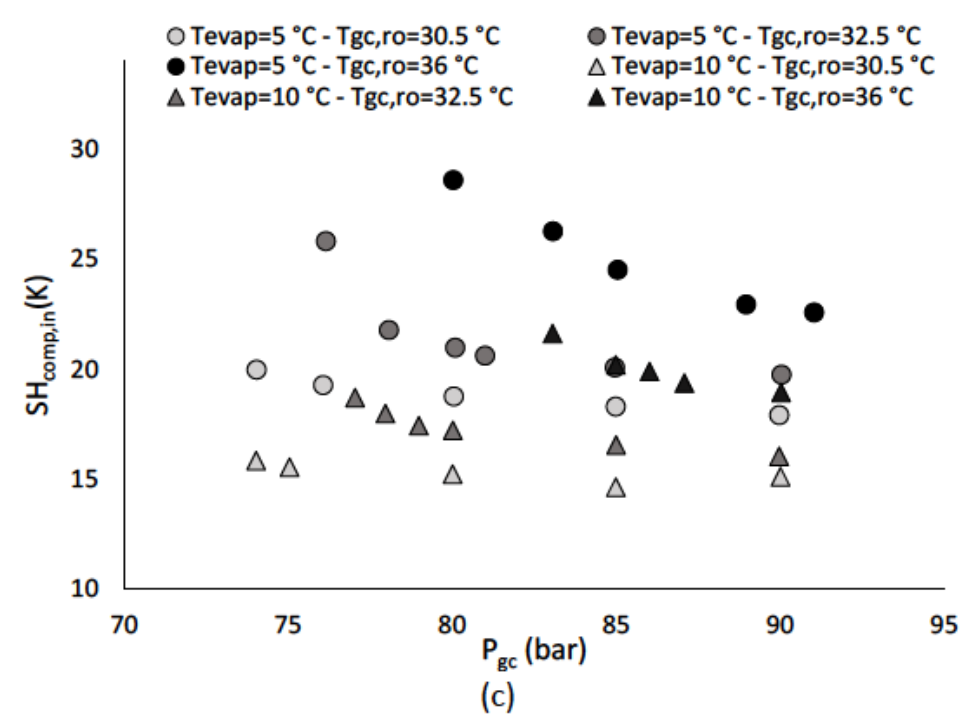

Fig. 65. Influence of gas cooler pressure on compressor's performance ( $\left.\mathrm{SH}=5 \mathrm{~K}, \eta_{I H X} \approx 0.7\right)$.

The increase in the specific heating capacity is in part due to a slight increase in the refrigerant enthalpy at the gas cooler inlet (Fig. 64.b) and mainly due to a clear decrease in the refrigerant enthalpy at the gas cooler outlet (Fig. 64.c) that occur when the gas cooler pressure increases.

According to Fig. 65.c, as the gas cooler pressure increases, the refrigerant suction temperature decreases (the superheating degree at compressor inlet decreases). Although that decrease has a positive effect on the compressor performance, the effect that the increase in the discharge pressure has on the outlet enthalpy is much stronger and the specific compression work clearly increases. Finally, despite the decrease in the refrigerant mass flow rate, the increase in the specific compression work is stronger, and the compressor power input clearly increases.

Once the capability of the model to reproduce the experimentally measured values is proved, it is employed to analyze the influence that the different operating variables have on the optimal pressure.

\subsubsection{Influence of the compressor efficiency}

Several authors have studied the influence that compressor efficiency has on the optimal pressure value in a transcritical $\mathrm{CO}_{2}$ system.

Liao et al. [51] adjusted the isentropic efficiency of a Danfoss compressor from experimental data by using the following expression shown in the equation (33):

$$
\eta_{i s}=C-K \cdot \tau
$$

Where $\tau$ is the compression ratio and $C$ and $K$ are adjustment coefficients. They analyzed different compressor efficiencies by varying the parameter $K / C$ between 0 and 0.3 and they obtained a correlation for the optimal pressure as a function of the evaporation temperature, the gas cooler outlet temperature and the parameter $K / C$. 
Chen \& Gu [53] used the expressions for the compressor isentropic efficiency obtained by Robinson \& Groll [33], Liao et al. [51] and Brown et al. [39] to analyze the influence that the compressor characteristics have on system's behavior. They observed that the predictions obtained by using Robinson \& Groll [33] and Brown et al. [39] expressions were very similar and clearly different from that obtained by means of Liao et al. [51] expression. Zhang et al. [62] added to the expression studied by Chen \& Gu [53] those obtained by Nekså [35] and Aprea \& Maiorino [52], as well as an adjustment to their own experimental results. They found that the optimal pressure varied depending on the expression employed for the compressor efficiency.

More recently Shao et al. [55] used the following expression to characterize the compressor efficiency and varied the adjustment parameter $K$ between 0.06 and 0.14 :

$$
\eta_{i s}=1-K \cdot \tau
$$

According to equation (34), compressor efficiency decreases as the compression ratio increases; the higher the value of $K$ is, the stronger that dependency is. As a result, they found that the optimal pressure decreased as the value of $K$ increased.

In order to assess the influence of the compressor's characteristics, the behavior curves of nine different compressors have been introduced in the MATLAB ${ }^{\circledR}$ model. Since those compressors have not been experimentally studied, that analysis has been made using the behavior curves according to the ANSI/AHRI Standard 540-2015 [134], that is, correlations (25) and (26). The adjustment coefficients for those expressions have been obtained from the selection software of three different semihermetic compressor manufacturers, such as Dorin [137], Bitzer [138] and Frascold [139], and three different compressor models for each manufacturer, and they are summarized in Table 25. A total of nine compressors, with nominal volumetric flow rates between 1.46 and $26.1 \mathrm{~m}^{3} \cdot \mathrm{h}^{-1}$, have been introduced in the MATLAB ${ }^{\circledR}$ model in order to analyze the influence that the compressor behavior has on the optimal pressure. Fig. 66 shows the results obtained for an evaporation temperature of $5^{\circ} \mathrm{C}$, a superheating degree of $5 \mathrm{~K}$ and an $\mathrm{IHX}$ efficiency of 0.7 . The trends for other operating conditions are very similar. 


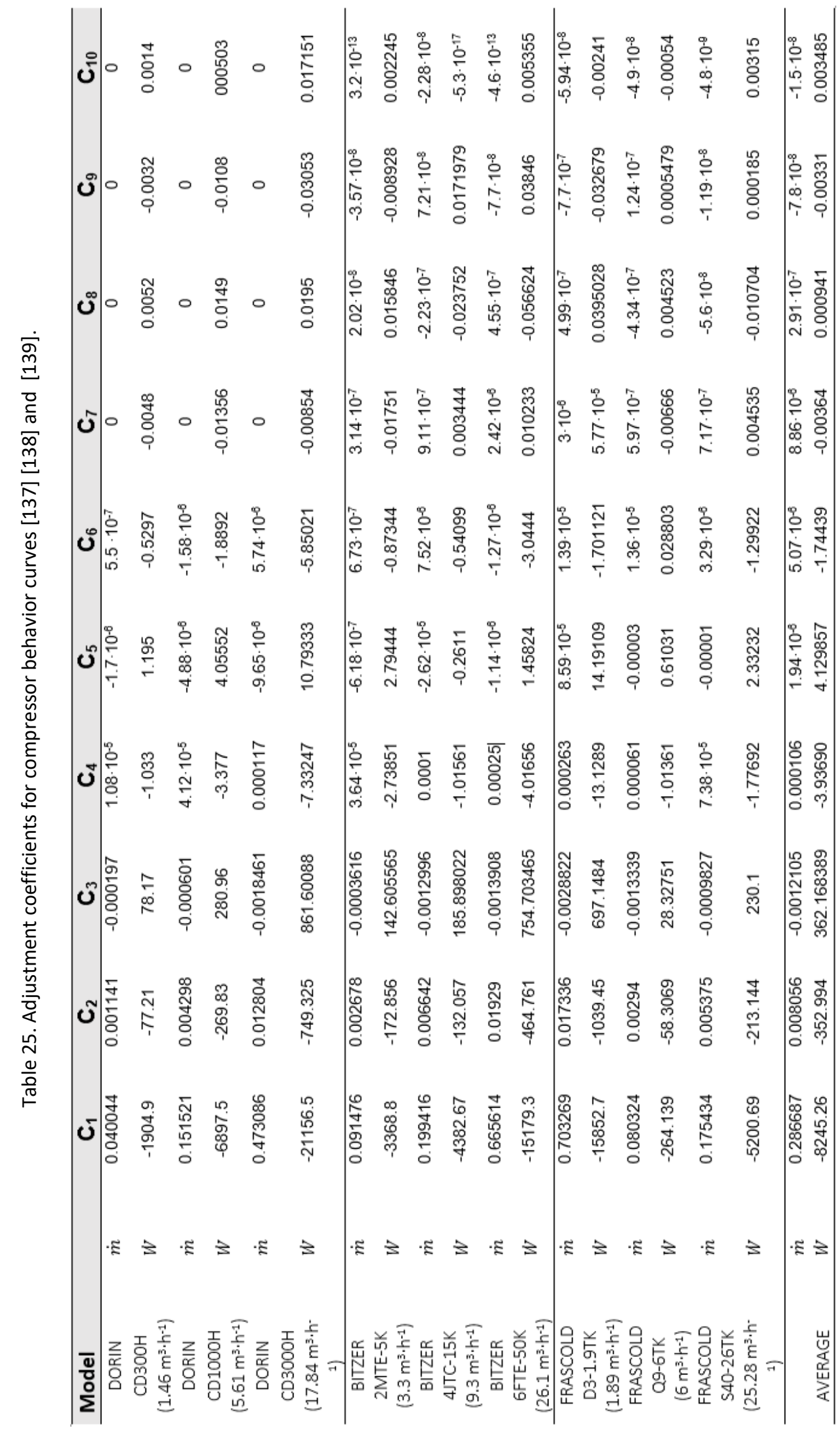



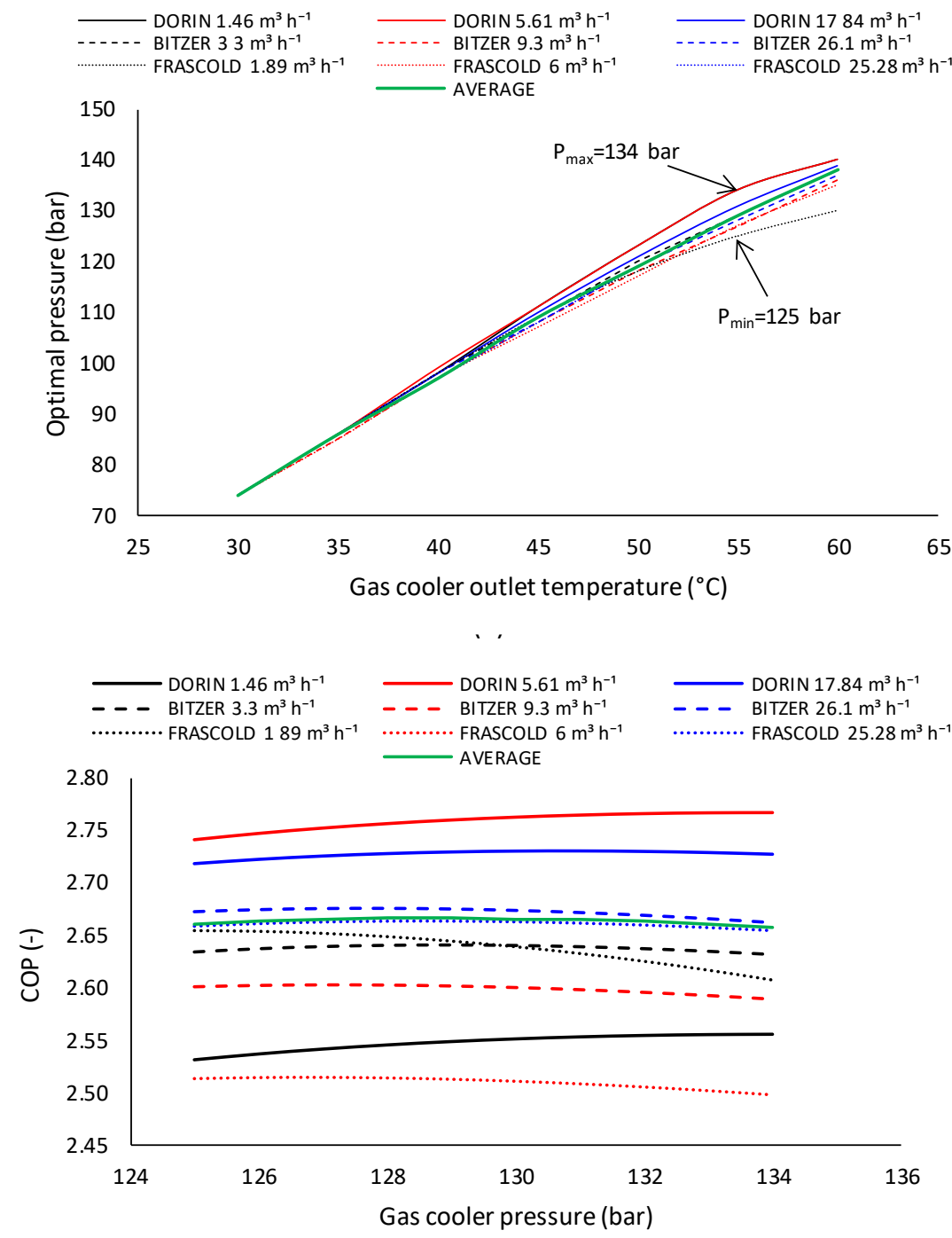

(b)

Fig. 66. Influence of compressor characteristics on system's behavior $\left(T_{\text {evap }}=5^{\circ} \mathrm{C}, S H=5 \mathrm{~K}, \eta_{\mathrm{IHX}}=0.7\right)$.

According to Fig. 66.a, the optimal pressure value given by the model is very similar for all the compressors studied, although the differences between different models increase as the gas cooler outlet temperature increases. The maximum difference is 9 bar at $55^{\circ} \mathrm{C}$ and $60^{\circ} \mathrm{C}$ (the maximum difference at $60{ }^{\circ} \mathrm{C}$ is not higher because the maximum pressure has been limited in the model to 140 bar). Although 9 bar is an important difference, as Fig. 66.b shows, in those conditions a difference of 9 bar in the gas cooler pressure has a weak influence on the system's COP. The variation in the COP within the analyzed pressure range is less than $2 \%$ in the worst case (Frascold compressor $1.89 \mathrm{~m}^{3} \cdot \mathrm{h}^{-1}$, dotted black line), while the maximum difference in COP between different models is less than $11 \%$. For this reason, in the final model adopted to obtain the optimal pressure expression, the compressor behavior has been modeled by using equations (29) and (30) and the adjustment coefficients obtained by averaging the coefficients provided by the manufacturers of the nine compressors analyzed. The results obtained in this case are those shown by the green solid lines (AVERAGE) in Fig. 66.a and Fig. 66.b. 
The differences found between the different compressors analyzed are clearly lower than those found by Zhang et al. [62] or Shao et al. [55]. Most of the expressions used by Zhang et al. [62] to characterize compressor efficiency were obtained by adjusting a few experimental data to very simple correlations, so its validity is limited to the experimental conditions tested. In the case of Shao et al. [55], the authors did not obtain the expression for the compressor efficiency from any previous work or any experimental adjustment, they just used a typical and simple correlation and vary the adjustment coefficient between two arbitrary values. On the contrary, the correlations employed in the present study are more complex and the adjustment coefficients have been directly obtained from the compressors' manufacturers. One might expect that these correlations, which come from a wider and updated database, are more adjusted to the current technological development of the compressors for $\mathrm{CO}_{2}$ and, therefore, are more capable to reproduce real compressor behavior.

\subsubsection{Influence of the IHX efficiency}

This section presents the influence that the IHX has on the optimal pressure. Fig. 67 shows the results provided by the model for an evaporation temperature of $10{ }^{\circ} \mathrm{C}$ and a superheating of $5 \mathrm{~K}$, varying the efficiency of the IHX between 0 (without IHX) and 0.9 .

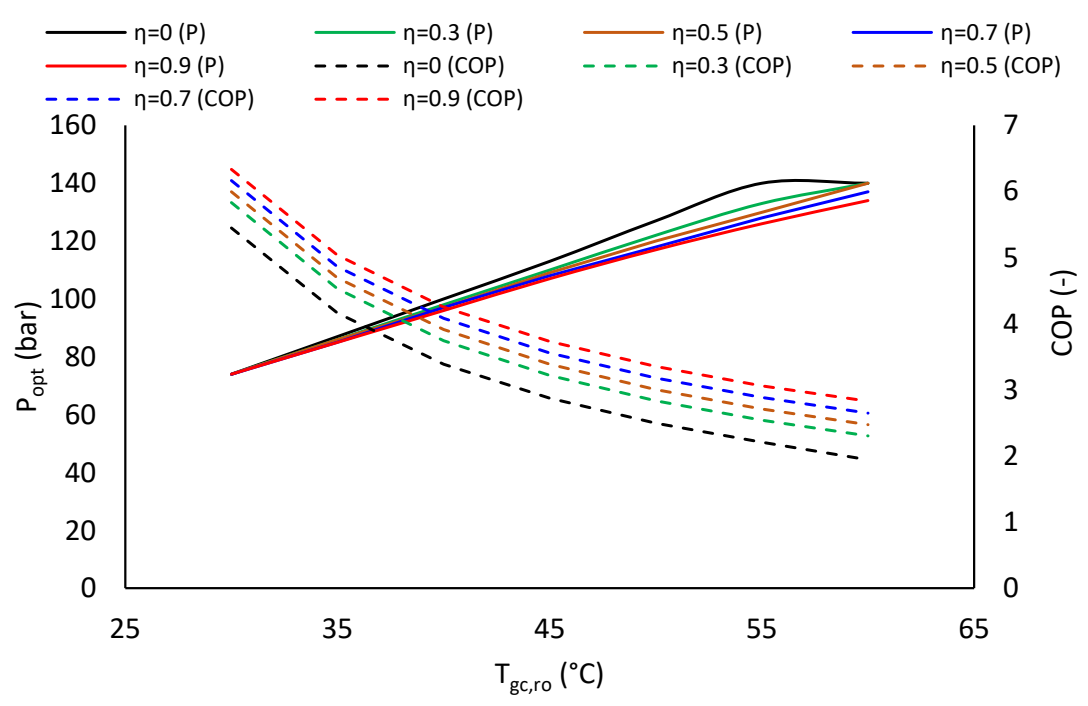

Fig. 67. Influence of IHX efficiency on system's behavior ( $T_{\text {evap }}=10^{\circ} \mathrm{C}, \mathrm{SH}=5 \mathrm{~K}$ ).

Black lines represent a facility that does not have an IHX, so this case should be analyzed independently from the rest. For systems including an IHX, the results show that its efficiency has an important influence on the COP (dashed lines) but a weak influence on the optimal pressure value (solid lines). The higher difference in optimal pressure has been obtained at a gas cooler outlet temperature of $55{ }^{\circ} \mathrm{C}$ (the maximum pressure is limited at 140 bar, which limits the differences at $60^{\circ} \mathrm{C}$ ), being the lower optimal pressure 126 bar for $\eta_{I H X}=0.9$ and the higher optimal pressure 134 
bar for $\eta_{1 H X}=0.3$. As previously discussed in section 4.4.3, a difference of 8 bar in gas cooler pressure has very low influence on the system's COP. For example, for $\eta_{1 H x}=0.5$, the difference between the maximum COP (2.677 at 131 bar) and the minimum COP ( 2.665 at 126 bar) is almost impossible to be experimentally seen. Those results are in line with previous works of Sarkar et al. [89], Chen \& Gu [53], and Shao et al. [55].

Although according to both, model results and the conclusions of previous works presented by Chen \& Gu [53], Torrella et al. [61], Cao et al. [56], (see Fig. 67), in most cases the use of an IHX improves system's efficiency, under certain operating conditions it can lead to very high compressor discharge temperatures and generate lubricating oil degradation [56,61]. For example, at an evaporation temperature of 5 ${ }^{\circ} \mathrm{C}$ with $5 \mathrm{~K}$ of superheating, gas cooler outlet temperature of $50{ }^{\circ} \mathrm{C}$ and $\mathrm{IHX}$ efficiency of 0.7 , the optimal pressure is 124 bar, the COP is 2.8 and the compressor discharge temperature is $145^{\circ} \mathrm{C}$. If under those conditions the IHX is bypassed, the optimal pressure increases to 131 bar. In that case, the COP decreases to 2.25 and the compressor discharge temperature decreases to $130^{\circ} \mathrm{C}$. Alternatively, the $\mathrm{IHX}$ can be kept and the discharge temperature can be reduced by making the system work under not optimal gas cooler pressure. By decreasing gas cooler pressure to 108 bar, the compressor discharge temperature also drops to $130{ }^{\circ} \mathrm{C}$, but the COP is 2.64 , lower than operating at optimal gas cooler pressure but higher than bypassing the $\mathrm{IHX}$. Therefore, even in those cases where the use of an IHX can lead to excessive compressor discharge temperature, it is preferable to keep the IHX and act on the gas cooler pressure regulation valve to reduce gas cooler pressure and thus compressor discharge temperature.

\subsubsection{Influence of the liquid receiver}

In the first part of this chapter, the influence that the liquid receiver pressure has on the COP is analyzed for a specific high pressure and without IHX. In this study, the liquid receiver pressure is tested for its highest and lowest value at different optimal pressures, and using the IHX.

Liquid receiver pressure can be controlled by acting on the bypass valve BPV-2, presented in Fig. 4 and Fig. 36.a (C1). Fig. 68 shows how that pressure affects optimal pressure and system's efficiency for evaporation temperatures of 5 and $15{ }^{\circ} \mathrm{C}$, gas cooler outlet temperatures of 35 and $45^{\circ} \mathrm{C}$ and IHX efficiencies of 0.3 and 0.7 . In all cases studied, the influence of the liquid receiver pressure is very weak, being even weaker as the IHX efficiency increases and almost independent of the other parameters. According to the model results, although the optimal pressure increases as the liquid receiver pressure increases, its influence on the system's COP is practically negligible.

The dashed red line in Fig. 68 corresponds to an evaporation temperature of $5{ }^{\circ} \mathrm{C}$, a gas cooler outlet temperature of $45^{\circ} \mathrm{C}$, an IHX efficiency of 0.3 and a superheating of $5 \mathrm{~K}$. According to the model, for a liquid receiver pressure of $40 \mathrm{bar}$, near to the 
evaporation pressure, the optimal pressure is 115 bar and the COP is 2.69. As the receiver pressure increases, the COP tends to decrease and the optimal pressure tends to increase, until the COP reaches its minimum value (2.635) at a liquid receiver pressure of 61.2 bar, being the optimal pressure 120 bar. From that receiver pressure on, the COP begins to increase slightly, and the optimal pressure continues increasing until reaching its maximum value (125 bar) at a receiver pressure of 70.5 bar, being the COP 2.71. At this point, the situation corresponds to that one shown in Fig. 69 . The refrigerant enters in the liquid receiver as saturated liquid, the liquid receiver pressure has reached its maximum value and there is no gas flow through the gas bypass.

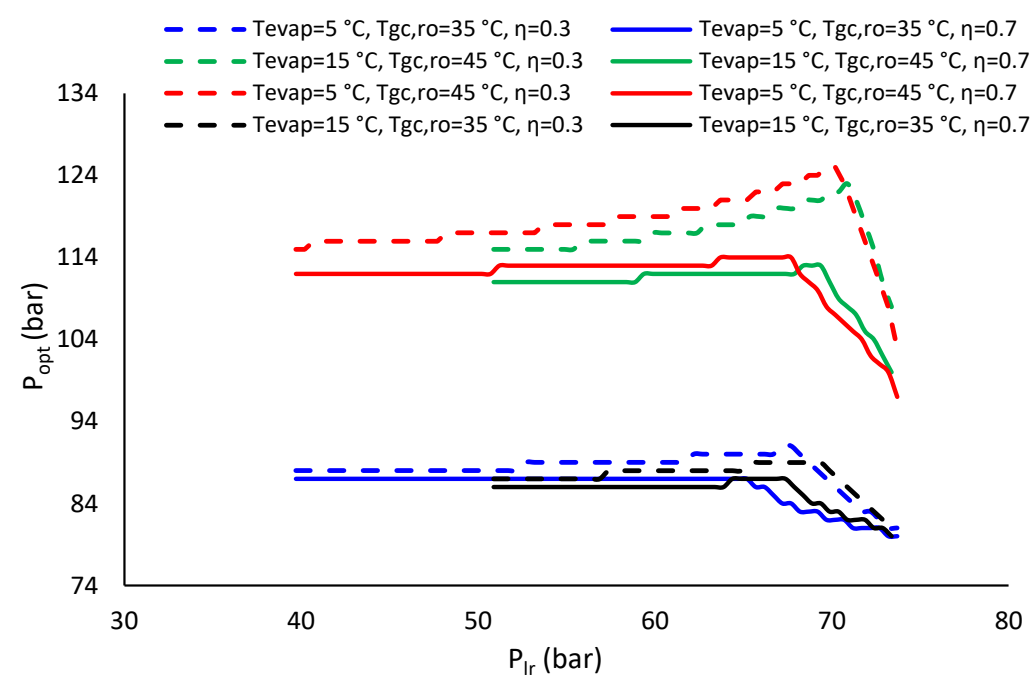

(a)

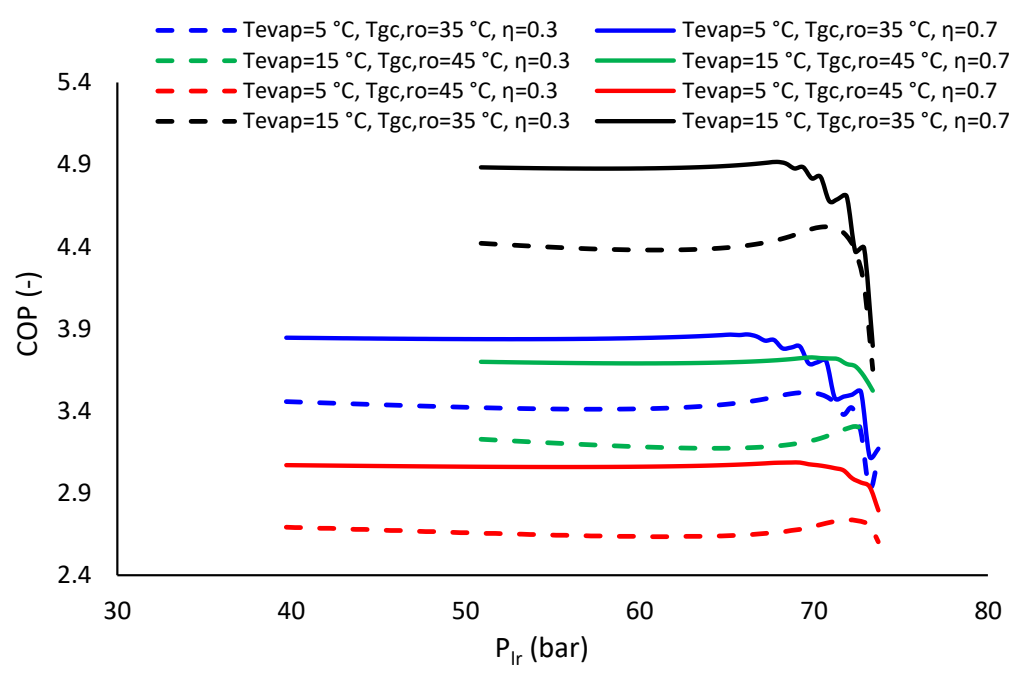

(b)

Fig. 68. Influence of liquid receiver pressure on system's performance ( $\mathrm{SH}=5 \mathrm{~K}$ ).

From that point on, the liquid receiver pressure only can increase if the gas cooler pressure decreases. That explains the decrease in gas cooler optimal pressure shown in Fig. 68.a when the receiver pressure increases beyond 70.5 bar. The COP reaches 
its maximum value (2.735) at a receiver pressure of 72.2 bar and a gas cooler pressure of 114 bar. If the liquid receiver pressure increases beyond this value both, the COP and the optimal pressure begin to decrease.

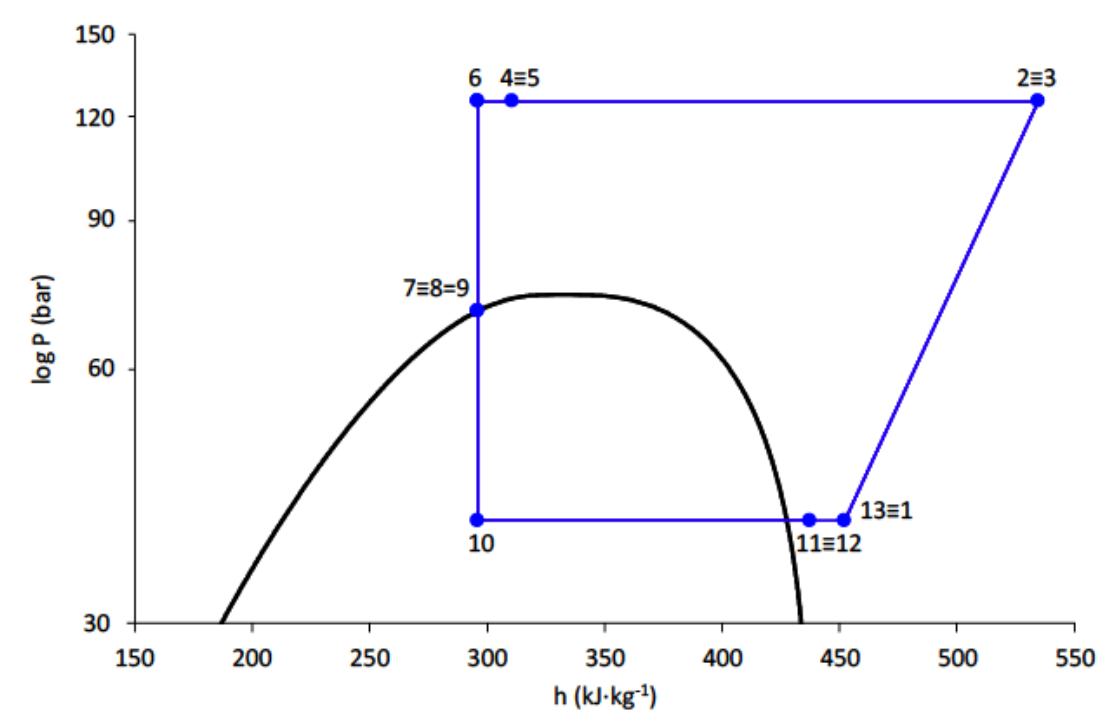

Fig. 69. P-h diagram $\left(T_{\text {evap }}=5^{\circ} \mathrm{C}, T_{g c, r o}=45^{\circ} \mathrm{C}, S H=5 \mathrm{~K}, \eta_{l H X}=0.3, P_{g c}=125 \mathrm{bar}, P_{l r}=70.5 \mathrm{bar}\right)$.

The same behavior is found in all operating conditions analyzed. Liquid receiver pressure only seems to have an appreciable influence at very low IHX efficiencies and very high receiver pressures, near to the critical point. Both conditions are not usual in practical terms.

The first conclusion that can be drawn from the previous analysis is that the optimal operating conditions are obtained by closing the gas bypass. Therefore, the use of a gas bypass only is justified in those cases when the liquid receiver is used as a method to reduce the pressure in the lines that distribute liquid to the evaporators. In those cases, since the influence of the receiver pressure on the system's efficiency is very low, that pressure should be kept as low as possible.

Despite the previous discussion, in some cases designers decide not to include IHX in their transcritical $\mathrm{CO}_{2}$ systems. In those cases, liquid receiver pressure could have an important influence on system's behavior under certain operating conditions. Fig. 70 illustrates one of those situations. Fig. 70.a corresponds to an extreme case in which the receiver pressure matches the evaporation pressure. In that case, the entire refrigerant passes through the evaporator, so the superheating at compressor suction is $5 \mathrm{~K}$ and the COP is 2.25 . 


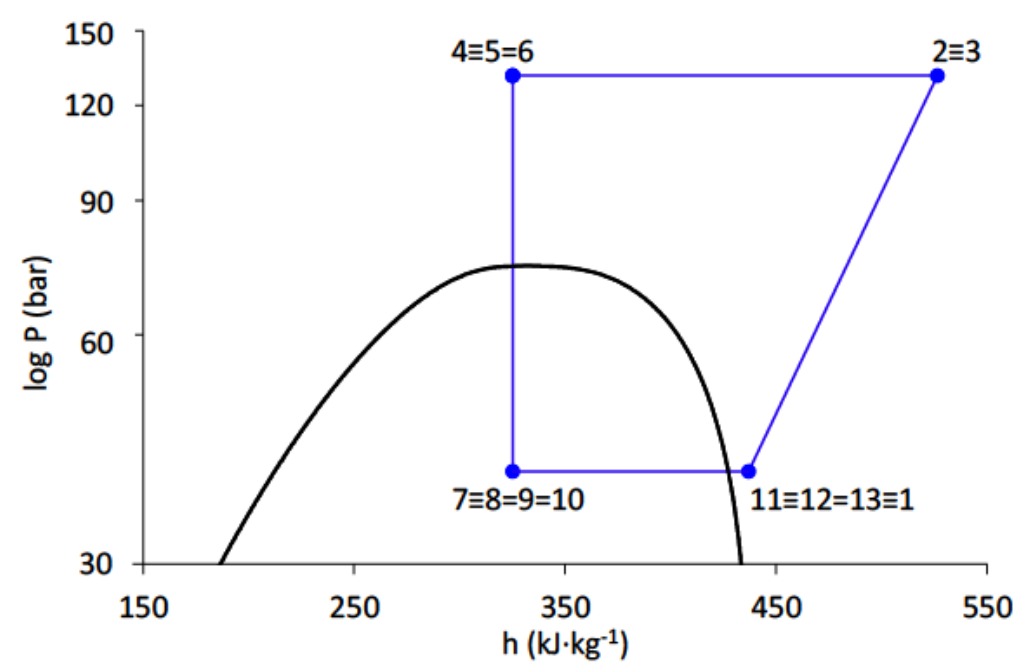

(a)

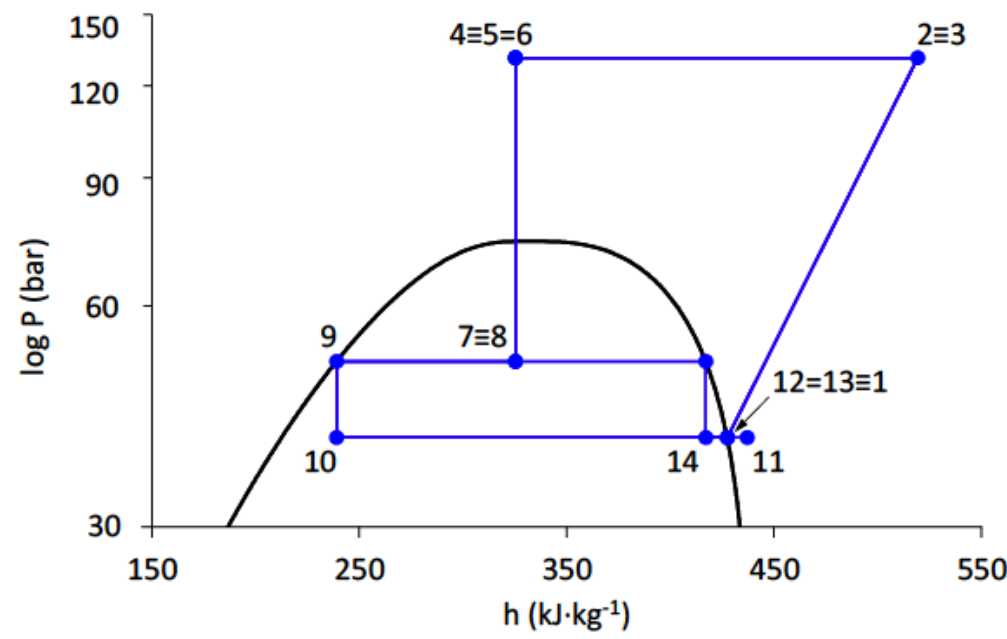

(b)

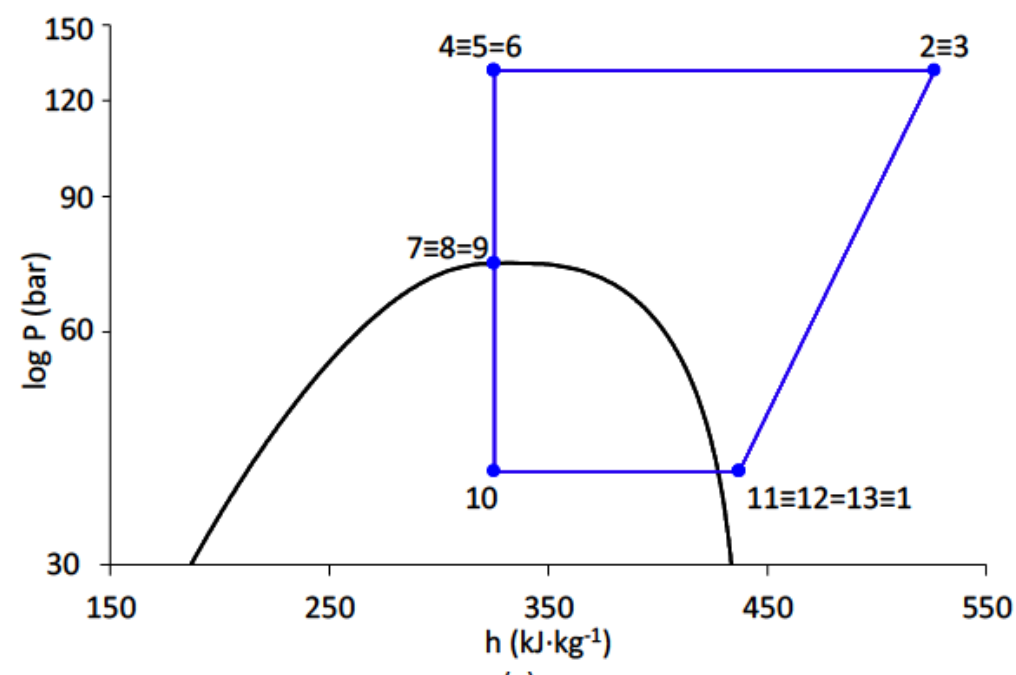

(c)

Fig. 70. P-h diagram ( $\eta_{I H \mathrm{X}}=0, T_{\text {evap }}=5^{\circ} \mathrm{C}, T_{g c, r o}=50^{\circ} \mathrm{C}, S H=5 \mathrm{~K}, P_{g c}=131$ bar). 
Fig. 70.b corresponds to the intermediate situation reached when the receiver pressure begins to increase. The receiver operates at an intermediate pressure, part of the refrigerant leaves the receiver through the gas bypass as saturated vapor and the rest enters at the expansion valve as saturated liquid (9). The bypassed gas leaves the bypass valve (BPV-2) as biphasic fluid (14) and mixes with the superheated vapor leaving the evaporator (11), so the superheating at compressor suction decreases. Fig. 70.b corresponds to a situation at which the receiver pressure is 50.52 bar, the mixing between (14) and (11) produces saturated vapor so there is no superheated at compressor suction (1) and the COP is 2.11 .

If the receiver pressure increases beyond 50.52 bar, the mixing point (12) enters in biphasic fluid conditions, which could cause malfunctioning of the compressor. That situation remains until the gas bypass is almost completely closed. When the bypass is closed (Fig. 70.C), the entire refrigerant passes through the evaporator and the situation is equivalent to that one shown in Fig. 70.a, the superheating at compressor suction is $5 \mathrm{~K}$ and the COP is 2.25 again.

Although, theoretically, the pressure in the storage tank is controlled by the gas bypass valve (BPV-2 in Fig. 36.a), its actual value depends on the vapor quality inside the liquid receiver, that is, it depends on the volume of the receiver and the mass of refrigerant it contains. Since the total amount of refrigerant is a fixed value, the mass contained in the receiver is the difference between the total amount of refrigerant and the mass of refrigerant contained in each of the facility's components. A change in receiver pressure only affects significantly to the evaporator, so the pressure actually reached in the receiver will mainly depend on the mass equilibrium between evaporator and receiver.

If the gas bypass valve closes, the pressure in the receiver tends to increase, that is, the mass contained in the receiver increases, and the vapor quality at evaporator inlet increases, so the mass of refrigerant contained in the evaporator decreases. The pressure in the receiver is that at which the increase of mass in the receiver equals the decrease of mass in the evaporator. Therefore, even if the gas bypass valve has a theoretical wide operation range, its practical operation range will depend on the receiver and evaporator volume, as well as the operating conditions. On the one hand, since there is an expansion valve between the liquid receiver and the evaporator, the receiver minimum pressure will always be higher than the evaporation pressure, so the situation presented in Fig. 70.a will never occur. On the other hand, although the situation presented in Fig. 70.c can be reached easily by closing the gas bypass valve, the actual pressure in the receiver will depend on the mass equilibrium previously cited and the vapor quality inside the receiver.

If the aim of the gas bypass is to reduce the pressure in the lines that distribute liquid to the evaporators, the receiver must have enough volume to assure that the vapor quality inside the receiver is high enough to maintain its pressure at low levels. 
Results provided by the model show that liquid receiver pressure has a clear influence on the fluid properties in the mixing point downstream the evaporator (12). If the system does not have an IHX, that point is going to be the same as the compressor suction and therefore the receiver pressure could affect the system's performance and even produce liquid suction by the compressor. If the system is equipped with an IHX, the superheating that occurs in that IHX, will normally minimize the influence of the liquid receiver pressure.

\subsubsection{Influence of the evaporation temperature}

Fig. 71 shows the influence of the evaporation temperature obtained with the model and compared to a few experimental data. Both, experimental and numerical results show that, similar to what happened with the IHX efficiency, the evaporation temperature has a relative important influence on the system's COP but very weak influence on the optimal pressure, even weaker than the influence of the IHX efficiency. Although this is in good agreement with most previous works presented by Sarkar et al [89], Chen \& Gu [53], Zhang et al. [62] and others, the results obtained by Shao et al. [55], show a higher variation in optimal pressure when varying the evaporation temperature.

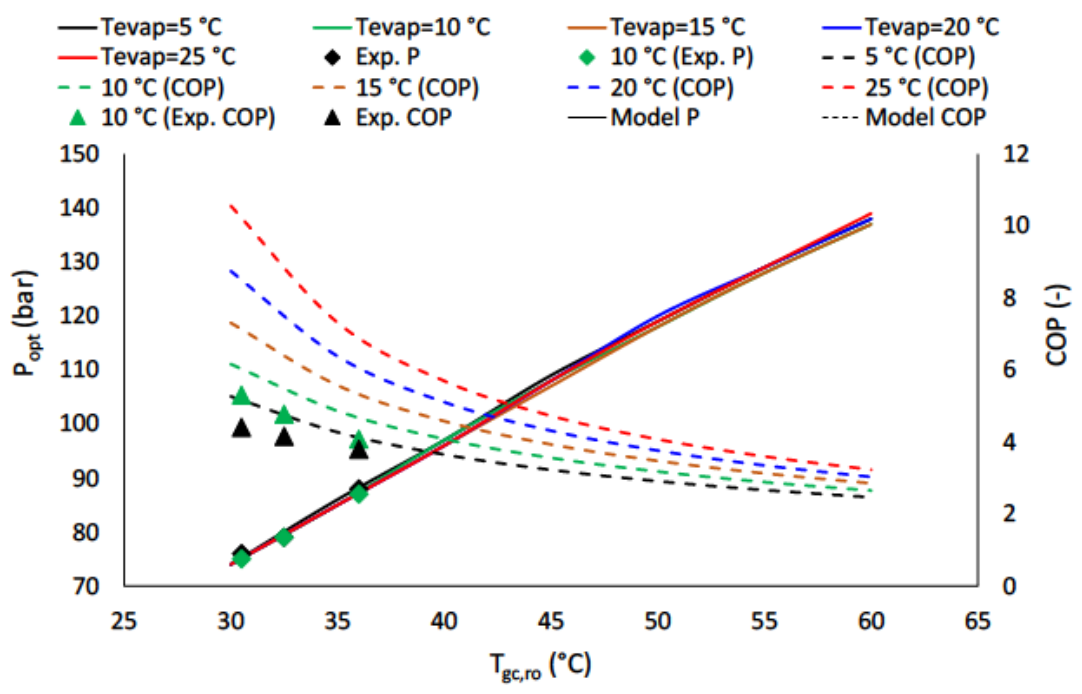

Fig. 71. Influence of evaporation temperature on system's behavior $\left(\mathrm{SH}=5 \mathrm{~K}, \eta_{\Perp H X}=0.7\right)$.

As green and black dashed lines show, the model provides higher COP values than those experimentally measured. That can be explained because the model finally adopted for the compressor is an average of nine different commercial compressors, instead of a model specifically developed for the compressor employed. When equations (31) and (32), specifically obtained for the compressor tested, are introduced in the MATLAB ${ }^{\circledR}$ model, the differences between predicted and experimentally measured values of COP are always lower than $8 \%$. 


\subsubsection{Influence of the superheating}

The results provided by the model for an evaporation temperature of $10^{\circ} \mathrm{C}$ and an IHX efficiency of 0.7 are shown in Fig. 72 . According to the model, the influence of the superheating in both, optimal pressure and system's COP is negligible. The conclusions are the same at any operating conditions which, as far as the authors' knowledge, is in good agreement with all previous works.

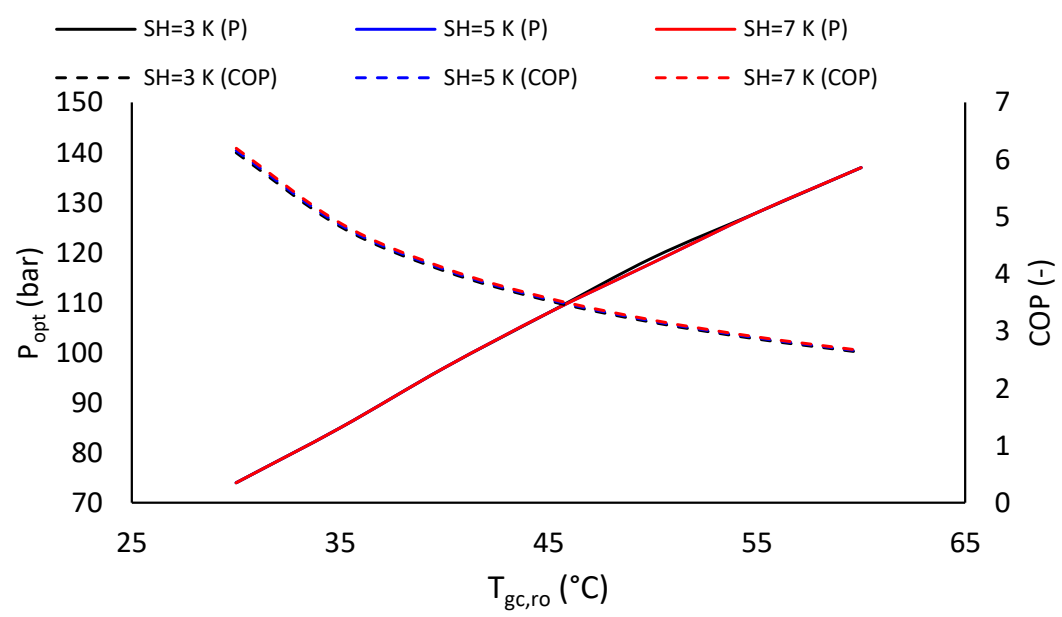

Fig. 72. Influence of superheating on system's behavior $\left(T_{\text {evap }}=10^{\circ} \mathrm{C}, \eta_{1 H x}=0.7\right)$.

\subsubsection{Correlations for optimal heat rejection pressure control}

As shown in previous sections, only the gas cooler outlet temperature has a decisive influence on the optimal pressure value. The evaporation temperature has a limited influence and the influence of the superheating degree is practically negligible. The IHX efficiency has a relatively important influence, but the user cannot act on this parameter. The IHX should be selected to obtain a high efficiency under nominal operating conditions and, as long as the system operates under normal conditions, the IHX efficiency should be similar to that obtained at nominal conditions. Additionally, an approximate determination of IHX efficiency (based on temperature variations instead of enthalpy variations), requires the use of four temperature probes. Therefore, for control purposes, it does not make much sense to obtain a correlation for the optimal pressure based on the IHX efficiency. So, as a first option, a simple correlation for the optimal pressure is proposed:

$$
P_{g c, o p t}=\min \left(140 ; 9.3267+2.1857 \cdot T_{g c, r o}\right)
$$

Fig. 73 shows the fit between correlation (35) and the results directly obtained using the model developed in MATLAB $^{\circledR}$. In general, the adjustment between the correlation and the model is quite good, however, as the gas cooler outlet temperature increases, this adjustment worsens. At outlet temperatures between 50 and $55{ }^{\circ} \mathrm{C}$, the differences between the model and the correlation can reach maximum values around 10 bar, although as it has been seen, such differences have 
very low influence on system's COP. At $60{ }^{\circ} \mathrm{C}$ these differences are smaller because both the model and the correlation limit the maximum pressure to 140 bar.

The main drawback of this adjustment is that, as can be seen in Fig. 73, both the model and the adjustment can lead to situations in which the temperature at compressor discharge reaches very high values, close to $170{ }^{\circ} \mathrm{C}$, which could produce lubricating oil degradation.

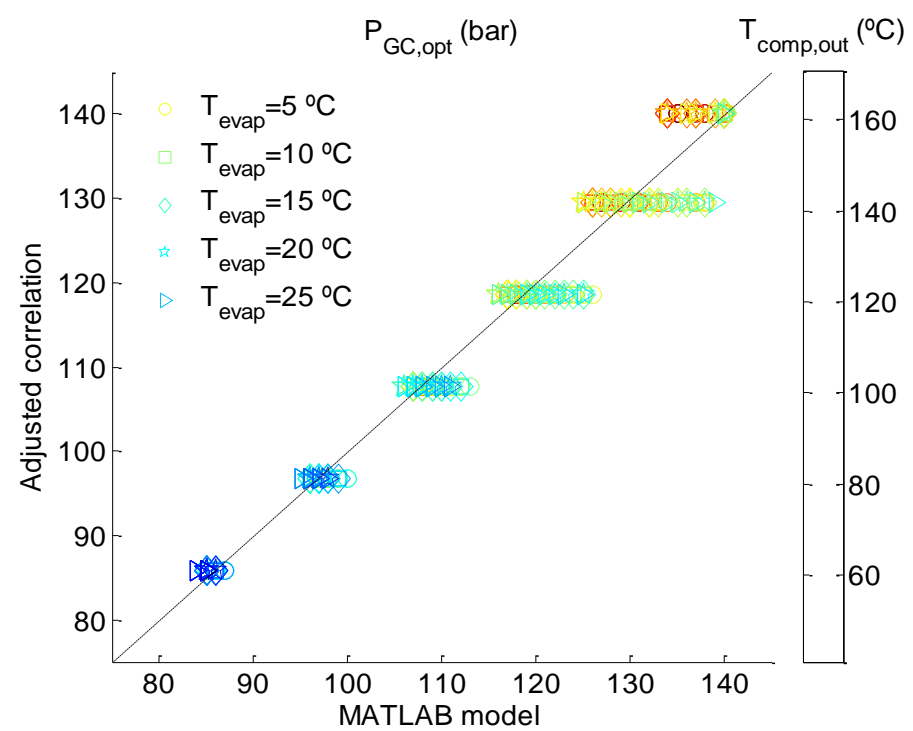

Fig. 73. Fit between numerical model and proposed correlation (35) without limiting the compressor discharge temperature $\left(T_{\text {evap }}=5-25^{\circ} \mathrm{C}, \mathrm{SH}=3-7 \mathrm{~K}, \eta_{1 \mathrm{HX}}=0-0.9, T_{g c, r o}=30-60^{\circ} \mathrm{C}\right)$.

The compressor discharge temperature depends, apart from its isentropic efficiency, on its suction temperature, the evaporation temperature (or pressure) and the discharge pressure. So, in order to limit the maximum compressor discharge temperature to $140^{\circ} \mathrm{C}$, a correlation based only on the gas cooler outlet temperature provides a poor fit with the model being necessary to take into account other variables.

When the system operates at optimal gas cooler pressure, the compressor discharge temperature can be correlated to the compressor suction temperature, the evaporation temperature and the gas cooler outlet temperature:

$$
T_{\text {comp }, \text { out }}=13.403+2.0657 \cdot T_{g c, r o}-2.3525 \cdot T_{\text {evap }}+0.86806 \cdot T_{\text {comp }, \text { in }}
$$

Where compressor suction temperature can be directly measured by a temperature probe, so it becomes unnecessary to measure the superheating degree or to estimate the IHX efficiency.

Two different correlations for the optimal pressure should be used depending on the value obtained from equation (36):

If $T_{\text {comp,out }}<140^{\circ} \mathrm{C}$ : 


$$
P_{g c, o p t}=\min \left(140 ; 11.047+2.2756 \cdot T_{g c, r o}+0.047279 \cdot T_{\text {evap }}-0.20814 \cdot T_{\text {comp }, \text { in }}\right)
$$

If $T_{\text {com,out }} \geq 140^{\circ} \mathrm{C}$ :

$$
P_{g c, o p t}=\min \left(140 ; 140.74+0.031555 \cdot T_{g c, r o}+2.7227 \cdot T_{\text {evap }}-1.0086 \cdot T_{\text {comp }, \text { in }}\right)
$$

Fig. 74 shows the fit between correlations (36) to (38) and the results obtained limiting the maximum compressor discharge temperature to $140{ }^{\circ} \mathrm{C}$ in the model developed in $M A T L A B^{\circledR}$. In this case, the compressor discharge temperature never exceeds $140{ }^{\circ} \mathrm{C}$, and there is a very good fit between the model and the adjusted correlations, with maximum deviations below 8.5 bar in the entire analyzed range.

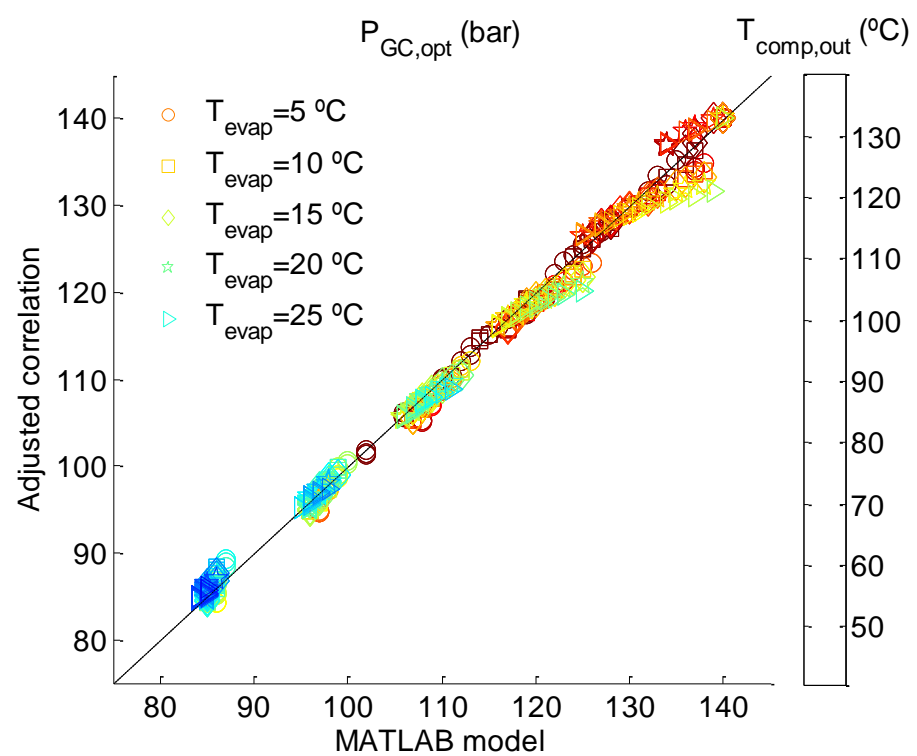

Fig. 74. Fit between numerical model limiting the compressor discharge temperature to $140{ }^{\circ} \mathrm{C}$ and correlations (36) to (38) proposed ( $T_{\text {evap }}=5-25^{\circ} \mathrm{C}, \mathrm{SH}=3-7 \mathrm{~K}, \eta_{1 \mathrm{HX}}=0-0.9, T_{g c, \text { ro }}=30-60{ }^{\circ} \mathrm{C}$ ).

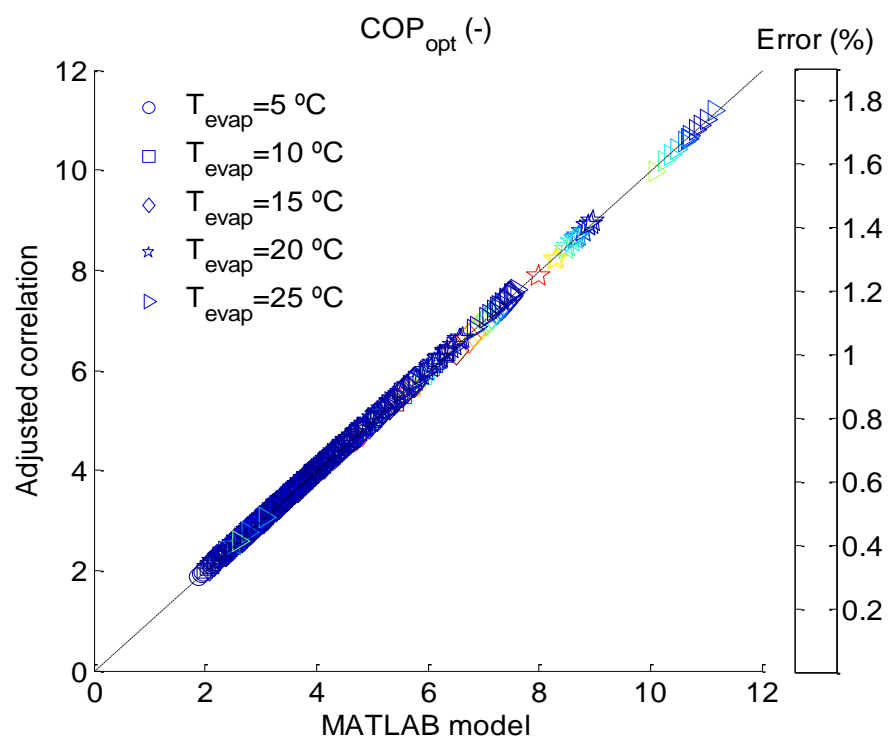

Fig. 75. Fit between the COP calculated by using the optimal pressure provided by the MATLAB ${ }^{\circledR}$ model and the pressure obtained using equations (36) to (38). 
As previously discussed, deviations of 8.5 bar from the optimal pressure value have a very low influence on the system's COP. Fig. 75 shows the deviation between the COP values calculated with the MATLAB ${ }^{\circledR}$ model under optimal pressure conditions and those calculated by using the same MATLAB ${ }^{\circledR}$ model, but with the optimal pressure values obtained with equations (36) to (38). In the entire range studied, the deviation is less than $2 \%$.

Fig. 76 shows a comparison for the optimal pressure calculated by using the model proposed in this work and some models proposed by previous authors. Up to a gas cooler outlet temperature of $49^{\circ} \mathrm{C}$, the results obtained using the proposed model are very similar to those obtained using Shao et al. [55] constrained model, but from $49{ }^{\circ} \mathrm{C}$ Shao's model clearly provides lower pressure values. Something similar occurs with the model proposed by Zhang et al. [62], although, in this case, since Zhang's model does not limit the pressure, it gives almost the same values up to $53^{\circ} \mathrm{C}$, but, from that temperature, Zhang's model clearly provides higher optimal pressure values. The models proposed by Qi et al. [93] and Sarkar et al. [89] are limited to a maximum gas cooler outlet temperature of $45^{\circ} \mathrm{C}$ and $50{ }^{\circ} \mathrm{C}$ respectively; within those limits, they provide very similar values to the model proposed in this work. The model proposed by Chen \& Gu [53] and the unconstrained model proposed by Shao et al. [55] provide very similar values, but clearly higher than those obtained using the model proposed in this work. Finally, the model proposed by Kauf [87] gives optimal pressure values between those given by Zhang's model and those given by the model proposed by Chen \& Gu or the unconstrained model proposed by Shao.

$$
\begin{array}{lll}
\text { - - Kauf } & \text { - Sarkar et al. } & \text { - Chen\&Gu } \\
\text { - Qi et al. } & \text { - Zhang et al. } & - \text { Shao et al. (constrained) } \\
\text { - - Shao et al. (unconstrained) } & \text { - Proposed model } &
\end{array}
$$

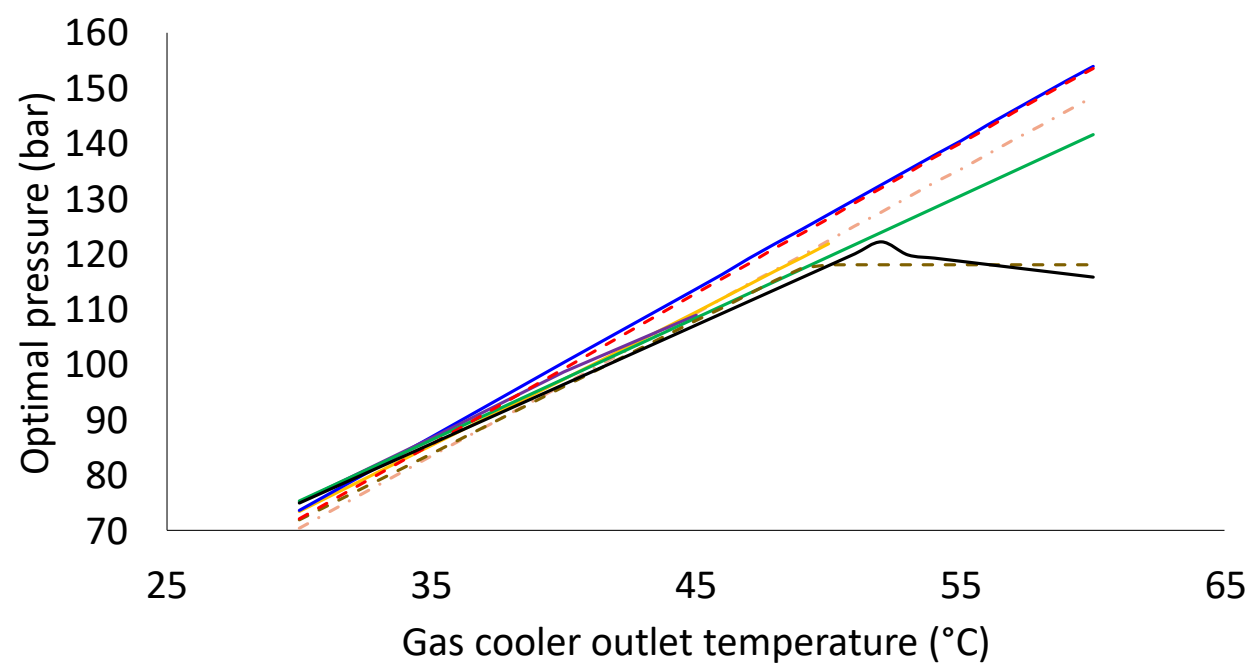

Fig. 76. Comparison between the proposed model and previous models $\left(T_{\text {evap }}=5{ }^{\circ} \mathrm{C}, \mathrm{SH}=5 \mathrm{~K}\right.$, $\eta_{1 H X}=0.6$.) 


\subsection{Space heating application, experimental and numerical results}

This section presents the results corresponding to the cases in which the heat pump is used to provide hot water for space heating, including comparisons of the different configurations, experimental validation of the model and a sensitivity study about varying the HXs surfaces.

\subsubsection{Model validation for the experimental and numerical study}

Fig. 77 presents the model validation with the experimental results. The numerical model used in this section is the one previously presented in the optimal pressure study. The experiments carried out in the installation have been numerically modeled. Fig. 77 compares the values of gas cooler heating capacity $\left(Q_{g c}\right)$, compressor work $\left(\dot{W}_{\text {comp }}\right)$, refrigerant mass flow rate $\left(\dot{m}_{r}\right)$, evaporator cooling capacity $\left(Q_{\text {evap }}\right)$, IHX heating capacity $\left(Q_{I H X}\right)$, and COP. As it is seen, in general, in most cases, the variation between the model and the experimental results is for about \pm $10 \%$.
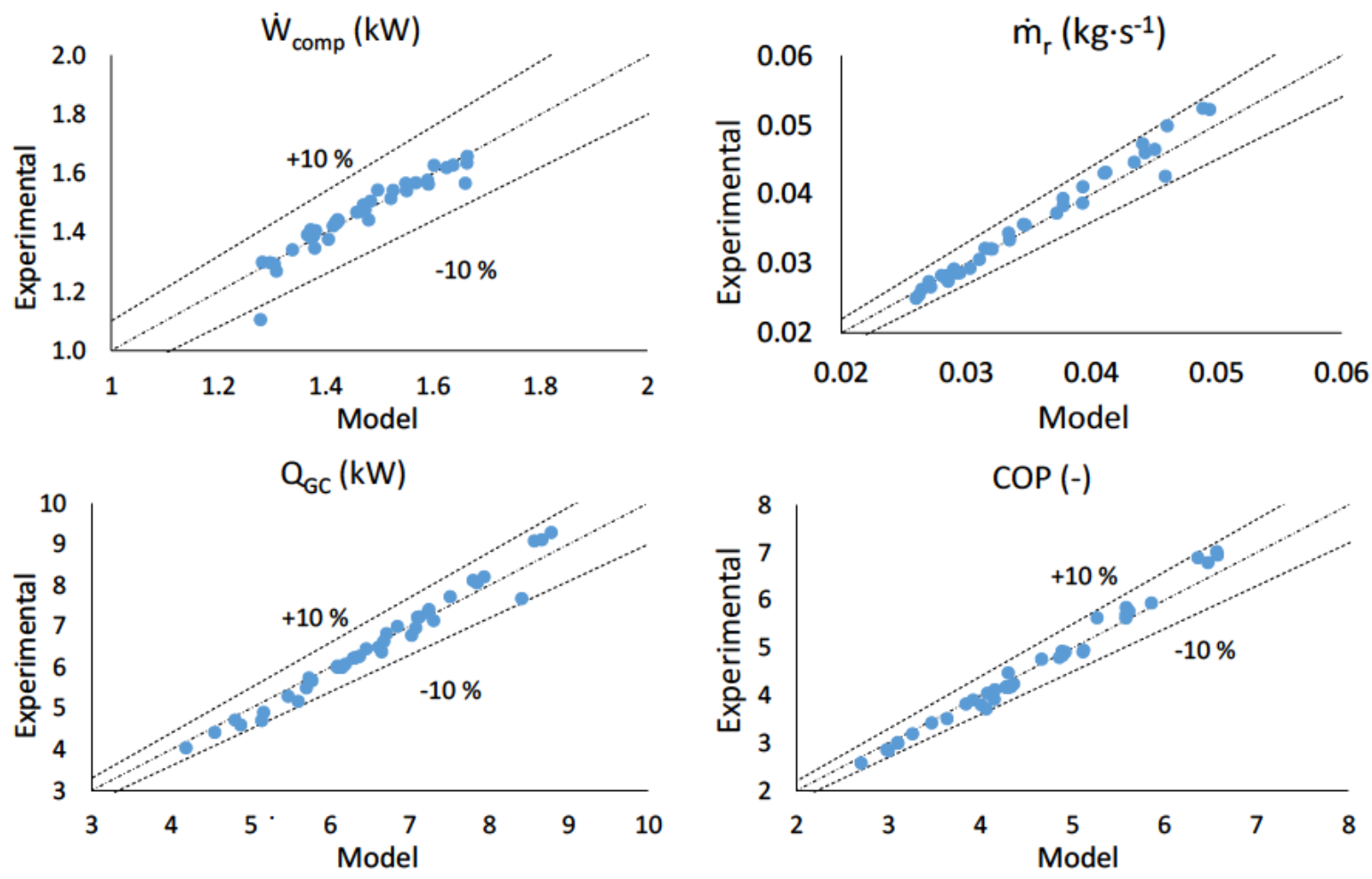

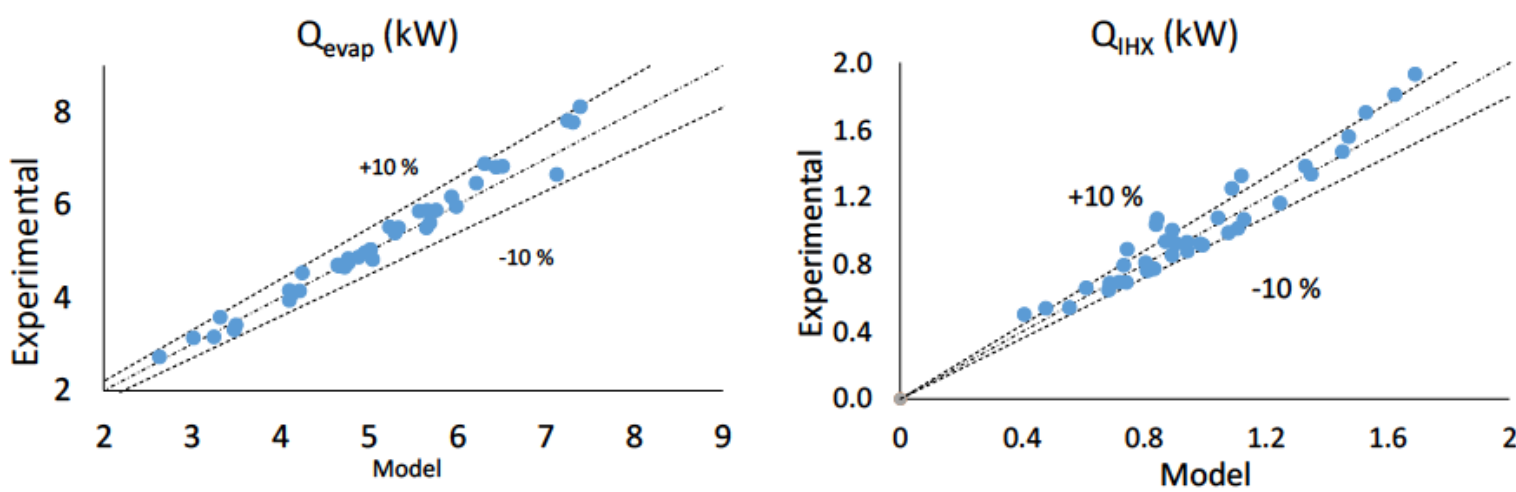

Fig. 77. Model validation.

\subsubsection{Optimal pressure in this facility and tests conditions}

To study the influence of the optimal pressure on the cycle performance, the COP and the discharge temperature are presented in Fig. 78.

The solid lines represent the COP evolution when increasing the high pressure for different water temperature at the gas cooler. The dashed lines correspond to the refrigerant temperature at the compressor outlet.

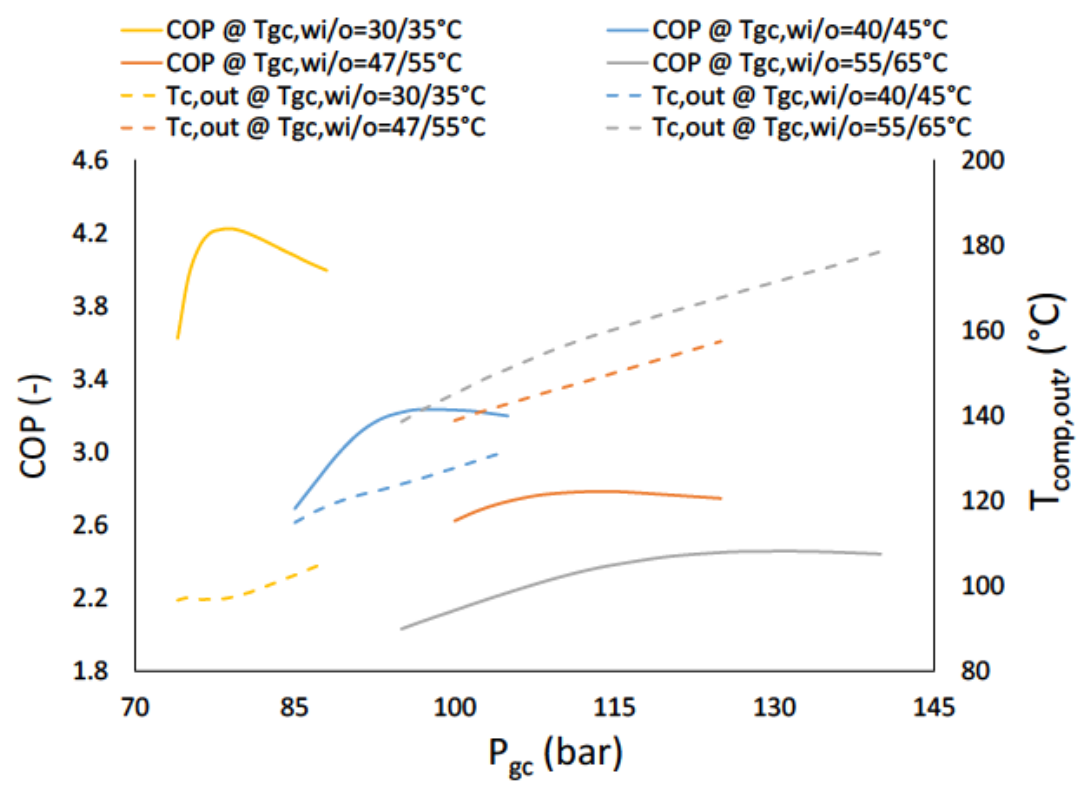

Fig. 78. COP and compressor outlet temperature according to the high pressure and water temperature.

Fig. 79 shows the influence that the water temperature in the evaporator has in the optimal pressure for the different hot water generation conditions, according to the model and limiting the refrigerant temperature out of the compressor to $140^{\circ} \mathrm{C}$.

As is seen, when the hot water temperature increases, the optimal pressure increases, resulting in high optimal pressure values for high water temperature setpoints. Then, for hot water temperature production at $55 / 65^{\circ} \mathrm{C}$, the optimal 
pressure goes around $130+$ bar, very closed to the compressor maximum working pressure, and a very high refrigerant discharge temperature $\left(175^{\circ} \mathrm{C}\right)$.

According to Fig. 79 , at $30 / 35^{\circ} \mathrm{C}$ hot water, the optimal pressure is almost constant for the evaporator water studied range. Another aspect that can be noticed is that when the system is working near the optimal pressure, is better to be a little bit above the optimal pressure than below.

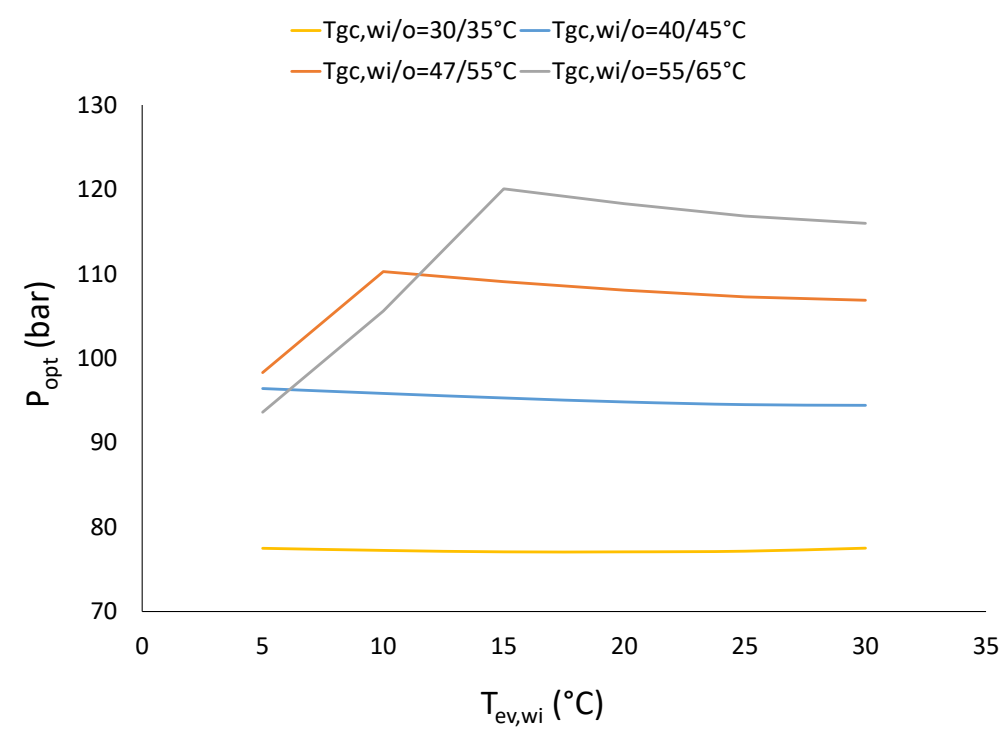

Fig. 79. Optimal pressure according to the evaporator water temperature for specific $T_{g c \text {,wi/o }}$ conditions.

\subsubsection{Seeking the optimal pressure manually}

The optimal pressure correlation is programmed in LabVIEW with the objective of calculating the optimal pressure at every instant measurement performed by the datalogger. After calculating the instant optimal pressure, the setpoint is modified in the control software (VPM) to produce the required optimal pressure for the instant conditions.

Fig. 80 shows how the optimal pressure is sought in the system. The instant optimal pressure is calculated in every 20 seconds measurement, and, according to the resulting optimal pressure, the high pressure setpoint is manually modified.

Something important to keep in mind when modifying the optimal pressure setpoint manually, is that, when the difference between the instant pressure and the optimal pressure is calculated, that is not the exact value that is going to be added or reduced to the previous setpoint, i.e.: for Fig. 80.a, the difference between the instant optimal pressure ( 76.5 bar) and the real gas cooler pressure ( 80 bar) is 3.5 bar, and, when the setpoint is reduced in 3.5 bar, the optimal pressure increased, but both meet at (79 bar). Then, for the next instant optimal pressure calculated (Fig. 80.b and Fig. 80.c), the setpoint is only modified in $30 \%$ of the difference between the real gas cooler pressure and the instant optimal pressure. When a PID control is used to read the 
optimal pressure and modify the setpoint, the system will do that correction automatically.

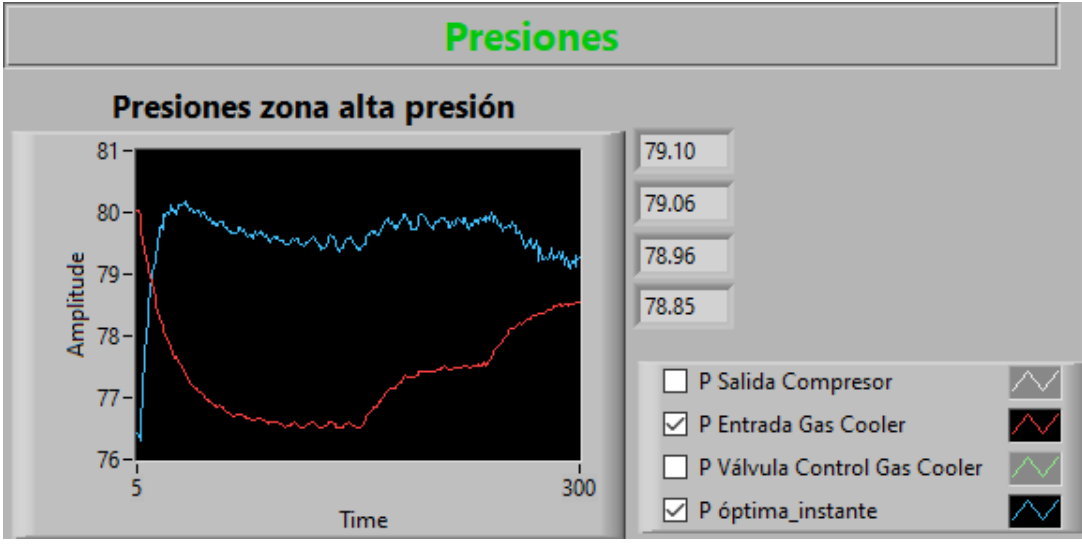

(a) Seeking the optimal pressure

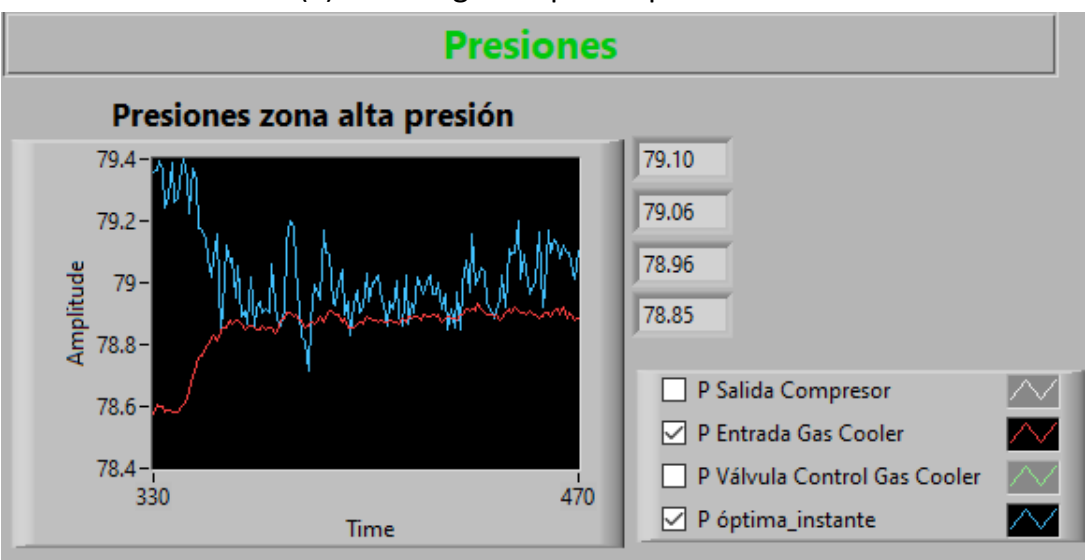

(b) Around the optimal pressure

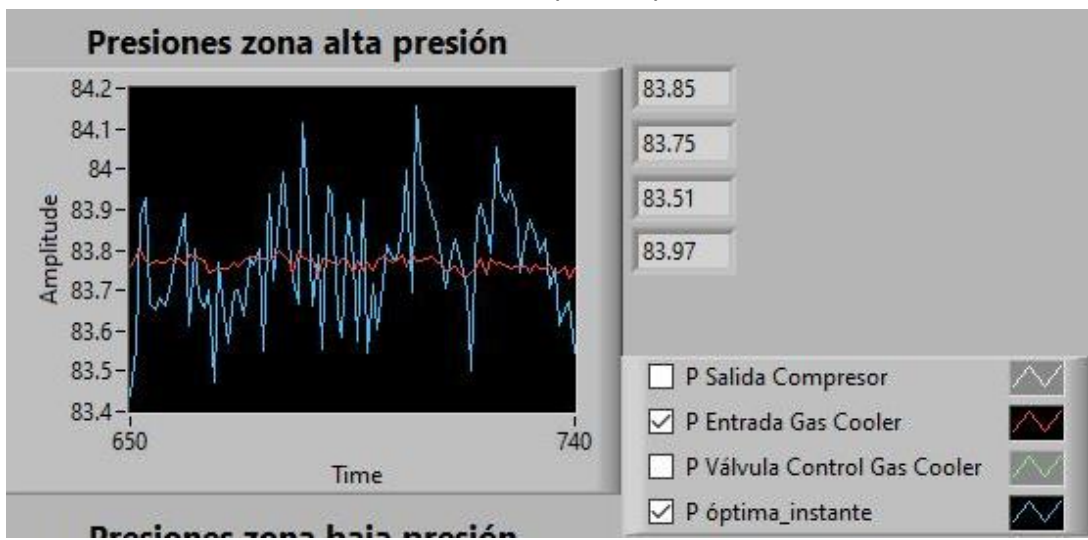

(c) Working on the optimal pressure

Fig. 80. Seeking the optimal pressure in the system. 


\subsubsection{Experimental and numerical comparison of the different configurations}

This section presents the results for the different cycles studied in the $\mathrm{CO}_{2}$ facility. Furthermore, the influence of different variables is presented, such as the evaporator water temperature and the superheating.

\subsubsection{Configuration $1 \& 2$ ( $C 1 \& C 2)$, experimental results}

As explained before, $\mathrm{C} 2$ is a particular case of $\mathrm{C} 1$, in which the gas bypass valve (BPV2 ) is totally closed. For simplicity, in what follows, C1 or C2 are referred as C1\&C2. Table 26 shows the experimental results for the dry evaporator double expansion cycle, with high pressure and superheating control and bypass.

Table 26. Space heating, C1\&C2, experimental results according to UNE-EN 14511 standard.

\begin{tabular}{|c|c|c|c|c|c|c|c|c|c|c|c|}
\hline \multirow{2}{*}{$\begin{array}{c}\text { Tests } \\
\text { order } \\
\text { (\#) }\end{array}$} & \multicolumn{4}{|c|}{ Evaporator } & \multicolumn{5}{|c|}{ Gas cooler } & \multicolumn{2}{|c|}{ Performance } \\
\hline & $\begin{array}{l}T_{e v, w i} \\
\left({ }^{\circ} \mathrm{C}\right)\end{array}$ & $\begin{array}{c}T_{e v, w o} \\
\left({ }^{\circ} \mathrm{C}\right)\end{array}$ & $\begin{array}{c}\dot{m}_{w} \\
\left(\mathrm{~kg} \cdot \mathrm{s}^{-1}\right)\end{array}$ & $\begin{array}{l}Q_{\text {evap }} \\
\text { (kW) }\end{array}$ & $\begin{array}{l}T_{g c, w i} \\
\left({ }^{\circ} \mathrm{C}\right)\end{array}$ & $\begin{array}{c}T_{g c, w o} \\
\left({ }^{\circ} \mathrm{C}\right)\end{array}$ & $\begin{array}{c}\dot{m}_{w} \\
\left(\mathrm{~kg} \cdot \mathrm{s}^{-1}\right)\end{array}$ & $\begin{array}{c}P_{g c} \\
\text { (bar) }\end{array}$ & $\begin{array}{c}Q_{g c} \\
(\mathrm{~kW})\end{array}$ & $\begin{array}{l}\dot{W}_{\text {comp }} \\
\text { (kW) }\end{array}$ & $\begin{array}{c}C O P_{H} \\
(-)\end{array}$ \\
\hline 1 & 10.03 & & & 1900 & 30.02 & & & & & & 4.172 \\
\hline 2 & & & & & & & & & & & \\
\hline 3 & Oم & & & & & & & & & & \\
\hline 4 & .9 & 15 & & & 27.67 & 00 & & 3.18 & & & .950 \\
\hline 5 & & & & 900 & 40.04 & 45.02 & & 91.09 & & & 3.003 \\
\hline 6 & .06 & & & & 39.21 & & & & & & 388 \\
\hline 7 & 19.99 & 15 & & & 38.42 & & & & & & 3.749 \\
\hline 8 & 24.97 & 20.03 & 0.273 & 4.862 & 37.68 & 45.00 & 0.238 & 90.98 & 6.100 & 1.4238 & 4.284 \\
\hline
\end{tabular}

\subsubsection{Configuration 3 (C3), experimental results}

As mentioned before, this configuration is that with the flooded evaporator in which the high pressure is controlled by means of BPV-1, with no thermostatic expansion valve (Fig. 36.c). Table 27 presents the experimental results obtained for this configuration.

Table 27. Space heating, C3, experimental results according to UNE-EN 14511 standard.

\begin{tabular}{|c|c|c|c|c|c|c|c|c|c|c|c|}
\hline \multirow{2}{*}{$\begin{array}{c}\text { Tests } \\
\text { order } \\
\text { (\#) }\end{array}$} & \multicolumn{4}{|c|}{ Evaporator } & \multicolumn{5}{|c|}{ Gas cooler } & \multicolumn{2}{|c|}{ Performance } \\
\hline & $\begin{array}{l}T_{e v, w i} \\
\left({ }^{\circ} \mathrm{C}\right)\end{array}$ & $\begin{array}{c}T_{e v, w o} \\
\left({ }^{\circ} \mathrm{C}\right)\end{array}$ & $\begin{array}{c}\dot{m}_{w} \\
\left(\mathrm{~kg} \cdot \mathrm{s}^{-1}\right)\end{array}$ & $\begin{array}{l}Q_{\text {evap }} \\
\text { (kW) }\end{array}$ & $\begin{array}{l}T_{g c, w i} \\
\left({ }^{\circ} \mathrm{C}\right)\end{array}$ & $\begin{array}{l}T_{g c, w o} \\
\left({ }^{\circ} \mathrm{C}\right)\end{array}$ & $\begin{array}{c}\dot{m}_{w} \\
\left(\mathrm{~kg} \cdot \mathrm{s}^{-1}\right)\end{array}$ & $\begin{array}{c}P_{g c} \\
\text { (bar) }\end{array}$ & $\begin{array}{c}Q_{g c} \\
(k W)\end{array}$ & $\begin{array}{l}\dot{W}_{\text {comp }} \\
(\mathrm{kW})\end{array}$ & $\begin{array}{c}C O P_{H} \\
(-)\end{array}$ \\
\hline 1 & 10.00 & 7.06 & 037 & 4681 & 29.99 & 35.00 & & 76.99 & .030 & & 4.178 \\
\hline 2 & & & & & & & & & & & \\
\hline 3 & .0 & 16 & & & 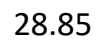 & .95 & & 5 & & & \\
\hline 4 & 24.9 & 19.5 & & 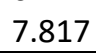 & 27.55 & 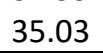 & 2 & 3.82 & 4 & & 25 \\
\hline 5 & 07 & 7 & 0.273 & 2 & 40.00 & 50 & 02 & 77 & 4 & & 97 \\
\hline 6 & .0 & 11 & 0.27 & 415 & 39.26 & 45.0 & 0. & 1.15 & 5.680 & 4 & 3.425 \\
\hline 7 & 19.94 & 15.8 & 0.2 & 4.708 & 38.60 & 45.02 & 0.2 & 91.03 & 6.223 & 1.6289 & 3.820 \\
\hline 8 & 24.98 & 20.07 & 0.272 & 5.525 & 37.75 & 44.98 & 0.234 & 91.04 & 6.997 & 1.5642 & 4.474 \\
\hline
\end{tabular}




\subsubsection{Configuration 4 (C4), experimental results}

This configuration corresponds to a transcritical single stage compression cycle with a thermostatic expansion valve. The pressure limitation of the installation makes difficult to perform the tests with this configuration in which gas cooler pressure is the result of the inlet conditions at the warm and cold sink. So, only the results corresponding to test $1 \& 2$ and $5 \& 6$ of the test matrix are shown in Table 28.

Table 28. Space heating, C4, experimental results according to UNE-EN 14511 standard.

\begin{tabular}{|c|c|c|c|c|c|c|c|c|c|c|c|}
\hline \multirow{2}{*}{$\begin{array}{c}\text { Tests } \\
\text { order } \\
(\#)\end{array}$} & \multicolumn{4}{|c|}{ Evaporator } & \multicolumn{5}{|c|}{ Gas cooler } & \multicolumn{2}{|c|}{ Performance } \\
\hline & $\begin{array}{l}T_{e v, w i} \\
\left({ }^{\circ} \mathrm{C}\right)\end{array}$ & $\begin{array}{l}T_{\text {ev,wo }} \\
\left({ }^{\circ} \mathrm{C}\right)\end{array}$ & $\begin{array}{c}\dot{m}_{w} \\
\left(\mathrm{~kg} \cdot \mathrm{s}^{-1}\right)\end{array}$ & $\begin{array}{l}Q_{\text {evap }} \\
\text { (kW) }\end{array}$ & $\begin{array}{c}T_{g c, w i} \\
\left({ }^{\circ} \mathrm{C}\right)\end{array}$ & $\begin{array}{c}T_{g c, w o} \\
\left({ }^{\circ} \mathrm{C}\right)\end{array}$ & $\begin{array}{c}\dot{m}_{w} \\
\left(\mathrm{~kg} \cdot \mathrm{s}^{-1}\right)\end{array}$ & $\begin{array}{c}P_{g c} \\
\text { (bar) }\end{array}$ & $\begin{array}{c}Q_{g c} \\
(\mathrm{~kW})\end{array}$ & $\begin{array}{l}\dot{W}_{\text {comp }} \\
\text { (kW) }\end{array}$ & $\begin{array}{c}C O P_{H} \\
(-)\end{array}$ \\
\hline 1 & 10.04 & 72 & & & 29.98 & & & & 4.331 & & 3.218 \\
\hline 2 & & 12. & & & 30. & & & 4 & & & .958 \\
\hline 5 & 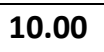 & & & & 39.97 & & & & & & 2.556 \\
\hline 6 &. .93 & 2.45 & .200 & 2.092 & 1.12 & 44.88 & 0.197 & 30.59 & 3.360 & 1.4290 & 2.351 \\
\hline
\end{tabular}

When comparing the results to C1\&C2 (Table 26) and C3 (Table 27) to those with C4 (Table 28), the heating capacity and COP decrease. Furthermore, due to the refrigerant conditions at each reference test, the $\dot{m}_{w}$ decreases when following the EN-14511-2-Standard [1].

Since this dry evaporator cycle has no liquid receiver to compensate the mass difference for the changing working conditions, all the tests for this configuration are performed with the refrigerant contained into the elements at the moment. Then, this configuration is only recommended for a specific water condition and refrigerant mass, which should be carefully established during the designing process.

\subsubsection{Summary of experimental results for all the configurations}

This section presents the results obtained for those tests which are comparable for all configurations.

Table 29. Space heating, C1\&C2, C3 and C4, experimental results according to UNE-EN 14511. standard

\begin{tabular}{|c|c|c|c|c|c|c|c|}
\hline \multirow{2}{*}{$\begin{array}{l}\text { Tests order } \\
\text { (\#) }\end{array}$} & \multicolumn{2}{|c|}{ Evaporator } & \multicolumn{2}{|c|}{ Gas cooler } & \multicolumn{3}{|c|}{$\operatorname{COP}_{H}(-)$} \\
\hline & $T_{e v, w i}\left({ }^{\circ} \mathrm{C}\right)$ & $T_{e v, w o}\left({ }^{\circ} \mathrm{C}\right)$ & $T_{g c, w i}\left({ }^{\circ} \mathrm{C}\right)$ & $T_{g c, w o}\left({ }^{\circ} \mathrm{C}\right)$ & C1\&C2 & C3 & C4 \\
\hline 1 & 10 & 7 & 30 & 35 & 4.172 & 4.178 & 3.218 \\
\hline 2 & 15 & $x$ & $x$ & 35 & 4.798 & 4.841 & 2.958 \\
\hline 3 & 20 & $Y$ & $Y$ & 35 & 5.628 & 5.708 & \\
\hline 4 & 25 & Z & Z & 35 & 6.950 & 7.025 & \\
\hline 5 & 10 & 7 & 40 & 45 & 3.003 & 2.997 & 2.556 \\
\hline 6 & 15 & $x$ & $x$ & 45 & 3.388 & 3.425 & 2.351 \\
\hline 7 & 20 & $Y$ & $Y$ & 45 & 3.749 & 3.820 & \\
\hline 8 & 25 & Z & Z & 45 & 4.284 & 4.474 & \\
\hline
\end{tabular}

The experimental results show that, from the energy point of view, there is not major difference between all configurations, but with $\mathrm{C4}$, which is limited to a specific refrigerant charge and has no high pressure control. 


\subsubsection{Influence of the evaporator water temperature for space heating}

The system performance is studied considering the evaporation temperature for the different configurations experimentally tested, being $\mathrm{C} 1 \& \mathrm{C} 2$ and $\mathrm{C} 3$. In the experimental tests, the optimal pressure is only reached in those cases in which the optimal pressure is not greater than 91 bar, due to the limitations of the studied facility. In a practical scenario, when trying to reach the optimal pressure, the tests conditions, including the refrigerant outlet temperature, might change, and the optimal pressure is being updated on every measurement until the actual pressure and the optimal one match each other as presented in Fig. 80 . So, for $30 / 35^{\circ} \mathrm{C}$ inlet/outlet water at the gas cooler, the optimal pressure is almost constant for the evaporator water range studied here. However, for $40 / 45^{\circ} \mathrm{C}$ the optimal pressure is not reached due to the facility limitations.

Fig. 81 shows the influence that evaporator water temperature has on the COP. Since configuration 1 (C1) without bypass is equal to configuration $2,(\mathrm{C} 2)$ represents both configurations. The standard conditions states that the reference test is $10 / 7^{\circ} \mathrm{C}$ in the evaporator and the inlet condition can be increased in $5{ }^{\circ} \mathrm{C}$ (up to $25{ }^{\circ} \mathrm{C}$ ) while increasing the inlet temperature in $5 \mathrm{~K}$. For the hot water production, the conditions for the reference tests in the gas cooler are $\left(30 / 35^{\circ} \mathrm{C}\right.$ and $\left.40 / 45^{\circ} \mathrm{C}\right)$, and, after following the $\dot{m}_{w}$ found in the reference tests for the evaporator and gas cooler when increasing the evaporator water temperature from $15^{\circ} \mathrm{C}$ to $25^{\circ} \mathrm{C}$, the gas cooler only guarantees the final water production in the mode of $\mathrm{X} / 35{ }^{\circ} \mathrm{C}$ and $\mathrm{X} / 45{ }^{\circ} \mathrm{C}$. Furthermore, considering the evaporator water, in this study, for the numerical part, $30{ }^{\circ} \mathrm{C}$ is also included considering a future scenario of using ground water or wastewater temperatures during whole year. However, something to keep in mind is that when the evaporator water temperature is $30^{\circ} \mathrm{C}$, the refrigerant evaporation temperature could reach $20^{\circ} \mathrm{C}$, which might be over the compressor limits according to the manufacturer information. 


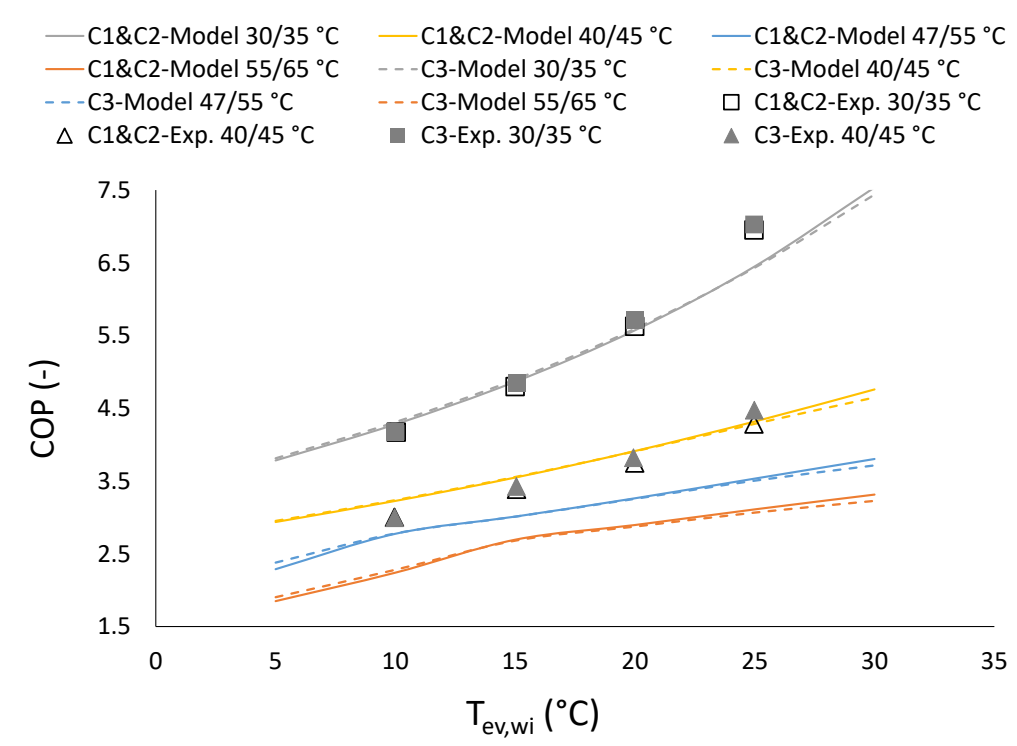

Fig. 81. Numerical and experimental COP for different $T_{g c \text {,wi/o }}$ and $T_{e v \text {,wi/o. }}$

As may be seen in Fig. 81, when the evaporator inlet water temperature varies from $10{ }^{\circ} \mathrm{C}$ to $25^{\circ} \mathrm{C}$ with an increment of $\Delta T=5 \mathrm{~K}$ at the inlet water temperature, while keeping the $\dot{m}_{w}$ found in the reference test, the differences among the studied configurations are negligible as already shown from Table 26 to Table 29. The results are similar if high $\left(47 / 55^{\circ} \mathrm{C}\right)$ and very high $\left(55 / 65^{\circ} \mathrm{C}\right)$ temperature conditions are numerically modelled, and the model also shows that the difference among the $\mathrm{C} 1 \& \mathrm{C} 2$ and $\mathrm{C} 3$ are negligible, including the COP difference of 0.10 of C1\&C2 over C3 when the evaporator water inlet temperature $\left(T_{e v, w i / o}\right)$ is increases to $30^{\circ} \mathrm{C}$.

\subsubsection{Influence of the superheating (SH)}

This section studies the influence of the superheating in the cycle performance. The results obtained are compared in Fig. 82 and Table 30. All tests, but those with $\mathrm{SH}=0$ $\mathrm{K}$, correspond to $\mathrm{C} 1 \& \mathrm{C} 2$ configurations. $S H=0 \mathrm{~K}$ corresponds to $\mathrm{C} 3$. The study is performed for all the water conditions in the gas cooler $\left(30 / 35{ }^{\circ} \mathrm{C}, 40 / 45^{\circ} \mathrm{C}, 47 / 55^{\circ} \mathrm{C}\right.$ and $55 / 65^{\circ} \mathrm{C}$ ) for low, medium, high and very high temperature, respectively by increasing the water evaporation temperature from $10{ }^{\circ} \mathrm{C}$ to $30{ }^{\circ} \mathrm{C}$ with a $\Delta T=3 \mathrm{~K}$ between the water inlet and outlet temperature in the evaporator. The $\dot{m}_{w}$ for the gas cooler and evaporator is not constant, but adapted to the test.

For low evaporation temperature, at $S H=0 \mathrm{~K}$ the $\mathrm{COP}$ is slightly better than $\mathrm{SH}=4 \mathrm{~K}$, but, for high evaporation temperature, is the opposite. The difference between $\mathrm{SH}=0$ $\mathrm{K}$ and $\mathrm{SH}=4 \mathrm{~K}$ is negligible, but, when working over $4 \mathrm{~K}$, the COP decreases. 


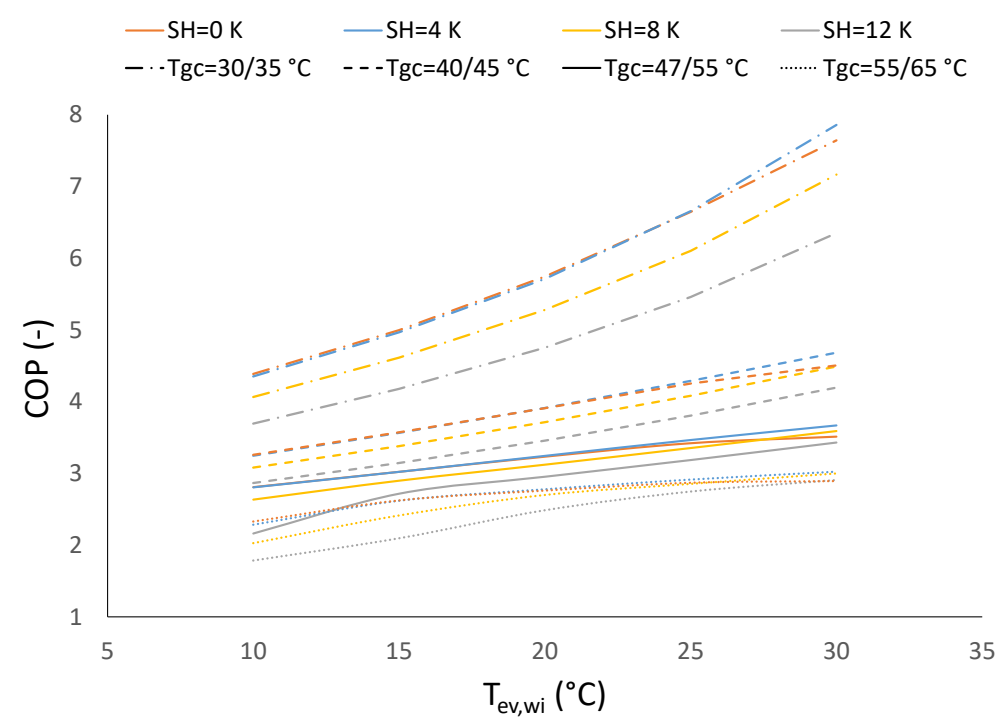

Fig. 82. Influence of the $S H$ on the COP for different $T_{g c, w i / o}$ and $T_{e v, w i / o .}$

Table 30 presents the optimum SH for different evaporator water temperature at two different hot water generation conditions, low $\left(30 / 35^{\circ} \mathrm{C}\right)$ and very high $\left(55 / 65^{\circ} \mathrm{C}\right)$. Also, the COP differences when compared those obtained with the second-best superheating values are presented. The closer to zero that difference is, the more negligible is the difference of using the optimum $\mathrm{SH}$ or the second-best $\mathrm{SH}$. As shown in Table 30, the optimal $\mathrm{SH}$ value decreases or stays as $4 \mathrm{~K}$ when decreasing the evaporation temperature at a specific hot water production temperature, and when increasing the hot water temperature at any specific evaporation temperatures. For high water temperature around $25{ }^{\circ} \mathrm{C}$ and $30{ }^{\circ} \mathrm{C}$ in the evaporator, the difference between $0 \mathrm{~K}, 4 \mathrm{~K}$ and $8 \mathrm{~K}$, is negligible, including that for $30^{\circ} \mathrm{C}$, the second optimal $\mathrm{SH}$ is $8 \mathrm{~K}$.

Table 30. $\mathrm{SH}$ behavior according to the hot water production and evaporator water temperature.

\begin{tabular}{|c|c|c|c|}
\hline$T_{e v, w i}\left({ }^{\circ} \mathrm{C}\right)$ & $T_{g c, w i / o}\left({ }^{\circ} \mathrm{C}\right)$ & Optimum SH (K) & COP improvement (-) \\
\hline 10 & \multirow{5}{*}{$30 / 35$} & 0 & +0.03465 (compared to $\mathrm{SH}=4 \mathrm{~K}$ ) \\
\hline 15 & & 0 & +0.02825 (compared to $\mathrm{SH}=4 \mathrm{~K}$ ) \\
\hline 20 & & 0 & +0.03198 (compared to $\mathrm{SH}=4 \mathrm{~K}$ ) \\
\hline 25 & & 4 & +0.00858 (compared to $\mathrm{SH}=0 \mathrm{~K}$ ) \\
\hline 30 & & 4 & +0.21698 (compared to $\mathrm{SH}=0 \mathrm{~K}$ ) \\
\hline 10 & \multirow{7}{*}{$55 / 65$} & 0 & +0.04397 (compared to $\mathrm{SH}=4 \mathrm{~K}$ ) \\
\hline 15 & & 0 & +0.00406 (compared to $\mathrm{SH}=4 \mathrm{~K}$ ) \\
\hline 20 & & 4 & +0.01813 (compared to $\mathrm{SH}=0 \mathrm{~K}$ ) \\
\hline 25 & & \multirow[t]{2}{*}{4} & +0.04399 (compared to $\mathrm{SH}=0 \mathrm{~K}$ ) \\
\hline & & & +0.06024 (compared to $\mathrm{SH}=8 \mathrm{~K}$ ) \\
\hline \multirow{2}{*}{30} & & \multirow{2}{*}{4} & +0.13074 (compared to $\mathrm{SH}=0 \mathrm{~K}$ ) \\
\hline & & & +0.02504 (compared to $\mathrm{SH}=8 \mathrm{~K}$ ) \\
\hline
\end{tabular}




\subsubsection{A brief on space cooling application}

Though this facility is mainly tested for hot water production to be used in space heating and DHW application, some tests are performed considering water cooling for space cooling application following the EN-14511-2-Standard [1].

A summary of the results obtained for space cooling applications for all the configurations is presented in Table 31. Although other tests are performed, only those comparable are presented; test $1\left(T_{e v, w i / o}=12 / 7^{\circ} \mathrm{C}\right.$ and $\left.T_{g c, w i / o}=30 / 35^{\circ} \mathrm{C}\right)$, and test $2\left(T_{e v, w i / o}=12 / 7^{\circ} \mathrm{C}\right.$ and $\left.T_{g c \text {, wi/o }}=25 / 30^{\circ} \mathrm{C}\right)$, which is not in the standard, but is often used for space cooling applications.

The experimental results show that for these tests, and as happens in space heating application, there is not mayor difference between the configurations for the space cooling applications.

Table 31. A brief of space cooling application, C1, C2, and C3, experimental results.

\begin{tabular}{|c|c|c|c|c|c|c|c|}
\hline \multirow{2}{*}{$\begin{array}{l}\text { Tests order } \\
\text { (\#) }\end{array}$} & \multicolumn{2}{|c|}{ Evaporator } & \multicolumn{2}{|c|}{ Gas cooler } & \multicolumn{3}{|c|}{$C O P_{c}$} \\
\hline & $T_{e v, w i}\left({ }^{\circ} \mathrm{C}\right)$ & $T_{e v, w o}\left({ }^{\circ} \mathrm{C}\right)$ & $T_{g c, w i}\left({ }^{\circ} \mathrm{C}\right)$ & $T_{g c, w o}\left({ }^{\circ} \mathrm{C}\right)$ & C1 & C2 & C3 \\
\hline 1 & 12 & 7 & 30 & 35 & 3.2891 & 3.3180 & 3.2486 \\
\hline 2 & 12 & 7 & 25 & 30 & 3.9280 & 3.9901 & 3.9947 \\
\hline
\end{tabular}

\subsubsection{Study about varying HXs surfaces}

This section is devoted to the study of the influence that the surface of the different HXs has on the cycle performance. To do so, several surfaces are going to be evaluated for the gas cooler, the evaporator and the IHX. The HXs surfaces evaluated are a quarter of the actual surface $\left(0.25^{*} \mathrm{~S}\right)$, a half $\left(0.5^{*}\right.$ Surface), the actual surface $(S)$, the double ( $2 *$ Surface) and the quadruple $(4 *$ Surface). In all cases this analysis is performed varying the number of plates, except for the IHX, which has only 4 plates and 2 channels, it means that for increasing the IHX surface, the number of plates can be increased, but for decreasing it, the size is modified. The evaporator water studied range is from $10{ }^{\circ} \mathrm{C}$ to $30{ }^{\circ} \mathrm{C}$ and the gas cooler water range is $30 / 35^{\circ} \mathrm{C}, 40 / 45^{\circ} \mathrm{C}$, $47 / 55^{\circ} \mathrm{C}$ and $55 / 65^{\circ} \mathrm{C}$. When studying a specific $\mathrm{HX}$, the others are left in the original surface (S).

\subsubsection{Influence of varying the IHX surface}

Fig. 83 represents the COP as a function of the evaporator water temperature when varying the IHX surface. Results show the influence that increasing the IHX surface has on the COP, and confirms that in almost all the studied conditions, the system improves when the IHX surface is increased. The higher the hot water generation temperature is, the stronger the improvement found in both, absolute and, specially, in relative terms.

For low temperature hot water at the gas cooler $\left(T_{g c \text {, wi/o }}=30 / 35^{\circ} \mathrm{C}\right)$ : when the evaporator water temperature is high $\left(T_{e v, w i / o}=30 / 27^{\circ} \mathrm{C}\right)$, if the actual surface $(\mathrm{S})$ is 
decreased to $0.25^{*} \mathrm{~S}$ and $0.5 * \mathrm{~S}$, the COP $(7.5213)$ decreases in $-0.1210(-1.61 \%)$ and $0.0675(-0.90 \%)$, respectively. Whereas, increasing the surface to $2 * S$ and $4 * S$, increases the COP in $0.0307(+0.41 \%)$ and $0.0673(+0.90 \%)$, respectively. On the other hand, for low evaporator water temperature $\left(T_{e v, \text { wi } / o}=10 / 7^{\circ} \mathrm{C}\right)$, decreasing the surface (S) to $0.25 * S$ and $0.5 * S$, decreases the COP (4.2756) in $-0.0829(-1.94 \%)$ and -0.0361 $(-0.85 \%)$, respectively. Whereas, increasing the surface $(S)$ to $2 * S$ and $4 * S$, increases the COP in $0.0144(0.34 \%)$ and $0.0228(0.53 \%)$, respectively. This indicates that for low temperature hot water generation, is better to increase the IHX surface.

For very high temperature hot water at the gas cooler $\left(T_{g c \text {, wi/o }}=55 / 65^{\circ} \mathrm{C}\right)$ : when the evaporator water temperature is high $\left(T_{e v, \text { wi } / o}=30 / 27^{\circ} \mathrm{C}\right)$, if the actual surface $(\mathrm{S})$ is decreased to $0.25^{*} \mathrm{~S}$ and $0.5^{*} \mathrm{~S}$, the $\operatorname{COP}(3.0013)$ decreases in $-0.2152(-7.17 \%)$ and $0.1086(-3.62 \%)$, respectively. Whereas, increasing the surface to $2 * S$ and $4 * S$, increases the COP in $0.0495(1.65 \%)$ and 0.0941 (3.13\%), respectively. On the other hand, for low evaporator water temperature $\left(T_{e v, \text { wi } / o}=10 / 7^{\circ} \mathrm{C}\right)$, decreasing the surface (S) to $0.25 * \mathrm{~S}$ and $0.5 * \mathrm{~S}$, increases the COP $(2.2405)$ in $0.0634(2.83 \%)$ and 0.0479 (2.14\%), respectively. Whereas, increasing the surface to $2 * S$ and $4 * S$, decreases the COP in $-0.0163-0.73 \%)$ and $-0.0277(-1.24 \%)$, respectively. This indicates that for very high temperature hot water generation is better to increase the IHX surface when working at high evaporation temperature. On the other hand, for low evaporation temperature, the system improves when decreasing the surface. Furthermore, 55/65 ${ }^{\circ} \mathrm{C}$ is an exception since the system improves when increasing the surface for low, media, and high temperatures, regardless the evaporator temperature.

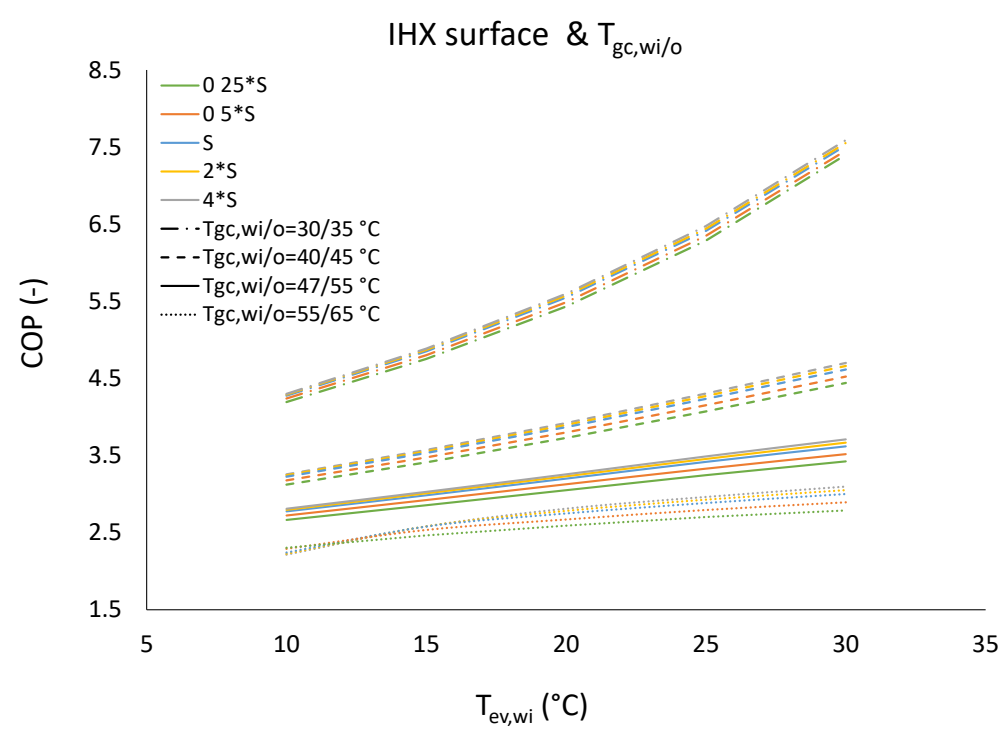

Fig. 83. COP considering the IHX surface.

The gas cooler heating capacity also shows a decrease when increasing the IHX heat transfer area for different gas cooler water temperature (Fig. 84), as reported by [59]. 
Fig. 84 shows the heating capacity for low $\left(30 / 35^{\circ} \mathrm{C}\right)$, medium $\left(40 / 45^{\circ} \mathrm{C}\right)$, high $(47 / 55$ ${ }^{\circ} \mathrm{C}$ ), and very high $\left(55 / 65^{\circ} \mathrm{C}\right)$ hot water generation temperatures when varying the IHX surface from $0.25^{*} \mathrm{~S}$ to $4^{*} \mathrm{~S}$, and the evaporator water temperature is low $(10 / 7$ $\left.{ }^{\circ} \mathrm{C}\right)$ and high $\left(30 / 27^{\circ} \mathrm{C}\right)$.

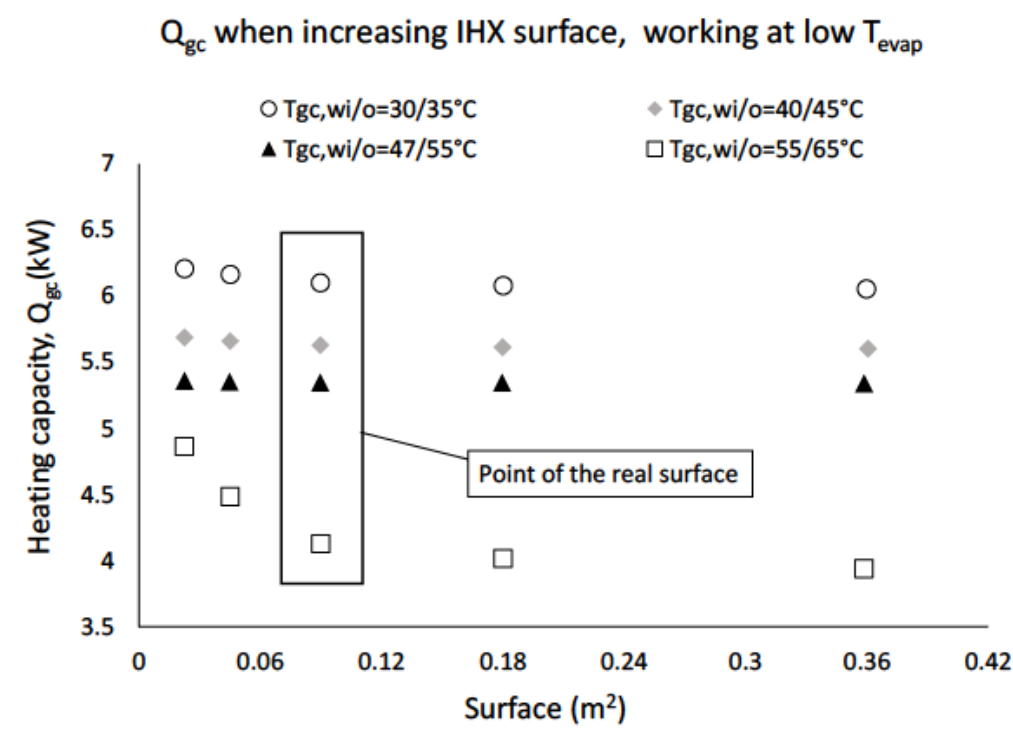

(a)

$\mathrm{Q}_{\mathrm{gc}}$ when increasing IHX surface, working at high $\mathrm{T}_{\text {evap }}$

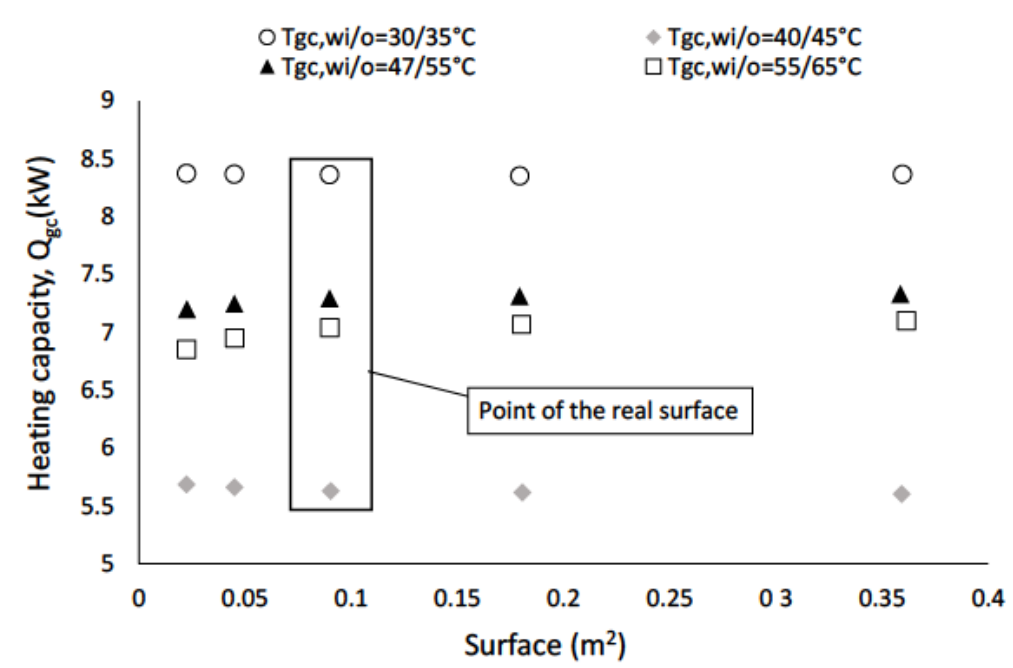

(b)

Fig. 84. Heating capacity according to the surface for a specific evaporator water temperature $\left(T_{\text {ev,wi/o }}=10 / 7^{\circ} \mathrm{C}\right.$ and $\left.30 / 27^{\circ} \mathrm{C}\right)$, when varying the IHX surface.

At low evaporator water temperature, Fig. 84.a, the decrease is negligible when increasing from the actual surface (S) to $4 * \mathrm{~S}$ for all hot water temperatures, and so is the increase of heating capacity when decreasing from $\mathrm{S}$ to $0.25^{*} \mathrm{~S}$ for low, medium and high hot water generation temperatures. For very high hot water temperature, an increase of $+0.73 \mathrm{~kW}(18 \%)$ is found when decreasing from S to $0.25 * \mathrm{~S}$. 
Whereas for high evaporator water temperature, Fig. 84.b, all changes are negligible when increasing from the actual surface $(S)$ to $4 * S$ for all hot water temperatures, and almost negligible when decreasing from $\mathrm{S}$ to $0.25 * \mathrm{~S}$ for all hot water temperatures, being the highest difference $+0.19 \mathrm{~kW}(2.7 \%)$ found at very high hot water temperature.

\subsubsection{Influence of varying the evaporator surface}

The influence of varying the evaporator surface is higher than varying the IHX surface, with very important $\mathrm{COP}$ variations, i.e.: for hot water production at $30 / 35^{\circ} \mathrm{C}$, varying the evaporator water range from $10{ }^{\circ} \mathrm{C}$ to $30{ }^{\circ} \mathrm{C}$, the surface of $0.25^{*} \mathrm{~S}$ and $4 * \mathrm{~S}$, produce COP average of 4.5177 and 6.0900 , respectively. Whereas, for the IHX case, the COP average are 5.6129 and 5.7687, respectively.

Fig. 85 shows the results obtained for the COP as function of the water temperature at the evaporator inlet when varying the evaporator surface. This is done for different gas cooler water temperature and evaporator heat transfer areas. Results show that increasing the evaporator surface has a clear improvement on the COP regardless the working conditions.

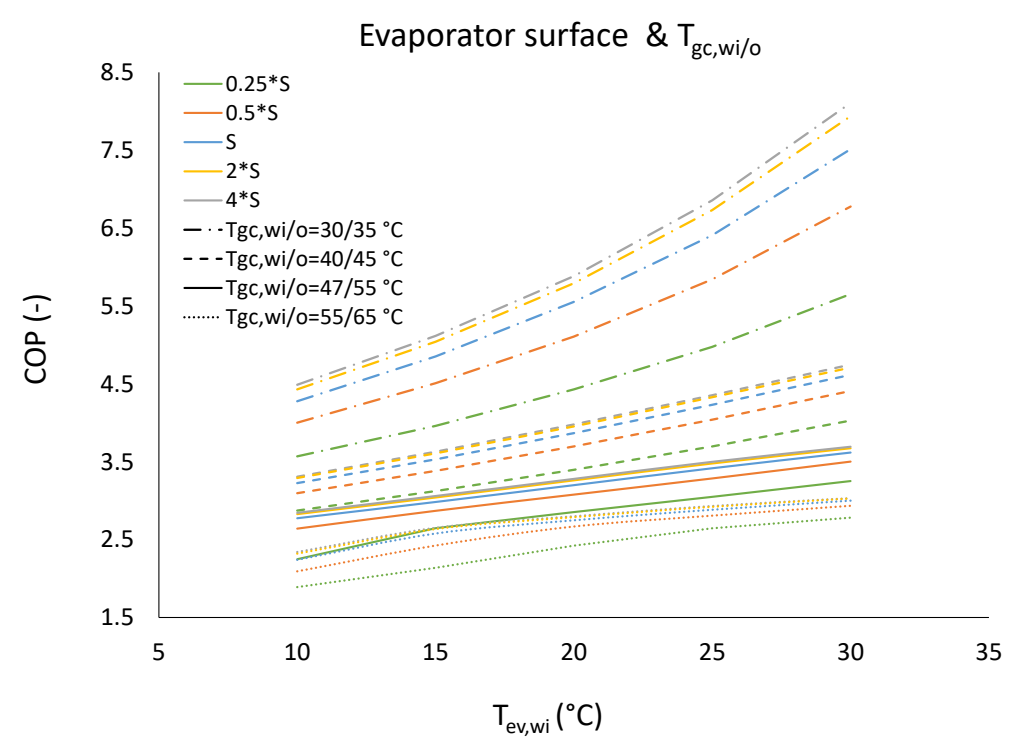

Fig. 85. COP considering the evaporator surface.

For low temperature hot water at the gas cooler $\left(T_{g c \text {, wi/o }}=30 / 35^{\circ} \mathrm{C}\right)$ : when the evaporator water temperature is high $\left(T_{e v, w i / o}=30 / 27^{\circ} \mathrm{C}\right)$, if the actual surface $(\mathrm{S})$ is decreased to $0.25^{*} \mathrm{~S}$ and $0.5^{*} \mathrm{~S}$, the COP $(7.5133)$ decreases in $-1.8591(-24.74 \%)$ and $-0.7372(-9.81 \%)$, respectively. Whereas, increasing the surface to $2 * S$ and $4 * S$, increases the COP in 0.4237 (5.64\%) and 0.5941 (7.91\%), respectively. On the other hand, for low evaporator water temperature $\left(T_{e v, w i / o}=10 / 7^{\circ} \mathrm{C}\right)$, decreasing the actual surface $(S)$ to $0.25^{*} \mathrm{~S}$ and $0.5 * \mathrm{~S}$, decreases the COP $(4.2776)$ in $-0.7086(-16.56 \%)$ and $-0.2749(-6.43 \%)$, respectively. Whereas, increasing the surface (S) to $2 * S$ and $4 * S$, increases the COP in 0.1516 (3.54\%) and 0.2101 (4.91\%), respectively. 
For very high temperature hot water at the gas cooler $\left(T_{g c \text {,wi/o }}=55 / 65^{\circ} \mathrm{C}\right)$ : for high evaporator water temperature $\left(T_{e v, w i / o}=30 / 27^{\circ} \mathrm{C}\right)$, decreasing the actual surface $(\mathrm{S})$ to $0.25 * S$ and $0.5 * S$, decreases the COP (3.0013) in $-0.2197(-7.32 \%)$ and -0.0669 ($2.23 \%)$, respectively. Whereas, increasing the surface to $2 * S$ and $4 * S$, increases the COP in $0.0258(0.86 \%)$ and $0.0316(1.05 \%)$, respectively. On the other hand, for low evaporator water temperature $\left(T_{e v, w i / o}=10 / 7^{\circ} \mathrm{C}\right)$, decreasing the actual surface $(\mathrm{S})$ to $0.25 * S$ and $0.5 * S$, decreases the COP $(2.2405)$ in $-0.3503(-15.64 \%)$ and -0.1473 ($6.57 \%)$, respectively. Whereas, increasing the surface to $2 * S$ and $4 * S$, increases the COP in $0.0800(3.57 \%)$ and $0.1004(4.48 \%)$, respectively.

\subsubsection{Influence of varying the gas cooler surface}

The influence of the gas cooler surface (S) is shown in Fig. 86 and Fig. 87. The results show that the gas cooler installed is closed to the optimum surface and that increasing or decreasing the surface, will affect the performance.

For low temperature hot water at the gas cooler $\left(T_{g c \text {, wi/o }}=30 / 35^{\circ} \mathrm{C}\right)$ : when the evaporator water temperature is high $\left(T_{e v, w i / o}=30 / 27^{\circ} \mathrm{C}\right)$, the COP for the actual surface $(7.5133)$ decreases in $-0.5870(-7.81 \%)$ and $-0.1512(-2.01 \%)$ when decreasing the surface $(S)$ to $0.25 * S$ and $0.5 * S$, respectively. Whereas, increasing the surface to $2 * S$ and $4 * S$, decreases the COP in $-0.1488(-1.98 \%)$ and $-0.6436(-8.57 \%)$, respectively. On the other hand, for low evaporator water temperature $\left(T_{e v, \text { wi/o }}=10 / 7\right.$ ${ }^{\circ} \mathrm{C}$ ), decreasing the actual surface (S) to $0.25 * \mathrm{~S}$ and $0.5^{*} \mathrm{~S}$, decreases the COP (4.2756) in $-0.1223(-2.86 \%)$ and $-0.0147(-0.34 \%)$, respectively. Whereas, increasing the surface $(S)$ to $2 * S$ and $4 * S$, decreases the COP in $-0.0730(-1.71 \%)$ and -0.2575 ($6.02 \%)$, respectively. This indicates that for low temperature hot water generation, the actual gas cooler surface is the optimum.

For very high temperature hot water at the gas cooler $\left(T_{g c \text {,wi/o }}=55 / 65^{\circ} \mathrm{C}\right)$ : for high evaporator water temperature $\left(T_{e v, w i / o}=30 / 27^{\circ} \mathrm{C}\right)$, decreasing the actual surface (S) to $0.25 * S$ and $0.5 * S$, decreases the COP $(3.0004)$ in $-0.0470(-1.57 \%)$ and -0.0053 ($0.18 \%)$, respectively. Whereas, increasing the surface to $2 * S$ and $4 * S$, decreases the COP in $-0.0245(-0.82 \%)$ and $-0.0874(-2.91 \%)$, respectively. On the other hand, for low evaporator water temperature $\left(T_{e v, w i / o}=10 / 7^{\circ} \mathrm{C}\right)$, decreasing the actual surface (S) to $0.25 * S$ and $0.5 * S$, the increases COP $(2.2405)$ in $0.0433(1.93 \%)$ and 0.0399 $(1.78 \%)$, respectively. Whereas, increasing the surface to $2 * S$ and $4 * S$, decreases the COP in $-0.0769(-3.43 \%)$ and $-0.1911(-8.53 \%)$, respectively. This indicates that for high temperature hot water generation, the actual gas cooler surface is the optimum regardless the negligible COP improvement of 0.04 when decreasing the actual surface at low evaporator water temperature. 
Gas cooler surface $\& T_{g c, w i / o}$

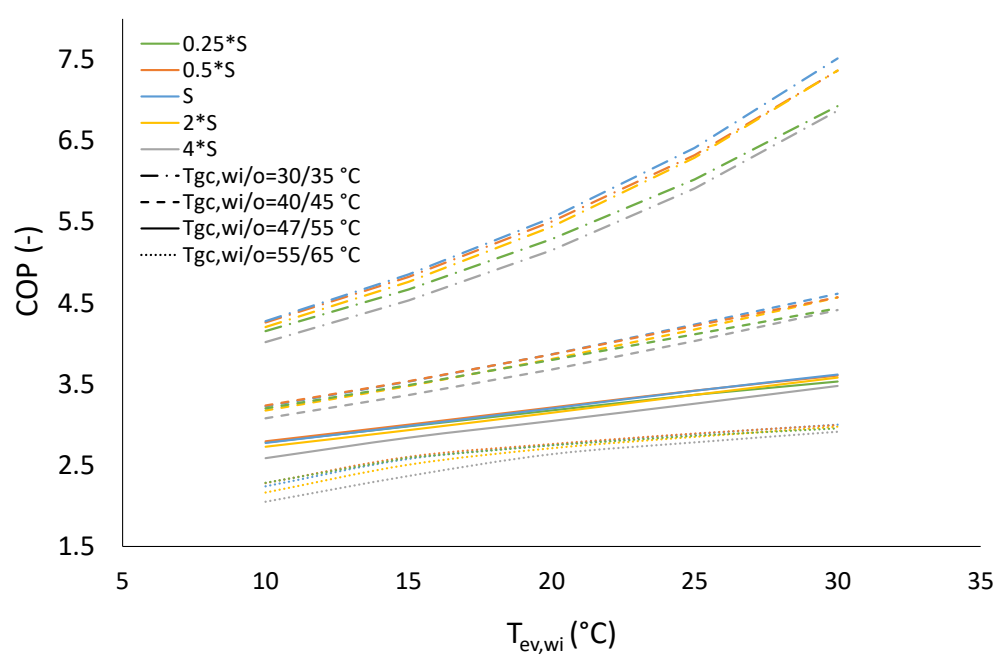

Fig. 86. COP according to the gas cooler surface.

As a summary, the actual surface $(S)$ is almost optimal for high space heating temperatures and low evaporator water temperatures, with a negligible -0.04 COP difference when compared to the optimal $(0.25 * \mathrm{~S})$. Whereas, for low space heating temperature and high evaporation temperature, the actual surface is the optimal with negligible differences only when decreasing the surface to $0.5 * S$ or increasing to $2 * \mathrm{~S}$. Furthermore, the actual surface is the optimal, with negligible differences among the studied surface range $(0.25 * S$ to $4 * S)$, for low space heating and low evaporation temperatures, and for high space heating temperatures and high evaporator water temperatures.

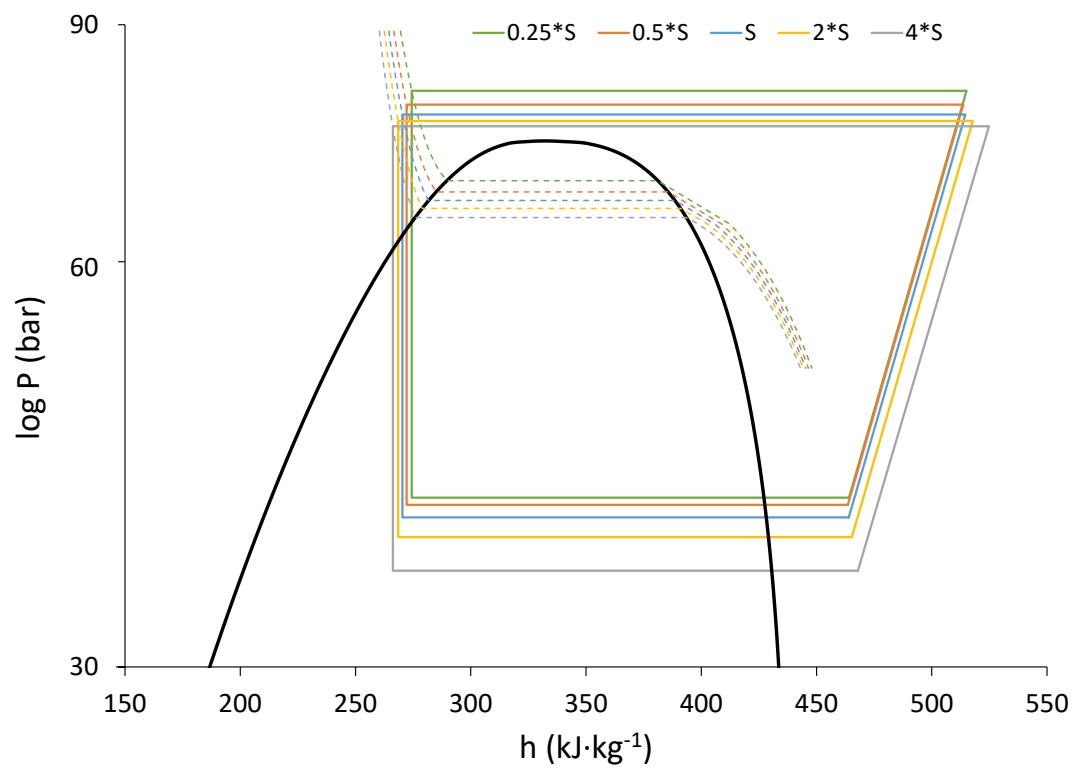

Fig. 87. Gas cooler surface, P-h diagram. 
Fig. 87 shows the influence of the gas cooler surface in the cycle when it is presented in a P-h diagram. When decreasing the surface of this $\mathrm{HX}$ the efficiency decreases, the temperature increases, and the refrigerant outlet enthalpy increases. An enthalpy increase in the high pressure zone is reflected in the evaporator inlet in such way that the system changes to a new condition in which the evaporation and gas cooler pressure increase and the global efficiency decreases. On the other hand, if the $\mathrm{HX}$ surface is increased, the system response is the opposite; the pressures decreases, the pressure ratio increases, however, the efficiency decreases as well.

\subsubsection{Influence of varying the surface of all the heat exchangers}

The influence of varying the surface of all HX simultaneously is show in Fig. 88. The system performance increases when increasing the HXs surfaces. Numerical results about increasing the HXs surface agree with other previous studies presented in the litterature review, such as White et al. [83], Cecchinato et al. [41], Kim et al. [59], and Wang et al. [140].

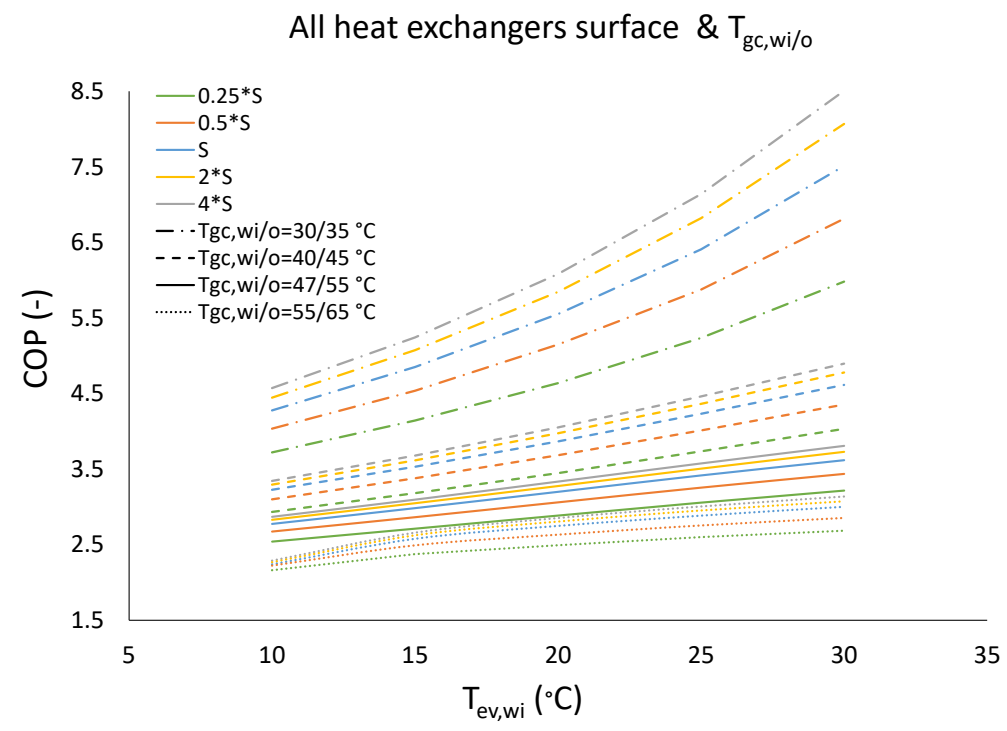

Fig. 88. Influence of varying all $\mathrm{HX}$ surface. 


\subsection{Domestic hot water generation, experimental results}

This section presents the results obtained during the experimental study of DHW generation. Finally, a comparison between the different configurations is going to be presented.

\subsubsection{Configuration $1 \& 2$ (C1\&C2)}

For the configuration $\mathrm{C} 1 \& \mathrm{C} 2$, the test are performed imposing a superheating of 10 $\mathrm{K}$, a totally opened IHX to produce the maximum efficiency. Table 32 and Table 33 show the experimental results for the tests carried out with and without optimal pressure $\left(P_{\text {opt }}\right)$

Table 32. DHW generation test matrix, C1\&C2 experimental results, with Popt.

\begin{tabular}{|c|c|c|c|c|c|c|c|c|c|c|c|}
\hline \multirow{2}{*}{$\begin{array}{c}\text { Tests } \\
\text { order } \\
\text { (\#) }\end{array}$} & \multicolumn{4}{|c|}{ Evaporator } & \multicolumn{5}{|c|}{ Gas cooler } & \multicolumn{2}{|c|}{ Performance } \\
\hline & $\begin{array}{c}T_{e v, w i} \\
\left({ }^{\circ} \mathrm{C}\right)\end{array}$ & $\begin{array}{c}T_{e v, w o} \\
\left({ }^{\circ} \mathrm{C}\right)\end{array}$ & $\begin{array}{c}\dot{m}_{w} \\
\left(\mathrm{~kg} \cdot \mathrm{s}^{-1}\right)\end{array}$ & $\begin{array}{l}Q_{\text {evap }} \\
(\mathrm{kW})\end{array}$ & $\begin{array}{c}T_{g c, w i} \\
\left({ }^{\circ} \mathrm{C}\right)\end{array}$ & $\begin{array}{c}T_{g c, w o} \\
\left({ }^{\circ} \mathrm{C}\right)\end{array}$ & $\begin{array}{c}\dot{m}_{w} \\
\left(\mathrm{~kg} \cdot \mathrm{s}^{-1}\right)\end{array}$ & $\begin{array}{c}P_{g c} \\
\text { (bar) }\end{array}$ & $\begin{array}{c}Q_{g c} \\
(k W)\end{array}$ & $\begin{array}{l}\dot{W}_{\text {comp }} \\
(\mathrm{kW})\end{array}$ & $\begin{array}{c}C O P_{H} \\
(-)\end{array}$ \\
\hline 1 & 10.05 & 4.98 & 0.202 & 3.743 & 10.00 & 60.06 & 0.026 & 77.32 & 4.664 & 1.275 & 3.658 \\
\hline 2 & 10.01 & 5.74 & 0.201 & 3.248 & 29.99 & 60.00 & 0.040 & 88.58 & 4.491 & 1.433 & 3.135 \\
\hline 3 & 10.01 & 8.24 & 0.201 & 1.325 & 50.00 & 60.00 & 0.069 & 90.90 & 2.437 & 1.313 & 1.856 \\
\hline 4 & 15.06 & 9.98 & 0.240 & 4.885 & 9.95 & 59.97 & 0.029 & 79.02 & 5.913 & 1.471 & 4.021 \\
\hline 5 & 19.99 & 15.00 & 0.272 & 5.277 & 10.02 & 60.04 & 0.033 & 81.00 & 6.241 & 1.375 & 4.540 \\
\hline 6 & 20.04 & 15.69 & 0.272 & 4.714 & 30.00 & 60.05 & 0.051 & 91.04 & 5.987 & 1.593 & 3.758 \\
\hline 7 & 19.99 & 18.25 & 0.272 & 2.058 & 49.97 & 60.01 & 0.082 & 91.06 & 3.407 & 1.598 & 2.132 \\
\hline 8 & 24.94 & 20.05 & 0.319 & 6.155 & 10.00 & 59.98 & 0.036 & 84.02 & 7.057 & 1.413 & 4.995 \\
\hline 9 & 29.98 & 25.03 & 0.354 & 7.130 & 9.98 & 59.98 & 0.041 & 87.66 & 7.911 & 1.357 & 5.828 \\
\hline 10 & 29.98 & 26.19 & 0.354 & 4.639 & 29.97 & 59.98 & 0.054 & 90.93 & 5.268 & 1.219 & 4.321 \\
\hline
\end{tabular}

Table 33. DHW generation test matrix, $\mathrm{C} 1 \& \mathrm{C} 2$ experimental results, with fix pressure $P_{g c}=80 \mathrm{bar}$.

\begin{tabular}{|c|c|c|c|c|c|c|c|c|c|c|c|}
\hline \multirow{2}{*}{$\begin{array}{c}\text { Tests } \\
\text { order } \\
\text { (\#) }\end{array}$} & \multicolumn{4}{|c|}{ Evaporator } & \multicolumn{5}{|c|}{ Gas cooler } & \multicolumn{2}{|c|}{ Performance } \\
\hline & $\begin{array}{c}T_{\text {ev,wi }} \\
\left({ }^{\circ} \mathrm{C}\right)\end{array}$ & $\begin{array}{c}T_{e v, w o} \\
\left({ }^{\circ} \mathrm{C}\right)\end{array}$ & $\begin{array}{c}\dot{m}_{w} \\
\left(\mathrm{~kg} \cdot \mathrm{s}^{-1}\right)\end{array}$ & $\begin{array}{l}Q_{\text {evap }} \\
(\mathrm{kW})\end{array}$ & $\begin{array}{c}T_{g c, w i} \\
\left({ }^{\circ} \mathrm{C}\right)\end{array}$ & $\begin{array}{c}T_{g c, w o} \\
\left({ }^{\circ} \mathrm{C}\right)\end{array}$ & $\begin{array}{c}\dot{m}_{w} \\
\left(\mathrm{~kg} \cdot \mathrm{s}^{-1}\right)\end{array}$ & $\begin{array}{c}P_{g c} \\
\text { (bar) }\end{array}$ & $\begin{array}{c}Q_{g c} \\
(\mathbf{k W})\end{array}$ & $\begin{array}{c}\dot{W}_{\text {comp }} \\
(\mathrm{kW})\end{array}$ & $\begin{array}{c}C O P_{H} \\
(-)\end{array}$ \\
\hline 1 & 9.98 & 5.01 & 0.221 & 4.434 & 10.06 & 60.13 & 0.028 & 80.03 & 5.657 & 1.510 & 3.747 \\
\hline 2 & 9.97 & 5.89 & 0.222 & 3.725 & 19.97 & 59.94 & 0.031 & 80.08 & 4.921 & 1.495 & 3.292 \\
\hline 3 & 9.95 & 6.98 & 0.222 & 2.760 & 29.99 & 60.00 & 0.033 & 80.05 & 3.877 & 1.470 & 2.638 \\
\hline 4 & 9.98 & 7.61 & 0.221 & 2.153 & 40.08 & 60.00 & 0.043 & 85.94 & 3.484 & 1.524 & 2.285 \\
\hline 5 & 15.00 & 9.99 & 0.241 & 4.961 & 10.04 & 59.94 & 0.030 & 79.98 & 6.111 & 1.510 & 4.046 \\
\hline 6 & 15.00 & 10.76 & 0.241 & 4.129 & 19.99 & 60.07 & & 80.04 & 5.192 & & 3.500 \\
\hline 7 & 14.99 & 11.82 & 0.240 & 3.171 & 29.99 & 59.99 & & 81.04 & 300 & 1.4 & 2.897 \\
\hline 8 & 15.08 & 12.54 & 0.240 & 2.502 & 39.99 & 60.02 & 0.047 & 86.28 & 3.898 & 1.559 & 2.500 \\
\hline 9 & 20.00 & 14.99 & 0.267 & 5.480 & 10.01 & 60.01 & 0.032 & 80.12 & 6.515 & 1.470 & 4.430 \\
\hline 10 & 20.00 & 15.82 & 0.268 & 4.561 & 20.01 & 60.06 & 0.035 & 80.88 & 5.586 & 1.455 & 3.839 \\
\hline 11 & 20.05 & 16.48 & & & 29.99 & & & 84.29 & & 16 & 3.317 \\
\hline 12 & 20.01 & 17.33 & 0.268 & 2.936 & 39.96 & 60.07 & 0.052 & 87.55 & 4.355 & 1.570 & 2.774 \\
\hline 13 & 24.99 & 20.03 & 0.299 & 6.083 & 10.01 & 60.01 & 0.035 & 82.36 & 7.042 & 1.433 & 4.913 \\
\hline 14 & 25.00 & 20.60 & 0.299 & 5.378 & 20.01 & 60.07 & 0.040 & 84.53 & 6.337 & 1.455 & 4.354 \\
\hline 15 & 25.07 & 21.20 & 0.299 & 4.726 & 29.99 & 60.03 & 0.050 & 87.90 & 5.741 & 1.524 & 3.767 \\
\hline 16 & 25.08 & 22.05 & 0.298 & 3.734 & 39.99 & 60.09 & 0.063 & 91.33 & 5.190 & 1.600 & 3.244 \\
\hline 17 & 30.05 & 24.99 & 0.351 & 7.294 & 10.01 & 60.06 & 0.041 & 88.06 & 8.153 & 1.419 & 5.746 \\
\hline 18 & 30.00 & 25.40 & 0.350 & 6.452 & 20.01 & 60.00 & 0.048 & 89.87 & 7.255 & 1.402 & 5.175 \\
\hline 19 & 29.94 & 25.94 & 0.349 & 5.730 & 29.94 & 59.95 & 0.058 & 91.98 & 6.726 & 1.556 & 4.323 \\
\hline
\end{tabular}


Considering the tests performed with or without optimal pressure control where water inlet temperature at the evaporator varies from 10 to $30 \circ \mathrm{C}$ and water temperatures at the gas cooler $10 / 60^{\circ} \mathrm{C}$, the average COP is 4,6084 when the system is working around optimal pressure and 4.5764 when it is not.

Whereas, for hot water production at $30 / 60{ }^{\circ} \mathrm{C}$ and evaporator water inlet at $10{ }^{\circ} \mathrm{C}$, $20^{\circ} \mathrm{C}$, and $30^{\circ} \mathrm{C}$, the COP average when working around the optimal pressure is 3.738 and 3.426 for a fix pressure of 80 bar.

This indicates that the more the inlet temperature at the gas cooler increases (being its outlet temperature $60^{\circ} \mathrm{C}$ ), the more important is to work at optimal pressure. It is important to keep in mind that, as shown in table 33 and 35, although the objective is to perform all tests with a fix high pressure of 80 bar, when the test conditions demand it, the pressure goes to higher values (i.e.: test \# 11, Table 33).

\subsubsection{Configuration 3 (C3)}

Since this configuration is a flooded evaporator cycle, the tests are carried out with $\mathrm{SH}=0 \mathrm{~K}$, and with the IHX totally opened to produce the maximum efficiency. The results obtained are gathered in Table 34 and Table 35, which include optimal pressure or not, respectively.

Table 34. DHW generation test matrix, C3 experimental results, with $P_{\text {opt }}$.

\begin{tabular}{|c|c|c|c|c|c|c|c|c|c|c|c|}
\hline \multirow{2}{*}{$\begin{array}{c}\text { Tests } \\
\text { order } \\
\text { (\#) }\end{array}$} & \multicolumn{4}{|c|}{ Evaporator } & \multicolumn{5}{|c|}{ Gas cooler } & \multicolumn{2}{|c|}{ Performance } \\
\hline & $\begin{array}{l}T_{\text {evv,wi }} \\
\left({ }^{\circ} \mathrm{C}\right)\end{array}$ & $\begin{array}{c}T_{e v, w o} \\
\left({ }^{\circ} \mathrm{C}\right)\end{array}$ & $\begin{array}{c}\dot{m}_{w} \\
\left(\mathrm{~kg} \cdot \mathrm{s}^{-1}\right)\end{array}$ & $\begin{array}{l}Q_{\text {evap }} \\
\text { (kW) }\end{array}$ & $\begin{array}{l}T_{g c, w i} \\
\left({ }^{\circ} \mathrm{C}\right)\end{array}$ & $\begin{array}{c}T_{g c, w o} \\
\left({ }^{\circ} \mathrm{C}\right)\end{array}$ & $\begin{array}{c}\dot{m}_{w} \\
\left(\mathrm{~kg} \cdot \mathrm{s}^{-1}\right)\end{array}$ & $\begin{array}{c}P_{g c} \\
\text { (bar) }\end{array}$ & $\begin{array}{c}Q_{g c} \\
(k W)\end{array}$ & $\begin{array}{l}\dot{W}_{\text {comp }} \\
(\mathrm{kW})\end{array}$ & $\begin{array}{c}C O P_{H} \\
(-)\end{array}$ \\
\hline 1 & 9.98 & 5.05 & 0.220 & 4.557 & 10.02 & 59.96 & 0.028 & 79.00 & 5.726 & 1.509 & 3.794 \\
\hline 2 & 10.03 & 6.00 & 0.218 & 3.715 & 29.92 & 60.01 & 0.042 & 87.02 & 5.109 & 1.608 & 3.177 \\
\hline 3 & 10.03 & 8.12 & 0.219 & 1.836 & 50.01 & 60.01 & 0.078 & 90.90 & 3.261 & 1.599 & 2.039 \\
\hline 4 & 15.04 & 10.00 & 0.246 & 5.203 & 9.98 & 60.00 & 0.031 & 80.80 & 6.397 & 1.527 & 4.190 \\
\hline 5 & 20.04 & 15.01 & 0.282 & 5.960 & 10.00 & 59.98 & 0.035 & 83.77 & 7.086 & 1.530 & 4.632 \\
\hline 6 & 19.97 & 15.69 & 0.281 & 5.036 & 30.01 & 59.99 & 0.052 & 91.30 & 6.281 & 1.643 & 3.824 \\
\hline 7 & 19.93 & 18.05 & 0.280 & 2.223 & 49.98 & 59.92 & 0.088 & 91.71 & 3.617 & 1.553 & 2.329 \\
\hline 8 & 25.05 & 20.02 & 0.319 & 6.683 & 10.00 & 60.05 & 0.039 & 87.74 & 7.648 & 1.525 & 5.015 \\
\hline
\end{tabular}

Considering the tests that are performed with or without optimal pressure control, for evaporator water inlet temperature $\left(T_{e v, w i}\right)$ from $10{ }^{\circ} \mathrm{C}$ to $25{ }^{\circ} \mathrm{C}$, and gas cooler water inlet and outlet temperature $\left(T_{g c, w i / o}\right)$ at $10 / 60{ }^{\circ} \mathrm{C}$, the COP average when the system is working around the optimal pressure is 4.4078 and 4.2503 when is not.

For hot water production at $30 / 60^{\circ} \mathrm{C}$, the COP average when working at the optimal pressure is 3.5005 , and 3.132 for a fix pressure.

Similar to the previous configuration, the more the inlet temperature increases, the more important is to work at the optimal pressure. 
Table 35. DHW generation test matrix, C3 experimental results, with fix pressure $P_{g c}=80$ bar.

\begin{tabular}{|c|c|c|c|c|c|c|c|c|c|c|c|}
\hline \multirow{2}{*}{$\begin{array}{c}\text { Tests } \\
\text { order } \\
\text { (\#) }\end{array}$} & \multicolumn{4}{|c|}{ Evaporator } & \multicolumn{5}{|c|}{ Gas cooler } & \multicolumn{2}{|c|}{ Performance } \\
\hline & $\begin{array}{l}T_{e v, w i} \\
\left({ }^{\circ} \mathrm{C}\right)\end{array}$ & $\begin{array}{c}T_{e v, w o} \\
\left({ }^{\circ} \mathrm{C}\right)\end{array}$ & $\underset{\left(\mathrm{kg} \cdot \mathrm{s}^{-1}\right)}{\dot{m}_{w}}$ & $\begin{array}{l}Q_{\text {evap }} \\
\text { (kW) }\end{array}$ & $\begin{array}{l}T_{g c, w i} \\
\left({ }^{\circ} \mathrm{C}\right)\end{array}$ & $\begin{array}{c}T_{g c, w o} \\
\left({ }^{\circ} \mathrm{C}\right)\end{array}$ & $\begin{array}{c}\dot{m}_{w} \\
\left(\mathrm{~kg} \cdot \mathrm{s}^{-1}\right)\end{array}$ & $\begin{array}{c}P_{\mathrm{gc}} \\
\text { (bar) }\end{array}$ & $\begin{array}{c}Q_{g c} \\
(k W)\end{array}$ & $\begin{array}{l}\dot{W}_{\text {comp }} \\
\text { (kW) }\end{array}$ & $\begin{array}{c}C O P_{H} \\
(-)\end{array}$ \\
\hline 1 & 10.00 & 5.04 & 0.219 & 4.631 & 9.99 & 60.03 & 0.029 & 80.12 & 5.890 & 1.549 & 3.802 \\
\hline 2 & 9.99 & 5.76 & 0.219 & 3.915 & 19.99 & 60.04 & 0.032 & 80.09 & 5.087 & 1.500 & 3.392 \\
\hline 3 & 9.97 & 6.85 & 0.220 & 3.005 & 29.97 & 60.05 & 0.034 & 80.09 & 4.124 & 1.475 & 2.795 \\
\hline 4 & 10.07 & 8.12 & 0.219 & 1.915 & 40.01 & 60.01 & 0.039 & 80.11 & 3.212 & 1.454 & 2.209 \\
\hline 5 & 9.88 & 8.75 & 0.219 & 1.095 & 50.01 & 60.01 & 0.058 & 80.11 & 2.427 & 1.443 & 1.682 \\
\hline 6 & 14.99 & 10.03 & 0.248 & 5.097 & 9.97 & 59.97 & 0.031 & 80.10 & 6.258 & 1.511 & 4.142 \\
\hline 7 & 14.98 & 10.90 & 0.249 & 4.245 & 20.00 & 60.01 & 0.034 & 80.11 & 5.325 & 1.463 & 3.639 \\
\hline 8 & 15.04 & 12.09 & 0.248 & 3.238 & 30.03 & 60.01 & 0.036 & 80.10 & 4.381 & 1.436 & 3.051 \\
\hline 9 & 15.00 & 12.93 & 0.248 & 2.294 & 39.97 & 59.99 & 0.043 & 82.03 & 3.606 & 1.470 & 2.452 \\
\hline 10 & 15.01 & 13.59 & 0.248 & 1.557 & 49.98 & 60.05 & 0.070 & 85.22 & 2.937 & 1.510 & 1.946 \\
\hline 11 & 19.97 & 15.00 & 0.251 & 5.278 & 10.00 & 59.96 & 0.031 & 80.09 & 6.187 & 1.431 & 4.324 \\
\hline 12 & 20.02 & 15.97 & 0.252 & 4.305 & 19.98 & 60.05 & 0.033 & 80.13 & 5.077 & 1.385 & 3.665 \\
\hline 13 & 19.97 & 16.44 & 0.252 & 3.793 & 29.99 & 60.07 & 0.041 & 83.61 & 4.985 & 1.437 & 3.469 \\
\hline 14 & 19.97 & 17.16 & 0.251 & 2.986 & 39.96 & 60.06 & 0.053 & 87.04 & 4.362 & 1.506 & 2.896 \\
\hline 15 & 19.98 & 17.94 & 0.252 & 2.171 & 50.02 & 60.02 & 0.089 & 91.60 & 3.626 & 1.580 & 2.295 \\
\hline 16 & 25.06 & 20.07 & 0.285 & 5.903 & 9.98 & 60.01 & 0.034 & 84.32 & 6.737 & 1.423 & 4.733 \\
\hline 17 & 25.02 & 20.46 & 0.285 & 5.445 & 19.96 & 60.05 & 0.041 & 86.50 & 6.207 & 1.458 & 4.257 \\
\hline 18 & 24.97 & 20.92 & 0.285 & 4.821 & 30.00 & 59.98 & 0.050 & 89.35 & 5.980 & 1.495 & 4.000 \\
\hline
\end{tabular}

\subsubsection{Comparison between the different configurations in DHW}

\section{application}

This section presents the results for both configurations and a comparison of the tests which conditions are similar. Table 36 shows the results for C1\&C2 and C3 for the 60 ${ }^{\circ} \mathrm{C}$ hot water production for the tests that are performed under optimal pressure conditions. Finally, Fig. 89 and Fig. 90, present the comparison from the evaporator water and gas cooler water perspective, both are a summary of table 36 , when working at the optimal pressure.

Table 36. DHW test matrix, C1\&C2 and C3 experimental results, with $P_{\text {opt }}$.

\begin{tabular}{|c|c|c|c|c|c|c|c|c|c|c|c|c|}
\hline \multirow{3}{*}{$\begin{array}{c}\text { Tests } \\
\text { order } \\
\text { (\#) }\end{array}$} & \multicolumn{3}{|c|}{ Evaporator } & \multicolumn{5}{|c|}{ Gas cooler } & \multicolumn{4}{|c|}{ Performance } \\
\hline & \multirow{2}{*}{$\begin{array}{l}T_{e v, w i} \\
\left({ }^{\circ} \mathrm{C}\right)\end{array}$} & \multicolumn{2}{|c|}{$\dot{\mathrm{m}}_{\mathrm{w}}\left(\mathrm{kg} \cdot \mathrm{s}^{-1}\right)$} & \multirow{2}{*}{$\begin{array}{c}T_{g c, w i} \\
\left({ }^{\circ} \mathrm{C}\right) \\
\mathrm{C} 1 \& \mathrm{C} 2\end{array}$} & \multicolumn{2}{|c|}{$\dot{\mathrm{m}}_{\mathrm{w}}\left(\mathrm{kg} \cdot \mathrm{s}^{-1}\right)$} & \multicolumn{2}{|c|}{$\mathrm{Q}_{\mathrm{gc}}(\mathrm{kW})$} & \multicolumn{2}{|c|}{$\dot{W}_{\text {comp }}(\mathrm{kW})$} & \multicolumn{2}{|c|}{$\mathrm{COP}_{H}(-)$} \\
\hline & & $\mathrm{C} 1 \& \mathrm{C2}$ & C3 & & C1\&C2 & C3 & C1\&C2 & C3 & C1\&C2 & C3 & C1\&C2 & C3 \\
\hline 1 & 10 & 0.202 & 0.220 & 10 & 0.026 & 0.028 & 4.664 & 5.726 & 1.275 & 1.509 & 3.658 & 3.794 \\
\hline 2 & 10 & 0.201 & 0.218 & 30 & 0.040 & 0.042 & 4.491 & 5.109 & 1.433 & 1.608 & 3.135 & 3.177 \\
\hline 3 & 10 & 0.201 & 0.219 & 50 & 0.069 & 0.078 & 2.437 & 3.261 & 1.313 & 1.599 & 1.856 & 2.039 \\
\hline 4 & 15 & 0.240 & 0.246 & 10 & 0.029 & 0.031 & 5.913 & 6.397 & 1.471 & 1.527 & 4.021 & 4.190 \\
\hline 5 & 20 & 0.272 & 0.282 & 10 & 0.033 & 0.035 & 6.241 & 7.086 & 1.375 & 1.530 & 4.540 & 4.632 \\
\hline 6 & 20 & 0.272 & 0.281 & 30 & 0.051 & 0.052 & 5.987 & 6.281 & 1.593 & 1.643 & 3.758 & 3.824 \\
\hline 7 & 20 & 0.272 & 0.280 & 50 & 0.082 & 0.088 & 3.407 & 3.617 & 1.598 & 1.553 & 2.132 & 2.329 \\
\hline 8 & 25 & 0.319 & 0.319 & 10 & 0.036 & 0.039 & 7.057 & 7.648 & 1.413 & 1.525 & 4.995 & 5.015 \\
\hline 9 & 30 & 0.354 & NP & 10 & 0.041 & NP & 7.911 & NP & 1.357 & NP & 5.828 & NP \\
\hline 10 & 30 & 0.354 & NP & 30 & 0.054 & NP & 5.268 & NP & 1.219 & NP & 4.321 & NP \\
\hline
\end{tabular}


When working around the optimal pressure, for the comparable conditions found in Table 36, considering evaporator water temperature from $10^{\circ} \mathrm{C}$ to $25^{\circ} \mathrm{C}$, and heating water from $10{ }^{\circ} \mathrm{C}$ to $60^{\circ} \mathrm{C}$, the COPs are 4.3035 for $\mathrm{C} 1 \& \mathrm{C} 2$, and 4.4078 for $\mathrm{C} 3$. When heating water from $30 / 60{ }^{\circ} \mathrm{C}$, for the same range at the evaporator, the COPs are 3.4465 for $\mathrm{C} 1 \& \mathrm{C} 2$ and 3.5005 for $\mathrm{C} 3$. When heating water at $50 / 60{ }^{\circ} \mathrm{C}$, the COPs are 2.00 for $\mathrm{C} 1 \& \mathrm{C} 2$ and 2.18 for C3. The overall COPs are, 3.512 for C1\&C2 and 3.625 for C3.

However, when the evaporator water inlet temperature is $30^{\circ} \mathrm{C}$, for heating water at $10 / 60{ }^{\circ} \mathrm{C}$ and $30 / 60^{\circ} \mathrm{C}$, the COP average for $\mathrm{C} 1 \& \mathrm{C} 2$ is 5.0745 , and $\mathrm{C} 3$ is not able to be tested due to the high pressure limitations.

Table 37. DHW generation test matrix, $\mathrm{C} 1 \& \mathrm{C} 2$ and $\mathrm{C} 3$ experimental results, with fix pressure $P_{g c}=80$ bar.

\begin{tabular}{|c|c|c|c|c|c|c|c|c|c|c|c|c|}
\hline \multirow{3}{*}{$\begin{array}{c}\text { Tests } \\
\text { order } \\
\text { (\#) }\end{array}$} & \multicolumn{3}{|c|}{ Evaporator } & \multicolumn{5}{|c|}{ Gas cooler } & \multicolumn{4}{|c|}{ Performance } \\
\hline & \multirow[t]{2}{*}{$\begin{array}{l}T_{e v, w i} \\
\left({ }^{\circ} \mathrm{C}\right)\end{array}$} & \multicolumn{2}{|c|}{$\dot{m}_{w}\left(\mathrm{~kg} \cdot \mathrm{s}^{-1}\right)$} & \multirow[t]{2}{*}{$\begin{array}{l}T_{g c, w i} \\
\left({ }^{\circ} \mathrm{C}\right)\end{array}$} & \multicolumn{2}{|c|}{$\dot{m}_{w}\left(\mathrm{~kg} \cdot \mathrm{s}^{-1}\right)$} & \multicolumn{2}{|c|}{$Q_{g c}(k W)$} & \multicolumn{2}{|c|}{$\dot{W}_{\text {comp }}(\mathrm{kW})$} & \multicolumn{2}{|c|}{$\operatorname{COP}_{H}(-)$} \\
\hline & & $\mathrm{C} 1 \& \mathrm{C} 2$ & C3 & & C1\&C2 & C3 & $\mathrm{C} 1 \& \mathrm{C} 2$ & C3 & $\mathrm{C} 1 \& \mathrm{C} 2$ & C3 & C1\&C2 & C3 \\
\hline 1 & 10 & 0.221 & 0.219 & 10 & 0.028 & 0.029 & 5.657 & 5.890 & 1.510 & 1.549 & 3.747 & 3.802 \\
\hline 2 & 10 & 0.222 & 0.219 & 20 & 0.031 & 0.032 & 4.921 & 5.087 & 1.495 & 1.500 & 3.292 & 3.392 \\
\hline 3 & 10 & 0.222 & 0.220 & 30 & 0.033 & 0.034 & 3.877 & 4.124 & 1.470 & 1.475 & 2.638 & 2.795 \\
\hline 4 & 10 & 0.221 & 0.219 & 40 & 0.043 & 0.039 & 3.484 & 3.212 & 1.524 & 1.454 & 2.285 & 2.209 \\
\hline 5 & 15 & 0.241 & 0.248 & 10 & 0.030 & 0.031 & 6.111 & 6.258 & 1.510 & 1.511 & 4.046 & 4.142 \\
\hline 6 & 15 & 0.241 & 0.249 & 20 & 0.032 & 0.034 & 5.192 & 5.325 & 1.483 & 1.463 & 3.500 & 3.639 \\
\hline 7 & 15 & 0.240 & 0. & 30 & 0 . & 0. & 4.300 & 4.381 & 1.485 & 1.436 & 2.897 & 3.051 \\
\hline 8 & 15 & 0.240 & 0.248 & 40 & 0.047 & 0.043 & 3.898 & 3.606 & 1.559 & 1.470 & 2.500 & 2.452 \\
\hline 9 & 20 & 0.267 & 0.251 & 10 & 0.032 & 0.031 & 6.515 & 6.187 & 1.470 & 1.431 & 4.430 & 4.324 \\
\hline 10 & 20 & 0.268 & 0.252 & 20 & 0.035 & 0.033 & 5.586 & 5.077 & 1.455 & 1.385 & 3.839 & 3.665 \\
\hline 11 & 20 & 0.267 & 0.252 & 30 & 0.042 & 0.041 & 5.029 & 4.985 & 1.516 & 1.437 & 3.317 & 3.469 \\
\hline 12 & 20 & 0.268 & 0.251 & 40 & 0.052 & 0.053 & 4.355 & 4.362 & 1.570 & 1.506 & 2.774 & 2.896 \\
\hline 13 & 25 & 0.299 & 0.285 & 10 & 0.035 & 0.034 & 7.042 & 6.737 & 1.433 & 1.423 & 4.913 & 4.733 \\
\hline 14 & 25 & 0.299 & 0.285 & 20 & 0.040 & 0.041 & 6.337 & 6.207 & 1.455 & 1.458 & 4.354 & 4.257 \\
\hline 15 & 25 & 0.299 & 0.285 & 30 & 0.050 & 0.050 & 5.741 & 5.980 & 1.524 & 1.495 & 3.767 & 4.000 \\
\hline 16 & 25 & 0.298 & NP & 40 & 0.063 & NP & 5.190 & NP & 1.600 & 1.549 & 3.244 & NP \\
\hline 17 & 30 & 0.351 & NP & 10 & 0.041 & NP & 8.153 & NP & 1.419 & 1.500 & 5.746 & NP \\
\hline 18 & 30 & 0.350 & NP & 20 & 0.048 & NP & 7.255 & NP & 1.402 & 1.475 & 5.175 & NP \\
\hline 19 & 30 & 0.349 & NP & 30 & 0.058 & NP & 6.726 & NP & 1.556 & 1.454 & 4.323 & NP \\
\hline
\end{tabular}

NP: No possible

When setting a fix pressure of 80 bar at the high side for the comparable conditions found in Table 37, considering evaporator water temperature from $10^{\circ} \mathrm{C}$ to $25^{\circ} \mathrm{C}$, and heating water at $10 / 60^{\circ} \mathrm{C}$, the COPs are 4.284 for $\mathrm{C} 1 \& \mathrm{C} 2$, and 4.25 for $\mathrm{C} 3$. When heating water at $20 / 60{ }^{\circ} \mathrm{C}$, the COPs are 3.7463 for $\mathrm{C} 1 \& \mathrm{C} 2$ and 3.7383 for $\mathrm{C} 3$. When heating water at $30 / 60^{\circ} \mathrm{C}$, the COPs are 3.155 for $\mathrm{C} 1 \& \mathrm{C} 2$ and 3.329 for $\mathrm{C} 3$. The overall COPs when increasing the evaporator water inlet temperature from $10{ }^{\circ} \mathrm{C}$ to $25^{\circ} \mathrm{C}$ and the gas cooler water inlet temperature from $10{ }^{\circ} \mathrm{C}$ to $40{ }^{\circ} \mathrm{C}$ in order to produce hot water at $60^{\circ} \mathrm{C}$, are 3.4866 for $\mathrm{C} 1 \& \mathrm{C} 2$ and 3.5217 for $\mathrm{C} 3$. When the evaporator water inlet temperature is $30^{\circ} \mathrm{C}$, while varying the gas cooler water inlet temperature 
from $10{ }^{\circ} \mathrm{C}$ to $30{ }^{\circ} \mathrm{C}$ for the production of hot water at $60{ }^{\circ} \mathrm{C}$, the COP average for $\mathrm{C} 1 \& \mathrm{C} 2$ is 5.0813 , but for same condition, $\mathrm{C} 3$ is not able to be tested due to the high pressure limitations. In general, the differences between the studied configurations are negligible.

\subsubsection{From the evaporator water temperature perspective}

Fig. 89 shows the experimental COP for different gas cooler water temperature when changing the evaporator water temperature at the inlet from $10^{\circ} \mathrm{C}$ to $30{ }^{\circ} \mathrm{C}$ while maintaining the outlet temperature of the gas cooler at $60^{\circ} \mathrm{C}$, and working at optimal pressure.

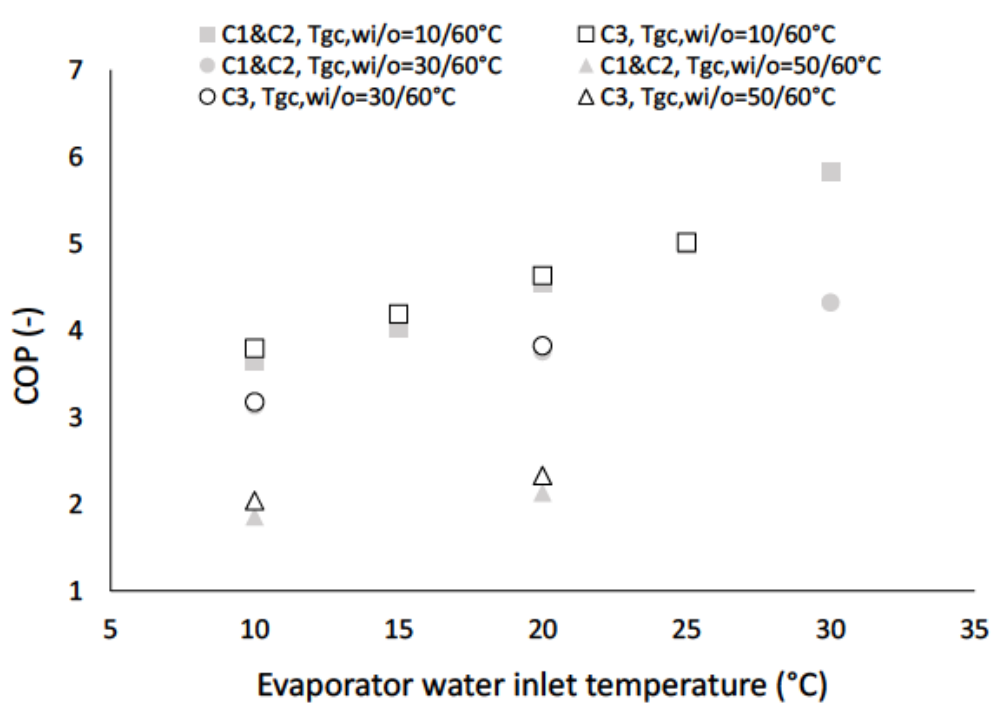

Fig. 89. COP according to the evaporator water temperature to produce $60{ }^{\circ} \mathrm{C} \mathrm{DHW}$, working at

$$
\text { Popt. }
$$

The COP differences between both configurations are negligible. As can be seen for the $10 / 60^{\circ} \mathrm{C}$ hot water condition, since the COP is increasing for $\mathrm{C} 1 \& \mathrm{C} 2$ with a higher percent than for $\mathrm{C} 3$, the COP difference between $\mathrm{C} 1 \& \mathrm{C} 2$ and $\mathrm{C} 3$ is being narrowed from $4 \%$ to $0 \%$ when changing the evaporator water temperature from $10{ }^{\circ} \mathrm{C}$ to 25 ${ }^{\circ} \mathrm{C}$ and maintaining a $\Delta T=5 \mathrm{~K}$ between the inlet and outlet water temperature. For $30 / 60{ }^{\circ} \mathrm{C}$, the COP difference between $\mathrm{C} 3$ and $\mathrm{C} 2$ is $1 \%$ and $2 \%$ when changing evaporator water inlet temperature from $10^{\circ} \mathrm{C}$ to $20^{\circ} \mathrm{C}$, respectively. In general, the maximum COP difference between $C 3$ and $C 2$ are around 0.15 and 0.20 , which is negligible.

As was said above, when the evaporator water inlet temperature is $30^{\circ} \mathrm{C}$, test can only be performed in $\mathrm{C} 1 \& \mathrm{C} 2$. And, for the gas cooler water inlet temperature at 50 ${ }^{\circ} \mathrm{C}$, tests are only performed for evaporator water temperature from $10^{\circ} \mathrm{C}$ to $20^{\circ} \mathrm{C}$ for both configurations due to the facility limitations around 90 bar (Table 5) and the compressor refrigerant evaporation temperature range (Fig. 6). 


\subsubsection{From the gas cooler water temperature perspective}

Fig. 90 shows the experimental COP for different gas cooler water temperature when changing the gas cooler water inlet temperature from $10{ }^{\circ} \mathrm{C}$ to $50{ }^{\circ} \mathrm{C}$ while maintaining its outlet temperature at $60^{\circ} \mathrm{C}$, and working at optimal pressure.

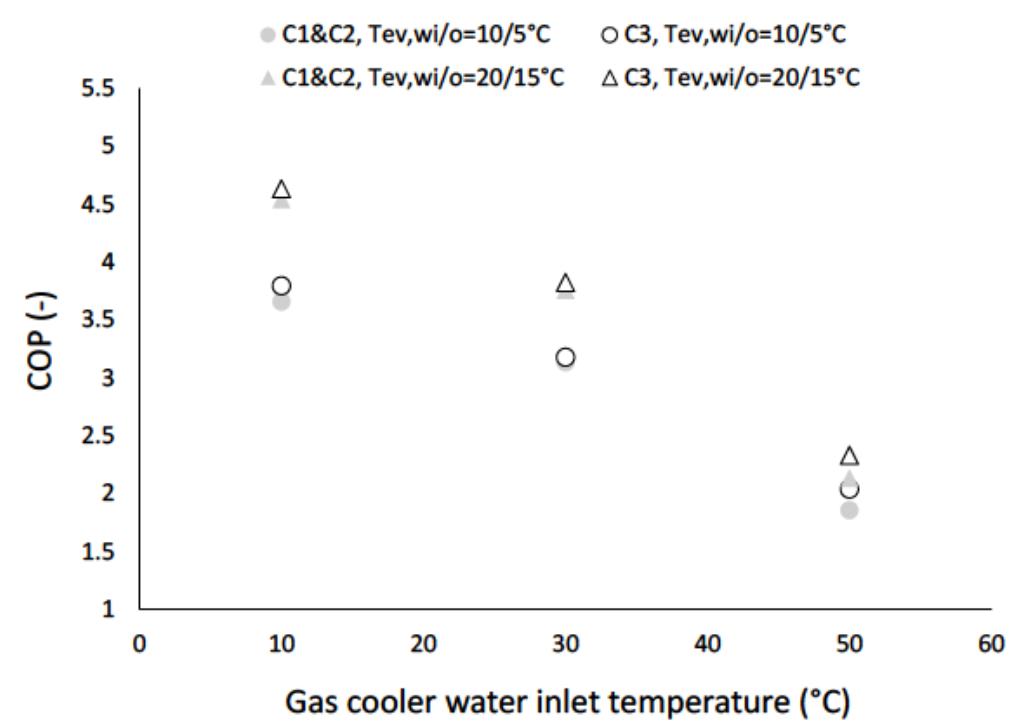

Fig. 90. COP according to the gas cooler water inlet temperature to produce $60^{\circ} \mathrm{C} \mathrm{DHW}$, working at Popt.

As explained before and is shown in Fig. 90, the difference between the compared configurations ( $\mathrm{C} 1 \& \mathrm{C} 2$ and $\mathrm{C} 3$ ), from this point of view, is almost negligible. When the gas cooler water inlet temperature is increased from $10{ }^{\circ} \mathrm{C}$ to $50{ }^{\circ} \mathrm{C}$ in order to produce $60{ }^{\circ} \mathrm{C}$ hot water out of the gas cooler; if the evaporator water inlet temperature is $10^{\circ} \mathrm{C}$, the COP average for $\mathrm{C} 1 \& \mathrm{C} 2$ is 2.883 and for $\mathrm{C} 3$ is 3.003 , and an overall average of 2.943 for both. Whereas when the evaporator water inlet temperature is $20^{\circ} \mathrm{C}$, the COP average for $\mathrm{C} 1 \& \mathrm{C} 2$ is 3.4767 and 3.5950 for $\mathrm{C} 3$, and the overall average for both is 3.5358 . 


\section{Conclusions, future works and recommendations}




\subsection{Introduction}

This chapter sums up the work performed on the $\mathrm{CO}_{2}$ water-to-water heat pump studied in this doctoral thesis by gathering the main conclusions on different aspects, such as the optimal pressure and the comparisons of different heat pumps configurations for space heating and DHW applications. Furthermore, some future works and recommendations complete this dissertation.

This doctoral thesis has involved the design, construction and monitoring of an installation for the analysis of different configurations of $\mathrm{CO}_{2}$ transcritical heat pumps. It has been located at the Calor y Frío laboratory.

In order to perform the experimental campaign, the facility has been constructed after selecting the most important elements in the refrigerant and water loop, such as the compressor, the gas cooler, the evaporator, the IHX, the liquid receiver, oil detector, measuring devices, control devices, water pumps, and water tanks, among other elements.

In order to perform studies and comparisons of the different configurations of the $\mathrm{CO}_{2}$ water-to-water heat pump, several tests matrices have been followed to study different parameters, such as the liquid receiver pressure, the influence of the IHX efficiency, the optimal pressure, the space heating and the DHW generation applications. During the main studies, the influence of different variables like the evaporator and gas cooler refrigerant and water temperatures, and the superheating, among others, have been analyzed.

The facility has been studied following the European standard mentioned during the thesis, where the tests conditions are established, such as the water temperature and water mass flow rate in the heat exchangers. Due to the limitations in the facility, some tests could not be performed for high pressures conditions over 90 bar, and those scenarios have been numerically simulated with the model developed to study the $\mathrm{CO}_{2}$ heat pump in hot water production along with the optimal pressure.

\subsection{Gas cooler optimal pressure}

A numerical model to describe the behavior of a $\mathrm{CO}_{2}$ transcritical heat pump for hot water production has been developed and validated experimentally, despite the current limitations of the facility, this model has allowed to obtain relatively simple expressions that may be programmed in a PLC to regulate the pressure in the gas cooler by measuring the temperature of the refrigerant in three points of the cycle and comparing the value obtained with the measured by a pressure transducer. The model proposed is capable of limiting the compressor discharge temperature to 140 ${ }^{\circ} \mathrm{C}$ while maintaining the COP with theoretical deviations of less than $2 \%$ respect to optimal pressure conditions.

Special attention has been paid to analyze the influence that different variables have on the optimal pressure, namely: the compressor efficiency, the evaporation 
temperature, the gas cooler outlet temperature, the superheating degree, the efficiency of the IHX, and the liquid receiver pressure. It has been concluded that the most influential parameter is clearly the gas cooler outlet temperature. The influence of the rest of the parameters can be summarized as:

- Within the range of variation of the different parameters analyzed, the influence of compressor efficiency is relatively low. So, the model derived for the characterization of the compressor has been proven to be applicable for a wide range of reciprocating semi-hermetic compressor models, which are the most common in the field of stationary heat pumps. The average difference found for the maximum COP obtained using the average compressor compared to the different compressor models studied has been $2.1 \%$, with a maximum difference of $10.4 \%$ (at $T_{\text {evap }}=15{ }^{\circ} \mathrm{C}, \mathrm{SH}=7 \mathrm{~K}, \eta_{\mathrm{HX}}=0.3$, and $T_{g c, r o}=60{ }^{\circ} \mathrm{C}$ ). For other technologies, such as reciprocating swash-plate compressors or rotary compressors (scroll or vane) typically used in automotive, the results may not be valid, although the use of $\mathrm{CO}_{2}$ as a refrigerant in these cases is still far from reaching the level of implementation it has in stationary applications.

- Considering the analysis carried out, the liquid receiver pressure has shown to have, in most cases, very low influence on the system's behavior. In practical terms, the variation of maximum COP with liquid receiver pressure is lower than $2 \%$, although theoretically, if this pressure could be increased to values near the critical pressure, the variation in maximum COP could increase up to values near to $5 \%$. This pressure is usually regulated by a gas bypass with the aim of reducing the pressure of the lines that distribute liquid to the evaporators. In those cases, to allow an adequate pressure regulation range, the liquid receiver should be sized according to the rest of the components and to the usual operating conditions.

- The rest of the parameters analyzed have a relatively low influence on the optimal pressure. The maximum variation of optimal pressure with the superheating degree is $2.5 \%$, the maximum variation of optimal pressure with the evaporation temperature is $3 \%$, and the maximum variation of optimal pressure with the IHX efficiency is $8 \%$. Therefore, it is possible to obtain an expression for the optimal pressure based only in the gas cooler outlet temperature. However, such an expression does not allow to limit the value of the compressor outlet temperature, which can reach in some cases values that could lead to lubricating oil degradation.

- This limitation can be overcome by adopting a model that considers as control variables, the evaporation temperature and the compressor suction temperature in addition to the temperature at the outlet of the gas cooler. 
The main advantages of the model proposed for the optimal pressure can be summarized as:

- While most previous works were developed for a specific compressor model or using very simplistic expressions for describing the compressor performance, the correlations for the optimal pressure proposed in this thesis have been obtained using ARHI 540 type expression and adjustment coefficients obtained from nine different compressor models from three different manufacturers, adjusted to the current technological development of the compressors for $\mathrm{CO}_{2}$ and, therefore, are more capable to reproduce real compressor behavior.

- The correlations proposed are capable of limiting the compressor discharge temperature to $140{ }^{\circ} \mathrm{C}$ while maintaining the COP with theoretical deviations of less than $2 \%$ respect to optimal pressure conditions. Therefore, unsafe operation conditions can be easily avoided.

- Since the expressions proposed only depends on cycle conditions, they can be applied to any type of heat pump (water-to-water, air-to-water or even airto-air) and can be easily programmed in a PLC to control de discharge pressure.

\subsection{Comparison of the different configurations (C1\&C2 and C3)}

The final main conclusions of the space heating and DHW application are presented.

\subsubsection{Space heating application}

The main conclusions of the study carried out on the use of $\mathrm{CO}_{2}$ transcritical heat pumps in space heating are summarized. Experiments have been designed to produce hot water at $35 \& 45^{\circ} \mathrm{C}$. They were performed varying evaporator water temperature from 10 to $25^{\circ} \mathrm{C}$.

Different parameters for hot water production have been studied besides the comparison of the different configurations, such as the influence of the IHX efficiency, the influence of varying the surface of all HX (gas cooler, evaporator and IHX), among others. As the first conclusion, the COP differences when comparing C1\&C2 with C3, are negligible.

- When changing evaporator inlet water temperature from $10{ }^{\circ} \mathrm{C}$ to $25^{\circ} \mathrm{C}$ with an increment of $\Delta T=5 \mathrm{~K}$ in the inlet water temperature, and keeping the water flow rates found in the reference tests in a facility with liquid receiver and IHX, according to the numerical and experimental results the differences between the configurations, are negligible. When changing the evaporator water inlet temperature from $10{ }^{\circ} \mathrm{C}$ to $25^{\circ} \mathrm{C}$, the COP increased in $68 \%$ and $50 \%$ for $35^{\circ} \mathrm{C}$ and $45{ }^{\circ} \mathrm{C}$ hot water production, respectively. 
- Considering the optimal pressure, for low temperature water production $\left(30 / 35{ }^{\circ} \mathrm{C}\right)$, the optimal pressure is independent of the range of evaporation water temperature $\left(5\right.$ to $30^{\circ} \mathrm{C}$ ), then a system able to maintain the pressure around the optimal value, is enough. On the other hand, for the conditions of medium $\left(40 / 45^{\circ} \mathrm{C}\right)$, high $\left(47 / 55^{\circ} \mathrm{C}\right)$ and very high $\left(55 / 65^{\circ} \mathrm{C}\right)$ temperatures, an adaptive control system assisted by a PLC control is needed. Furthermore, in order to preserve the elements of the facility, avoid oil degradation and meet the maximum operating conditions that could affect the compressor life, the system should be able to control the gas cooler optimal pressure maintaining the refrigerant discharge temperature under $140^{\circ} \mathrm{C}$.

- Considering the superheating, according to the numerical study, and for the temperature range and superheating values used in the numerical analysis, it seems that there exists an optimal SH for every tests conditions and the COP starts to decrease if the $\mathrm{SH}$ continues increasing. For the present study, the optimal $\mathrm{SH}$ is between $\mathrm{OK}$ and $4 \mathrm{~K}$. However, when comparing $\mathrm{C} 1 \& \mathrm{C} 2$ with $\mathrm{C} 3$, the differences are negligible due to the small influence of the $\mathrm{SH}$ on the system COP.

- For the configurations studied in this thesis, the influence of the IHX efficiency has been experimentally and numerically confirmed. The devices should be totally opened in order to guarantee the highest efficiency.

- Considering all the HXs surfaces, when increasing them, the COP increases, but in the present facility, the gas cooler surface is around the optimal value. The best alternative is to determine the optimal surface for every $\mathrm{HX}$ to be used in the installation. Furthermore, this value will depend on the hot water generation temperature (low, medium and high), therefore, ideally a device should be designed distinguishing at least for low/medium and high/very high applications.

\subsubsection{Domestic hot water generation}

An experimental study has been performed for DHW generation application during this thesis. The objective here is to produce water at $60^{\circ} \mathrm{C}$ while increasing the water inlet temperature from $10{ }^{\circ} \mathrm{C}$ to $50{ }^{\circ} \mathrm{C}$. In this application, the only water flow rate maintained is the one found for the evaporator in the reference tests, and those are performed keeping a $\Delta T=5 \mathrm{~K}$ between the inlet and outlet temperature for the reference tests $\left(10 / 5{ }^{\circ} \mathrm{C}, 20 / 15^{\circ} \mathrm{C}, 30 / 25^{\circ} \mathrm{C}\right)$. C1\&C2 are compared with $\mathrm{C} 3$. All tests for the $\mathrm{C} 1 \& \mathrm{C} 2$ are performed with a superheating of $10 \mathrm{~K}$, and the IHX is totally opened to produce the maximum efficiency for all the configurations compared in this work. As in the case of space heating, the COP differences when comparing $\mathrm{C} 1 \& \mathrm{C} 2$ with $\mathrm{C} 3$, were negligible.

- For the $10 / 60{ }^{\circ} \mathrm{C}$ hot water condition, since the COP is increasing for C1\&C2 with a higher percent than for C3, the COP difference between C1\&C2 and C3 is being narrowed from $4 \%$ to $0 \%$ when changing the evaporator water 
temperature from $10{ }^{\circ} \mathrm{C}$ to $25^{\circ} \mathrm{C}$. For $30 / 60{ }^{\circ} \mathrm{C}$, the COP difference between $\mathrm{C} 3$ and $\mathrm{C} 2$ is around $1 \%$ and $2 \%$ when changing evaporator water inlet temperature from $10^{\circ} \mathrm{C}$ to $20^{\circ} \mathrm{C}$, respectively. In general, the maximum COP differences between $\mathrm{C} 1 \& \mathrm{C} 2$ and $\mathrm{C} 3$ are around 0.15 and 0.20 .

o When the evaporator water inlet temperature is $30{ }^{\circ} \mathrm{C}$, tests are only performed in $\mathrm{C} 1 \& \mathrm{C} 2$ since $\mathrm{C} 3$ could not reach that evaporator water conditions due to the evaporation temperature and high pressure limits. And, for the gas cooler water inlet temperature at $50^{\circ} \mathrm{C}$, tests are only performed for evaporator water temperature from $10^{\circ} \mathrm{C}$ to $20^{\circ} \mathrm{C}$ for both configurations due to the facility high pressure limitations.

\section{To conclude:}

- The results are in line with the COPs found in the different experimental studies presented in the literature and the heat pumps offered in the market, which suggest that $\mathrm{CO}_{2}$ is a real replacement refrigerant for water-to-water heat pumps applications for the water temperature range studied in this thesis. The use of wastewater and borehole sources as heat source might offer good COPs since the heat pump systems improve when increasing the heat source temperature. However, attention must be paid to the limitations presented by the compressor manufacturers for the pressure limits and the evaporation temperature.

- The high pressure control is very important in $\mathrm{CO}_{2}$ transcritical cycles, thus, different optimal pressure correlations applicable for a wide range of reciprocating semi-hermetic compressor models, which are the most common in the field of stationary heat pumps, are proposed in this thesis. Such correlations could be programmed and controlled by means of a PLC controller that might limit refrigerant discharge temperature to $140{ }^{\circ} \mathrm{C}$, which will preserve oil, compressor life and lastly, the facility.

O In the space heating and DHW application, the differences of using dry evaporator (C1\&C2) and flooded evaporator (C3) cycles, are negligible. However, in the dry evaporator cycles, if the liquid receiver is usually regulated by a gas bypass with the aim of reducing the pressure of the lines that distribute liquid to the evaporators to allow an adequate pressure regulation range, the liquid receiver should be sized according to the rest of the components and to the usual operating conditions. The use of the IHX turns out to be an improvement in most of the cases studied for hot water generation in $\mathrm{CO}_{2}$ transcritical cycles. Regarding the $\mathrm{HXs}$ surfaces (evaporator, gas cooler and $\mathrm{IHX}$ ), in most cases, the system has shown improvements when increasing the HXs surfaces. The best alternative could be to determine the optimal surface for every $\mathrm{HX}$ to be used in the installation. Furthermore, this value will depend on the hot water generation temperature (low, medium, 
high and very high), therefore, ideally a device should be designed distinguishing at least for "low/medium" and "high/very high" applications.

\subsection{Future works and recommendations}

This work might be continued by studying the use of wastewater as heat source for $\mathrm{HP}$, and the relation of optimal pressure and different control strategies.

\subsubsection{About the use of wastewater source jointly with a $\mathrm{CO}_{2}$ heat pump}

As was studied in the literature, WWSHP represents a challenge, and, considering that $\mathrm{CO}_{2}$ is resurging alternative, the challenge increases. Studying wastewater as heat source, would require:

- To study the water reclamation policy, procedure, and all the legal information that need to be evaluated.

- To consider if the system is going to be direct or indirect. Indirect systems need a WWHX, and, on the other hand, direct systems use the heat of the wastewater circulating through one side of the evaporator of the heat pump while the refrigerant circulates thought the other side. In both cases, an electrical resistance to maintain a fix temperature around a desired value in a wastewater tank is recommended to guarantee an appropriate feeding to the evaporator.

- To consider if the wastewater is going to be treated or untreated. Untreated wastewater would need defouling function either in the direct or indirect systems. Treated wastewater would not need defouling function and comes directly from the available treatment plant. If using untreated system, the cleaning device for the WWHX or the evaporator HX should be considered. Since this facility is already working, either indirect system with defouling function in the WWHX or treated wastewater source is recommended. If direct system is used, wastewater should be treated before entering the evaporator, since the evaporator is not equipped with defouling function.

\subsubsection{About the optimal pressure and hot water generation for space heating and DHW applications}

- At the moment of this thesis, the correlation for the optimal pressure realtime calculation is set in LabVIEW, and, after calculating the instant optimal pressure, the setpoint is manually modified following the calculated value at every instant until the optimal pressure is the pressure of the cycle. In the near future, the researching team is going to install a PLC device to perform the real time calculations and automatically adjust the optimal pressure following a PID controller. 
- A refrigerant-to-water $\mathrm{HX}$ is going to be installed after the gas cooler. The objective is to decrease the refrigerant outlet temperature, and subsequently, to decrease the optimal pressure. Doing so, the influence on the system efficiency is going to be analyzed when comparing the results with the ones presented in this thesis.

- The researching team will also study the heat pump in air-to-water mode through a climatic chamber that has been used to study other heat pumps. The results are also going to be used to compare with the water-to-water mode. 


\section{References}

[1] EN-14511-2-Standard, Acondicionadores de aire, enfriadoras de líquido y bombas de calor con compresores accionados eléctricamente para la calefacción y la refrigeración de locales, vol. Part 2, Génova, Madrid: Asociación Española de Normalización y Certificación, 2018.

[2] Montreal-Protocol, Manual del protocolo de Montreal relativo a las sustancias que agotan la capa de ozono, vol. 13, Nairobi, Kenya: Secretaría del Ozono, ONU Medio Ambiente, 2020.

[3] Kyoto-Protocol, «Kyoto protocol to the united nations framework convention on climate change,» United Nations, Kioto, Japan, 1998.

[4] Paris-Agreement, «Paris agreement,» United Nations, NY, USA, 2015.

[5] UNE-EN-16147-Standard, Bombas de calor con compresor accionado eléctricamente. Ensayos y requisitos para el marcado de equipos para agua caliente sanitaria, vol. Part 1, Génova, Madrid: Asociación Española de Normalización, 2017.

[6] M. Molina y F. Rowland, «Stratospheric sink for chlorofluoromethanes: Chlorine atom-catalysed destruction of ozone,» Nature, vol. 249, nํ5460, pp. 810-812, 1974.

[7] F. Kaufman, «The 1976 Reports of National Academy of Sciences on the Chlorofluorocarbon-ozone problem," SAE Transactions, vol. 86, no Section 1: 770010-770187, pp. 58-77, 1977.

[8] J. Farman, B. Gardiner y J. Shanklin, «Large losses of total ozone in Antarctica reveal seasonal ClOx/NOx interaction," Nature, vol. 315, p. 207-210, 1985.

[9] The Kigali-Amendment-Montreal-Protocol, "The Kigali Amendment to the Montreal Protocol,» OzonAction Fact Sheet, Kigali, Rwanda, 2016.

[10] T. Asano, M. Maeda y M. Takaki, «Wastewater reclamation and reuse in Japan: overview and implementation examples," Water Science and Tecnology, vol. 34, no 11, pp. 219-226, 1996.

[11] W. Zhou y J. Li, «Sewage Heat Source Pump System's Application Examples and Prospect Analysis in China,» Purdue, 2004. 
[12] F. Schmid, "Sewage water: Interesting heat source for heat pumps and chillers, " Swiss Energy Agency for Infrastructure Plants, Zürich, Switzerland, 2008.

[13] A. Hepbasli, E. Biyik, O. Ekren, H. Gunerhan y M. Araz, "A key review of wastewater source hat pump (WWSHP) system," Energy Conversion and Management, vol. 88, p. 700-722, 2014.

[14] S. Cipolla y M. Maglionico, "Heat recovery from urban wastewater: analysis of the variability of flow rate and temperature in the sewer of Bologna, Italy, » Energy Procedia, vol. 45, pp. 288-297, 2014.

[15] O. Culha, H. Gunerhan, E. Biyik, O. Ekren y A. Hepbasli, «Heat exchanger applications in wastewater source heat pumps for buildings: A key review,» Energy and Buildings, vol. 104, pp. 215-232, 2015.

[16] C. Shen, Z. Lei, Y. Wang, C. Zhang y Y. Yao, "A review of the current research and appliaction of wastewater source heat pumps in China," Thermal Science and Engineering Progress, vol. 6, p. 140-156, 2018.

[17] C. Shen, Y. Jiang, Y. Yao y X. Yao, "An experimental comparison of two heat exchangers used in wastewater source heat pump: A novel dry-expansion shell-and-tube evaporator versus a conventional immersed evaporator," Energy, vol. 47, pp. 600-608, 2012b.

[18] N. Baek, U. Shin y J. Yoon, "A study on the design and analysis of a heat pump heating system using wastewater as a heat source," Solar Energy, vol. 78, p. 427-440, 2005.

[19] L. Ni, S. Lau, H. Li, T. Zhang, J. Standsbury, J. Shi y N. J., «Feasibility study of a localized residential grey water energy-recovery system," Applied Thermal Engineering, vol. 39, pp. 53-62, 2012.

[20] S. Tassou, "Heat recovery from sewage effluent using heat pumps," Heat Recovery Systems and CHP, vol. 8, no 2, pp. 141-148, 1988.

[21] S. Walker, «Energy from waste in the sewage treatment process,» Durham, UK, 1996.

[22] Japan-National-Team, "First DHC System in Japan Using Untreated Sewage as a Heat Source,» CADDET Newsletter, vol. 2, pp. 8-10, 1997.

[23] US-DOE, «Heat Recovery from Wastewater Using Gravity-Film Heat Exchanger, " US Department OF Energy, Oak Ridge, TN, USA, 2001. 
[24] J. Qian, "Analysis of Energy and Soft Dirt in an Urban Untreated Sewage Source Heat," Renewable Energy Resources and a Greener Future, vol. VIII, no 9-3, 2006.

[25] S. Garmsiri, S. Koohi y M. Rosen, "Recovery of Sewer Waste Heat vs. Heat Pumps Using Borehole Geothermal Energy Storage for a Small Community Water Heating System: Comparison and Feasibility Analysis,» Ontario, Canada, 2014.

[26] Y. Gu y H. Deng, "The Feasibility Analysis of Wastewater Source Heat Pump Using the Urban Wastewater Heat," Research Journal of Applied Sciences, Engineering and Technology, vol. 4, no 18, pp. 3501-3504, 2012.

[27] J. Lines, "Heat Exchangers in Municipal Wastewater Treatment Plants,» Manufacturing Co., Inc, Houston, TX, USA, 2014.

[28] A. Mazhar, S. Liu y A. Shukla, "A Key Review of Non-Industrial Greywater Heat Harnessing,» Energies, vol. 11, p. 386, 2018.

[29] M. Pitarch, E. Navarro-Peris, J. Gonzálvez-Maciá y J. Corberán, «Experimental study of a subcritical heat pump booster for sanitary hot water production using a subcooler in order to enhance the efficiency of the system with a natural refrigerant (R290), " International Journal of Refrigeration, vol. 73, pp. 226-234, 2017a.

[30] M. Pitarch, E. Navarro-Peris, J. Gonzálvez-Maciá y J. Coberán, «Experimental study of a heat pump with high subcooling," Science and Technology for the Built Environment, vol. 24, p. 105-114, 2018.

[31] M. Pitarch, E. Navarro-Peris, J. Gonzálvez-Maciá y J. Corberán, «Evaluation of different heat pump systems for sanitary hot water production using natural refrigerants," Applied Energy, vol. 190, p. 911-919, 2017b.

[32] G. Lorentzen, «Revival of carbon dioxide as a refrigerant,» Int J. Refrigeration, vol. 17, p. 292-301, 1994.

[33] D. Robinson y E. Groll, «Efficiencies of transcritical CO2 cycles with and without an expansion turbine," Int J. Refrig., vol. 21, no 7, p. 577-589, 1998.

[34] J. Pettersen, A. Hafner y G. Skaugen, «Development of compact heat exchanger for $\mathrm{CO} 2$ air-conditioning systems, » Int. J. Refrig., vol. 21, no 3, pp. 180-193, 1998. 
[35] P. Nekså, H. Rekstad, G. Zakeri y P. Schiefloe, «CO2 heat pump water heater: characteristics, system, design and experimental results," Int J. Refrig., vol. 21, pp. 172-179, 1998.

[36] J. Sarkar, S. Bhattacharyya y M. Ramgopal, «Natural refrigerant-based subcritical and transcritical cycles for high temperature heating," International Journal of Refrigeration, vol. 30, pp. 3-10, 2007.

[37] M. Saikawa y S. Koyama, «Thermodynamic analysis of vapor compression heat pump cycle for tap water heating and development of CO2 heat pump water heater for residential use," Applied Thermal Engineering, vol. 106, pp. 1236-1243, 2016.

[38] C. Bullard, J. Yin y P. Hrnjak, «Transcritical CO2 Mobile Heat Pump and A/C System. Experimental and Model Results,» 2000.

[39] J. Brown, S. Yana-Motta y P. Domanski, "Comparitive analysis of an automotive air conditioning systems operating with CO2 and R134a," International Journal of Refrigeration, vol. 25, pp. 19-32, 2002.

[40] M. Richter, S. Song, J. Yin, M. Kim, C. Bullard y P. Hrnjak, «Experimental results of transcritical CO heat pump for residential application,» Energy, vol. 28, pp. 1005-1019, 2003.

[41] L. Cecchinato, M. Corradi, E. Fornasieri y L. Zamboni, «Carbon dioxide as refrigerant for tap water heat pumps: A comparison with the traditional solution,» International Journal of Refrigeration, vol. 28, p. 1250-1258, 2005.

[42] S. Minetto, L. Cecchinato, R. Brignoli, S. Marinetti y M. Rossetti, «Water-side, reversible CO2 heat pump for residential application,» International journal of refrigeration, vol. 63, p. 237-250, 2016.

[43] J. Stene, "Residential CO2 heat pump systems for combined space heating and hot water heating," International Journal of Refrigeration, vol. 28, p. 1259-1265, 2005.

[44] K. Nawaz, B. Shen, A. Elatar, V. Baxter y O. Abdelaziz, «Performance optimization of CO2 heat pump water heater," International Journal of Refrigeration, vol. 85, p. 213-228, 2018.

[45] Y. Song, D. Li, D. Yang, L. Jin y F. W. X. Cao, "Performance comparison between the combined $\mathrm{R} 134 \mathrm{a} / \mathrm{CO} 2$ heat pump and cascade $\mathrm{R} 134 \mathrm{a} / \mathrm{CO} 2$ heat pump for space heating," International Journal of Refrigeration, vol. 74, pp. 592-605, 2017. 
[46] Y. Ma, Z. Liu y H. Tian, «A review of transcritical carbon dioxide heat pump and refrigeration cycles," Energy, vol. 55, pp. 156-172, 2013.

[47] D. Wang, Y. Lu y L. Tao, «Thermodynamic analysis of CO2 blends with R41 as an azeotropy refrigerant applied in small refrigerated cabinet and heat pump water heater," Applied Thermal Engineering, vol. 125, pp. 1490-1500, 2017.

[48] B. Niu y Y. Zhang, "Experimental study of the refrigeration cycle performance for the R744/R290 mixture,» International Journal Of Refrigeration, vol. 30, pp. 37-42, 2007.

[49] F. Ju, X. Fan, Y. Chen, T. Wang, X. Tang y A. Kuang, «Experimental investigation on a heat pump water heater using R744/R290 mixture for domestic hot water, " International Journal of Thermal Sciences, vol. 132, pp. 1-13, 2018.

[50] F. Ju, X. Fan, Y. Chen, H. Ouyang, A. Kuang, S. Ma y F. Wang, «Experiment and simulation study on performances of heat pump water heater using blend of R744/R290, " vol. 169, pp. 148-156, 2018b.

[51] S. Liao, T. Zhao y A. Jakobsen, "A correlation of optimal heat rejection pressure in transcritical carbon dioxide cycles, " Applied Thermal Engineering, vol. 20, pp. 831-841, 2000.

[52] C. Aprea y A. Maiorino, «Heat rejection pressure optimization for a carbon dioxide split system: An experimental study," Applied Energy, vol. 86, p. 2373-2380, 2009.

[53] Y. Chen y J. Gu, «The optimum high pressure for $\mathrm{CO} 2$ transcritical refrigeration systems with internal heat exchangers," International Journal of Refrigeration, vol. 28, pp. 1238-1249, 2005.

[54] V. Pérez-García, J. Belman-Flores, J. Navarro-Esbrí y C. Rubio-Maya, "Comparative study of transcritical vapor compression configurations using $\mathrm{CO} 2$ as a refrigeration mode base on simulation," Engineering, Applied Thermal, vol. 51, pp. 1038-1046, 2013.

[55] L.-L. Shao, Z.-Y. Zhang y C.-L. Zhang, "Constrained optimal high pressure equation of $\mathrm{CO} 2$ transcritical cycle," Applied Thermal Engineering, vol. 128, p. $173-178,2018$.

[56] F. Cao, Z. Ye y Y. Wang, «Experimental investigation on the influence of internal heat exchanger in a transcritical $\mathrm{CO} 2$ heat pump water heater, » vol. $168,2020$. 
[57] J. Sarkar, S. Bhattacharyya y M. Ramgopal, «Performance of a Transcritical CO2 Heat Pump for simultaneous water cooling and heating," International Journal of Mechanical and Mechatronics Engineering, vol. 4, 2010.

[58] J. Yang, Y. Ma, M. Li y J. Hua, «Modeling and simulating the transcritical CO2 Heat Pump System,» Energy, vol. 35, pp. 4812-4818, 2010.

[59] S. Kim, Y. Kim, G. Lee y M. Kim, «The performance of a transcritical CO2 cycle with an internal heat exchanger for hot water heating," International Journal of Refrigeration, vol. 28, p. 1064-1072, 2005.

[60] R. Cabello, D. Sánchez, R. Llopis y E. Torrella, «Experimental evaluation of the energy efficiency of a $\mathrm{CO} 2$ refrigeration plant working in transcritical conditions, " Applied Thermal Engineering, vol. 28, p. 1596-1604, 2008.

[61] E. Torrella, D. Sánchez, R. Llopis y R. Cabello, «Energetic evaluation of an internal heat exchanger in a $\mathrm{CO} 2$ transcritical refrigeration plant using experimental data, » International Journal of Refrigeration, vol. 34, pp. 40-49, 2011.

[62] X. Zhang, X. Fan, F. Wang y H. Shen, «Theoretical and experimental studies on optimum heat rejection pressure for a $\mathrm{CO} 2$ heat pump system," Applied Thermal Engineering, vol. 30, pp. 2537-2544, 2010.

[63] R. Cabello, D. Sánchez, J. Patiño, R. Llopis y E. Torrella, «Experimental analysis of energy performance of modified single-stage $\mathrm{CO} 2$ transcritical vapor compression cycles based on vapor injection in the suction line," Applied Thermal Engineering, vol. 47, pp. 86-94, 2012.

[64] D. Sánchez, J. Patiño, R. Llopis, R. Cabello, E. Torrella y F. Fuentes, «New positions for an internal heat exchanger in a $\mathrm{CO} 2$ supercritical refrigeration plant. Experimental analysis and energetic evaluation," Applied Thermal Engineering, vol. 63, pp. 129-139, 2014a.

[65] L. Nebot-Andrés, J. Catalán-Gil, D. Sánchez, D. Calleja-Anta, R. Cabello y R. Llopis, «Experimental determination of the optimum working conditions of a transcritical $\mathrm{CO} 2$ refrigeration plant with integrated mechanical subcooling," International Journal of Refrigeration, vol. 113, p. 266-275, 2020.

[66] J. Deng, P. Jiang, T. Lu y W. Lu, «Particular characteristics of transcritical CO2 refrigeration cycle with an ejector," Applied Thermal Engineering, vol. 27, pp. 381-388, 2007. 
[67] S. Elbel y P. Hrnjak, «Experimental validation of a prototype ejector designed to reduce throttling losses encountered in transcritical R744 system operation, " International Journal of Refrigeration, vol. 31, pp. 411-422, 2008.

[68] M. Yari, «Performance analysis and optimization of a new two-stage ejectorexpansion transcritical CO2 refrigeration cycle,» International Journal of Thermal Sciences, vol. 48, pp. 1997-2005, 2009.

[69] V. Casson, L. Cecchinato, M. Corradi, E. Fornasieri, S. Girotto, S. Minetto, L. Zamboni y C. Zilio, "Optimisation of the throttling system in a $\mathrm{CO} 2$ refrigerating machine," International Journal of Refrigeration, vol. 26, pp. 926-935, 2003.

[70] D. Sánchez, J. Patiño, C. Sanz-Kock, R. Llopis, R. Cabello y E. Torrella, «Energetic evaluation of a $\mathrm{CO} 2$ refrigeration plant working in supercritical and subcritical conditions, " Applied Thermal Engineering, vol. 66, pp. 227$238,2014 b$.

[71] I. Peñarrocha, R. Llopis, L. Tárrega, D. Sánchez y R. Cabello, «A new approach to optimize the energy efficiency of $\mathrm{CO} 2$ transcritical refrigeration plants," Applied Thermal Engineering, vol. 67, pp. 137-146, 2014.

[72] J. Sarkar, «Optimization of ejector-expansion transcritical CO2 heat pump cycle,» Energy, vol. 33, pp. 1399-1406, 2008.

[73] X. Xu, G. Chen, L. Tang y Z. Zhu, «Experimental investigation on performance of transcritical $\mathrm{CO} 2$, heat pump system with ejector under optimum high-side pressure,» Energy, vol. 44, pp. 870-877, 2012.

[74] N. Agrawal, S. Bhattacharyya y J. Sarkar, "Optimization of two-stage transcritical carbon dioxide heat pump cycles," International Journal of Thermal Sciences, vol. 46, pp. 180-187, 2007.

[75] S. Sawalha, «Theoretical evaluation of trans-critical $\mathrm{CO} 2$ systems in supermarket refrigeration. Part I: Modeling, simulation and optimization of two system solutions.," International Journal of Refrigeration, vol. 31, p. 516-524, 2008.

[76] S. Zhili, L. Minxia, H. Guangming y Y. Ma, «Performance study of a transcritical carbon dioxide cycle with and expansor, » Energy, vol. 60, pp. 77-86, 2013.

[77] P. Nekså, «CO2 Heat Pump Systems, » International Journal of Refrigeration, vol. 25, pp. 421-427, 2002. 
[78] M. Rampazzo, A. Cervato, C. Corazzol, L. Mattiello, A. Beghi, L. Cecchinato y A. Virzi, «Energy-efficientoperation of transcriticalandsubcritical $\mathrm{CO} 2$ inverse cycle via Extremum Seeking Control," Journal of Process Control, vol. 81, pp. 87-97, 2019.

[79] X. Qin, H. Liu, X. Meng, X. Wei y L. Zhao, "A study on the compressor frequency and optimal discharge pressure of the transcritical $\mathrm{CO} 2$ heat pump system,» International Journal of Refrigeration, vol. 99, pp. 101-113, 2019.

[80] F. Jang, Y. Wang, B. Yu, B. Wang, J. Shi y J. Chen, «Effects of various operating conditions on the performance of a $\mathrm{CO} 2$ air conditioning system for trains, " International Journal of Refrigeration, vol. 107, pp. 105-113, 2019.

[81] R. Sian y C. Wang, «Comparative study for CO2 and R-134a heat pump tumble dryer a rational approach a rational approach," International Journal of Refrigeration, vol. 106, pp. 474-491, 2019.

[82] Y. Song, D. Yang, M. Li y F. Cao, «Investigations on optimal discharge pressure in $\mathrm{CO} 2$ heat pumps using the GMDH and PSO-BP type neural network-part B: Experimental study," International Journal of Refrigeration, vol. 106, pp. 248-257, 2019.

[83] S. White, M. Yarrall, D. Cleland y R. Hedley, «Modelling the performance of a transcritical CO2 heat pump for high temperature heating," International Journal of Refrigeration, vol. 25, p. 479-486, 2002.

[84] S. Wang, H. Tuo, F. Cao y Z. Xing, «Experimental investigation on air-source transcritical $\mathrm{CO} 2$ heat pump water heater system at a fixed water inlet temperature," International Journal of Refrigeration, vol. 36 , pp. 701-716, 2013.

[85] F. Zhang, P. Jiang, Y. Lin y Y. Zhang, «Efficiencies of subcritical and transcritical CO2 inverse cycles with and without an internal heat exchanger, " Applied Thermal Engineering, vol. 31, pp. 432-438, 2011.

[86] Y. Jiang, Y. Ma, M. Li y L. Fu, «An experimental study of trans-critical CO2 water-water heat pump using compact tube-in-tube heat exchangers," Energy Conversion and Management, vol. 76, p. 92-100, 2013.

[87] F. Kauf, «Determination of the optimal high pressure for transcritical CO2refrigeration cycles," Int. J. Therm., vol. 38, pp. 325-330, 1998. 
[88] L. Yang, H. Li, S. Cai, L.-L. Shao y C.-L. Zhang, «Minimizing COP loss from optimal high pressure correlation for transcritical CO2 cycle,» Applied Thermal Engineering, vol. 89, pp. 656-662, 2015.

[89] J. Sarkar, S. Bhattacharyya y M. Ramgopal, "Optimization of a transcritical CO2 heat pump cycle for simultaneous cooling and heating applications," International Journal of Refrigeration, vol. 27, pp. 830-838, 2004.

[90] J. Sarkar, S. Bhattacharyya y M. Ramgopal, «Simulation of a transcritical CO2 heat pump cycle for simultaneous cooling and heating applicationgs,» International Journal of Refrigeration, vol. 29, pp. 735-743, 2006.

[91] S. Kim, J. Won y M. Kim, «Effects of operating parameters on the performance of a $\mathrm{CO} 2$ air conditioning system for vehicles, " Applied Thermal Engineering, vol. 29, pp. 2408-2416, 2009.

[92] Y. Ge y S. Tassou, «Performance evaluation and optimal design of supermarket refrigeration systems with supermarket model "SuperSim". Part II: Model applications," international Journal of Refrigeration, vol. 34, pp. 540-549, 2011.

[93] P.-C. Qi, Y.-L. He, X.-L. Wang y X.-Z. Meng, «Experimental investigation of the optimal heat rejection pressure for a transcritical CO2 heat pump water heater," Applied Thermal Engineering, vol. 56, pp. 120-125, 2013.

[94] Y. Song y F. Cao, "The evaluation of optimal discharge pressure in a waterprecooler-based transcritical CO2 heat pump system," Applied Thermal Engineering, vol. 131, pp. 8-18, 2018.

[95] L. Cecchinato, M. Corradi y S. Minetto, «A critical approach to the determination of optimal heat rejection pressure in transcritical systems," Applied Thermal Engineering, vol. 30, pp. 1812-1823, 2010.

[96] W.-J. Zhang y C.-L. Zhang, "A correlation-free on-line optimal control method of heat rejection pressures in $\mathrm{CO} 2$ transcritical systems," International Journal of Refrigeration, vol. 34, pp. 844-850, 2011.

[97] S. Minetto, «Theoretical and experimental analysis of a $\mathrm{CO} 2$ heat pump for domestic hot water," International journal of refrigeration, vol. 34, pp. 742751, 2011.

[98] L. Cecchinato, M. Corradi, S. Minetto, G. Cosi y M. Rampazzo, «A real-time algorithm for the determination of R744 systems optimal high pressure,» International journal of refrigeration, vol. 35, pp. 817-826, 2012. 
[99] F. Liu, W. Zhu, J. Zhao, J. Ren, E. Groll y Y. Cai, «A new method for optimal control of a dual-mode $\mathrm{CO} 2$ heat pump with thermal storage," Applied Thermal Engineering, vol. 125, p. 1123-1132, 2017.

[100] F. Liu, W. Zhu y J. Zhao, «Model-based dynamic optimal control of a CO2 heat pump coupled with hot and cold thermal storages," Applied Thermal Engineering, vol. 128, p. $1116-125,2018$.

[101] X. Yin, F. Cao, J. Wang, M. Li y X. Wang, «Investigations on Optimal Discharge Pressure in $\mathrm{CO} 2$ Heat Pumps Using the GMDH and PSO-BP Type Neural Network-Part A: Theoretical Modeling," International Journal of Refrigeration, 2019.

[102] B. Hu, Y. Li, F. Cao y Z. Xing, «Extremum seeking control of COP optimization for air-source transcritical CO2 heat pump water heater system," Applied Energy, vol. 147, pp. 361-372, 2015.

[103] Y.-G. Chen, «Pinch point analysis and design considerations of $\mathrm{CO} 2$ gas cooler for heat pump water heaters, " International Journal of Refrigeration, vol. 69, pp. 136-146, 2016.

[104] Y.-G. Chen, "Optimal heat rejection pressure of CO2 heat pump water heaters based on pinch point analysis," International Journal of Refrigeration, vol. 106, pp. 592-603, 2019.

[105] X.-Y. Liang, Y.-J. He, J.-H. Cheng, L.-L. Shao y C.-L. Zhang, «International Journal of Refrigeration,» vol. 106, pp. 384-391, 2019.

[106] Dorin-Innovation, Operating instructions for CO2 semi-hermetic compressors, Officine Mario Dorin S.p.A., 1LTG665_01.

[107] Camille-Bauer, Datasheet $M \quad 561 / M \quad 562 / M \quad 563$, https://beving.se/images/files/products/Camille_Bauer_Sineax_M560_en.p df, 2005.

[108] SWEP, B16 product sheet, https://www.swep.net/products/b16/.

[109] SWEP, BX8T product sheet, https://www.swep.net/products/bx8t/.

[110] SWEP, B17 product sheet, https://www.swep.cn/globalassets/products/b17/b17-en.pdf.

[111] Folleto técnico Transmisor electrónico de nivel de líquido AKS 4100/4100U, Danfoss, 2012. 
[112] EVD evolution electronic expansion valve driver. User manual, Carel.

[113] INT275 L Level monitor, KRIWAN Industrie-Elektronik GmbH.

[114] Swagelok, Tubo de acero inoxidable sin soldadura y sistemas de soporte para tubo, https://www.swagelok.com/es-ES/product/tubing-and-tubeaccessories/tubing.

[115] Swagelok, Válvulas de bola, https://www.swagelok.com/esES/product/Valves/Ball.

[116] Swagelok, Racores para Tubo Galgables y Adaptadores, https://www.swagelok.com/downloads/webcatalogs/ES/MS-01-140.pdf.

[117] AIRWELL, AQL/AQH 20-75, Installation and maintenance manual.

[118] Gabarrón, Electric boilers for central heating, Installation instructions and user guide.

[119] Sauter, AVM105SF132, Valve actuator with SAUTER Universal Technology, https://www.sauter-controls.com/en/product/valve-actuator-with-sauteruniversal-technology-sut/.

[120] Wilo, Wilo-Stratos/-D/-Z/-ZD, Instrucciones de instalación y funcionamiento, https://wilo.com/es/es/Productos-y-campos-de-

aplicaci\%C3\%B3n/B\%C3\%BAsqueda-de-series/Wilo-Stratos-Z_325.html.

[121] Alfa-Laval, Industrial heat exchangers, https://www.alfalaval.es/productos$\mathrm{y}$-soluciones/transferencia-de-calor/intercambiadores-de-calor-deplacas/intercambiadores-de-calor-de-placas-con-juntas/linea-industrial/.

[122] WATLOW, EZ-ZONE, user's guide, Winona, MN, USA, 2016.

[123] WATLOW, Practical PID guide for process control, Winona, MN, USA, 2005.

[124] SbsTech, Thermoplastic High Density Polyethylene (HDPE), https://www.substech.com/dokuwiki/doku.php?id=thermoplastic_high_de nsity_polyethylene_hdpe.

[125] EJX510A and EJX530A Absolute Pressure and Gauge Pressure Transmitters, Yokogawa Electric Corporation, IM 01C25F01-01E, 9th Edition.

[126] Differential Pressure and Pressure Transmitters EJ*110*, EJ*120*, EJ*130*, EJ*310*, EJ*430*: User's manual, Yokogawa Electric Corporation, 18th edition, 2015. 
[127] RotaMASS 3 Series Coriolis Mass Flow and Density Meter: Integral Type RCCT3, Remote Type RCCF31+RCCS3, Remote Type RCCR31+RCCS3. User's Manual, KG, Germany.: Rota Yokogawa GmbH \& Co, 12th edition, 2015.

[128] Caudalímetros electromagnéticos SITRANS F M MAG 5100 W instrucciones de servicio, SIEMENS, 2010.

[129] Caudalímetro electromagnético Convertidor de señal tipo MAG 5000 y MAG 6000, Manual del operador, 2006.

[130] Agilent 34970A Data Acquisition/Switch unit family, Agilent Technologies Inc, 2011.

[131] E. Lemmon, M. Huber y M. McLinden, NIST Standard Reference Database 23: Reference Fluid Thermodynamic and Transport Properties (REFPROP), Version 9.0, (2010).

[132] JCGM100:2008, Evaluation of measurement data-Guide to the expression of uncertainty in measurement, 2008.

[133] H. Fritschi, F. Tillenkamp, R. Löhrer y M. Brügger, «Efficiency increase in carbon dioxide refrigeration technology with parallel compression,» International Journal of Low-Carbon Technologies, vol. 12, pp. 171-180., 2017.

[134] ANSI/AHRI, Performance Rating of Positive Displacement Compressors and Compressor Units, 2111 Wilson Boulevard, Suite 500, Arlington, VA 22201, U.S.A.: Air-Conditioning, Heating, and Refrigeration Institute, 540-2015.

[135] UNE-EN-12900-Standard, Refrigerant compressors. Rating conditions, tolerances and presentation of manufacturer's performance data, Genova, 6, 28004., Madrid: AENOR, 2013.

[136] A. Dabiri y C. Rice, "Compressor Simulation Model with Corrections for the Level of Suction Gas Superheat," ASHRAE Transactions, vol. 87, no Part 2, pp. 771-782, 1981.

[137] Dorin, Dorin software, https://www.dorin.com/en/Software/ (accessed March 5, 2020).

[138] Bitzer, Bitzer web software, https://www.bitzer.de/websoftware/ (accessed March 5, 2020). 
[139] Frascold, https://www.frascold.it/en/download/software/fss_3_frascold_selection_s oftware (accessed March 5, 2020).

[140] S. Wang, Y. He, H. Tuo, F. Cao y Z. Xing, "Effect of heat transfer area and refrigerant mass flux in a gas cooler on heating performance of air-source transcritical CO2 heat pump water heater system,» Energy and Building, vol. 67, pp. 1-10, 2013.

[141] E. Hervás-Blasco, E. Navarro-Peris, F. Barceló-Ruevas y J. Coberán, «Improved water to water heat pump design for low-temperature waste heat recovery based on subcooling control,» International Journal of Refrigeration, vol. 106, pp. 374-383, 2019.

[142] C. Shen, J. Yiqiang, Y. Yang, D. Shiming y W. Xinlei, «A field study of a wastewater source heat pump for domestic hot water heating," Building Serv. Eng. Res. Technology, vol. 0, no 0, p. 1-16, 2012.

[143] G. Nehm, L. Palandre y D. Clodic, «High Efficiency Heat Pump for Domestic Hot Water Generation,» 2008.

[144] A. Kahraman y A. Çelebi, «Investigation of the Performance of a Heat Pump Using Waste Water as a Heat Source,» Energies, vol. 2, pp. 697-713, 2009.

[145] L. Liu, L. Fu y Y. Jiang, «Application of an exhaust heat recovery system for domestic hot water, » Energy, vol. 35 , pp. 1476-1481, 2010.

[146] M. Niemelä y R. Saarela, The wastewater utilization in Kakola heat pump plant, The International District Energy Climate Awards, 2009.

[147] J. Qian, Z. J. y S. D, «Form and applicability of a new urban sewage source heat pump system with freezing latent heat collection,» Guilin, Guangxi, China, 2009.

[148] F. Meggers y H. Leibundgut, «The potential of wastewater heat and exergy: decentralized high-temperature recovery with a heat pump," Energy Build, vol. 43, no 4, p. 879-86, 2011.

[149] Yamankaradeniz, "Comparing the heat pump with the classical system in energy saving by using waste heat in the textile industry, " Journal of Uludag University Faculty of Engineering and Architecture, vol. 12, no 1, pp. 115-124, 2007.

[150] X. Li y Y. Li, «Second law-based thermodynamic analysis of a heat pump system utilizing sewage source,» Chengdu, China, 2010. 
[151] X. Zhao, L. Fu, S. Zhang, Y. Jiang y Z. Lai, «Study of the performance of an urban original source heat pump system,» Energy Conversion and Management, vol. 51, pp. 765-770, 2010.

[152] J. Qian, «Optimization design of urban sewage source heat pump system with freezing latent heat collection,» 2011.

[153] C. Shen, J. Yiqiang, Y. Yang y D. Shiming, «Experimental performance evaluation of a novel dry-expansion evaporator with defouling function in a wastewater source heat pump,» Applied Energy, vol. 95, pp. 202-209, 2012a.

[154] S. Coskun, A. Motorcu, N. Yamankaradeniz y E. Pulat, «Evaluation of control parameters' effects on system performance with Taguchi method in waste heat recovery application using mechanical heat pump," International journal of refrigeration, vol. 35, pp. 795-809, 2012.

[155] X. Liu, L. Ni, S. Lau y H. Li, «Performance analysis of a multi-functional Heat pump system in heating mode," Applied Thermal Engineering, vol. 51, pp. 698-710, 2013a.

[156] X. Liu, L. Ni, S. Lau y H. Li, «Performance analysis of a multi-functional heat pump system in cooling mode," Applied Thermal Engineering, vol. 59, pp. 253-266, 2013b.

[157] K. Chae y J. Kang, "Estimating the energy independence of a municipal wastewater treatment plant incorporating green energy resources," Energy Convers Manage, vol. 75, p. 664-672, 2013.

[158] S. Oh, Y. Cho y R. Yun, "Raw-water source heat pump for a vertical water treatment building,» Energy and Buildings, vol. 68, p. 321-328, 2014.

[159] H. Wang, Q. Wang y G. Chen, "Experimental performance analysis of an improved multifunctional heat pump system," Energy and Buildings, vol. 62, pp. 581-589, 2013.

[160] Y. Gu y J. Fang, "Research on the energy-saving and heat transfer performance of wastewater source heat pump,» Changsha, China, 2013.

[161] Z. Liu, L. Ma y J. Zhang, «Application of a heat pump system using untreated urban sewage as a heat source," Applied Thermal Engineering, vol. 62, pp. 747-757, 2014.

[162] Z. Weijie, L. Cen y L. Yanyan, «Potential capacity research on application of sewage- source heat pump system in bath centers, " Handan, China, 2013. 
[163] L. Alekseiko, V. Slesarenko y A. Yudakov, "Combination of wastewater treatment plants and heat pumps,» Pacific Science Review, vol. 16, pp. 36-39, 2014.

[164] X. Liu, S. Lau y H. Li, «Optimization and analysis of a multi-functional heat pump system with air source and gray water source in heating mode, " Energy and Buildings, vol. 69, pp. 1-13, 2014.

[165] N. Hytiris, K. Ninikas, R. Emmanuel y B. Aaen, "Heat energy recovery from waste water in the Glasgow subway system," Procedia Engineering, vol. 165, pp. 394-403, 2016.

[166] Y. Song, Y. Yao, Z. Ma y W. Na, «Study of Performance of Heat Pump Usage in Sewage Treatment and Fouling Impact on System," China Renewable Energy Resources and a Greener Future, vol. VIII, no 8-2, 2006.

[167] C. Shen, L. Yang, X. Wang, Y. Jiang y Y. Yao, «An experimental and numerical study of a de-fouling evaporator used in a wastewater source heat pump," Applied Thermal Engineering, vol. 70, pp. 501-509, 2014.

[168] Emerson, Rosemount 3051 Pressure Transmitter Reference Manual, 2012. 